\title{
QUELQUES ASPECTS DES RELATIONS NUTRITIONNELLES ENTRE LA GESTATION ET LA LACTATION CHEZ LA TRUIE (1)
}

\author{
E. SALMON-LEGAGNEUR \\ Station de Recherches sur l'élevage des Porcs. \\ Centre national de Recherches zootechniques, (Yvelines) Jouy-en-Josas
}

\section{TABLE DES MATIÈRES}

INTRODUCTION

A - Intérêt de l'étude des relations nutritionnelles............. 5

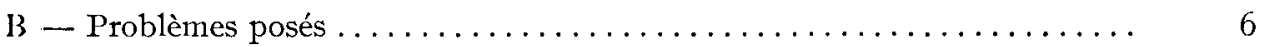

C - Choix de l'animal . . . . . . . . . . . . . . . 7

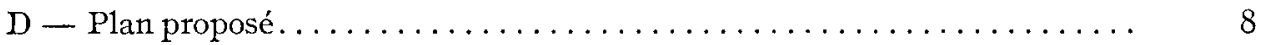

CHAPITRE PREMIER. - TECHNIQUES EXPÉRIMENTALES

A - Variations corporelles $\ldots \ldots \ldots \ldots \ldots \ldots \ldots \ldots \ldots \ldots \ldots \ldots \ldots \ldots \ldots \ldots$

B - Contenus utérins . . . . . . . . .

$\mathrm{C} \longrightarrow$ Production laitière $\ldots \ldots \ldots \ldots \ldots \ldots \ldots \ldots \ldots \ldots \ldots \ldots \ldots \ldots \ldots \ldots \ldots \ldots \ldots$

CHAPITRE II. - CARACTÈRES GÉNÉRAUX ET PARTICULIERS

DES FONCTIONS DE REPRODUCTION CHEZ IA TRUIE

A - Le cycle de reproduction et ses différentes phases............ 18

I Puberté, cycles sexuels, ovulation

$2^{\circ}$ Gestation

$3^{\text {o Lactation }}$

B - Variations de poids au cours de la reproduction $\ldots \ldots \ldots \ldots \ldots \ldots \ldots$

${ }^{\circ}$ Gestation

$2^{\circ}$ Lactation

(1) Cette étude a fait l'objet d'une thèse de Docteur Ingénieur, soutemue le 12 juin 1965, à la Faculté des Sciences de l'Université de Paris. 


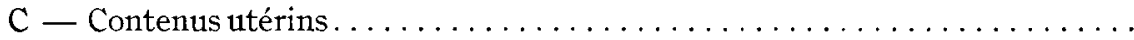

$I^{\circ}$ Parturition

$2^{0}$ Évolution des contenus utérins

$\mathrm{D}$ - Production laitière.

$1^{0}$ Variations quantitatives

$\mathbf{2}^{\circ}$ Variations qualitatives

$\mathrm{E}-$ Discussion

\section{CHAPITRE III. - REIATIONS QUANTITATIVES}

ENTRE I,E NIVEAU AIIMENTAIRE, GI,OBAL, ET LA RUPRODUCTION

$A-$ Effets sur la gestation. . . . . . . . . . . . . . . . . . .

$\mathrm{I}^{\mathrm{O}}$ Augmentation du niveau alimentaire

$2^{\circ}$ Réduction du niveau alimentaire

$\mathrm{B}$ - Effets sur la lactation

I $^{0}$ Augmentation du niveau alimentaire

$2^{\text {o }}$ Réduction du niveau alimentaire

$\mathrm{C}$ - Relations gestation-lactation

$\mathrm{D}$ - Discussion .

CHAPITRE IV. - REI,ATIONS ENTRF LFS PROTIDES DU RÉGIME,

\section{I,A GESTATION ET IA LACTATION}

A - Effets de l'apport quantitatif d'azote au cours de la gestation . . . . . . .

$\mathrm{I}^{\mathrm{O}}$ Augnentation du niveau azoté en fin de gestation

$2^{0}$ Bilans azotés

$3^{0}$ Relations Énergie/Protéine

B - Fffets de 1'apport quantitatif d'azote au cours de la lactation ........ I $^{\circ}$ Augmentation du niveau azoté

$2^{0}$ Bilans azotés - Relations avec la gestation

C - Effets de l'apport qualitatif d'azote au cours de la gestation et de la lactation

$\mathrm{D}$ - I)iscussion .

CHAPITRE V. - RELATIONS ENTRE LES LIPIDES DU RÉGIME, I.A GESTATION ETT IA LACTATION

A - Influence de l'introduction de lipides dans la ration de la truie en lac-

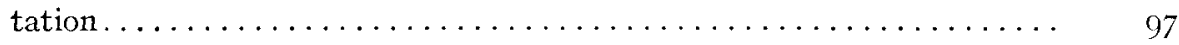

B - Relations se rapportant aux acides gras polyinsaturés . . . . . . . . I05

C - Relations se rapportant aux acides gras saturés . . . . . . . . . . III

$\mathrm{D}-$ Discussion $\ldots \ldots \ldots \ldots \ldots \ldots \ldots \ldots \ldots \ldots \ldots \ldots \ldots \ldots \ldots \ldots \ldots \ldots \ldots \ldots \ldots$

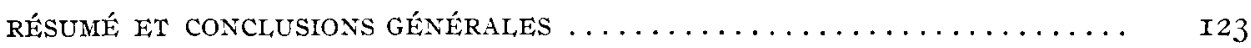

RÉFÉRENCES BIBLIOGRAPHIQUES $\ldots \ldots \ldots \ldots \ldots \ldots \ldots \ldots \ldots \ldots \ldots \ldots \ldots \ldots \ldots \ldots \ldots$ I 27 


\section{INTRODLCTION}

\section{A - Intérèt de l'étude des relations nutritionnelles}

C'est sans doute BAR et DAUNAY (Ig05) qui les premiers ont attiré l'attention sur le bénéfice nutritionnel que la mère peut retirer de sa gestation et les faits ne manquent pas depuis pour montrer que dans beaucoup d'espèces le comportement nutritionnel de la femelle gravide met en jeu un anabolisme qui dépasse de loin les besoins de construction du fœtus. Cette notion ressort avec évidence des travaux poursuivis sur la Truie (MItchel, et al., I93I), la Femme (ILACy et al., I934), la Souris (Newton, I935), la Ratte (Poo et al., I940), le Singe (Van Wagenen, I943), la Vache (JACOBsen et al., I957) et la Brebis (Rombauts, I959).

Mais c'est surtout à JACQUOT (I953, I959) et à ses collaborateurs, notamment à Bourder, (I956, I960), que revient le mérite d'avoir étudié plus en détail le déterminisme hormonal et nutritionnel de cet anabolisme gravidique et d'avoir précisé, en particulier, qu'il résultait d'une aptitude très particulière de la gestante à épargner au niveau des dépenses basales, ce qui lui permet de mieux utiliser les nutriments qu'elle reçoit. Cette découverte éclaira d'un jour nouveau la notion de besoin de gestation, que l'on s'accorde aujourd'hui à évaluer à un niveau beaucoup moins élevé qu'on ne l'avait longtemps pensé.

Contrastant avec cette modicité relative du besoin alimentaire de la gestante, la lactation apparaît au contraire, chez la plupart des espèces, comme un phénomène très coûteux. Cela réstulte avant tout des performances de la mère, qui dans un laps de temps souvent inférieur à celui d'une gestation, arrive à exporter dans son lait plus de matière sèche qu'elle n'en contient dans son corps (MAYnard, I956). Pour cette raison, toute étude de base des facteurs de production devra être effectuée avec des régimes alimentaires aussi parfaits que possible. Mais, même dans ce cas, il n'est pas rare que les apports soient insuffisants à couvrir les dépenses et la femelle doit emprunter à ses propres tissus les nutriments qui lui manquent. Elle perd du poids et termine parfois sa lactation dans un état d'épuisement considérable : c'est ainsi, par exemple, qu'un bas niveau nutritionnel, qui permet un déroulement normal de la gestation chez la Ratte, provoque chez cette dernières une délipidation à 85 p. Ioo s'il est maintenu pendant la lactation (PÉRISsE et SALMON-LEGAGNEUR, I960). Les besoins alimentaires de lactation ont été souvent étudiés et ont fait l'objet de mises au point récentes parmi lesquelles on peut citer celles de BREIREM (I957) sur la Vache, Thomson et Aitren (I959) sur la Brebis, Duncan et Lodge (I960) sur la Truie, HytTen (I96I) sur la Femme, Nelson et Evans (I96I) sur les animaux de laboratoire.

Mais on peut se demander comment réagit l'animal lorsqu'il passe d'un niveau nutritionriel relativement modeste de gestation aux besoins très intenses de la lacta- 
tion. Ce changement qui coïncide avec la parturition se signale en particulier par une inversion du sens des variations de poids. Il est assez vraisemblable toutefois qu'il ne se limite pas à ce seul phénomène et que le comportement de gestation n'est pas sans influencer celui de la lactation. Mais il existe ici un hiatus dans nos connaissances qui tient essentiellement à ce que la gestation et la lactation sont deux fonctions que les nutritionnistes ont presque toujours étudiées séparément. En effet, si les relations nutritionnelles entre les deux phénomènes ont été souvent évoquées, peu de travaux en ont concrétisé les modalités. Une exception doit être faite pour les quelques auteurs qui, comme WALr.ACE (r948), Coop (r950) sur la Brebis, Gardner et al. (I955) sur la Vache, LENkEit et al. (I955) et Suith (I960) chez la Truie, ont examiné l'effet du prolongement de certains régimes de gestation sur les performances des laitières.

Il n'en reste pas moins qu'aucune tentative sérieuse n'a été faite pour interprêter dans leur ensemble les phénomènes nutritionnels de la lactation, compte tenu de ceux de la gestation. Outre l'intérêt particulier présenté par ce problème, on peut y trouver la condition à une connaissance plus précise des besoins de reproduction et à l'établissement des normes alimentaires de l'animal en gestation ou en lactation. C'est à ce double titre donc que nous avons essayé d'étudier quelques unes des relations nutritionnelles entre la gestation et la lactation chez la Truie.

\section{B - Problèmes posés par les relations nutritionnelles}

Parmi les différents aspects des relations nutritionnelles, nous avons été surtout attiré par ceux qui mettent en jeu des variations corporelles de l'animal. D'une part parce que celles-ci prennent une place importante au cours de la reproduction, d'autre part parce qu'elles constituent, en première approximation, un des critères immédiats de l'efficacité des régimes.

Vus sous cet angle, les problèmes sont encore très nombreux et l'on peut retenir notamment les points suivants :

I $^{o}$ On ignore quels sont les facteurs qui conditionnent l'importance des variations de poids au cours des différentes étapes physiologiques de la reproduction. Existe-t-il une relation et laquelle entre l'anabolisme pondéral que l'on observe pendant la gestation et la perte de poids qui survient fréquemment au cours de la lactation?

$2^{\circ}$ On dispose de quelques informations sur la nature et l'importance des éléments fixés par l'organisme maternel au cours de la gestation. C'est ainsi que l'on a signalé chez diverses espèces des rétentions d'azote (ROMBAU'Ts et al. I956 ; LENKEIT et al., I955), d'énergie (BEATON et al., I954; Morrison, I956), de minéraux (FourNIER et al., I952; GutTe et al., I965 ; KIRSKEY et al., I962) et d'eau (BOURDEL, I960; Lichton, I963). Mais, à l'exception du métabolisme des minéraux (FourNiER et al., I953 ; VeNNING, I959) et de l'azote (LENkEIT, I956), les renseignements sont beaucoup moins nombreux pour la période de lactation. On ignore, en particulier, si ce sont les mêmes tissus qui sont affectés au cours des deux périodes. La reproduction n'est-elle pas l'occasion de modifications plus ou moins importantes de la composition corporelle qui, même si le poids reste constant, peuvent conđuire à un affaiblissement de l'animal? 
$3^{\circ}$ Quelles sont les relations entre, d'une part les variations de poids de l'animal et de l'autre, soit de la croissance embryonnaire, soit de la production laitière? Ces relations peuvent s'envisager de différentes façons : cas où les phénomènes varients parallèlement (croissance embryonnaire et anabolisme maternel), ce qui confère aux variations de poids la signification d'un test commode pour apprécier la valeur du régime alimentaire (PIKE et al., I954); cas où il existe une relation directe ou un antagonisme entre 1'intensité des p'rénomènes (par exemple, gain de poids élevé au cours de la gestation passant pour améliorer la performance de lactation (CAMPBELI, I948; WALLACE, I948)). Le bien-fondé de telles observations est sujet à discussion (REID, I96I), mais leur intérêt pratique a souvent retenu l'attention.

$4^{\circ}$ Les différents phénomènes se passant au cours de la reproduction peuvent modifier l'utilisation des nutriments. La notion de besoin doit également faire l'objet de nuances qui n'apparaissent pas toujours dans les mesures expérimentales effectuées. C'est ainsi que 1'activité musculaire, qui constitue une part importante du besoin énergétique d'entretien, diffère chez la gestante et chez la laitière, sans qu'il soit toujours facile de l'évaluer. Pour cette autre raison, 1'efficacité alimentaire des rations sera différente selon qu'on s'adresse à un animal au repos sexuel, à une gestante cu à une mère allaitante. Compte tenu des modifications éventuelles de la composition corporelle, 1'étude de l'efficacité alimentaire de la ration (production/ingéré) doit renseigner à la fois sur l'intensité des dépenses et l'opportunité des divers systèmes de rationnement (chronologie des apports).

Ces problèmes constituent quelques exemples de ceux qui sont à résoudre. Ce sont là des phénomènes complexes qui mettent en jeu quantité de facteurs, nutritionnels ou non, dont l'étude complète peut paraître ambitieuse. Aussi, est-ce volontairement que dans notre travail nous nous sommes limités à étudier l'influence de deux constituants de la ration : l'azote et l'énergie, tout en reconnaissant l'arbitraire de catte façon de procéder. Toutefois, ce sont ceux que l'on a le plus souvent coutume d'associer et les études de Bourdei, et JACoUoT sur la Ratte gestante leur confèrent un intérêt très particulier qui nous a séduit.

\section{C - Choix de l'animal}

Le choix de la Truie comme matériel animal de cette étude se justifie, non seulement par le fait que les informations sur le comportement nutritionnel de cette espèce sont assez incomplètes et même controversées, mais encore par diverses considérations en rapport avec les problèmes précédents :

$\mathrm{I}^{0}$ La Truie présente au cours de sa reproduction des variations pondérales importantes qui soulignent sa sensibilité aux facteurs nutritionnels (SCHAFFER et GRANZ, I955, LoDGE et al., I96I) : la variation de poids au cours de la gestation ou de la lactation est couramment de 20 p. IoO, mais dans certains cas elle peut dépasser 40 p. IOO.

$2^{\circ}$ L'espèce a une prédisposition naturelle à une lipogenèse intense qui facilite l'observation. Des variations importantes de composition corporelle peuvent être suivies chez l'animal vivant en mesurant l'épaisseur du tissu adipeux sous-cutané dorsal (Aunan et WinTERs, I949). 
$3^{0}$ Le taux des productions est particulièrement élevé chez la Truie en gestation et en lactation : les performances réalisées (nombre et poids des petits, quantité et composition du lait) paraissent supérieures à celles des grands animaux domestiques et témoignent d'une aptitude particulière à la reproduction. Elle n'a pour équivalent à cette échelle zoologique que celle des animaux de laboratoire (Ratte, Lapine), mais elle permet des déterminations relativement plus aisées (par exemple, l'étude de la composition du lait qui est très délicate chez la Ratte).

$4^{0}$ Malgré une certaine abondance de travaux (environ 300 références) les besoins alimentaires fondamentaux de la Truie en reproduction sont encore très imparfaitement connus. Les déterminations, souvent empiriques, dont ils ont fait l'objet, font apparaître une absence de cohérence regrettable : par exemple, l'évaluation de la dépense énergétique de gestation varie pratiquement du simple au double selon les auteurs (N. R. C., I953; Popehina, I957).

\section{I) - Plan proposé}

Après l'exposé des techniques utilisées (chap. I), nous exposerons en y apportant le maximum de précisions ce qu'on connaît des phénomènes de reproduction (gestation, lactation) chez la Truie (chap. II). Nous avons utilisé à cette fin les observations que nous avions pu faire sur des animaux placés dans des conditions habituelles d'élevage et en dehors de toute contrainte nutritionnelle. Nous avons considéré d'une part les modifications de poids et, d'autre part, les productions proprement dites (contenus utérins, lait) en essayant d'analyser chaque fois la nature et l'importance des principales variations observées.

Parmi les différents facteurs pouvant intervenir, nous avons étudié ensuite l'influence du niveau alimentaire global (chap. III), qui doit différer selon qu'il s'agit de la gestation ou de la lactation, et dont les effets peuvent se manifester dans 1'immédiat ou a retardement. Nous avons entrepris d'étudier dans une première recherche dans quelle mesure le niveau alimentaire de la gestation conditionnait le comportement et les performances de la mère allaitante.

Les variations expérimentales de l'apport azoté de la ration constituent un second moyen d'approfondir ces relations nutritionnelles (chap. IV). Nous avons essayé d'apprécier les facteurs quantitatifs et qualitatifs qu'elles mettaient en jeu. Mais ces derniers dépendent aussi dans une large part de l'apport énergétique de la ration, ce qui introduit un nouveau type de relations.

L'aspect énergétique a surtout été examiné en considérant le devenir ou la signification physiologique des réserves édifiées par l'animal pendant la gestation (chap. V). A cet effet, nous nous sommes livrés à une étude particulière de la participation respective du tissu adipeux et des graisses alimentaires dans l'élaboration des lipides du lait, ce qui constitue le dernier type de relations étudiées. 


\section{CHAPITRE I}

\section{TECHNIQUES EXPÉRIMENTALES}

Des phénomènes physiologiquement aussi différents que la gestation et la lactation ne peuvent être étudiés, même du seul point de vue nutritionnel, à l'aide de techniques identiques. En fait, compte tenu de la multiplicité des aspects que nous avons essayé d'envisager, le nombre des techniques nécessaires risquait de devenir considérable et par là même hors de possibilité.

Il nous a donc fallu nous limiter à l'emploi de quelques méthodes tout en reconnaissant qu'aucune de celles que nous avons utilisées n'est idéale ou complète. L'expérimentation sur truies pose en effet de nombreux problèmes:

Tout d'abord l'animal est volumineux et peu maniable: les truies que nous avons utilisées pesaient en moyenne $200 \mathrm{~kg}$ et l'entretien de notre troupeau expérimental, comportant en permanence I50 truies, nécessite une infrastructure (porcheries, personnel, aliments) importante, qu'il est facile d'imaginer.

Certaines techniques analytiques d'un usage courant sur les animaux de laboratoire ne sont pas applicables à cet animal, soit que trop difficiles à réaliser sur le plan matériel, soit que trop coûteuses : par exemple, la détermination chimique de la composition corporelle ne peut, sauf exception, être pratiquée par les procédés habituels, car l'échantillonnage à partir de la carcasse totale homogénéisée paraît difficilement réalisable.

Le manque de précision est un défaut commun à beaucoup de techniques sur l'animal vivant. Il peut tenir à l'appareillage (par exemple, la précisoin des balances) ou aux servitudes imposées par l'animal (variabilité des contenus digestifs : 2 à Io $p$. Ioo du poids vif, qui entache d'erreurs la détermination du poids vif).

Toutes ces raisons font que, dans bien des cas, les mesures que nous avons pu effectuer comportaient des erreurs systématiques que nous ne méconnaissons pas, mais qu'il était difficile d'éviter. Lorsque cela a été possible, nous avons essayé de compenser l'imprécision de certaines données en augmentant le nombre des observations individuelles (pour diminuer l'erreur moyenne). Mais il n'en reste pas moins que nous avons dû souvent nous contenter de techniques assez grossières, qui ne pouvaient nous conduire à des conclusions définitives, mais plutôt à des hypothèses et que nos résultats posent parfois plus de problèmes qu'ils n'en résolvent. C'est, pensons-nous, le cas pour bien des recherches de ce type où il faut opérer par étapes. 


\section{CONDITIONS GÉNÉRALES DE L'EXPÉRIMENTATION}

Les animaux utilisés étaient des truies de la race Yorkshire Large-White, la plus répandue en France, et provenaient de l'élevage expérimental du C. N. R. Z. Ces animaux étaient placés dans des conditions de logement uniformisées (porcheries conditionnées à I $8^{\circ} \mathrm{C}$ et $60 \mathrm{p}$. Ioo d'état hygrométrique) de façon à éliminer autant que possible les variations dues au milieu.

Dès l'apparition de la puberté, les truies étaient soumises à la reproduction, mais dans la plupart des cas la période expérimentale ne débutait qu'après la première portée, car cette dernière survient en général à un âge où l'animal est encore en pleine croissance, ce qui complique la signification des résultats par suite d'interférences entre les phénomènes, notamment d'ordre nutrionnel.

Les régimes utilisés variaient selon les expériences, mais étaient tous d'un type relativement simple et constitués d'aliments (céréales, farines animales, tourteaux, minéraux, vitamines) dont les caractéristiques analytiques étaient parfaitement connues. Ces régimes étaient confectionnés, en proportions définies par leurs constituants, en quantité suffisante pour chaque expérience à l'usine d'aliments du C. N. R. Z. et présentés sous forme d'un mélange farineux homogène distribué individuellement et en quantité connue aux animaux. Chaque fabrication donnait lieu à un échantillonnage aux fins d'analyses. Sauf lorsque les conditions de l'expérience le nécessitaient, les quantités allouées par animal et par jour étaient celles précisées par les normes françaises d'alimentation du Porc (LEROY, I949).

Outre la détermination des ingérés et des excretas, les mesures effectuées au cours des expériences se rapportaient essentiellement aux variations corporelles de la Truie, aux contenus utérins et à la production laitière.

\section{A - Variations corporelles}

a) Poids vif

La mesure du poids vif des animaux permet d'avoir une idée d'ensemble des phénomènes de croissance, car il est bien connu que le poids vif reflète approximativement l'état nutritionnel. Cette mesure offre l'avantage d'une grande simplicité et nous 1'avons souvent utilisée. La précision de la mesure elle-même est voisine de I p. Ioo, mais la signification physiologique est entachée d'une erreur qui provient des variations individuelles des animaux au cours de la journée (ingestion des repas). Pour atténuer cette influence, nous avons veillé à ce que nos animaux soient toujours pesés dans les mêmes conditions et aux mêmes heures, précaution élémentaire pas toujours observée.

La différence entre les poids à deux époques constitue le gain ou la perte de poids, offrant plus d'intérêt que les poids eux-mêmes. A cet effet, nous avons utilisé la terminologie suivante:

- Gain total de gestation : différence entre le poids avant la parturition (dilatation du col de l'utérus), et le poids à l'accouplement, 
- Gain net de gestation : différence entre le poids après parturition (expulsion du placenta), et le poids à l'accouplement,

- Perte de lactation : différence entre le poids au sevrage $\left(5^{6}\right.$ e jour de lactation), et le poids après parturition.

- Bilan global : différence entre le poids au sevrage et le poids à l'accouplement.

Pour un lot de ro animaux, on peut estimer que l'erreur moyenne sur chacune de ces mesures est d'environ 2 p. Ioo.

Dans deux de nos expériences, nous avons utilisé également les coefficients d'efficacité protidique (Osbonne et al., IgI9) qu'il est possible de calculer, connaissant les gains de poids et la quantité d'aliment consommée :

$$
\text { C. E. P. }=\frac{\text { Gain de poids }(\mathrm{kg})}{\text { Protides ingérées }(\mathrm{kg})}
$$

En théorie, ce coefficient permet une classification des protides alimentaires basée sur l'efficacité de croissance. On lui a fait de nombreuses critiques lapportées par ADRIAN et RÉra'T (I958). Nous lui reprochons surtout quant à nous de ne pas tenir compte des importantes variations de la composition corporelle qui surviennent, notamment chez la Truie en gestation.

\section{b) Composition corporelle de l'animal vivant}

Chaque fois qu'il n'a pas été possible de procéder au sacrifice des animaux, les variations de la composition corporelle ont été étudiées à partir de l'évolution de l'épaisseur du tissu adipeux sous-cutané dorsal. Il existe en effet chez le Porc une corrélation positive élevée entre l'épaisseur dé ce tissu et les lipides totaux de l'organisme, qui autorise à utiliser cette mesure comme critère d'adiposité (ZoBRIsky et al., I954). Parmi les différents procédés utilisés à cet effet, nous avons retenu la méthode de Dumon' (I958) par sondage aux ultrasons qui offre le double avantage de présenter tune bonne précision relative et d'être indolore pour les animaux. L'appareil utilisé était du type Métalloradar R. V. émettant une onde de fréquence $5 \mathrm{Mc} / \mathrm{s}$ qui traverse les tissus à la vitesse approximative de $\mathrm{I} 750 \mathrm{~m} / \mathrm{s}$.

En supposant connu le pourcentage initial de lipides de l'organisme et sous réserve que les lipides totaux de l'organisme varient linéairement avec l'épaisseur du tissu adipeux (ce qui n'est pas entièrement exact), on peut déterminer, pour une période donnée, le gain en tissu adipeux. Par différence, à partir du gain de poids total, on peut apprécier le gain en autres tissus. Bien entendu, les résultats ainsi obtenus sont sujets à de nombreuses imprécisions et doivent être interprêtés avec prudence.

L'étude qualitative de la compcsition en acides gras du tissu adipetıx a été entreprise dans certaines expériences et a nécessité l'exécution de biopsies. Celles-ci ont été effectuées sous anesthésie au niveau du cou ( $5^{\mathrm{e}}$ vertèbre cervicale). Les échantillons, d'un poids de I g, étaient prélevés sous la peau, à l'interface des couches interne et externe du tissu adipeux dorsal.

Les lipides totaux étaient extraits à froid dans un homogénéiseur M. S. E. par un mélange de $3 / \mathrm{I}$ de chloroforme-méthanol. Après saponification et méthylation, 
les acides gras étaient dosés par chromatographie en phase gazeuse sur un appareil Aerograph $35^{\circ} \mathrm{B}$ (colonne de ro pieds $\times \frac{1}{4}$ pouce, portée à $205^{\circ} \mathrm{C}$, phase stationnaire : 20 p. Ioo de D. E. G. S. sur chromosorb, détection par catharomètre, débit $50 \mathrm{ml} / \mathrm{mn}$ ).

\section{c) Composition corporelle de l'animal mort}

Les techniques d'analy'se chimique que l'on peut utiliser pour des animaux de petite taille étant difficilement applicables, l'étude de la composition corporelle des truies sacrifiées a été faite par dissection. A cet effet, nous avons séparé et pesé aussitôt après l'abattage les différentes masses corporelles ou organes suivants : tête, masse musculaire + squelette (carcasse), tissu adipeux sous-cutané dorsal (bardière), tissu adipeux périrénal (panne), appareil respiratoire, cœur, foie, rate, mésentère, estomac, intestin, utérus

Cette analyse corporelle, effectuée sur des truies, soit au repos sexuel, soit à différents stades de gestation ou de lactation, a essentiellement permis de suivre l'évolution pondérale des différents tissus ou organes en fonction du stade physiologique.

\section{d) Bilans nutritionnels}

L'étude des bilans azoté et énergétique a été entreprise au cours de cycles complets de reproduction (repos + gestation + lactation) sur quelques animaux placés dans des cages à métabolisme d'un type original mis au point à cet effet.

Dans le cas de la Truie en gestation, la principale difficulté vient de la séparation de l'urine et des fèces. Celle-ci a été résolue grâce à un jeu de plans inclinés en matière plastique qui acheminent les excréments vers des bacs de récolte séparés (fig. I). Ce dispositif, voisin de celui utilisé par Rombauts (I962), est d'une parfaite efficacité et évite le "rinçage " des fèces et des urines.

Dans le cas de la Truie en lactation, il s'y adjoint une autre difficulté due à la présence des porcelets qui doivent pouvoir téter librement sans que leurs déjections risquent de se mélanger avec celles de la mère. Il faut également prévoir un dispositif de contrôle de la production laitière. Une installation complète de ce type permettant de travailler simultanément sur 2 truies a été réalisée et est représentée sur la figure 2.

Dans tous les cas, la récolte des excretas a été faite sous acide sulfurique $\mathrm{N}$ pour prévenir les pertes d'ammoniac, et l'on a procédé à un échantillonnage hebdomadaire d'une quantité aliquote préparée à partir des récoltes quotidiennes conservées à $0^{\circ} \mathrm{C}$.

L,e dosage de l'azote a été effectué par la méthode Kjeldahl sur les échantillons frais et l'énergie a été mesurée à la bombe calorimétrique à thermocouple de Féry sur produits séchés à $100^{\circ} \mathrm{C}$.

\section{B - Contenus utérins}

Dans la plupart des cas, nous nous sommes contenté de faire le compte des porcelets et de peser les différents produits de la conception (porcelets, annexes placentaires, liquides) au moment de la parturition.

Toutefois, chez les truies placées en cage à métabolisme et pour compléter les données du bilan, nous avons sacrifié deux porcelets au moment de la parturition. 


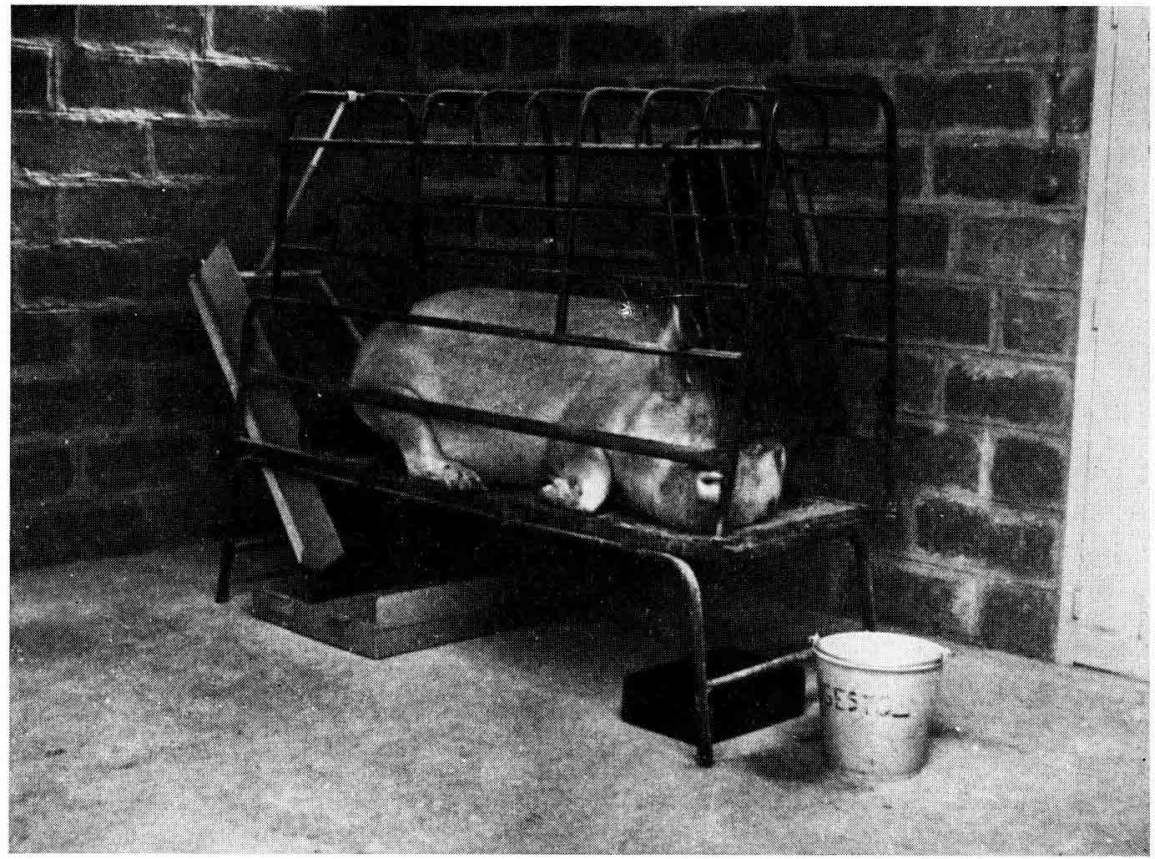

FIG. I. - Cage à méiabolisme pour truies gestantes

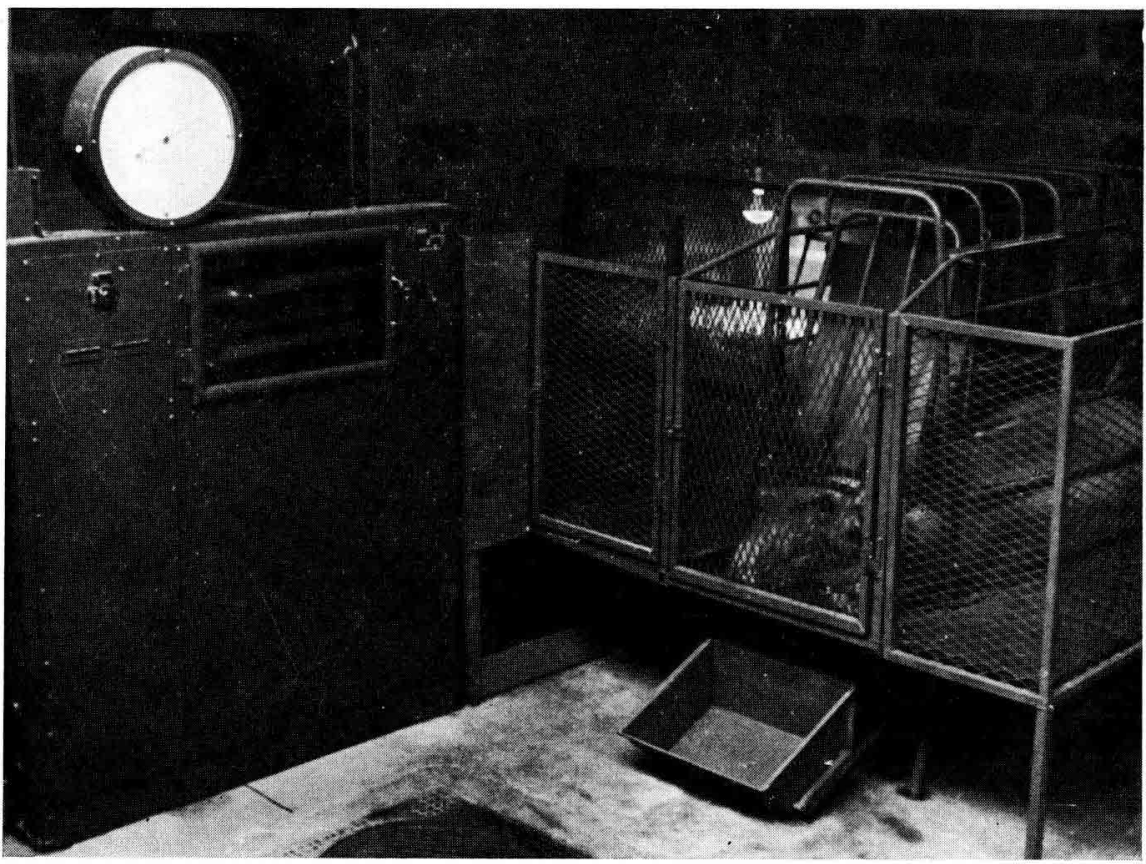

FIG. 2, - Cage à métabolisme pour truies en lactation

(à gauche, dispositif pour la mesure de la production laitière) 
Ces derniers, de même que les annexes placentaires, ont été finement broyés, puis homogénéisés, afin de constituer des échantillons sur lesquels on a déterminé l'azote (Kjeldahl) et l'énergie (bombe calorimétrique) des productions utérines.

Par ailleurs, une étude plus complète de l'évolution du contenu utérin, au cours de la gestation, a été entreprise sur 48 truies sacrifiées à des stades variés de gestation Cette étude comportait, outre la dissection des carcasses, la pesée des différents produits de la conception et l'analyse chimique des embryons par les procédés habituels (azote Kjeldahl, lipides extraits selon la méthode de BrIGH et Dy̌r, (I959), minéraux par minéralisation à $550^{\circ} \mathrm{C}$ ).

\section{C - Production laitière}

La principale difficulté dans l'étude de la production laitière de la 'Truie vient de ce qu'il n'est pas possible de pratiquer une traite ordinaire, car l'animal retient son lait. Aussi, selon la nature des problèmes étudiés, avons-nous utilisé les différents procédés suivants :

\section{a) Mesure directe de la production par contrôle des tétées}

Cette technique, la plus classique, a été employée avant nous par de nombreux auteurs parmi lesquels on peut citer : VAx GOHREN (I865), HeNRy (I897), CARI.YLE (I903), Hemper, (I928), Wohrbier (I929), Orofsson (I930), Thompson (I93 I), Hughes (I935), Bonsma (I935), Donald (I936), Dschaparidse (I936), Weils (i940), Filmer (i949), Niwa (I95I), Smith (i952), Lalevic (i953), Berge (i953), BARBER (I955). Elle consiste à apprécier la quantité de lait délivrée par la Truie au cours d'une tétée par différence entre les poids des porcelets immédiatement avant et après cette tétée (ce procédé est également utilisé pour l'espèce humaine). Fille est en général plus précise que celle qui consiste à peser la mère avant et après la tétée (Clausen, I952).

Pour l'utilisation pratique de cette méthode, deux conditions principales sont nécessaires :

Io La pesée des porcelets doit être effectuée sur un appareil donnant une précision de Io à $20 \mathrm{~g}$ pour une pesée (ce qui correspond à une erreur relative sur un contrôle de 3 à 5 p. I00). Compte tenu de la charge utile (200 kg) et des vibrations dues aux mouvements des animaux, ceci constitue souvent une performance délicate à réaliser. Des balances adaptées à cet usage nous ont toutefois été construites par les $\hat{\mathrm{E}}^{\text {ts }}$ Dyona et Polossat. (fig. 2)

$2^{0}$ Le protocole doit ressembler autant que possible aux conditions naturelles de la tétée. A cet effet, on doit veiller principalement à limiter au maximum les manipulations d'animaux et 1'on doit respecter le rythme propre des tétées des porcelets. Une étude préliminaire sur 20 truies nous a montré que les truies donnaient à boire à leurs petits en moyenne toutes les 65 minutes le jour et toutes les 66 minutes pendant la nuit. Toutefois, cet intervalle varie assez largement avec les individus et également avec le stade de lactation (SALmox-LEGagneur, I956). Par contre, le rythme des tétées et les quantités de lait délivrées varient peu au cours de la journée. 
Ces différentes considérations nous ont conduit à adopter pour nos mesures un intervalle constant de 75 minutes pour 6 contrôles journaliers pratiqués entre 8 heures et $I 5$ h 30 , après avoir vérifié que cet intervalle correspondait à une fraction constante de la production journalière. Les porcelets étaient successivement acheminés yar un jeu de trappes et de plans inclinés vers un couloir à déjection, la balance, la truie (tétée) et de nouveau la balance. L'ensemble des opérations durait Io à $\mathrm{I}_{5} \mathrm{mi}$ nutes, mais le temps entre les 2 pesées n'était que de 3 minutes, ce qui permettait de réduire certaines causes d'erreurs (défécations). La précision de la mesure de la production pour une période de 24 heures est d'environ 8 p. roo.

Environ 800 lactations d'une durée de 8 semaines ont été suivies par ce procédé.

\section{b) Mesure indirecte par pesée des porcelets à un âge donné}

La méthode précédente offre le double inconvénient de nécessiter beaucoup de temps et d'employer un matériel assez onéreux (balance de précision). Aussi avonsnous parfois utilisé une autre technique basée sur la corrélation qui existe entre la quantité de lait consommée par les porcelets et la croissance de ces derniers. Le système est couramment employé pour les animaux de laboratoire (Litter grouth index de Cowie, I947).

A cet effet, nous avons déterminé expérimentalement l'équation de régression de la production laitière sur le poids de la portée à 8 semaines :

P. laitière $(\mathrm{kg})=\mathrm{I}, 98$ poids des porcelets à 8 semaines $(\mathrm{kg})+77,3 \mathbf{I}$

Cette formule permet de calculer avec une précision expérimentale d'environ I 4 p. Ioo la production laitière à partir du poids de la portée. Ce procédé est extrêmement simple et rapide ; on peut par contre lui reprocher son manque de précision qui tient aux variations individuelles de l'utilisation du lait par les porcelets.

\section{c) Récolte des échantillons de lait}

Le problème se posait d'obtenir des échantillons de lait de Truie suffisamment représentatifs pour en analyser les constituants. Puisque la traite ordinaire n'était pas possible, nous avons provoqué l'éjection du lait par des injections intraveineuses d'ocytocine.

Une machine à traire spéciale munie de $\mathbf{I} 2$ gobelets légers a été mise au point pour permettre la récolte séparée du lait de chaque trayon (fig. 3). Fondamentalement, ce procédé n'est pas à l'abri de toutes critiques en raison de la stimulation possible de la production par l'hormone et l'action éventuelle de cette dernière sur la sécrétion des matières grasses. L,es réactions individuelles à l'injection sont, en outre, variables et la dose à injecter est difficile à déterminer ${ }^{1}$ ). En effet, la quantité de lait à obtenir doit être aussi proche que possible de celle que tètent les porcelets et celle-ci peut varier de 100 à $500 \mathrm{~m}$. Selon les circonstances et les quantités de lait que nous désirions récolter, nous avons été amenés à injecter des doses d'ocytocine comprises entre I et Io UI.

(1) A fortiori, il n'est pas possible d'utiliser cette méthode comme technique de mesure des quantités de lait produites, comme le proposent ALLEn et LASLEY (i960). 
Dans nos conditions expérimentales, nous nous limitions en général à la récolte d'un échantillon de lait de Truie par animal et par semaine.

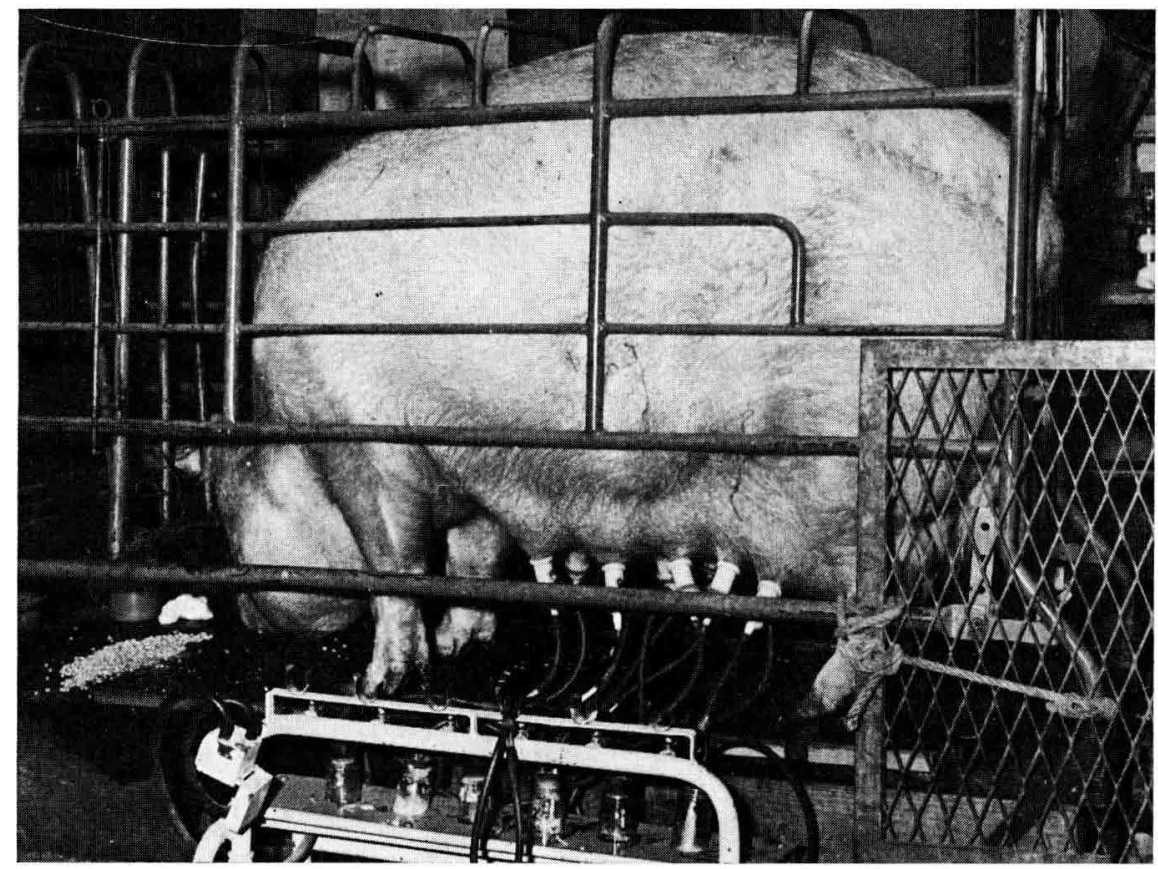

FIG. 3. - . Wachine à traire pour la récolte d'échantillons de lait de Truie

\section{d) Composition du lait de Truie}

Les échantillons de lait de Truie étaient en général analysés par série après stockage, selon les cas, de I à 8 jours à $0^{\circ} \mathrm{C}$ et sans conservateur.

L'analyse chimique des principaux constituants lu lait a été effectuée par les procédés classiques que nous énumérons ci-dessous :

- Matière sèche : dessiccation à l'étuve à vide à $40^{\circ} \mathrm{C}$ pendant 48 heures.

- Lactose : technique iodométrique de Sonogrr ( 1952 ) après défécation à l'acétate de zinc et au ferrocyanure de potassium.

- Azote total : méthode Kjeldahl.

- Fractions azotées : technicjue de précipitations fractionnées de RowiaND (I938), d'Aschalfexburg (I959) et de Shahaxi (I95I).

- Lipides totaux : extraction éthéro-ammoniacale selon RosE-GotTLIËB et séchage sous vide.

- Acides gras volatils : hydrolyse et entraînement à la vapeur.

- Acides gras libres : adsorption sur amberlite I. R. A. (FRANkEI, I955) et chromatographie en phase gazeuse.

- Acides gras polyéniques : isomérisation alcaline et dosage spectrophotométrique en ultraviolet (A. O. C. S., I958). 
- Acides gras saturés et insaturés, C6-C20 : chromatographie en phase gazeuse sur D. E. G. S., après extraction et méthylation par méthanol/ ClH (LudDy et al., I958; JENSEN et al., Ig62).

- Phospholipides : dosage colorimétrique du P lipidique (SMITH et al., I959) ou adsorption sur acide silicique et chromatographie en phase gazeuse (DEUTSCH et al., I958).

- Glycérol : dosage de l'acide formique après scission oxydante au periodate (A. O. C. S., I956).

- Minéraux totaux : incinération à $55^{\circ} \mathrm{C}$.

- $\mathrm{Ca}, \mathrm{K}, \mathrm{Na}, \mathrm{Mg}$ : spectrophotométrie de flamme (GUEGUEN, I96r).

-- P : réaction colorimétrique au vanadomolybdate (FLEURY, I943).

-- Énergie : Bombe calorimétrique à thermccouple de Féry.

Certaines de ces techniques sont critiquables en raison de leur manque de précision (fractions azotées), mais elles avaient l'avantage d'être faciles et rapides à exécuter pour des dosages en série. Nous avons pu vérifier en outre que leur répétabilité était, en général, très satisfaisante (exception faite pour les lipides totaux pour lesquels aucun procédé de dosage ne s'est montré réellement satisfaisant).

L'ensemble de ces techniques a été appliqué à environ 2 ooo échantillons de lait de Truie. 


\section{CHAPI'TRE II}

\section{CARACTÈRS GÉNÉRA UX ET PARTICULIERS DE LA REPRODUCTION DE LA TRUIE}

Ce chapitre étudie l'influence que peuvent avoir des facteurs autres que nutritionnels sur les phénomènes de reproduction de la Truie. Il convient, en effet, d'en connaître la diversité et l'importance afin de pouvoir interprêter par la suite le sens de nos résultats et dégager la part qui revient aux facteurs strictement alimentaires.

\section{A - Le cyele de la reproduction et ses difíérentes phases}

$$
\mathbf{I}^{\circ} \text { Puberté, cycles sexuels et ovulation }
$$

Suivant les races et les conditions de milieu, la puberté apparaît chez la Truie à des âges variant de 5 à $\mathrm{I} 3$ mois pour des poids vifs allant de 50 à $\mathrm{I} 80 \mathrm{~kg}$ (SchmidT et BREITCHNEIDER, I954).

En ce qui concerne les animaux dont nous disposions, l'âge au premier œestrus se situait à $28 \mathrm{I} \pm 6 \mathrm{I}$ jours pour un poids de $\mathrm{I} 20 \pm 2 \mathrm{I} \mathrm{kg}$, valeurs du même ordre que celles rapportées par GOODE (I95I), mais un peu plus élevées que celles indiquées par ROBERTSON (I95I a) et BURGER (I952).

Selon ASDEL, (I946), la durée moyenne du cycle sexuel (écart entre deux œestrus) est de $2 \mathrm{r}$ jours avec des limites de I 8 à 25 jours (MCKENZIE, I926). Toutefois, nous avons noté une légère différence selon qu'il s'agissait de jeunes truies à leur premier ostrus ou d'animaux ayant déjà reproduit :

\section{Durée du cycle}

$$
\begin{aligned}
& \text { Truies à la puberté ......... I } 9,6 \pm 2, \mathrm{I} \text { jours } \\
& \text { Truies âgées............ 24,5 } \pm 5,2 \text { jours }
\end{aligned}
$$

Pendant la gestation et la lactation, la présence de corps jaunes en activité empêche le retour des cycles sexuels. A l'exception d'un œstrus post-partum qui n'est généralement pas suivi d'ovulation, la reprise des ovulations ne s'effectue qu'avec le sevrage et dans un délai variable de 6 à 15 jours suivant la date de ce dernier (BAKER, I953, DYRENDAHL, I958 ; SELF, I958). Ceci a pour effet d'empêcher tout recouvrement entre ces deux périodes.

Par la suite, et si la Truie n'est pas fécondée à nouveau, les cycles continuent normalement tous les $2 \mathrm{I}$ jours. Le temps qui s'écoule entre le sevrage et l'accou- 
plement correspond à la période dite de "repos " de l'animal. Dans la pratique courante de l'élevage, cette période se limite le plus souvent au I I $^{\text {or }}$ au $2^{\mathbf{e}}$ œstrus après le sevrage ( 6 à 30 jours).

La durée moyenne de l'ostrus est voisine de $50 \mathrm{~h}$ pour la race Large-White (BURGER, I952) avec des extrêmes de un à cinq jours. Cette durée varie sensiblement avec la race et l'âge des animaux. Le moment exact de l'ovulation est difficile à situer avec précision, car il ne semble pas que tous les ovules soient libérés en même temps, ce qui peut expliquer certaines différences de développement entre les embryons (GREEN et WinTERS, I946). Dans la majorité des cas, il semble toutefois se situer entre $\mathbf{I} 8$ et 24 heures après les premières manifestations de 1'œstrus, ce qui fournit donc des indications sur le moment auquel 1'accouplement doit être effectué (BURGFr, I952).

Le nombre d'ovules pondus par une Truie au cours d'un cestrus paraît très variable et dépend en premier lieu de l'âge et de la race des animaux : suivant les circonstances, ce nombre peut varier de o à 30 (HAMmond, I9I4; CoRNER, I923; PERRY, I955) et la moyenne se situe en général entre I 2 et 16 , ce que confirment nos propres observations :

$$
\begin{aligned}
& \text { au } \mathrm{I}^{\text {er }} \text { cestrus } \ldots \ldots \ldots \ldots \\
& \text { à } 1 \text { 'âge adulte } \ldots \ldots \ldots \ldots
\end{aligned}
$$

\section{$2^{\circ}$ Gestation}

La durée de la gestation chez les truies de notre troupeau était de II5 jours. Cette valeur, très voisine de celles indiquées par MCKENZIE (I928) et KRIZENECKY (I942), souligne une constance remarquable qui n'est affectée ni par la race, ni par l'âge, ni par la nutrition.

Le nombre de fœtus qui se développent et donnent lieu à des naissances est, par contre, très variable : suivant les races, il oscille entre 6 et I 2 porcelets par portée (DunCAN et LoDGE, I96I) avec une moyenne de Io,8 pout la race Large-White. Le poids moyen d'un porcelet est d'autant plus élevé que ces derniers sont moins nombreux (CESBRON, I958) et varie généralement dans les limites de 0,9 à $2 \mathrm{~kg}$ (GohNER, I933 ; LUSH, I934; KoblischeK, I939; KRIZENECKY, I954 ; TOTEV, I955 ; KolAT, I96I ; LODGE, I96I ; CHAPMAN, I962).

\section{$3^{\circ}$ Lactation}

Si la durée de la lactation chez la Truie est assez variable, ce n'est pas tellement à cause des possibilités de l'animal lui-même, qu'en raison de contingences économiques qui amènent les éleveurs à sevrer les truies à une époque où la lactation est souvent loin d'être terminée. Dans la pratique, les sevrages ont lieu le plus fréquemment à 8 semaines, date que nous avons nous-mêmes conservée dans nos expériences.

La montée laiteuse a lieu chez la Truie dans les quelques heures qui précèdent le part (Cross et $a l$., I958), ce qui constitue une différence par rapport à certaines. autres espèces comme les Ruminants où elle est plus précoce. Elle est suivie pendant 24 à 48 h de la production d'un colostrum très coloré et visqueux. riche en protéines, notamment en globuline (HEMPEL, I928) et contenant beaucoup d'anticorps (BEA- 
COM et BoWlaND, I95I ; NORDBRING, I957) et de vitamines (BRAUdE et al., I946 ; BowlAND, I949; DAvis, I95I). Les porcelets privés de colostrum présentent une mauvaise croissance, une mortalité élevée et s'avèrent incapables de réagir aux antigènes avant 1'âge de 8 semaines (HOERLEIN), I957).

Le lait de Truie est blanc, assez épais et d'un goût plus douceâtre que celui du lait de Vache (Hempei, I928). Sa composition chimique a fait l'objet de nombreuses déterminations, passées en revue par NeuHaus (I960) et LuCAS et Lodge (I96I), mais quii laissent de côté l'influence de la plupart des facteurs de variations sur lesquels nous aurons l'occasion de revenir.

La valeur énergétique brute du lait de Truie se situe selon PERRIN (I958) entre 0,93 et I,I5 calories/g. I1 faut ajouter que 1'énergie nécessaire à la production de ce lait paraît difficile, sinon impossible, à mesurer, car la variation du métabolisme basal au cours de la lactation n'est pas elle-même connue avec précision (BRODY et al. I938; WASHBURN et al., I939; RrTzMAN, I94I ; GUTTE, I960; LODGE, I959). La principale difficulté vient en effet de ce qu'il est très difficile de maintenir la 'Truie allaitante en équilibre de poids. De nombreuses études soulignent en effet l'existence d'une perte de poids plus ou moins importante de l'animal dont la signification est mal connue (ZEI,LER et $a l .$, I937; LODGE et al., I96I ; MAJERCIAK, I962)

\section{B - Les variations de poids au cours de la reproduction}

\section{I ${ }^{\circ}$ Gestation}

a) Mise en évidence.

Il suffit de jeter un coup d'œil sar des travaux déjà anciens pour voir qu'en toutes circonstances, même les plus défavorables, les truies prennent du poids pendant la gestation (MCKFNZIE, I926, I928). Cette prise de poids est complexe et résulte de plusieurs phénomènes:

- croissance normale de la Truie qui se poursuit,

- développement des contenus utérins : fotus et annexes,

- restauration des tissus détruits pendant la lactation antérieure,

- gains extra utérins spécifiques de la gestation.

Ce dernier phénomène, parfaitement décrit chez la Ratte par BouRder et JACQUOT (I957) constitue l'anabolisme gravidique au sens strict et désigne donc le bénéfice pondéral des tissus purement maternels chez une femelle en équilibre de poids avant sa gestation.

Par extension, lorsque la croissance normale n'est pas encore terminée, on le confond parfois avec le gain net de gestation qui désigne alors la croissance normale et le gain spécifique de gestation. Un sondage effectué sur roo truies de notre troupeau, d'un poids moyen de I $84 \mathrm{~kg}$ à l'accouplement et maintenues dans des conditions normales d'alimentation, a permis d'établir la répartition des gains de poids rapportée au tableau $I$.

La première chose qu'il faut souligner est l'importance du gain de poids net de la mère, dont la valeur, aussi surprenant que cela paraisse, représente environ 2 fois 
celle du contenu utérin et relègue donc celui-ci au $2^{\mathrm{e}}$ rang des productions de la gestation.

TABLEAU I

Gain de poids des gestantes

\begin{tabular}{|c|c|c|}
\hline & $\mathrm{kg}$ & p. 100 du poids initial \\
\hline Gain de poids total ..... & $74,5 \pm 45$ & 40,5 \\
\hline $\begin{array}{l}\text { Contenu utérin }(+ \text { perte de } \\
\text { poids durant la partu- } \\
\text { rition) } \ldots \ldots \ldots \ldots \ldots \ldots \text {. }\end{array}$ & $20,4 \pm 15$ & 11,0 \\
\hline Gain net $\quad \ldots \ldots \ldots \ldots$. & $54,2 \pm 48$ & $29, \dot{t}$ \\
\hline Croissance normale (1) ... & $27,8 \pm 17$ & 15,0 \\
\hline Anabolisme gravidique.... & $26,4 \pm 17$ & 14,3 \\
\hline
\end{tabular}

(1) Déterminée sur des témoins non gestants de même âge.

Un calcul simple, basé sur nos résultats de bilans (6 truies) pour l'azote et sur les données de CIAUSEN (I952) pour l'énergie, montre que ce phénomène prend encore beaucoup plus de relief lorsque les comparaisons sont effectuées à partir de l'azote et de l'énergie retenus (tableau 2).

TABLEAU 2

Répartition de l'azote et de l'énergie retenus au cours de la gestation

\begin{tabular}{|c|c|c|c|c|}
\hline & \multicolumn{2}{|c|}{ Azote } & \multicolumn{2}{|c|}{ Énergie } \\
\hline & $\mathrm{g}$ de $\mathrm{N}$ & P. 100 du total & thermies & p. $100 \mathrm{du}$ total \\
\hline Gain net............. & 1248 & 81,8 & 155 & 91,7 \\
\hline Contenu utérin...$\ldots \ldots$ & 276 & 19,2 & $11^{\prime}$ & 8,3 \\
\hline Total ..... & $152 \%$ & 100 & 169 & 100 \\
\hline
\end{tabular}

On constate, en effet, que les rétentions extra-utérines d'azote et surtout d'énergie constituent un des phénomènes nutritionnels les plus importants de la gestation. On peut s'étonner que des auteurs comme MiTcheliL (I93I) ainsi que MoustgaARD (I958) semblent ignorer ces rétentions et n'en tiennent pas compte dans leur évaluation des besoins nutritifs de la Truie gestante.

Il convient de souligner l'importance et la signification de l'anabolisme gravidique, cette "super-retention" (LENKEIT, I955) qui se greffe sur la croissance normale. Il est responsable d'un bénéfice pondéral qui équivaut au poids du contenu de l'utérus. Chose remarquable, il ne coûte théoriquement rien à l'animal, car pour une même dépense alimentaire, il s'ajoute à la croissance normale, ce qui suppose donc une réduction du besoin d'entretien. Toutefois, son examen s'avère difficile 
en raison de la persistance de la croissance normale de la Truie et de la difficulté à atteindre un état d'équilibre chez cette espèce. Pour cette raison, c'est surtout le gain net de gestation (anabolisme gravidique + croissance normale) qui a été pris en considération dans les études de nutrition chez la Truie.

Le gain net de gestation est susceptible de variations individuelles importantes. L'origine de celles-ci doit être surtout recherchée dans les variations des quantités d'aliment ingérées avec lesquelles on trouve une corrélation de coefficient $r=+0,43$ $(\mathrm{P}<\mathrm{o}, \mathrm{or})$. On observe également une certaine variation avec 1'âge de l'animal, le gain de poids étant étant généralement plus important au cours des $2^{\mathrm{e}}$ et $3^{\mathrm{e}}$ portées, comme le montrent les résultats suivants :

\begin{tabular}{|c|c|c|c|c|c|c|}
\hline No de la portée & I & 2 & 3 & 4 & 5 & 6 \\
\hline Gain de poids net $(\mathrm{kg})$ & 48,8 & 55,2 & $57, \mathrm{I}$ & 50,6 & 54,4 & 46,7 \\
\hline
\end{tabular}

Par contre, ce même gain net semble pratiquement indépendant du poids de l'animal à l'accouplement, du nombre et du poids des embryons et également de l'importance du placenta, comme le montrent les résultats suivants de calcul de corrélations effectué sur 75 données:

Coefficient de corrélation gain net de gestation/poids des truies :

$$
r=+o, \mathrm{I} 5 \text { non significatif. }
$$

Coefficient de corrélation gain net de gestation/nombre des embryons :

$$
r=+o, 09 \text { non significatif. }
$$

Coefficient de corrélation gain net de gestation/ poids du placenta :

$$
r=-0,38 \mathrm{P}<0,05 \text {. }
$$

\section{b) Nature du gain net de gestation.}

Plusieurs auteurs, tels que LENkeit et al. (I956), PEnzes (I959), Rombauts (I962), ont montré que l'anabolisme gravidique de la Truie mettait en jeu, en premier lieu, une augmentation de la rétention d'azote. S'il est logique de penser que celleci s'accompagne de la formation de nouveaux tissus, le problème de leur localisation se pose.

Pour Boyne (I953) et MoustgaARd (I958) les synthèses protéiques se limiteraient au niveaı de l'utérus lui-même qui s'hypertrophie considérablement et du tissu mammaire qui présente effectivement un développement important pendant les deux dernières semaines de gestation; mais cette explication paraît insuffisante compte-tenu de l'importance des rétentions. Aussi, pour répondre à cette question, nous avons sacrifié Io truies en fin de gestation (IO5 ${ }^{\mathrm{e}}$ jour) et nous avons comparé leur composition obtenue par dissection à celle de ro autres truies prises comme témoins de début de gestation. Les résultats sont les suivants. (tabl. 3).

On constate tout d'abord qu'à l'exception du tissu adipeux périrénal et du mésentère, la gestation se solde par un bénéfice pondéral de tous les tissus ou organes. Mais c'est dans la masse musculaire et osseuse que les gains de poids sont les plus élevés (ce qui explique parfaitement les rétentions d'azote) ; l'utérus et son contenu viennent en deuxième rang, suivis par le tissu adipeux externe ; par contre, les variations des organes de la respiration et de la digestion sont insignifiantes. En pourcentage des poids initiaux, c'est évidemment l'utérus qui effectue le gain le plus important, ce qui souligne son extraordinaire plasticité, mais le tissu musculaire et le foie 
TABLEAU 3

Répartition anatomique du gain de gestation

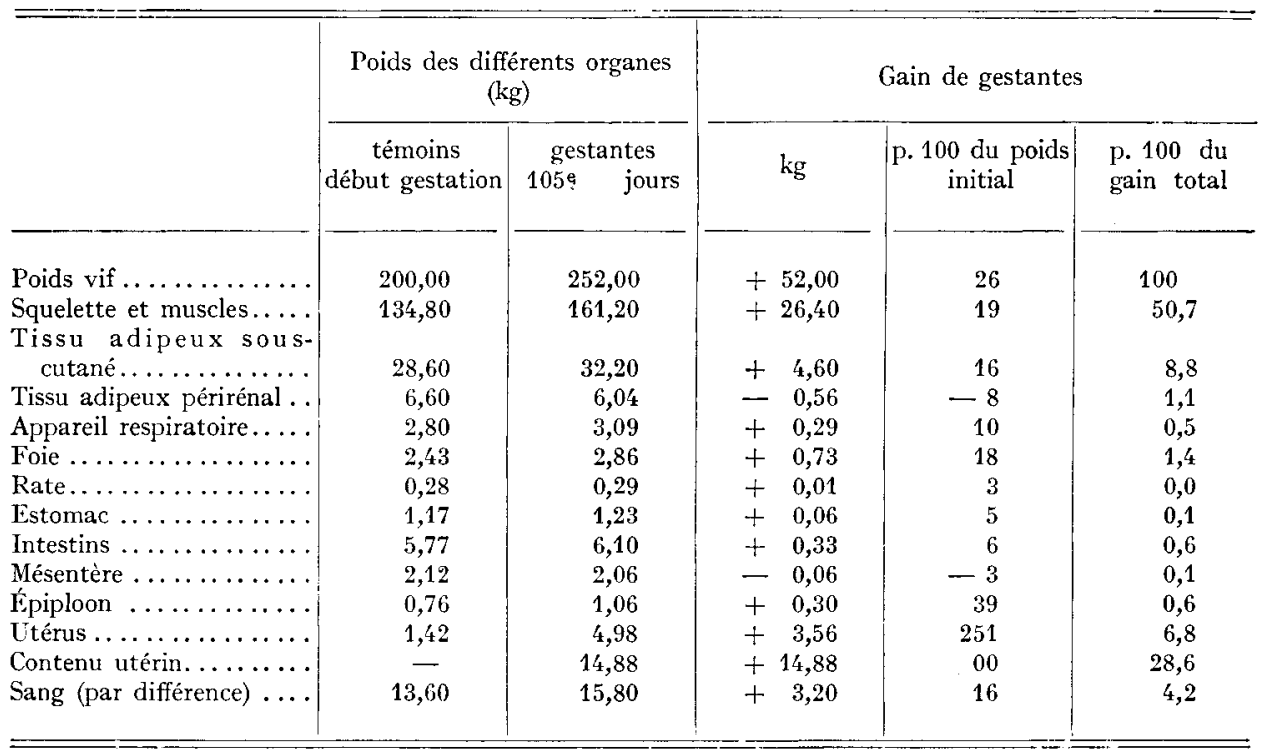

\section{TABIEAU 4}

Comparaison des compositions corporelles à poids corrigé égal (1)

\begin{tabular}{|c|c|c|c|c|c|}
\hline & \multicolumn{2}{|c|}{ Poids des différents organes $(\mathrm{kg})$} & \multicolumn{3}{|c|}{ Gain de gestantes } \\
\hline & $\begin{array}{c}\text { témoins } \\
\text { non gestants }\end{array}$ & gestantes & $\mathrm{kg}$ & p. $100 \mathrm{de}$ & es témoins \\
\hline Poids vif. ........... & 238 & 252 & $n$ & & " \\
\hline Carcasse corrigée $\left({ }^{1}\right) \ldots \ldots$ & 193,50 & 193,50 & 0 & & 0 \\
\hline Squelette et muscle ..... & 156,68 & 161,30 & $+4,62$ & & 2,9 \\
\hline Tissu adipeux sous-cutané & 36,82 & 32,20 & $-4,62$ & - & 12,6 \\
\hline Tissu adipeux périrénal... & 8,40 & 6,04 & $-2,36$ & - & 28,0 \\
\hline Appareil respiratoire. ..... & 3,30 & 3,09 & $-0,21$ & - & 6,4 \\
\hline Foie................. & 3,04 & 2,86 & $-0,18$ & - & 5,9 \\
\hline 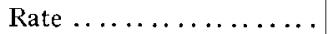 & 0,31 & 0,29 & $-0,02$ & - & 6,4 \\
\hline Estomac ............. & 1,32 & 1,23 & $-0,09$ & - & 6,8 \\
\hline Intestin $\ldots \ldots \ldots \ldots \ldots$ & 6,84 & 6,10 & $-0,74$ & - & 10,8 \\
\hline Mésentère............ & 2,86 & 2,06 & $-0,80$ & $\ldots$ & 27,9 \\
\hline Épiploon. . . . . . . . . . . & 1,26 & 1,06 & $-0,20$ & - & 15,8 \\
\hline Utérus.............. & 1,60 & 4,98 & $+3,38$ & +2 & 211,2 \\
\hline Sang..$\ldots \ldots \ldots \ldots \ldots$ & 15,60 & 15,80 & $+0,20$ & + & 1,3 \\
\hline
\end{tabular}

(1) Poids vif - (contenu digestif + contenu utérus). 
viennent ensuite et font sensiblement jeu égal avec le tissu adipeux sous-cutané. Ce dernier résultat peut paraitre quelque peu surprenant, car l'on sait depuis les travaux de McMeekan (I940, Clausen (I952), Oslage (I962) que le développement du tissu adipeux l'emporte généralement sur celui du tissu musculaire chez le Porc en croissance et que le pourcentage des lipides est d'autant plus élevé que l'animal est plus vieux ou plus lourd.

Nos résultats font donc apparaître chez la gestante une certaine modification dans la composition corporelle, mais qui ne peut se manifester pleinement que si les comparaisons sont effectuées sur des animaux de poids identique, ce qui n'est pas le cas dans cette expérience. Nous avons alors cherché à réaliser une meilleure comparaison en sacrifiant Io autres animaux témoins non gestants, choisis de façon. à présenter le même poids après sacrifice que les gestantes, déduction faite des contenus digestifs et du contenu de l'utérus. Les résultats sont alors ceux du tableau 4.

Ces derniers résultats accentuent les différences de composition précédentes entre les animaux gestants et ceux au repos sexuel. Ils permettent de souligner deux faits importants :

- A poids égal, les gestantes sont toujours moins grasses que les témoins. Ce phénomène apparaît, à des degrés divers, dans la diminution relative de tous les tissus ou organes riches en graisse (tissu sous-cutané, tissu périrénal, mésentère, panne) et donne donc un sens très particulier à la notion de croissance chez la gestante. L'ensemble du processus, particulièrement bien analysé par BoURDEL (Ig60) chez la Ratte, va à l'encontre de l'évolution normale des tissus avec l'âge et pourrait s'interprêter sinon comme un "retour à un état antérieur ", du moins comme un " frein " à l'évolution biologique de l'adulte.

- Par ailleurs, l'utérus est le seul des organes de la cavité digestive à présenter un développement important au cours de la gestation. Celui-ci est compensé par une diminution en valeur relative et absolue des organes de la digestion, ce qui peut être à l'origine d'un ralentissement du transit intestinal chez les gestantes. Ce phénomène n'est peut être pas étranger à la fréquence des troubles de constipation que l'on observe souvent chez ces dernières.

\section{c) Évolution du gain de poids de gestation.}

L'importance et la répartition du gain maternel sont susceptibles de varier au cours de la gestation. C'est ce que nous avons voulu étudier en procédant à l'examen de 40 truies sacrifiées à des dates variées de gestation (allant de la conception à la parturition) et réparties a posteriori en 5 lots égaux de même poids initial, mais de chronologie différente. Les résultats d'ensemble de cette expérience figurent dans le tableau 5 .

L'augmentation régulière du poids vif résulte essentiellement de deux facteurs : développement de la masse musculaire qui apparaît dès les premiers stades de gestation et se poursuit jusqu'à la parturition, et celui de l'utérus gravide dont l'importance s'accroît en fin de gestation. Par contre, comme on pouvait s'y attendre, on note peu de variations pour la plupart des autres viscères. Mais 1'un des points les plus remarquables concerne le compartiment lipidique (tissu adipeux sous-cutané, périrénal et mésentère) qui présente une diminution sensible aux deux derniers stades de gestation, après s'être accru au début. 
L'ensemble de ces constatations indique une diversité et une certaine discontinuité dans le développement des différentes masses anatomiques. Celles-ci apparaissent plus nettement lorsque l'on considère non plus les poids, mais les gains de poids aux différents époques (tabl. 6).

\section{TABLEAU 5}

Évolution du poids et de la compssition corporelle chez la Truie gestante (kg)

\begin{tabular}{|c|c|c|c|c|c|}
\hline Stade de gestation & Accouplement & $0.30 \mathrm{j}$ & $30-60 j$ & $60-90 \mathrm{j}$. & $90-114 \mathrm{j}$, \\
\hline Poids vif $\ldots \ldots \ldots \ldots \ldots \ldots \ldots$ & 200 & 213,6 & 227,3 & 242,8 & 252,2 \\
\hline Muscle + squelette.......... & 134,6 & 140,7 & 147,1 & 155,7 & 161,2 \\
\hline Tissu adipeux sous-cutané,....... & 28,6 & 32,0 & 34,8 & 34,0 & 32,4 \\
\hline Tissu adipeux périrènal . . . . . . . . . & 6,6 & 6,8 & 6,7 & 6,5 & 6,0 \\
\hline Appareil respiratoire...$\ldots \ldots \ldots$ & 2,8 & 2,8 & 2,8 & 3,1 & 3,1 \\
\hline Foie $\ldots \ldots \ldots \ldots \ldots \ldots \ldots \ldots$ & 2,4 & 2,8 & 2,9 & 2,7 & 2,9 \\
\hline Rate $\ldots \ldots \ldots \ldots \ldots \ldots \ldots$ & 0,3 & 0,3 & 0,3 & 0,3 & 0,3 \\
\hline 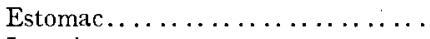 & 1,2 & 1,2 & 1,2 & 1,3 & 1,2 \\
\hline Intestins $\ldots \ldots \ldots \ldots \ldots \ldots \ldots$. & 5,8 & 6,3 & 6,3 & 6,6 & 6,1 \\
\hline Mésentère $\ldots \ldots \ldots \ldots \ldots \ldots \ldots$. & 2,1 & 1,9 & 2,0 & 2,3 & 2,1 \\
\hline Épiploon . . . . . . . . . . & 0,8 & 0,8 & 1,0 & 1,0 & 1,3 \\
\hline Utérus $\ldots \ldots \ldots \ldots \ldots \ldots \ldots$ & 1,4 & 2,1 & 2,8 & 4,1 & 5,0 \\
\hline Contenu utérin $\ldots \ldots \ldots \ldots \ldots \ldots$ & 0 & 1,9 & 5,0 & 10,0 & 15,0 \\
\hline Sang $\ldots \ldots \ldots \ldots \ldots \ldots \ldots \ldots$ & 13,2 & 14,0 & 14,4 & 15,2 & 15,6 \\
\hline
\end{tabular}

\section{TABLEAU 6}

Évolution des gains de poids journaliers

(g/jour)

\begin{tabular}{|c|c|c|c|c|}
\hline Période...$\ldots \ldots \ldots \ldots \ldots \ldots \ldots$ & $0-30 \mathrm{j}$ & $30-60 \mathrm{j}$ & $60-90 \mathrm{j}$. & $90-114 \mathrm{j}$. \\
\hline 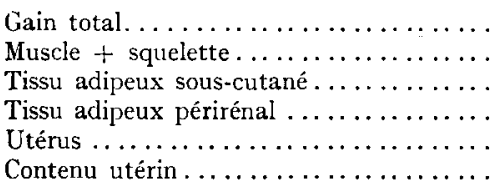 & $\begin{array}{r}647 \\
290 \\
162 \\
10 \\
33 \\
62\end{array}$ & $\begin{array}{r}622 \\
278 \\
122 \\
-\quad 4 \\
30 \\
148\end{array}$ & $\begin{array}{r}456 \\
253 \\
-\quad 23 \\
-\quad 6 \\
38 \\
156\end{array}$ & $\begin{array}{r}408 \\
239 \\
-\quad 69 \\
-22 \\
39 \\
217\end{array}$ \\
\hline
\end{tabular}

Seul le contenu utérin présente des gains journaliers de plus en plus importants au cours de la gestation. Par contre, si le bénéfice maternel quotidien a tendance à diminuer à mesure que la gestation avance, ceci résulte davantage d'une diminution absolue et relative de la synthèse des tissus adipeux que de celle des tissus protéiques

Les résultats sont encore plus nets, lorsqu'ils sont exprimés en pourcentage du gain de poids (tabl. 7 )

On voit donc apparaître ici deux tendances bien marquées, qui s'accentuent au cours de la gestation 
fotal

- l'anabolisme maternel (lipidique) fait place progressivement à l'anabolisme

- la protéinogenèse l'emporte sur la lipogenèse. Cette dernière présente même un arrêt total en fin de gestation.

TABLEAU 7

Composition du gain de poids de gestation

(p. I00)

\begin{tabular}{|c|c|c|c|c|}
\hline Période.. & $0-30 \mathrm{j}$. & $30-60 \mathrm{j}$. & $60-90 \mathrm{j}$. & $90-114 \mathrm{j}$. \\
\hline $\begin{array}{l}\text { Tissu musculaire }+ \text { os ... } \\
\text { Tissu adipeux ......... } \\
\text { Utérus }+ \text { contenus ..... } \\
\text { Divers (viscères, sang)... }\end{array}$ & $\begin{array}{l}42,5 \\
26,5 \\
14,7 \\
16,3\end{array}$ & $\left.\begin{array}{r}43,7 \\
19,6 \\
28,6 \\
8,1\end{array}\right\} 64,3$ & $\left.\begin{array}{r}55,4 \\
-\quad 6,3 \\
42,5 \\
8,4\end{array}\right\} 49,1$ & $\left.\begin{array}{r}57,1 \\
-21,8 \\
62,6 \\
2,1\end{array}\right\} 35,3$ \\
\hline
\end{tabular}

Nous avons alors voulu voir si ces phénomènes se traduisent au niveau des bilans de l'azote et de l'énergie. A cet effet, nous avons placé deux truies A et B en cage de métabolisme et mesuré leurs bilans tout au long de la gestation. Ces truies recevaient une ration constante de $43 \mathrm{~g}$ d'azote et 9 , I mégacalories par jour, ce qui constitue un régime relativement restreint en protides, mais libéral en énergie. Les résultats sont rapportés dans le tableau 8 et diffèrent assez nettement suivant qu'il s'agit de l'azote ou de l'énergie.

En ce qui concerne le métabolisme azoté, on constate que si l'azote absorbé, et donc le coefficient d'utilisation digestive, varient peu au cours de la gestation, il n'en va pas de même pour l'azote retenu. Ce dernier présente, après une période de stabilité relative, une nette augmentation visible à partir de la $\mathrm{I} 2^{\mathrm{e}}$ semaine. Certes, nos résultats ne permettent pas de dissocier dans ce phénomène la part qui revient à la mère de celle du fotus, mais il paraît logique de relier cette augmentation des rétentions à la grande poussée pondérale des fœtus qui s'effectue précisément à cette époque (MoustgaARD, I958; MiTChel, et al., I93I). I1 n'en reste pas moins que cette amélioration très remarquable de l'utilisation alimentaire de l'azote chez la gestante place cette dernière dans des conditions très favorables qui lui permettent de réaliser un bénéfice personnel, ce qu'avait montré 1'analyse corporelle.

Rien de tel en ce qui concerne l'énergie. L,e bilan ne fait apparaître à aucun moment une augmentation de l'énergie absorbée ou métabolisable si minime soit-elle. Aucun facteur d'économie ne pouvant être invoqué, il y a lieu de penser que la croissance fœtale conduit à une augmentation des dépenses énergétiques dont les gains miternels font principalement les frais.

\section{$2^{\circ}$ Lactation}

a) Mise en évidence.

Contrairement à ce qui se passe pendant la gestation, les truies en lactation perdent généralement du poids et de nombreux auteurs ont signalé ou chiffré ce phénomène (SchNeIDER, I934; BrEIREM, I934; SchaFFER et GRANZ, I955; ZELLER, I937 ; LODGE et al., I96I ; MAJERCiAK, I962; VANSCHOUBRGK, I962). 
GESTATION ET LACTATION CHEZ LA TRUIE

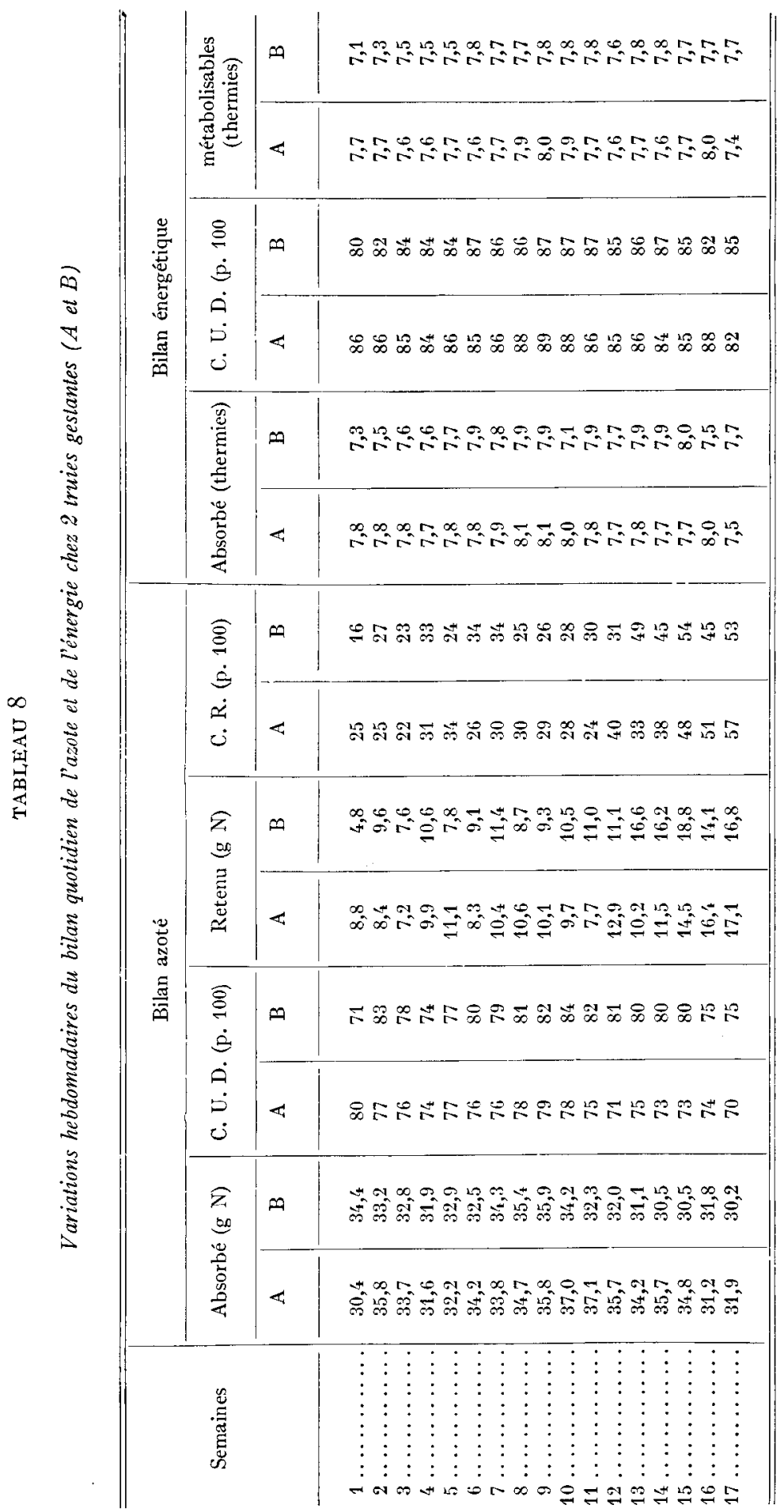


Dans nos conditions expérimentales, cette perte de poids entre la parturition et le $56^{\mathrm{e}}$ jour de lactation, peut être évaluée à $36,7 \pm 2 \mathrm{r} \mathrm{kg}$ pour des animaux pesant $240 \mathrm{~kg}$ après parturition, soit environ I 5 p. IoO du poids vif. Ce résultat est sensiblement du même ordre que celui rapporté par SchafFer (I955).

On constate que la perte pondérale est légèrement inférieure au gain de poids net de gestation et laisse donc en fin d'exercice un certain bénéfice (Io à $30 \mathrm{~kg}$ ) à la mère.

Il apparaît par ailleurs que cette perte de poids est susceptible de varier assez largement suivant les individus ou les conditions de milieu.

En premier lieu, nos résultats montrent une certaine augmentation de la chute de poids au cours des lactations successives : la perte de poids est en général moins importante au cours des premières portées que des suivantes, ce qui a été confirmé par Smith (I960), LodGE (Ig6I) et TRIBble (I963).

$\begin{array}{lrrrrrrrr}\text { Numéro de lactation } & \text { I } & 2 & 3 & 4 & 5 & 6 & 7 & \text { et } \\ \text { Perte }(\mathrm{kg}) \ldots \ldots & 29 & 33 & 39 & 40 & 43 & 42 & 3 \mathrm{I} & \end{array}$

Ce phénomène n'est pas sans rappeler l'évolution du gain de poids de gestation dans les mêmes conditions et est à rapprocher également des variations de poids et du nombre de porcelets sevrés au cours des portées successives.

On trouve, en effet, une corrélation, assez faible il est vrai, entre ces différents paramètres, qui semble indiquer que les pertes de poids sont plus importantes chez les truies lourdes ou celles qui sèvrent beaucoup de porcelets.

Coefficient corrélation perte de poids/poids parturition :

$$
r=0,23, \mathrm{P}<0,05 \text {. }
$$

Coefficient corrélation perte de poids/nombre de porcelets :

$$
r=0,30, \mathrm{P}<\text { o,or. }
$$

Cette dernière relation a été confirmée par VANSchOUBRGK (Ig62), mais non par SchAFFER (I955). Le facteur le plus important de la perte de poids semble être, par ailleurs, la quantité d'aliment consommée pendant la lactation, avec laquelle il existe une corrélation négative de coefficient $r=-0,40(\mathrm{P}>0,0 \mathrm{I})$. Les truies perdent d'autant moins de poids qu'elles ingèrent plus d'aliment.

b) Nature de la perte de poids.

Les observations de I,ENkEIT (I956), GUTTE (I960), VANSchoubRCEK (I962), LAUPRECHT ( $\mathrm{I} 962$ ) montrent que la perte de poids de lactation est complexe : pour les deux premiers auteurs, il s'agit en premier lieu d'un catabolisme protéique et minéral ; pour les deux autres, il s'agiraít davantage d'une perte de lipides.

Nous avons abordé ce problème par la même technique de dissection que précédemment, en sacrifiant Io truies en fin de lactation et en comparant leur composition corporelle à celle de 8 truies en fin de gestation (tabl. 9).

En cours de lactation, la perte de poids affecte principalement le tissu musculaire et le tissu adipeux sous-cutané ; mais, en valeur relative, le catabolisme protéique paraît nettement plus important que le catabolisme lipidique. Ceci ne présume en rien du déterminisme ou des fins auxquelles sont effectuées ces remaniements, le tissu musculaire pouvant parfaitement être utilisé par la laitière à des fins énergé- 
tiques. Comme pour la gestation, on remarque, par ailleurs, que les variations de poids des viscères autres que l'utérus sont très faibles. Ce dernier présente par contre une involution importante qui le ramène à son poids de début de gestation.

TABLEAU 9

Répartition anatomique de la perte de poids de lactation

\begin{tabular}{|c|c|c|c|c|}
\hline & \multicolumn{2}{|c|}{ Poids des différents organes $(\mathrm{kg})$} & \multicolumn{2}{|c|}{ Perte de poids } \\
\hline & Gestation & Lactation & $\mathrm{kg}$ & ${ }_{\text {totale }}^{\text {p. } 100 \text { de la perte }}$ \\
\hline Poids vif $\ldots \ldots \ldots \ldots \ldots \ldots \ldots$ & 237,6 & 199,2 & 38,4 & 100 \\
\hline Muscle + squelette .......... & 161,3 & 139,4 & 21,9 & 57,0 \\
\hline Tissu adipeux sous-cutané ....... & 32,2 & 24,9 & 7,3 & 19,0 \\
\hline Tissu adipeux périrénal. ........ & 6,0 & 5,7 & 0,3 & 0,8 \\
\hline Mésentère $\ldots \ldots \ldots \ldots \ldots \ldots \ldots$ & 2,1 & 1,9 & 0,2 & 0,5 \\
\hline Epiploon................. & 1,0 & 0,7 & 0,3 & 0,8 \\
\hline Foie $\ldots \ldots \ldots \ldots \ldots \ldots \ldots$ & 2,9 & 2,9 & 0 & 0 \\
\hline Rate $\ldots \ldots \ldots \ldots \ldots \ldots \ldots$ & 0,3 & 0,2 & 0,1 & 0,2 \\
\hline Estomac . . . . . . . . . . . . & 1,2 & 1,2 & 0 & 0 \\
\hline Intestin. . . . . . . . . . . . & 6,1 & 5,9 & 0,2 & 0,5 \\
\hline Appareil respiratoire .......... & 3,1 & 2,9 & 0,2 & 0,5 \\
\hline Utérus $\ldots \ldots \ldots \ldots \ldots \ldots \ldots$ & 5,0 & 1,4 & 3,6 & 9,3 \\
\hline Sang $\ldots \ldots \ldots \ldots \ldots \ldots \ldots$ & 16,4 & 12,2 & 4,2 & 10,9 \\
\hline Épaisseur du lard dorsal $(\mathrm{mm}) \ldots$ & 58 & 48 & - & - \\
\hline
\end{tabular}

L'examen de la composition corporelle de la 'Truie en lactation prend en outre un relief particulier lorsqu'il est effectué comme nous l'avions fait pour les gestantes, en comparaison à poids égal avec les autres stades physiologiques (repos sexuel, gestation). Ces résultats figurent au tableau ro.

TABIEAU IO

Comparaison de la composition corporelle des Truies à poids égal

\begin{tabular}{|c|c|c|c|}
\hline & \multicolumn{3}{|c|}{ Poids des différents organes de la Truie $(\mathrm{kg})$} \\
\hline & Repos & Gestation & Lactation \\
\hline Poids vif................ & 201,0 & 201,0 & 199,2 \\
\hline Muscle + squelette .......... & 137,3 & 139,8 & 139,4 \\
\hline Tissu adipeux externe......... & 28,6 & 26,4 & 24,9 \\
\hline Tissu adipeux périrénal ........ & 6,6 & 5,0 & 5,7 \\
\hline Mésentère................ & 2,1 & 1,7 & 1,9 \\
\hline Épiploon................... & 1,0 & 0,7 & 0,7 \\
\hline Foie $\ldots \ldots \ldots \ldots \ldots \ldots \ldots \ldots \ldots$ & 2,6 & 2,6 & 2,9 \\
\hline Rate $\ldots \ldots \ldots \ldots \ldots \ldots \ldots \ldots$ & 0,3 & 0,3 & 0,2 \\
\hline Estomac ............. & 1,2 & 1,2 & 1,2 \\
\hline Intestin $\ldots \ldots \ldots \ldots \ldots \ldots \ldots$ & 5,8 & 5,6 & 5,9 \\
\hline Utérus $\ldots \ldots \ldots \ldots \ldots \ldots \ldots$ & 1,4 & 4,6 & 1,4 \\
\hline Appareil respiratoire .......... & 3,0 & 2,8 & 2,8 \\
\hline Épaisseur du lard dorsal $(\mathrm{mm}) . .$. & 52 & 49 & 48 \\
\hline
\end{tabular}


Il ressort de cette comparaison à poids égal $(200 \pm \mathrm{I} \mathrm{kg})$ que les truies en lactation présentent sensiblement le même développement musculaire et osseux que les truies au repos ou en gestation, mais qu'elles sont moins grasses (tissu adipeux externe) que les truies gestantes, elles-mêmes moins grasses que les truies au repos.

c) Évolution.

Il ne nous a pas été possible d'opérer comme pour la gestation et de suivre par dissection les variations de poids des différents organes. Nous nous sommes bornés ici à établir un parallèle entre les variations de poids vif et l'évolution au cours de la lactation de l'épaisseur du lard dorsal mesurée sur l'animal vivant par la technique aux ultrasons. Les mesures ont été effectuées sur I75 animaux et les moyennes sont rapportées dans le tableau II et la figure 4 .

TABLEAU II

Évolution de la perte de poids au cours de la lactation

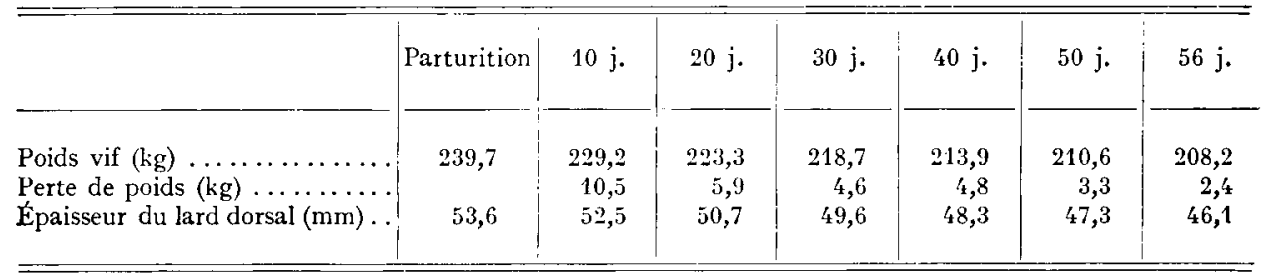

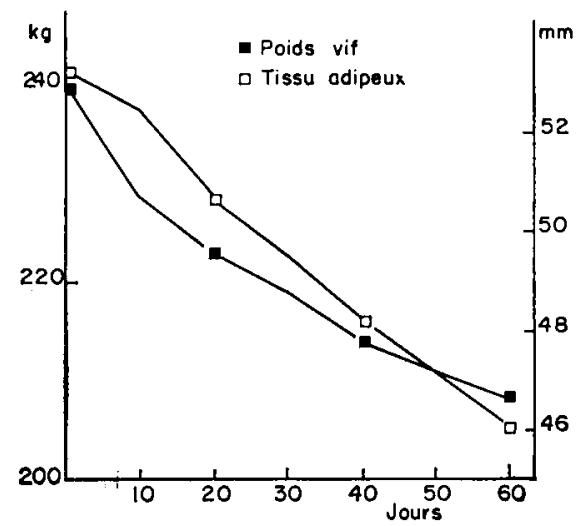

FIG. 4. -- Évolution du poids vif el de l'épaisseur du tissu adipeux au cours de la lactation

La perte de poids suit une évolution régulière, mais elle est surtout importante au début de la lactation, phénomène déjà signalé par LODGE (I96I) et par SCHAFFER (I955). Par contre, elle a tendance à s'amenuiser à mesure que la lactation avance, ce qui peut s'interpréter de deux façons, soit que l'animal arrive progressivement à l'épuisement des réserves mobilisables, soit qu'un certain équilibre nutritionnel soit atteint entre les ressources et les besoins.

L'épaisseur du lard dorsal suit une évolution un pet1 différente. La diminution 
paraît relativement peu importante pendant les premiers jours de lactation, ce qui peut indiquer une forte prédominance à ce stade de la mobilisation des tissus non lipidiques et notamment du tissu musculaire. La fonte lipidique tend ensuite à s'accroître et se maintient avec une intensité sensiblement constante du Io jour au $5^{\circ}$ jour de lactation. Il en résulte donc que pendant cette dernière période, la part qui revient aux graisses dans la perte de poids corporelle s'accroit, alors qu'en contrepartie celle des protéines diminue. Il semblerait donc que la mobilisation corporelle de la Truie porte essentiellement sur les protéines au début de la lactation, alors qu'elle affecte les lipides en fin de lactation. Il s'ensuit qu'en valeur relative et absolue, le corps de l'animal a tendance à s'appauvrir en lipides au cours de la lactation, ce que nous avions déjà constaté au cours d'une expérience sur la Ratte (PÉRIssE et SALMON-I,EGAGNEUR, Ig6o).

Cette hypothèse semble trouver une confirmation dans les variations du bilan azoté de truies placées en cage de métabolisme. Nous avons utilisé à cet effet les deux truies sur lesquelles des observations avaient été faites au cours de la gestation. Pendant la lactation, ces truies recevaient une ration riche en azote ( $\mathrm{I} 70 \mathrm{~g}$ de matières azotées totales $/ \mathrm{kg}$ ) distribuée à volonté. Les mesures effectuées ont donné lieu aux résultats suivants (tabl. I2).

TABLEAU I2

Variations du bilan azoté quotidien au cours de la lactation

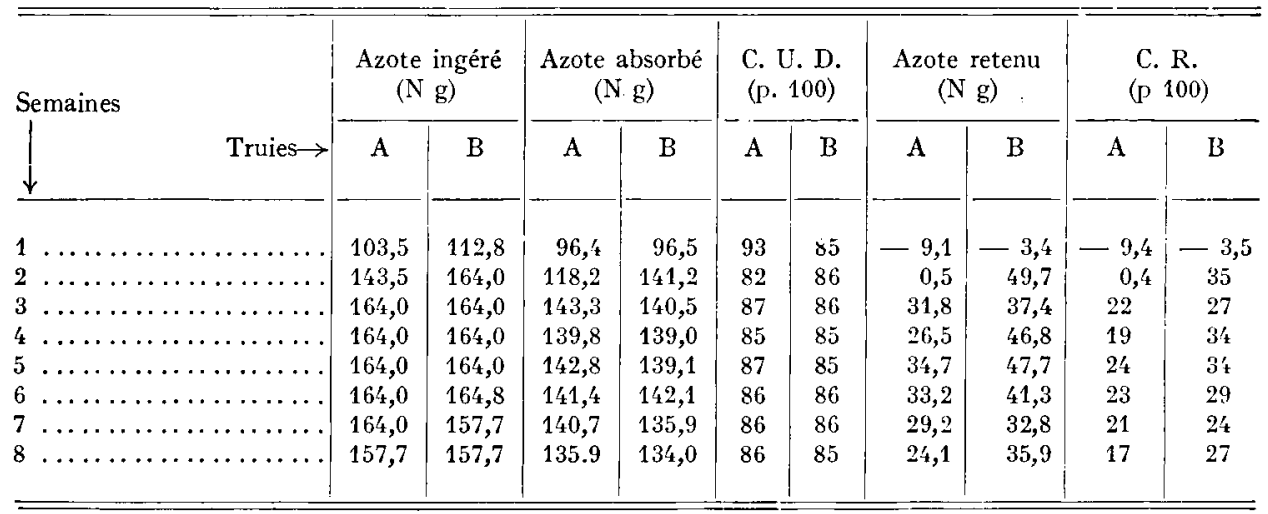

Bien que théoriquement la ration utilisée fût apte à couvrir largement les besoins de l'animal (LODGE, I959), on constate une certaine mobilisation d'azote corporel (période de bilan négatif), qui s'effectue essentiellement pendant la première semaine de lactation. Peut-être s'agit-il simplement dans ce cas particulier de l'azote libéré par l'involution des tissus utérins. Il n'en reste pas moins que ce phénomène paraît général, si l'on en croit les observations de L.ENkEIT et al. (I956) qui montrent que les pertes d'azote les plus importantes s'effectuent au début de la lactation et diminuent ensuite. Ceci ne veut pas dire que, même en période de bilan positif, des remaniements des tissus protéiques ne continuent pas de s'effectuer, mais il est vraisemblable que les variations de poids que 1 'on observe alors sont essentiellement d'une autre origine et concernent en particulier le tissu adipeux. 


\section{C - Contenus utérins}

L'étude des contenus utérins et de la croissance embryonnaire chez la Truie a fait l'objet de déterminations relativement nombreuses de la part d'auteurs tels que Mitcheli, et al. (I93I), Gortner (I945), Widdowson (I950), URbanyi (I950), LENKEIT et al. (I957), BECZE (I958) et de VII,IIER (I958). Aussi, nous y sommes-nous peu attardés.

Nous avons tenu, toutefois, à rapporter ici quelques résultats personnels qui complètent les observations de ces auteurs et permettent de mieux situer le niveau de nos conditions expérimentales.

Nos résultats ont été obtenus de deux façons, soit sur animaux vivants au moment de la parturition, soit sur des animaux sacrifiés au cours de la gestation (étude cinétique).

\section{Io Contenus utérins à la parturition}

a) Valeurs moyennes.

L'ensemble des mesures effectuées sur plus de 200 truies au moment de la parturition a permis d'établir les valeurs moyennes suivantes :

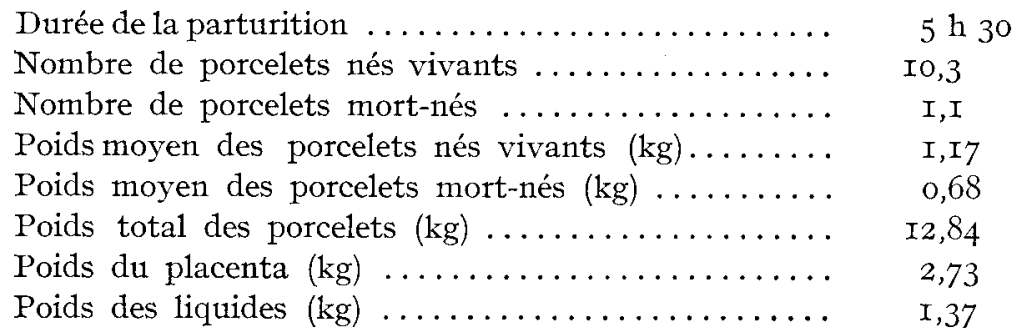

Certaines de ces données sont interdépendantes : par exemple, nous avons trouvé une corrélation négative $\gamma=-0,29$ entre le nombre et le poids des porcelets à la naissance (les porcelets sont d'autant moins lourds qu'ils sont plus nombreux). En conséquence, ces deux critères, nombre et poids, doivent toujours être considérés simultanément pour juger de la valeur d'une portée. Dans ce domaine, le poids total des porcelets constitue une donnée de synthèse intéressante. Le poids du placenta est sensiblement proportionnel au poids total de la portée (corrélation $r=+0,72$ ), ce qui pourrait signifier que les porcelets sont d'autant plus lourds qu'ils peuvent disposer d'une quantité plus importante de placenta. Par contre, il existe une corrélation négative entre le nombre de porcelets d'une portée et le poids de placenta dont peut disposer chacun. On peut trouver dans cette relation une explication à la diminution du poids moyen des porcelets à mesure que la taille de la portée augmente.

\section{b) Facteurs de variations.}

A côté de facteurs héréditaires, qui agissent davantage sur le poids des porcelets que sur leur nombre, le facteur le plus important paraît être 1'âge de la Truie : les truies primipares donnent naissance à des portées plus légères, mais ceci résulte essentiellement de leur moins bonne fécondité, comme le montre le tableau $\Upsilon_{3}$. 
TABLEAU I3

Variations du contenu utérin avec l'âge

\begin{tabular}{l|c|c|c}
\hline \hline & Truies primipares & Truies âgées & $\begin{array}{c}\text { Signification } \\
\text { des différences }\end{array}$ \\
\hline & & & \\
Poids total de la portée $(\mathrm{kg}) \ldots \ldots$ & 10,73 & 13,99 & 0,01 \\
Nombre de porcelets vivants.... & 9,6 & 10,7 & 0,01 \\
Nombre de porcelets mort-nés ... & 0,9 & 1,2 & 0,05 \\
Poids moyen des porcelets (kg).. & 1,10 & 1,22 & $\mathrm{~N}$ S \\
Poids du placenta .............. & 2,40 & 2,92 & 0,01 \\
Poids des liquides .............. & 0,70 & 0,63 & 0,05 \\
\hline \hline
\end{tabular}

Pour cette raison, la comparaison des contenus utérins au cours des expériences doit toujours être effectuée entre animaux de même âge.

Par contre, des facteurs tels que le poids des truies (corrélation $r=+0,15$, N. S.), ou la quantité d'aliment consommée pendant la gestation (corrélation $r=$ - o, I 8, N. S.) ne semblent exercer qu'un effet très limité sur le contenu utérin, ce qui rejoint les conclusions de la plupart des auteurs précédemment cités.

c) Composition chimique.

Celle-ci a été déterminée sur les contenus utérins récoltés au cours de la parturition de 6 truies placées en cages de métabolisme (tabl. I4). Les résultats sont parfaitement conformes à ceux de MiTcheLI (I93I), et de LENkEIT (I957).

TABLEAU 14

Composition chimique et valeur énergétique des produits de la conception

\begin{tabular}{|c|c|c|c|c|c|c|c|c|c|c|c|}
\hline & \multirow{2}{*}{$\begin{array}{l}\text { Poids } \\
\text { frais } \\
(\mathrm{kg})\end{array}$} & \multicolumn{2}{|c|}{ Eau } & \multicolumn{2}{|c|}{ Azote } & \multicolumn{2}{|c|}{ Lipides } & \multicolumn{2}{|c|}{ Cendres } & \multicolumn{2}{|c|}{ Énergie kcal } \\
\hline & & p. 100 & $\begin{array}{l}\text { total } \\
\text { (g) }\end{array}$ & p. 100 & $\begin{array}{c}\text { total } \\
(\mathrm{g})\end{array}$ & p. 100 & $\begin{array}{c}\text { total } \\
(\mathrm{g})\end{array}$ & p. 100 & $\begin{array}{c}\text { total } \\
\text { (g) }\end{array}$ & $\begin{array}{c}\text { calories } \\
\text { par } \\
\mathrm{g}\end{array}$ & $\begin{array}{l}\text { total } \\
\text { méga- } \\
\text { calories }\end{array}$ \\
\hline Porcelets ..... & 13,930 & 79,60 & 11,073 & 1,81 & 253,4 & 1,41 & $196,,^{\prime} t$ & 3,62 & 502,5 & 0,93 & 13,01 \\
\hline Placenta ..... & 2,650 & 92,09 & 2,642 & 0,88 & 23,6 & 0,49 & 12,9 & 2,25 & 22,5 & 0,38 & 0,86 \\
\hline Liquides ....... & $0,6^{\prime}+0$ & 94,75 & 634,8 & 0,56 & 3,2 & 0 & 0 & 0,82 & 4,9 & 0,02 & 0,13 \\
\hline
\end{tabular}

\section{$2^{\circ}$ Evolution des contenus utérins}

a) Évolution pondérale.

Le tableau I 5 rapporte cette évolution, telle qu'elle ressort des mesures effectuées sur 32 truies sacrifiées à différents stades de gestation et 6 truies en cages de métabolisme.

Deux choses sont à souligner : tout d'abord l'allure exponentielle de la croissance 
des fœetus, phénomène déjà parfaitement décrit par de VILLIERS (I958), dont il résulte que le développement pondéral de la portée s'effectue surtout tardivement. Pratiquement, le porcelet accomplit les $2 / 3$ de sa croissance au cours du dernier mois de gestation, ce qu'indiquait déjà l'examen des bilans azotés des truies gestantes.

TABLEAU I5

Évolution du contenu utérin au cours de la gestation

\begin{tabular}{|c|c|c|c|c|c|}
\hline & $22 \mathrm{j}$. & $49 \mathrm{j}$. & $77 \mathrm{j}$. & $101 \mathrm{j}$. & $116 \mathrm{j}$. \\
\hline Poids total porcelets $(\mathrm{kg}) \ldots \ldots \ldots \ldots \ldots \ldots$ & 0,05 & 0,4 & 5,4 & 10,9 & 13,9 \\
\hline Poids du placenta $(\mathrm{kg}) \ldots \ldots \ldots \ldots \ldots \ldots$ & 0,1 & 1,0 & 2,3 & 2,6 & 2,6 \\
\hline Poids des liquides $(\mathrm{kg}) \ldots \ldots \ldots \ldots \ldots \ldots$ & 1,8 & 3,6 & 2,3 & 1,5 & 1,1 \\
\hline Poids du contenu utérin $(\mathrm{kg}) \ldots \ldots \ldots \ldots \ldots$ & 1,9 & 5,0 & 10,0 & 15,0 & 17,7 \\
\hline
\end{tabular}

L'évolution des annexes placentaires et des liquides est différente : si en valeur absolue la croissance du placenta se poursuit jusqu'au terme, il n'en est pas de même des liquides qui diminuent progressivement à partir du $2^{\mathrm{e}}$ mois de gestation. En valeur relative, l'importance pondérale du placenta et des liquides diminue à mesure que la croissance du fœtus s'intensifie.

b) Evolution de la composition chimique des embryons.

A titre de curiosité, celle-ci a été déterminée à partir des résultats d'analyse de Io portées représentant différents stades de gestation et dont les embryons furent analysés séparément. Ces valeurs expérimentales figurent dans le tableau í et sont exprimées en p. coo du produit frais et en p. Ioo de la matière sèche.

\section{TABLEAU I 6}

Évolution de la composition chimique des embryons

\begin{tabular}{|c|c|c|c|c|c|c|c|c|}
\hline \multirow{2}{*}{$\begin{array}{l}\text { Stade de } \\
\text { gestation } \\
\text { (jours) }\end{array}$} & \multirow{2}{*}{$\begin{array}{l}\text { Poids de } \\
\text { l'embryon } \\
\text { (g) }\end{array}$} & \multicolumn{4}{|c|}{ Composition \% poids frais } & \multicolumn{3}{|c|}{$\%$ de la matière sèche } \\
\hline & & $\begin{array}{c}\text { Eau } \\
\vdots\end{array}$ & Lipides & $\begin{array}{c}\text { Matière } \\
\text { azotée } \\
\mathrm{N} \times 6,25\end{array}$ & $\begin{array}{c}\text { Cendres } \\
:\end{array}$ & Lipides & $\begin{array}{c}\text { Matière } \\
\text { azotée } \\
\mathrm{N} \times 6,25\end{array}$ & Cendres \\
\hline 27 & 3,0 & 95,67 & 0,47 & 3,03 & 0,84 & 10,6 & 69,9 & 19,4 \\
\hline 30 & 5,1 & 94,72 & 0,54 & 3,58 & 0,91 & 10,7 & 71,1 & 18,1 \\
\hline 45 & 116,8 & 90,19 & 0,74 & 6,71 & 1,64 & 8,1 & 71,4 & 18,0 \\
\hline 60 & 119,4 & 89,58 & 0,91 & 6,20 & 1,98 & 10,1 & 68,6 & 21,9 \\
\hline 73 & 283,7 & 89,47 & 0,97 & 6,61 & 2,29 & 10,1 & 67,0 & 23,2 \\
\hline 79 & 422,0 & 88,45 & 0,97 & 7,20 & 2,56 & 9,0 & 67,1 & 23,8 \\
\hline 84 & 529,0 & 88,02 & 0,98 & 7,41 & 2,81 & 8,7 & 66,2 & 25,1 \\
\hline 100 & 777,8 & 85,31 & 1,25 & 8,61 & 2,96 . & 9,7 & 67,2 & 23,1 \\
\hline 103 & 862,1 & 84,47 & 1,27 & 9,14 & 3,07 & 9,4 & 67,8 & 22,8 \\
\hline 107 & 1137,0 & 83,56 & 1,39 & 9,71 & 3,21 & 9,7 & 67,8 & 22,4 \\
\hline
\end{tabular}


Ces résultats concordent avec les données classiques établies par MITCHEL et al. (I93I).

A mesure que l'embryon se développe, sa teneur en matière sèche s'accroît alors que 1 'hydratation diminue. Les protéines se concentrent et deviennent le constituant le plus important, mais, en valeur relative, le pourcentage d'augmentation est de même ordre pour les matières azotées, les lipides et les cendres, de sorte qu'en définitive la composition de la matière sèche varie peu.

On aura une idée plus précise de ce qui est déposé dans l'utérus par le tableau I7 qui indique les quantités totales d'azote, de lipides et de minéraux contenues dans la portée. Pour être complets, ces résultats devraient également tenir compte du placenta et des liquides, ce que nous n'avons pas pu faire, mais ils suffisent déjà pour donner une idée représentative de l'évolution du besoin de l'utérus gravide.

\section{TABLEAU I7}

Évolution pondérale du contenu utérin (embryons)

\begin{tabular}{|c|c|c|c|c|}
\hline $\begin{array}{c}\text { Stade } \\
\text { de gestation (j) }\end{array}$ & $\begin{array}{l}\text { Poids frais } \\
\text { (g) }\end{array}$ & $\begin{array}{l}\text { Matière azotée } \\
M \times 6,25(\mathrm{~g})\end{array}$ & $\begin{array}{l}\text { Lipides } \\
\quad(g)\end{array}$ & $\begin{array}{l}\text { Cendres } \\
(\mathrm{g})\end{array}$ \\
\hline 27 & 46 & 1,4 & 0,2 & $0, f_{t}^{\prime}$ \\
\hline 30 & 51 & 1,8 & 0,3 & 0,5 \\
\hline 45 & 922 & 62,6 & 6,9 & 1,5 \\
\hline 60 & 2255 & 149,0 & 21,8 & 51,6 \\
\hline 73 & 3130 & 225,4 & $30,{ }_{4}$ & 71,7 \\
\hline 79 & 4460 & 321,1 & 43,3 & 114,2 \\
\hline $8 '$ & 7140 & 529,1 & 69,9 & 200,6 \\
\hline 100 & 10480 & 902,3 & 133,1 & 310,2 \\
\hline 103 & 12060 & 1184,5 & $16^{\prime}, 6$ & 397,8 \\
\hline 107 & 14790 & 1436,1 & 265,6 & 474,7 \\
\hline
\end{tabular}

\section{D - La production laitière}

Pour la commodité de l'exposé, nous distinguerons l'aspect quantitatif et l'aspect qualitatif.

\section{Io Variations quantitatives}

\section{a) Production laitière moyenne.}

La quantité moyenne de lait produite par jour par la Truie a été déterminée par le procédé du contrôle des tétées à partir de 500 lactations individuelles et s'élève, dans nos conditions, à $5,3 \mathrm{~kg}$ par Truie, soit enviton $\mathrm{I} / 4^{\circ}$ du poids de l'animal. Cette valeur est du même ordre que celle que l'on trouve dans les travaux récents (BARBER, I955 ; GILL, I956), mais elle est notablement plus élevée que celle indiquée par les premiers auteurs (VON GoHREN, I865; CARLYLE, I903; BONSMA, I935), ce qui s'explique vraisemblablement par l'amélioration des techniques de mesure et, en particulier, par le raccourcissement des intervalles de contrôle. 
I a production journalière moyenne la plus élevée que nous ayons enregistrée a été celle d'une truie à sa deuxième lactation qui a produit 9,64 $\mathrm{kg}$ de lait par jour avec un maximum de $12,6 \mathrm{~kg}$ au milieu de la lactation.

Rapportée à l'ensemble de la lactation ( 56 jours), la production laitière totale par truie a été en moyenne de $297 \pm 91 \mathrm{~kg}$ de lait.

b) Évolution au cours de la lactation.

Comme chez les autres espèces, la production laitière de la Truie suit des fluctuations journalières que reflète la courbe de lactation.

On trouvera à la figure 5 la courbe moyenne établie à partir de nos résultats.
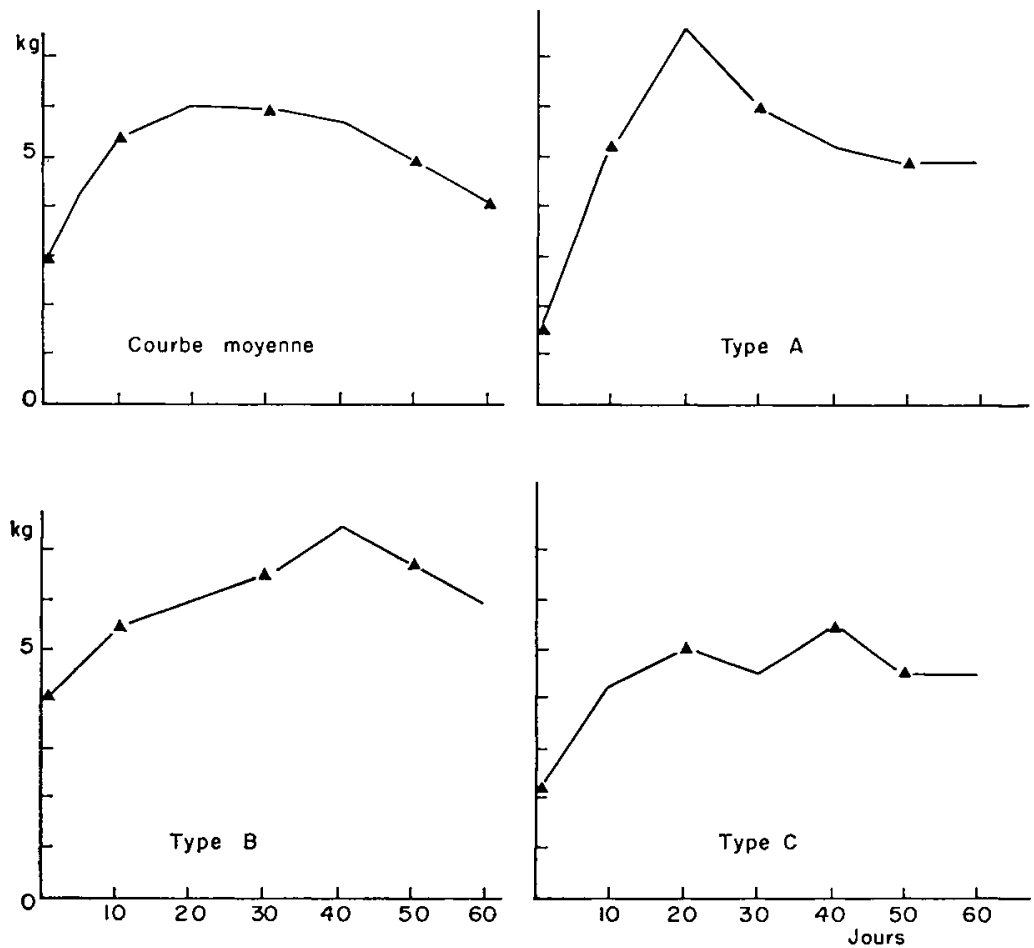

FIG. 5. - Divers types de courbes de lactation

Bien qu'assez semblable à celle trouvée par d'autres chercheurs (SMith, I952; Niwa, I95I), il nous paraît cependant difficile de la considérer comme courbe-type de lactation de la 'Truie. Il ne semble pas qu'il y ait un type unique de courbe de lactation, mais plusieurs types assez différents qui se caractérisent par la place de leur maximum (types $A, B, C$ ).

Celles à maximum précoce sont les plus fréquentes (5I p. IOO) et correspondent à l'image classique de la lactation déjà décrite par Bonsma (I953), Braude (I955) et GILL (I956). Celles à maximum tardif ou imprécis ont été décrites par BERGE (I952) et sont en général le fait de truies mauvaises laitières, ou de truies en début ou fin de carrière. 
Dans le cas le plus fréquent, le maximum de production survient aux environs de la $3^{\mathrm{e}}$ semaine (moyenne $24 \pm \mathrm{I} 8$ jours), mais sa date exacte et son volume ne sont pas sans intérêt.

On constate, en effet, que toutes conditions égales par ailleurs, les truies qui ont la plus forte production au début de la lactation sont aussi celles qui produisent les portées les plus lourdes au sevrage (corrélation $r=0,2 \mathrm{I}$ ), ce qui revient à dire que pour une même quantité de lait, la croissance du porcelet est d'autant plus rapide que le lait est consommé à un stade plus précoce. On serait ainsi conduit dans la pratique à rechercher des truies qui aient un maximum de production précoce et important.

Il faut remarquer également que le choix de la huitième semaine comme terme de lactation est assez arbitraire. Suivant les truies, le tarissement naturel s'effectue entre la $6^{\mathrm{e}}$ et la $12^{\mathrm{e}}$ semaine, mais à la $8^{\mathrm{e}}$ semaine la plupart des truies ont encore des productions assez importantes (70 p. Ioo de la production maximum).

c) Facteurs de variation.

Ces facteurs sont nombreux, mais nous n'avons retenu ici que les plus importants et notamment ceux dont l'étude pouvait présenter un intérêt nutritionnel.

Soixante et onze lactations de truies ont été utilisées à cet effet.

I. Nombre de porcelets des portées. - Bonsma avait déjà remarqué que les truies donnant le plus de lait étaient celles qui avaient les portées les plus nombreuses. Cette observation trouve une illustration dans la figure 6 , où nous reproduisons les variations de production avec le nombre de porcelets des portées.

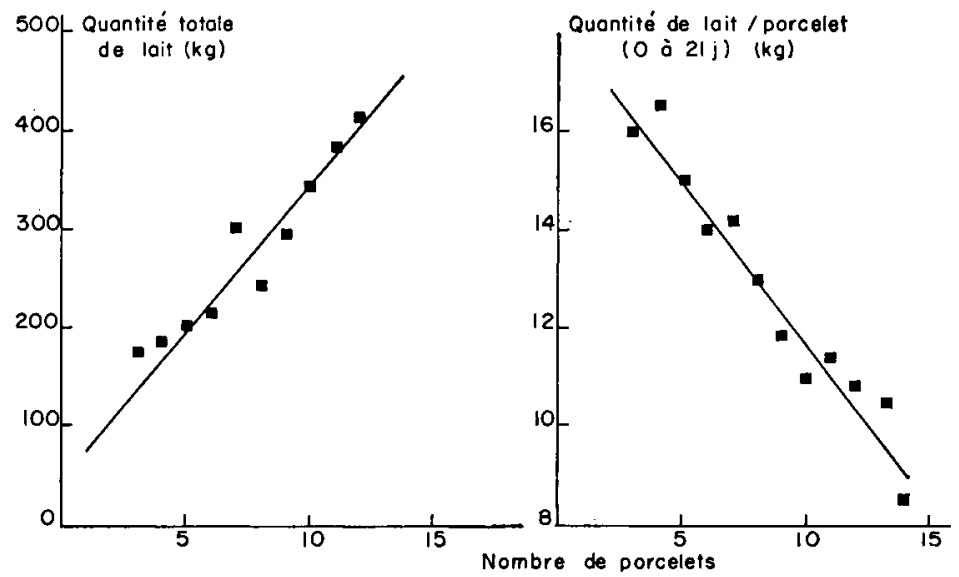

FIG. 6. - Influence du nombre de porcelets sur la production laitière

Nous avons à ce sujet calculé les coefficients de corrélation suivants :

Nombre de porcelets à la naissance/Production laitière Nombre de porcelets à 3 semaines/Production laitière Nombre de porcelets au sevrage/Production laitière

$$
\begin{aligned}
r & =0,35 \mathrm{P}<0, \text { OI } \\
& =0,6 \mathrm{I} \mathrm{P}<0, \mathrm{OI} \\
r & =0,72 \mathrm{P}<0, \text { OI }
\end{aligned}
$$

Les deux derniers résultats montrent que, pour une truie donnée, la quantité de lait produite est liée au nombre de porcelets allaités : plus une truie nourrit de 
porcelets, plus elle produit de lait. Ceci s'explique par le fait que le nombre de tétines productives chez la Truie est généralement égal au nombre de porcelets.

Par contre, la liaison entre la production laitière et la prolificité des truies, qui réstulte de la I $^{\text {re }}$ corrélation, n'est qu'apparente, car la corrélation partielle qui lie ces deux variables est nulle. Ce n'est donc pas le nombre de porcelets à la naissance, mais le nombre de porcelets élevés qui est l'un des facteurs déterminants de la production laitière, ce que l'on peut vérifier en changeant arbitrairement le nombre de porcelets après la parturition.

Cependant, il faut noter, comme l'a fait remarquer BERGE (I953), que la production laitière et le nombre des porcelets ne varient pas à la même vitesse : lorsque le nombre de porcelets croit, la quantité de lait reçue par chaque porcelet diminue (fig. 6). Nous avons trouvé en effet une corrélation négative $r=-0,31$ entre la quantité de lait consommée par porcelet et le nombre de porcelets.

Ces deux remarques ont pour intérêt de souligner l'importance du nombre de porcelets sous la mère chaque fois que l'expérimentation nécessite la mesure des quantités de lait produites.

2. L'áge de la Truie. - Bonsma (I935), Dschaparidse (I936), Donal, (I937), SMITH (I950), BERGE (I953), LODGE (I957) avaient remarqué que les truies donnaient généralement moins de lait aux premières lactations qu'aux suivantes. Nos propres résultats rapportés au tableau $\mathrm{I} 8$ confirment cette observation, mais seuls les résultats concernant les premières et detuxième lactations sont significativement différents. Dans l'ensemble, on note en effet une assez forte augmentation (28 p. Ioo) entre la $\mathrm{I}^{\mathrm{re}}$ et la $2^{\mathrm{e}}$ lactation, puis une relative stabilité jusqu'à la $4^{\mathrm{e}}$ lactation.

TABLEAU I 8

Varialions de la production laitiere au cours des lactations successives

\begin{tabular}{c|c|c}
\hline \hline $\begin{array}{c}\text { Numéro } \\
\text { de la lactation }\end{array}$ & $\begin{array}{c}\text { Productions laitières } \\
(\mathrm{kg})\end{array}$ & n porcelets \\
\hline & & \\
\hline 2 & $266^{\prime}$ & 7,8 \\
3 & 337 & 9,1 \\
4 & 316 & 8,1 \\
5 & 309 & 8,0 \\
6 & 251 & 8,1 \\
& 276 & 7,7 \\
\hline
\end{tabular}

Il n'est pas sans intérêt de rapprocher ces variations de celles du nombre de porcelets par portée. Ces dernières semblent suffisantes pour justifier les variations de production laitière observées.

3. Poids de la Truie. - L'opinion sur l'influence de ce facteur est très partagée puisque Groudev (I956) croit à une action favorable du poids sur la production laitière, alors que Bonsma (I935), de son côté, avait trouvé une corrélation négative. Peut-être les divergences viennent-elles de ce que ces auteurs ne semblent pas avoir dissocié les facteurs poids des truies et nombre de porcelets, qui varient parfois dans le même sens. 
Selon nous, sauf peut-être le cas de la I $^{\text {re }}$ portée, le poids propre des truies ne semble pas influencer directement la production laitière :

Corrélation poids des truies à l'accouplement/Production laitière :

$$
r=- \text { o,or N.S. }
$$

Corrélation poids des truies à la parturition/Production laitière :

$$
r=+0,08 \text { N.S. }
$$

Nous avons trouvé, par contre, une certaine corrélation $\left(r=+0,4^{\circ} ; \mathrm{P}=0, \mathrm{oI}\right)$ entre le gain de poids de la Truie pendant la gestation et la production laitière. On peut donc penser qu'une petite truie peut être aussi laitière d'une grosse, à condition d'être bien nourrie et de prendre du poids pendant la gestation.

De la même façon, nous avons trouvé une corrélation très nette $(r=+0,54$; $\mathrm{P}=0, \mathrm{OI}$ ) entre la perte de poids des truies pendant la lactation et les quantités de lait produites : les truies fortes laitières sont souvent celles qui perdent le plus de poids pendant la lactation : Il y a donc lieu d'attirer dès à présent l'attention sur de telles relations entre les variations de poids et la production laitière, car elles semblent présenter une signification nutritionnelle manifeste.

4. Variations d'origine anatomique. - Les tétines antérieures, ou mamelles frontales, produisent plus de lait que les postérieures (on sait que c'est là une des raisons invoquées pour expliquer la préférence des porcelets pour ces tétines). Nous avons pu vérifier ce phénomène, déjà signalé par DONALD (I937) en pesant les quantités de lait recueillies après une traite sous ocytocine :

$$
\begin{array}{ll}
\text { Tétines antérieures } \ldots \ldots \ldots \ldots & 34,2 \mathrm{~g} \\
\text { Tétines postérieures } \ldots \ldots \ldots \ldots & \text { I9,0 } \mathrm{g}
\end{array}
$$

Ces résultats ne sont peut être pas sans rapport avec l'observation de TURNER (I952) selon laquelle 1'irrigation des mamelles inguinales serait différente de celle des frontales.

Par ailleurs, et malgré une opinion couramment répandue, le nombre de tétines de la truie (ligne de mamelle) paraît sans rapport avec la production laitière (corrélation $r=+0,05 ; \mathrm{N}$. S.).

\section{$2^{0}$ Variations qualitatives}

Ces dernières ont été étudiées à partir des résultats de $\mathrm{I} 67$ lactations comportant la récolte et l'analyse d'environ r 500 échantillons de lait.

a) Composition moyenne du lait de Truie.

Celle-ci peut se déduire de l'ensemble des déterminations que nous avons pra-

\begin{tabular}{|c|c|}
\hline Eau ...... & $8 \mathrm{I}, 60 \pm 2,84$ \\
\hline Matières azotées .. & $5,83 \pm$ \\
\hline Lipides . . . . . . . . & $6,17 \pm 0,7$ \\
\hline$\ldots \ldots \ldots$ & $5,42 \pm 0,2$ \\
\hline endres $\ldots \ldots \ldots \ldots$ & 0,92 \\
\hline
\end{tabular}
tiquées. Ses principaux aspects sont les suivants :

I. Composition globale. - Les taux des principaux constituants sont exprimés en $g$. Ioo $g$ de lait frais: 
Ces valeurs voisines dans l'ensemble des moyennes rapportées par les autres auteurs (NEUHAUs, I96I), diffèrent assez de celles du lait des autres espèces. En particulier, le lait de Truie, est beaucoup plus riche en matières azotées et en lipides que ceux de la Femme, de la Jument et de la plupart des Ruminants. Il est, par contre, plus pauvre que celui de la Ratte ou de la Lapine. Peut-être faut-il voir ici un certain rapport avec la vitesse de croissance du jeune (le porcelet est le seul des animaux de ferme à doubler son poids de naissance en moins de 8 jours) ; le fait est à prendre en considération pour la prévision du besoin nutritionnel de lactation. Compte tenu des quantités de lait produites, on voit en effet qu'une truie exporte dans ses 2 mois de lactation : trois fois son contenu corporel en eau et une fois son contenu en lipides et en azote, soit 2 à 3 fois plus que ce que réalise la meilleure vache dans le même temps.

2. Constituants azotés. - Ceux-ci ont été exprimés en pourcentages de l'azote total. La répartition en est la suivante :

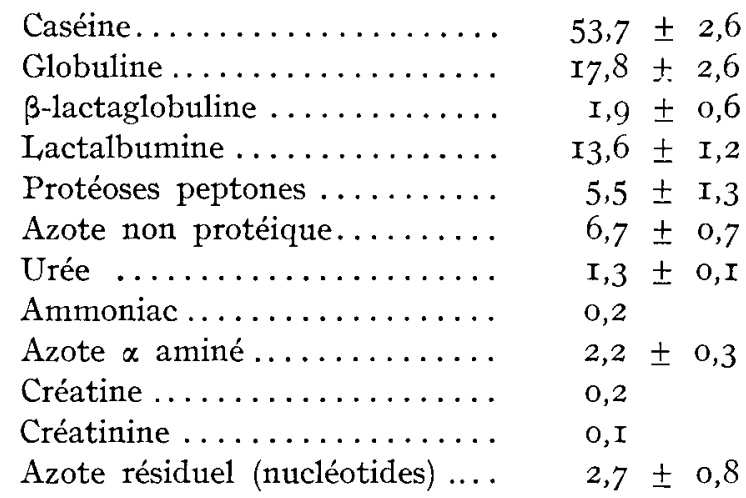

Seul avant nous, SHEFFy (I952) s'était livré au dosage de certains de ces constituants du lait de Truie, et à l'exception des protéoses peptones et des albumines qui ont été dosées par des techniques différentes, nos résultats concordent assez bien avec les siens, Par comparaison avec le lait des autres espèces, on relève quelques différences importantes, notamment dans les proportions relatives des différentes protéines. On remarque en particulier que le pourcentage de caséine est beaucoup moins élevé que chez les Ruminants ou même que chez la Ratte (Cox, I93I). Par contre, il est plus élevé que dans les laits de Femme (MACY, I96I) ou de Jument (Neuhauss, I960). Le fait que le rapport protéines du sérum/caséine du lait de Truie soit plus élevé que celui de la Vache pourrait éventuellement avoir pour conséquence une meilleure valeur biologique des protéines du lait de Truie; toutefois, ceci n'a pu être démontré jusqu'à présent (BRAUDE, I95I).

Par ailleurs, la répartition même des protéines du lactosérum paraît assez différente chez la Truie et chez la Vache : c'est ainsi qu'il y a davantage de globuline que d'albumine dans le lait de Truie et surtout beaucoup moins de $\beta$-lactoglobuline que de lactalbumine, alors que c'est le contraire chez la Vache (Shahani, I95I).

Enfin, le lait de Truie contient plus d'azote non protéique en valeur absolue et relative que le lait de Vache. Ceci est surtout dû aux fractions azote $\alpha$ aminé et azote indéterminé, car la quantité d'urée est sensiblement la même. Notons qu'il en va de 
même pour d'autres espèces (Femme, Anesse) dont le lait présente en valeur absolue des quantités voisines d'urée alors que les teneurs en azote total varient beaucoup. Il semble que chez toutes ces espèces les teneurs en urée et en azote total du lait soient indépendantes.

3. Constituants lipidiques. - Une première série de déterminations sur des échantillons moyens a permis d'établir la répartition des principaux constituants de l'extrait lipidique total.

\begin{tabular}{|c|c|}
\hline Triglycérides & $\begin{array}{l}\text { glycérol . . . . . . . . . . . } \\
\text { acides gras volatils ...... } \\
\text { acides gras concrets ..... }\end{array}$ \\
\hline cides gras libres & \\
\hline iable & \\
\hline Iospholipides . . & \\
\hline
\end{tabular}

Le lait de Truie contient beaucoup moins d'acides volatils que le lait de Vache et celui des Ruminants en général, ce qui le rapproche, par contre, des laits de Femme et de Ratte (LING et al., I96I). A l'opposé, les teneurs en substances insaponifiables et phospholipides paraissent notablement plus élevées dans le lait de Truie que dans les autres laits (DEUEL, I957).

Dans l'ensemble nos résultats confirment les quelques données existantes dues à LAXA (I93I), de la MARE (I940), et à ShEFFy et al. (I962). Nous nous sommes davantage intéressés à la répartition des acides gras, surtout ceux des glycérides (300 déterminations). Nos résultats, obtenus en chromatographie gazeuse, sont exprimés en p. Ioo des esters méthyliques.

TABLEAU I9

Composition en acides gras des lipides du lait de Truie (p. Iоo)

\begin{tabular}{|c|c|c|c|}
\hline & Tryglycérides & Phospholipides & Acides gras libres \\
\hline 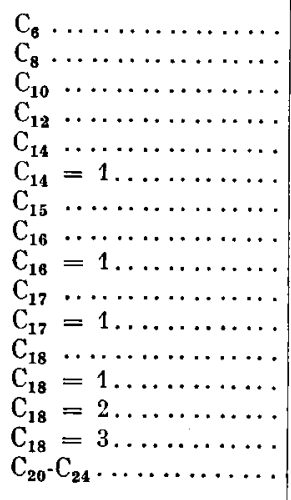 & \begin{tabular}{r}
\multicolumn{1}{c}{0,3} \\
0,5 \\
1,2 \\
4,3 \\
0,6 \\
0,3 \\
31,4 \\
10,0 \\
0,7 \\
0,5 \\
5,0 \\
36,9 \\
6,2 \\
0,9 \\
1,2
\end{tabular} & \begin{tabular}{r}
\multicolumn{1}{c}{$"$} \\
$"$ \\
$"$ \\
1,4 \\
2,5 \\
0,6 \\
0,2 \\
19,9 \\
4,6 \\
0,6 \\
0,3 \\
12,0 \\
26,9 \\
7,9 \\
0,3 \\
22,8
\end{tabular} & $\begin{array}{r}2,5 \\
3,9 \\
2,1 \\
6,0 \\
5,5 \\
4,7 \\
1,0 \\
15,3 \\
9,5 \\
1,8 \\
1,3 \\
6,6 \\
28,7 \\
8,9 \\
1,3 \\
0,9\end{array}$ \\
\hline & 100,0 & 100,0 & 100,0 \\
\hline
\end{tabular}


Il convient de noter la très grande diversité des acides gras qui, figurent dans cette répartition, puisque acides volatils mis à part, on retrouve des quantités assez importantes de tous les acides gras saturés et insaturés, pairs et impairs de $C_{8}$ à $C_{24}$. Nous n'avons rapporté ici que les principaux, mais sans avoir été jusqu'à retrouver les 64 acides gras séparés dans le lait de Vache par Magidmax et al. (I962), nous avons pu en identifier environ une trentaine dans le lait de Truie.

La répartition des acides gras diffère quelque peu suivant la fraction à laquelle ils appartiennent. La plus importante de ces différences a trait à la teneur en acides gras à longue chaîne $\left(\mathrm{C}_{20}, \mathrm{C}_{24}\right)$, particulièrement élevée dans les phospholipides (ces derniers contiennent notamment des proportions importantes d'acide saturé $\mathrm{C}_{22}$ ); le même phénomène a été signalé dans le lait des bovins (Matrson, I962; BADINGS, I962) et résulte vraisemblablement de la présence d'une proportion importante de sphingomyéline dans ces phospholipides. La composition de la fraction acides gras libres est plus difficile à interpréter, compte tenu de ce que cette fraction est très faible dans le lait et sans doute très variable. Elle paraît, toutefois, nettement plus riche en acides gras courts et moyens.

Enfin, il est intéressant de relever les différences importantes qui existent entre la Truie et les autres espèces dans les pourcentages de certains acides gras. C'est ainsi que le lait de Truie contient moins d'acides gras courts ou moyens que celui des Ruminants et même que ceux de certains monogastriques, comme la Femme et la Jument (LING et al., I936) ; en contrepartie, on y trouve davantage d'acides gras à longue chaîne et surtout beaucoup plus d'acides gras insaturés ou polyinsaturés. Ces divergences s'expliquent assez bien, compte tenu des phénomènes digestifs et du type d'alimentation propres à l'espèce.

4. Constituants minéraux. - Pour souligner certaines différences avec le lait des bovins, nous indiquons ici les teneurs du lait de Truie en quelques minéraux (g par litre) :

\begin{tabular}{|c|c|}
\hline Phosphore..... & $\mathrm{I}, 54 \pm 0, \mathrm{I} 3$ \\
\hline Calcium... & $2,13 \pm$ \\
\hline Potassium . & $\mathrm{I}, \mathrm{OO}$ \\
\hline Sodium ......... & $0,34 \pm$ \\
\hline Magnésium & $0,20 \pm 0,02$ \\
\hline
\end{tabular}

Le lait de 'Truie est riche en calcium et en phosphore et sa composition se rapproche de celle du lait de Brebis. Contrairement au lait de Vache, il est plus pauvre en potassium qu'en calcium et phosphore.

\section{b) Évolution au cours de la lactation.}

Il est possible de définir pour chaque constituant du lait une courbe d'évolution au cours de la lactation analogue à celle que 1'on observe chez d'autres espèces. Ira figure 7 et le tableau 20 rapportent cette évolution pour les constituants majeurs du lait.

Le sens de ces variations est en général conforme à celui qu'ont observé d'autres auteurs (SMITH, I952 ; PERRIN, I954 ; LODGE, I957), mais il apparaît une différence importante dans l'évolution des lipides ou de certains minéraux (calcium, phosphore) entre la Truie et la Vache. Chez la Vache, le taux de lipides est très élevé 
au début de la lactation, puis diminue très sensiblement pour remonter en fin de lactation. Rien de pareil chez la Truie : le taux de lipides initialement assez bas, atteint rapidement un maximum et décroît ensuite jusqu'à la fin de lactation.

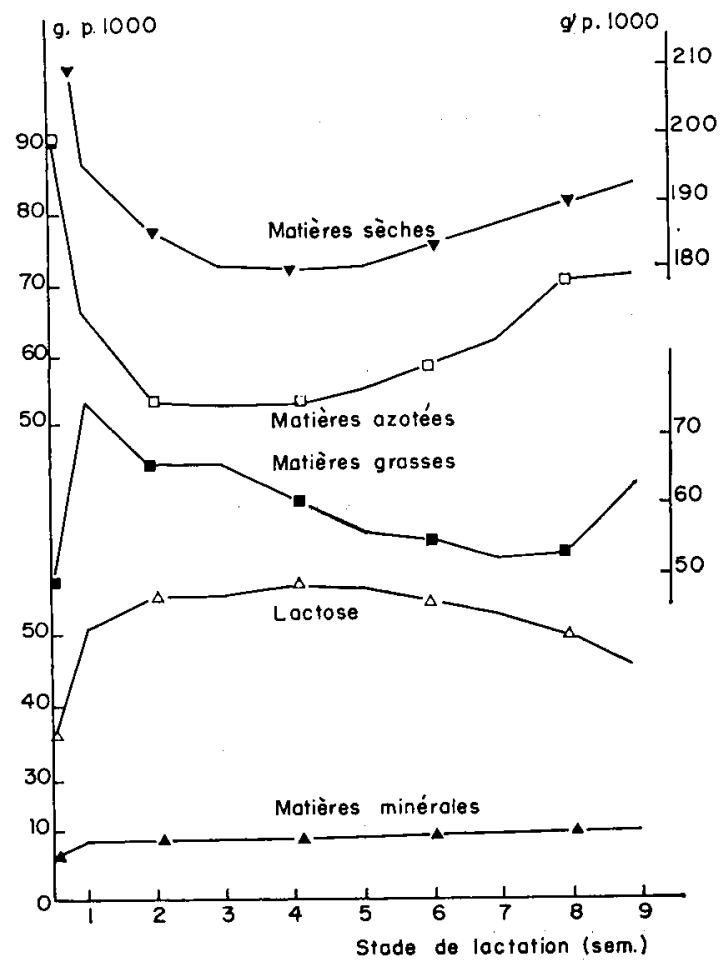

IIIG. 7. - Variation de la composition du lait de Truie au cours de la lactation

TABLEAU 20

Evolution de_la composition dus lait de Truie au cours de la lactation

\begin{tabular}{|c|c|c|c|c|c|c|c|c|c|}
\hline Stade de lactation (semaines) & Colost. & 1 & 2 & 3 & 4 & 5 & 6 & 7 & 8 \\
\hline Matières azotées totales..... & 10,17 & 6,09 & 5,77 & 5.33 & 5,36 & 5,61 & 5,91 & 6,19 & 6,69 \\
\hline Lipides . . . . . . . . . . . . . . & 5,21 & 7,21 & 6,69 & 6,60 & 6,30 & 5,92 & 5,89 & 5,86 & 5,75 \\
\hline Lactose $\ldots \ldots \ldots \ldots \ldots \ldots$ & 3,72 & 5,06 & 5,68 & $5,5^{\prime}$ & 5,67 & 5,56 & 5,43 & 5,36 & 5,15 \\
\hline Matières minérales totales..... & 0,59 & 0,76 & 0,78 & 0,82 & 0,88 & 0,92 & 0,99 & 7,06 & 1,16 \\
\hline$P$ p. $100 \ldots \ldots \ldots \ldots \ldots$ & 0,98 & 1,39 & 1,28 & 1,46 & 1,54 & 1,62 & 1,63 & 1,63 & 1,72 \\
\hline $\mathrm{Ca}_{\mathrm{p}} .100 . \ldots \ldots \ldots$ & 0,60 & 1,79 & 1,75 & 1,90 & 2,02 & 2,20 & 2,32 & 2,46 & 2,31 \\
\hline
\end{tabular}

Aucune explication n'a été fournie jusqu'à présent à ce phénomène. Il faut reconnaître toutefois que l'accord est loin d'être fait sur le moment où ce maximum se produit, puisque certains auteurs, comme BraUde (I947), PERrin (I954) et BARBER (I957) le placent vers la $3^{\text {e }}$ semaine de lactation. D'autres comme HEIDELBREch' (I95I), 
SHEFFY (I952) et LODGE (I957) n'observent pas l'accroissement initial du taux butyreux, mais seulement sa diminution ultérieure. De telles divergences sont vraisemblablement à mettre au compte des variations quotidiennes et surtout des difficultés d'échantillonnage, ou même des méthodes d'analyse. Aussi, avons-nous examiné de plus près, dans une étude détaillée sur ro truies traites toutes les 6 heures, les variations de composition de lait au cours de la période qui suit la parturition. Le résultat de ces investigations est rapporté dans la figure 8.

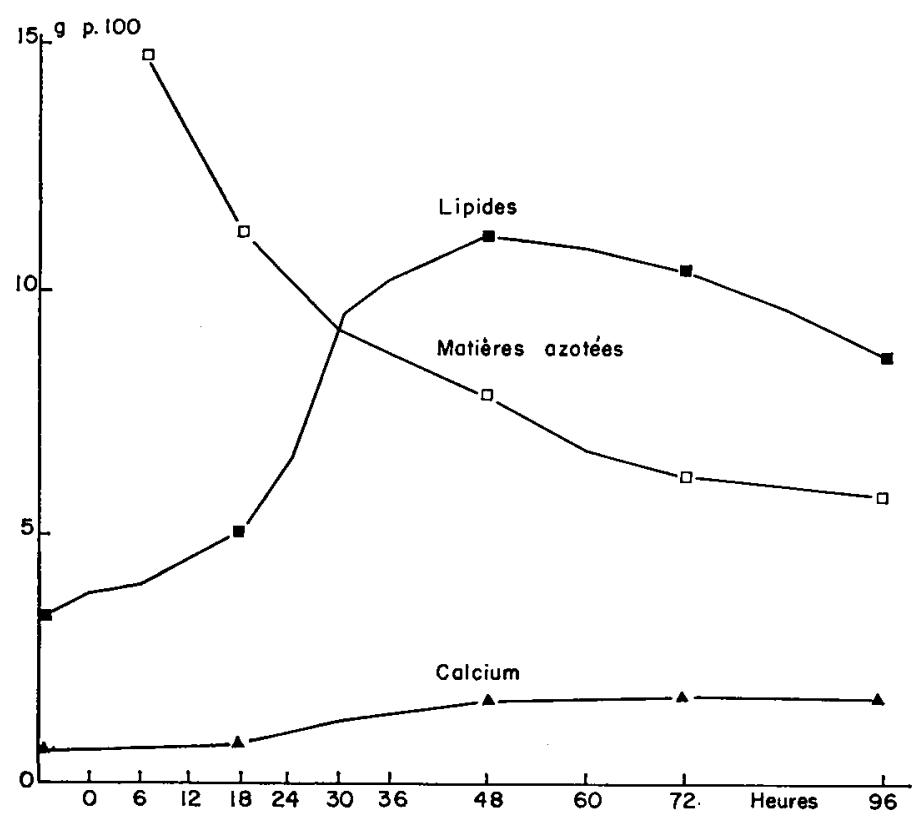

FIG. 8. - Evolution de la composition chimique du colostrum de Truie

On constate que l'évolution des teneurs de certains constituants, notamment la matière grasse et le calcium, est très rapide dans les quelques heures qui suivent la mise bas, ce qui traduit sans nul doute l'augmentation de l'activité sécrétoire de la mamelle et en particulier l'augmentation du volume de la sécrétion. Par définition (HoUdiniÈRE, I944), ce processus caractérise la période colostrale ; celle-ci n'excéderait pas 48 heures chez la Truie. Si cette évolution est en tout point comparable à celle que l'on observe chez la Jument (LIN'TON, I93I; FLADE, I955), elle ne diffère de celle de la vache que par le moment auquel elle survient. RowLAND et al. (I953), PIETRE (I934) ont en effet montré dans une étude sur les sécrétions antepartum de la vache que l'on observait dans les io jours qui précèdent la mise bas, une évolution du taux butyreux et des teneurs en $\mathrm{P}$ et $\mathrm{Ca}$ tout à fait comparable à celle que nous indiquons pour la période colostrale de la Truie (montée rapide des teneurs). Cela est a rapprocher du fait qu'en dépit de l'aptitude de la mamelle à sécréter bien avant la fin de la gestation (MAYER, I96r), on sait maintenant que la Truie est l'une des espèces chez laquelle ce phénomène est le plus tardif (CRoss et $a l$., I957). Tout semblerait se passer comme si la phase de sécrétion précolostrale était retardée et réduite chez la Truie (il en va de même chez la Femme). Contrai- 
rement à ce que l'on a parfois avancé, la Truie ne fait pas exception aux mécanismes habituels de la sécrétion lactée : ce sont seulement les modalités chronologiques qui diffèrent.

Une évolution du même type est à signaler en ce qui concerne la répartition des constituants azotés. Outre leur chute très brutale, à l'exception de l'azote non protéique, que l'on observe au début de la lactation chez la Truie. les proportions relatives de ces constituants se modifient (fig. 9). On assiste en particulier à un effondrement du pourcentage des globulines, alors que celui de la caséine passe au contraire de 20 à 50 p. Ioo de l'azote total en moins de $48 \mathrm{~h}$ et que les autres protéines diminuent légèrement. Ces modifications se stabilisent assez vite et par la suite les proportions relatives de ces différents constituants (en particulier le rapport Caséine/ $\mathrm{N}$ total) restent relativement constantes jusqu'au sevrage.

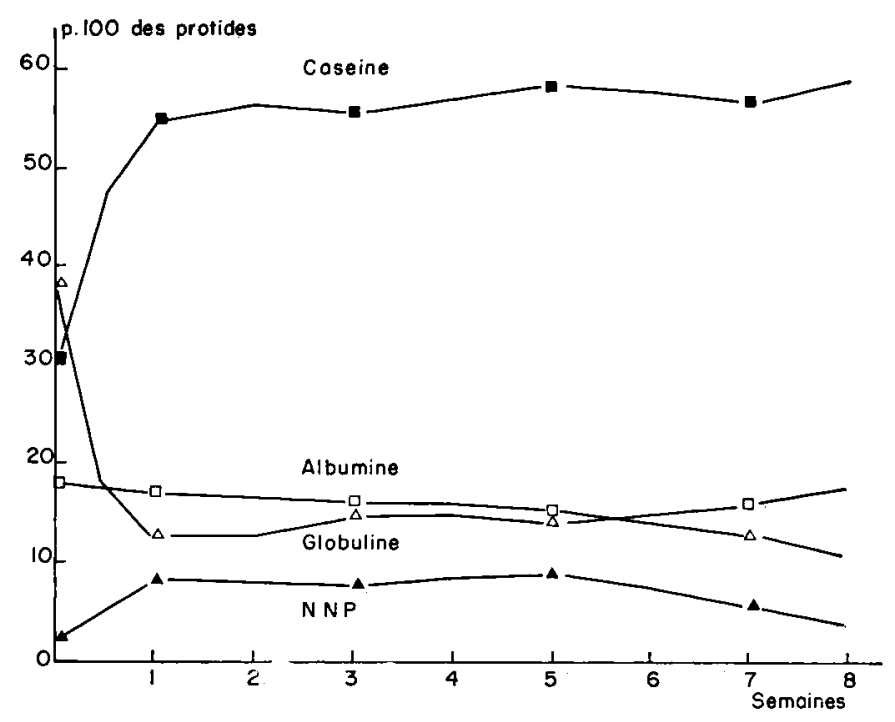

FIG. 9. - Évolution de la répartition des constituants azotés du lait de Truie

\section{c) Relations entre constituants.}

Comme pour la plupart des autres espèces, il existe chez la 'Truie des relations entre les variations des constituants du lait.

Il existe, par exemple, une corrélation élevée entre la teneur en lactose et le volume de la sécrétion $(r=+0,97)$. Cette corrélation se manifeste aussi bien au cours de la lactation (pour une truie donnée) qu'entre lactations individuelles de différentes truies. Cette relation, analogue à celle décrite par NArro (1958) sur le Cobaye, par Journet (I960) sur la Vache et par Denamur (I96I) sur la Brebis, peut s'interprêter comme une présomption du rôle du lactose dans le maintien de la pression osmotique du lait: lorsque la sécrétion du lactose augmente, la quantité d'eau excrétée (et donc le volume de la sécrétion) crôit également et la pression osmotique reste constante.

Une autre relation intéressante est celle qui oppose les variations des matières azotées à celles du lactose. Chaque fois que l'une de ces teneurs augmente, que ce soit 
au cours de la lactation ou en valeur pondérée pour des lactations individuelles, l'autre diminue (coefficient de corrélation partielle $r=-0,62$ ). Cette relation est curieuse, car on ne la trouve pas, du moins avec tant de netteté chez les Ruminants. Peut-on y voir, comme le propose Graham (I937) pour le Rat, une preuve d'une certaine gluconéogenèse à partir des déchets azotés libérés par le foie. Ceci n'est pas impossible comme le reconnaît LODGE (I959). Si cette hypothèse se vérifiait, elle constituerait en outre une des modalités d'intervention possible des nutriments azotés dans le métabolisme énergétique de la Truie en lactation.

\section{d) Facteurs de variation.}

Il faut remarquer tout d'abord que les teneurs des différents constituants n'ont pas la même propension à varier. Cette notion apparaît dans les coefficients de variation (moyenne/écart-type p.roo):

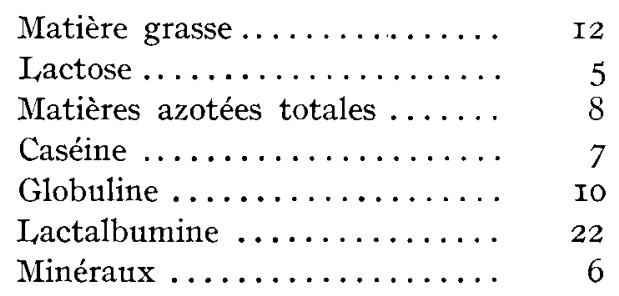

Les teneurs en matière grasse et en protéines solubles sont celles qui varient le plus. Par contre, la teneur en lactose est relativement stable et ses variations offrent peu d'intérêt à considérer. Ce phénomène traduit d'abord l'importance du facteur individuel, mais également la sensibilité aux conditions de milieu, ou même les fluctuations dues à l'échantillonnage et aux dosages. Les principaux facteurs de variation que l'on peut retenir sont les suivants :

I. L'âge. - C'est surtout chez les Bovins que les variations liées au numéro de la lactation ont été signalées (Waite et al., I956; Johansson, r957). Chez la Truie, LODGE (I956) avait trouvé, entre 6 premières et secondes lactations, une augmentation des teneurs de tous les éléments du lait sauf le lactose. Nos propres résultats ne confirment pas cette observation. Les variations d'une lactation à la suivante semblent assez minimes et n'obéissent pas à une loi bien définie (tabl. 2I). Tout au

TABLEAU 2 I

Évolution de la composition du lait avec l'âge

(p. 100)

\begin{tabular}{|c|c|c|c|c|c|c|c|c|}
\hline No lactation $\ldots \ldots \ldots \ldots \ldots \ldots \ldots$ & 1 & 2 & 3 & 4 & 5 & 6 & 7 & 8 \\
\hline$n$. lactations $\ldots \ldots \ldots \ldots \ldots \ldots$ & 35 & 32 & 25 & 16 & 15 & 9 & 9 & 9 \\
\hline Matière azotée $\ldots \ldots \ldots \ldots \ldots \ldots \ldots$ & 5,69 & 5,53 & 5,62 & 5,75 & 5,68 & 5,78 & 5,70 & 6,12 \\
\hline Lipides ................ & 6,46 & 6,06 & 6,07 & 6,42 & 6,12 & 6,52 & 6,41 & 6,76 \\
\hline Lactose $\ldots \ldots \ldots \ldots \ldots \ldots \ldots \ldots$ & 5,40 & 5,49 & 5,44 & 5,33 & 5,42 & 5,45 & 5,38 & 5,28 \\
\hline
\end{tabular}


plus peut-on noter une légère diminution ( 8 p. IOo) de la teneur en lipides entre les $I^{\text {re }}$ et $2^{\text {e }}$ lactation qui va de pair avec l'augmentation de la quantité de lait sécrétée.

2. Variations au cours de la traite. - PERRIN (I954) ąvait analysé lạ composition de prélèvements successifs de lait obtenus au cours de la traite, principalement la teneur en matière grasse. Cette étude, qui portait sur un nombre restreint d'échantillons, n'avait pas révélé de variations régulières ou systématiques de la composition du lait au cours de la traite et vraisemblablement donc au cours de la tétée.

Nous avons repris cette étude en utilisant 3 prélèvements successifs obtenus au cours de I 5 traites sur différents animaux à différents stades de lactation. Les résultats figurent au tableau 22.

TABLEAU 22

Évolution de la composition du lait de Truie au cours de la traite

(p. IоO)

\begin{tabular}{|c|c|c|c|}
\hline & \multicolumn{3}{|c|}{ Fractions } \\
\hline Échantillons $\ldots \ldots \ldots \ldots$ & 1 & 2 & 3 \\
\hline Matière sèche $\ldots . . \ldots \ldots$ & 18,47 & 18,71 & 19,06 \\
\hline Lactose . . . . . . . . . . . & 5,58 & 5,65 & 5,59 \\
\hline Matières azotées....... & 5,18 & 5,13 & 5,10 \\
\hline Matière grasse. ......... & 6,44 & 6,95 & 7,09 \\
\hline Minéraux ............ & 0,98 & 0,98 & 0,99 \\
\hline
\end{tabular}

S'il semble n'y avoir que peu de variations pour le lactose (légère augmentation), les matières azotées (légère baisse) et les minératıx (légère augmentation), par contre les matières grasses et la matière sèche paraissent augmenter assez nettement,' résultat tout à fait comparable à celui que l'on observe chez la Vache.

Ceci est important et montre que pour être représentatifs de la composition du lait tété par les porcelets, les prélèvements destinés à l'analyse doivent être effectués sur des quantités équivalentes à celles qui auraient été obtenues au cours d'une tétée naturelle.

3. Variations de poids. - Le calcul des corrélations montre qu'il existe une certaine relation entre la perte du poids des truies pendant la lactation et la composition du lait : les teneurs en lipides et en protides du lait sont en effet plus élevées chez les truies qui perdent beaucoup de poids :

Corrélation perte de poids/teneur en lipides ......... $r=+0,32$

Corrélation perte de poids/teneur en protides $\ldots \ldots \ldots, \quad r=+0,36$

Corrélation perte de poids/teneur en lactose ........ $\quad r=-0,25$

Sans se hasarder à donner un sens précis à cette relation, on peut toutefois penser qu'elle traduit la participation possible des constituants corporels à la synthèse d'une partie des éléments du lait, hypothèse sur laquelle nous aurons l'occasion de revenir. 


\section{E - Discussion générale}

Si l'on ne tient pas compte de la période prépubertaire et des intervalles de repos qui précèdent ou suivent chaque cycle, la reproduction de la Truie apparaît comme constituée de deux périodes de durée et d'importance inégales: la gestation et la lactation.

La gestation est la phase la plus longue et se caractérise essentiellement, à côté de l'élaboration des produits de la conception, par un anabolisme gravidique qui laisse à la mère un bénéfice corporel non négligeable après la parturition.

Il y a lieu d'insister sur le fait qu'aussi bien sur le plan pondéral que sur la base de l'azote ou l'énergie retenus, cet anabolisme maternel constitue, dans les conditions habituelles, le phénomène le plus important, mais aussi le plus variable de la gestation. C'est ce qui a fait dire à PIKE (I955), en d'autres circonstances chez le Rat, que le gain de poids de la mère était en définitive le meilleur reflet de l'efficacité du régime alimentaire de gestation.

Toutefois, si la croissance de l'embryon et celle des tissus extra-utérins peuvent apparaître comme le résultat d'une heureuse symbiose, leurs évolutions ne sont pas parfaitement identiques. C'est ainsi qu'au début, la gestation profite essentiellement à la mère, alors que dans sa deuxième moitié la croissance embryonnaire l'emporte sur la prise de poids maternelle. Il peut donc apparaître une certaine concurrence nutritionnelle dont le fotus bénéficie en priorité et qui s'intensifie avec le temps. I1 en résulte que l'importance et la nature des tissus élaborés en dehors de l'utérus gravide peuvent s'en trouver affectées. En tout premier lieu, on observe souvent en fin de gestation un arrêt de la lipogenèse et même une diminution des réserves adipeuses qui peuvent s'expliquer par les exigences propres du foetus en matériaux énergétiques. Celles-ci s'intensifient au cours des dernières semaines de gestation et l'augmentation de la dépense métabolique de base qu'ont observée à ce stade certains auteurs (BRODY, I945; MOUSTGAARD, I962) peut trouver une compensation dans l'utilisation des ressources endogènes. Par contre, il en va différemment du besoin azoté pour lequel nos propres résultats de bilans, joints aux observations de Rombaurs et $a l$. (I956) et de Champigny (I962) sur la Ratte et de Rombauts (I959) sur la Brebis permettent d'envisager un facteur d'épargne lié à l'état de gestation. Il en résulte donc, que même aux périodes de besoin maximum de l'utérus gravide, la Truie peut bénéficier d'un certain reliquat azoté qui ne lui interdit pas toute synthèse protéique. Ces capacités de rétention se manifestent paradoxalement en dépit et peut-être au prix de la disparition du tissu adipeux. Ainsi explique qu'au moment de la parturition. la Truie gestante contienne dans son organisme davantage de tissu musculaire, mais moins de tissu adipeux que la Truie de même poids au repos, résultat qui rejoint les observations de Bourde et Jacquot (I959) et de PÉRISSE (I960) sur la Ratte.

En définitive, et si l'on s'en tient aux stricts besoins de l'utérus gravide, la gestation apparaît donc comme un phénomène assez peu coûteux sur le plan nutritionnel. La satisfaction des besoins peut être réalisée compte tenu de la réduction de la dépense azotée et des transferts internes d'énergie sans qu'à aucun moment la croissance du fœtus ne paraisse en être ralentie.

Par comparaison et bien que deux fois moins longue que la gestation, la lactation de la Truie fait apparaître des phénomènes différents. 
Tout d'abord, il convient de souligner l'importance de la production laitière de la Truie qui, toute proportion gardée, réalise des performances supérieures à celles d'animaux que l'on considère parfois comme plus laitiers. Avec une moyenne de $6 \mathbf{g}$ de matière sèche de lait sécrétée par jour et par $\mathrm{kg}$ de poids vif, la Truie devance dans l'ordre : la Chèvre $(5 \mathrm{~g})$, la Vache $(3 \mathrm{~g})$ et la Femme $(\mathrm{I}, 5 \mathrm{~g})$.

Toutefois, les facteurs de variations sont nombreux et certains d'entre eux, comme le nombre de porcelets, l'âge et le poids de la Truie, le stade de lactation doivent être pris en considération dans toute étude ayant pour objet l'examen des performances ou de certains aspects nutritionnels.

Il ne faut pas perdre de vue non plus que contrairement à une espèce comme la Vache, les variations de production chez la Truie en lactation concernent plus souvent la qualité que la quantité du lait. La composition du lait de Truie et les phénomènes de régulation qui s'y rapportent paraissent en effet assez différents de ceux que l'on observe chez les Ruminants. Le lait de Truie contient davantage de protides et de lipides que le lait de Vache, avec une répartition elle-même différente (moins de caséine, davantage d'acides gras insaturés), caractères qui paraissent propres aux espèces monogastriques. Les facteurs de variation de cette composition sont mal connus, mais font apparaître certaines relations entre constituants. Par exemple, celles qui relient le lactose à l'eau et aux matières azotées. Ces interrelations peuvent donner lieu à certaines hypothèses sur 1'origine biochimique des constituants de la sécrétion. comme la gluconéogenèse déjà invoquée par GRAHAM (I937) et par FoLLEY et al, (I947) chez la Ratte.

L'évolution de certains constituants, comme les lipides, au cours de la lactation obéit également à des règles particulières : par exemple, la présence d'un maximum de la teneur en lipides au cours de la prenière semaine de lactation est un phénomène assez constant mais qui peut donner lieu à des difficultés ou même des erreurs d'interprétation, dont il importe que le nutritionniste soit averti.

D’une manière générale, le constituant le plus variable entre individus, ou au cours de la lactation, est la teneur en lipides du lait. Ceci met l'accent sur la dépense énergétique très élevée que constitue la production laitière de la Truie. Compte tenu de la valeur énergétique du lait de Truie ( $200 \mathrm{cal} / \mathrm{g}$ ), le besoin en énergie nette de lactation paraît environ deux fois supérieur à celui de la gestation et trois fois à celui de l'entretien, ce que confirme les expériences de LoDGE (I957) et de Smith (I960).

Il n'y a rien donc d'étonnant à ce que la lactation provoque chez la Truie, en dépit d'une efficacité alimentaire qui peut être très élevée (notamment pour l'azote). une perte de poids importante. Cette dernière affecte principalement les réserves édifiées pendant la gestation. Mais il semble que le catabolisme porte en premier lieu sur les tissus protéiques au début de la lactation et ultérieurement sur les tissus adipeux en fin de lactation. Il en résulte que la lactation peut être à l'origine également d'une nouvelle modification de la composition corporelle : à poids égal, les truies en fin de lactation sont moins grasses que les truies gestantes ou au repos de même poids. La lactation intensifie donc la délipidation qui apparaît en fin de gestation, conclusion que SPRAY (I950) et nous-même (I960) avaient déjà formulée à l'égard de la Ratte. Ainsi se pose le problème des relations entre le niveau d'alimentation et les modifications induites par l'une ou l'autre phase de la reproduction. 
CHAPITRE III

\section{RELATIONS QUANTITATIVES ENTRE LE NIVEAU ALIMENTAIRE GLOBAL ET LA REPHODUCTION}

\section{Introduction}

La littérature mentionne d'assez nombreux travaux consacrés à l'influence du niveau alimentaire sur les performances de reproduction de la Truie (DUNCAN et L,ODGE, I960). Cette influence est parfois discrète, parfois manifeste, selon le phénomène considéré, c'est-à-dire en fonction de la phase du cycle de reproduction : puberté, fécondité, gestation, lactation.

\section{Io Puberté}

Les conditions nutritionnelles sont susceptibles d'influencer l'âge pubertaire, c'est-à-dire la date d'apparition du premier cestrus. D'observations parfois contradictoires, il se dégage que la sous-alimentation peut retarder la puberté. D'autres carences semblent agir dans le même sens : la déficience en azote (DAvidson, I93I) en acides gras essentiels (WITz et al., I95I), en vitamine A (Hughes, I934; TiknoNov, I957), en vitamine $B_{12}$ (Johnson et al., I952). Cependant, chez la Truie, la précocité sexuelle est moins contingente du niveau alimentaire global que la prise de poids (LoDGE et al., r96r). On admet, en général, que l'âge aut premier œstrus est une caractéristique individuelle beaucoup moins variable que le poids, ce qui revient à dire que la précocité sexuelle n'est pas forcément liée à la vitesse de croissance (ZIMMERMAN et al., I960).

\section{$2^{\circ}$ Fécondité}

Le niveau d'alimentation exerce peu d'effets sur la durée des cycles et le moment de l'ovulation. Il n'en est pas de même pour le taux d'ovulation. Plusieurs auteurs ont montré que l'augmentation des ingérés énergétiques accroît sensiblement le nombre des ovules pondus (Christian, I952; WISE et ROBERTSON, I953; SELF et al., I955; ZIMMERMAN et al., I958).

Il ne s'ensuit pas forcément des portées plus abondantes car, dans ces conditions, une proportion importante des embryons pouvant dépasser $40 \mathrm{p}$. Ioo est résorbée in utero (RATHNASABAPATHY, I956). On s'est souvent interrogé sur la signification de ce phénomène dont les causes demeurent mal connues. L'opinion qui prévaut est celle de CASIDA (I956) : si la suralimentation favorise la ponte ovulaire, elle est par contre nuisible au métabolisme de l'utérus et limite les capacités nutritionnelles de cet 
organe. Les risques de résorption seront alors d'autant plus grands que le nombre des embryons est plus élevé, de sorte que les deux phénomènes s'équilibrent en définitive. Cette explication semble également valable pour l'alimentation protéique dont les fluctuations n'affectent que très peu le nombre des embryons survivants (ROBERTson et al., I95I ; TRIBLE et al., I956).

\section{$3^{\circ}$ Gestation}

Tous les auteurs semblent d'accord sur le fait qu'une augmentation du niveau alimentaire (azoté ou énergétique) pendant la gestation a pour principal effet une augmentation du gain de poids de la mère : McKENZIE (I928), ZELLER (I937), DEAN et Trible (I960), GoOde (I960), LODGE et al. (I96I), MAjerciak (I962), McGilitVRAY (I962), CLAwSON et al. (r963) 1'ont montré à des degrés divers. Toutefois, cette prise de poids, variable avec l'animal et le régime alimentaire, n'a fait l'objet que de peu d'études approfondies: seuls Lenkert et al. (I955, I956, I957), PENZES (I959, I960) ont accordé quelque attention à la rétention corporelle d'azote chez la Truie gestante, mais sans jamais en étudier l'incidence sur la lactation.

Quelques auteurs n'ont pas été sans remarquer qu'une prise de poids élevée pendant la gestation était parfois l'indice d'une moins bonne fécondité et prolificité (Robertson et al., I95I ; Moustgaard, I959; Dean, I96I ; Donald et Flemming, I938). Ce phénomène est souvent interprété comme la conséquence d'une adiposité excessive, consécutive à un rationnement trop riche en énergie (KRUTYPOROKH, I957; MOUSTGAARD, I96r).

En fait on connaît mal l'influence que peut avoir l'alimentation sur l'état des portées à la naissance. Les études poursuivies dans ce sens sont souvent contradictoires. Selon Christran et al. (I952), Fanbranks et al. (I945), Haines et al. (I955, I959), Clawson et al. (I963), un haut niveau énergétique a pour effet d'augmenter légèrement la taille de la portée et le poids des porcelets. Pour Hansov et al. (I953), le niveau énergétique est sans effet. Enfin, Vestal (I936), WEIPERS (I956), Trible, et DEAN (I960), GOODE ( $196 \mathrm{I}$ ) estiment at contraire que les truies rationnées sont les plus prolifiques et donnent les poids de naissance les plus élevées.

Même incertitude en ce qui concerne l'apport protidique: si quelques auteurs ont pu montrer qu'une déficience en protides affectait légèrement la production des porcelets (McELROY, I950; TERrili, I955 ; IVANOV, I957 ; MoustGaARD, I962), beaucoup semblent penser que des variations dans des limites très importantes du taux de protides de la ration restent sans effets sur les résultats de la gestation (DAviDson, I930 ; GaRd et $a l$., I955 ; KMEnt, I955 ; LENkEIT, I957 ; AdAms et al., I960 ; BoAz, I962 ; RIPPEL, I962; CLAWSON, I963).

\section{$4^{\circ}$ Lactation}

A l'exception des travaux de Smith (I959, I960) et de LodGe (I959, I96I), on dispose de peu de renseignements sur l'influence de la consommation alimentaire sur la production laitière de la Truie. Aussi nous retiendrons surtout les différentes corrélations calculées à partir de nos propres données expérimentales.

- Il existe un rapport étroit entre la quantité de lait produite et la consommation totale de matière sèche au cours de la lactation. La corrélation entre ces 
données a pour coefficient $r=+0,63(\mathrm{P}=0,0 \mathrm{I})$ et montre que les truies qui ingèrent des quantités importantes d'aliment prođuisent généralement plus de lait.

- Cette relation s'exerce également dans les variations quotidiennes de l'appétit. On constate en effet un parallélisme intéressant entre les variations des quantités d'aliment consommées chaque jour par un animal donné et la production laitière correspondante. Ce phénomène se traduit par une corrélation moyeune $r=+0,55$ entre les deux paramètres.

- Toutefois, cet ajustement de l'appétit sur la production laitière (ou vice versa) n'est pas parfait, puisqu'il apparaît un certain décalage entre le maximum de l'ingestion et celui de la production laitière (fig. Io). Cela conduit à penser que, pendant une certaine période au moins, l'équilibre n'est pas réalisé et, malgré la participation possible des tissus corporels, cette insuffisance de consommation d'aliments peut constituer un facteur limitant de la production laitière chez la Truie.

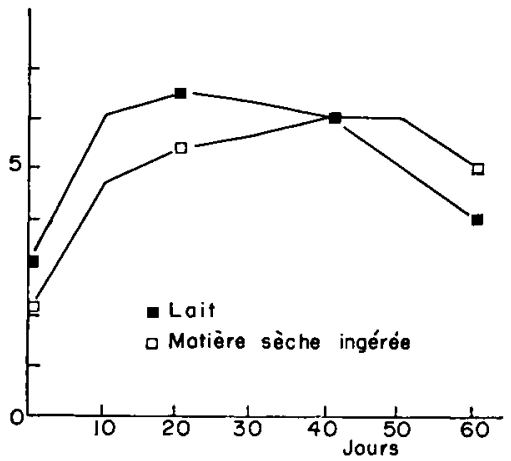

FIG. 10. - Relation entre la production laitière et la consommation d'aliment

\section{$5^{\circ}$ Etude expérimentale des relations nutritionnelles}

Deux notions sont déjà à retenir au vu des travaux antérieurs : pendant la gestation, la quantité d'aliment consommée paraît affecter davantage le gain de poids maternel que la croissance embryonnaire. Pendant la lactation, la quantité de lait produite et la perte de poids de la Truie semblent s'équilibrer avec le niveau de l'ingestion alimentaire.

L'étude plus détaillée de ces relations fait l'objet du présent chapitre. A cet effet, nous avons substitué aux variations aléatoires du comportement de l'animal des variations expérimentales de rationnement, imposées aux animaux, mais toujours à l'aide d'un même régime équilibré.

Par souci de simplification, toutes les expériences ne portent que sur la comparaison de deux niveaux alimentaires différents. L'un de ces niveaux correspond en général à une alimentation normale (qui peut être $a b$ libitum) basée sur les normes alimentaires les plus usuelles; 1'autre niveau est choisi de façon à être nettement en dessus ou en dessous (d'environ 50 p. Ioo) du premier rationnement. Dans tous les cas, il s'agit d'une ration équilibrée et la variation ne porte que sur le volume global de la ration.

L'influence de ces différents niveaux alimentaires a été étudiée, soit au cours de la gestation, soit au cours de la lactation, soit encore au cours des deux périodes successivement. 


\section{A - Eifets sur la gestation}

\section{$\mathrm{I}^{\circ}$ Augmentation $d u$ niveau alimentaire}

Cette première expérience n'a porté exclusivement que sur la suralimentation au cours du dernier mois de gestation.

C'est à cette période que la concurrence nutritionnelle entre la mère et les fœtus risque d'être la plus grande et de nombreux auteurs ont attiré l'attention sur la nécessité de fournir un supplément alimentaire à la Truie en fin de gestation (JEsPERSEN, I949; LEROY, I949; POTEHINA, I957). Dans l'esprit de ces auteurs, ce supplément avait pour premier objet de subvenir aux besoins du foetus (UNDERWOOD, I943; MoustGaARD, I962), mais en deuxième lieu de stimuler la prise de poids maternelle à un moment où celle-ci a tendance à se ralentir et placer ainsi l'animal dans des conditions plus favorables au bon déroulement de la lactation (CARROLL, I950; Stevenson et Eliris, I954, I957). Ceci semblait apparaittre également dans nos observations préliminaires.

Dans le but d'appronfondir ce premier point, nous avons constitué deux lots de 9 truies adultes, appariées deux à deux suivant leur poids et leurs antécédents. Pendant le dernier mois de gestation certains animaux étaient soumis à une alimentation normale (lot B), les autres étant suralimentés (lot $\mathrm{H}$ ). Pendant les trois mois de gestation précédents, les animaux avaient reçu une même alimentation rationnée. L'aliment utilisé au cours de la gestation était le même dans les deux lots et contenait I4 p. Ioo de protides. Il était distribué à raison de $2 \mathrm{~kg}$ par Ioo $\mathrm{kg}$ de poids vif (normes F. E. Z.) aux animaux du lot $\mathrm{B}$ et à volonté à ceux du lot $\mathrm{H}$. Après la parturition, les truies disposaient à volonté pendant 2 mois d'un même aliment équilibré de lactation à $\mathrm{I} 7 \mathrm{p}$. Ioo de protides.

On notait pour les truies de chaque lot les renseignements concernant la consommation alimentaire, les variations de poids et les poids des portées à différents stades (parturition, 2I jours, sevrage). Les productions laitières étaient déterminées par calcul, en utilisant la régression qui lie la quantité de lait produite au poids total de la portée à $5^{6}$ jours.

a) Résultats

Les principaux résultats sont rassemblés dans les deux tableaux 23 et 24 .

TABLEAU 23

Variations de poids et consommations

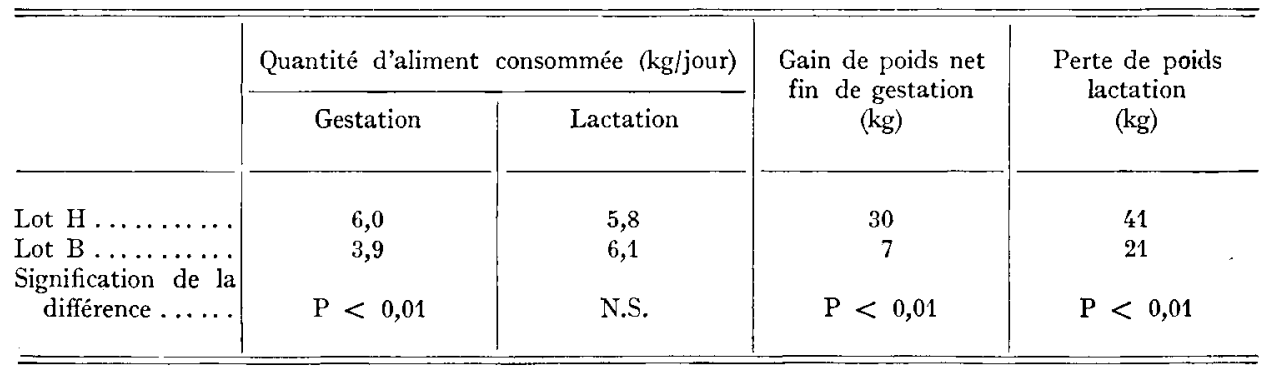




\section{b) Discussion}

L'examen du tableau 23 montre que les truies recevant un supplément alimentaire en fin de gestation ont présenté un gain de poids supplémentaire de $23 \mathrm{~kg}$ par truie, par rapport aux truies du lot $B$.

Au cours de la lactation, les truies du lot $\mathrm{H}$ ont également perdu davantage de poids que celles du lot $\mathrm{B}$. I a légère augmentation de consommation observée pendant la lactation chez les truies les plus rationnées pendant la gestation ne suffit pas à expliquer cette différence. L'on peut donc penser qu'il s'établit une sorte d'équilibre dans les variations de poids, puisque les truies suralimentées ont perdu au cours de la lactation la majeure partie des excédents de tissu corporel qu'elles avaient acquis au cours de la gestation : comme précédemment, on peut montrer qu'il existe dans cette expérience une corrélation $r=+0,44$ entre les variations de poids des deux périodes. Cela indique que la perte de poids au cours de la lactation est en grande partie fonction de l'état de l'animal au moment de la parturition.

TABLEAU 24

Parturition et productions laitières

\begin{tabular}{|c|c|c|c|c|c|c|c|c|}
\hline & \multirow[b]{2}{*}{$\begin{array}{l}\text { Nombre to- } \\
\text { tal de } \\
\text { porcelets } \\
\text { par portée }\end{array}$} & \multirow[b]{2}{*}{$\begin{array}{c}\text { Nombre de } \\
\text { mort-nés }\end{array}$} & \multirow{2}{*}{$\begin{array}{c}\text { Poids } \\
\text { moyen des } \\
\text { porcelets } \\
\text { naissance } \\
(\mathrm{kg})\end{array}$} & \multicolumn{2}{|c|}{ Portée à 21 jours. } & \multicolumn{2}{|c|}{ Portée à 56 jours. } & \multirow[b]{2}{*}{$\begin{array}{l}\text { Production } \\
\text { laitière } \\
(\mathrm{kg})\end{array}$} \\
\hline & & & & $\begin{array}{l}n \\
\text { porce- } \\
\text { lets }\end{array}$ & $\begin{array}{c}\text { Poids } \\
\text { moyen } \\
\text { porcelet } \\
(\mathrm{kg})\end{array}$ & $\begin{array}{c}n \\
\text { porce. } \\
\text { lets }\end{array}$ & $\begin{array}{c}\text { Poids } \\
\text { moyen } \\
\text { porcelet } \\
(\mathrm{kg})\end{array}$ & \\
\hline Lot H... & 11,6 & 1,6 & 1,17 & 8,6 & 5,9 & 8,4 & 16,7 & 354 \\
\hline Lot $B \ldots \ldots \ldots$ & 11,2 & 0,5 & 1,10 & 8,1 & 5,0 & 7,7 & 15,2 & 307 \\
\hline Signification .. & N.S. & N.S. & N.S. & N.S. & $\mathrm{P}<0,01$ & N.S. & $P<0,05$ & $\mathrm{P}<0,05$ \\
\hline
\end{tabular}

L'examen du tableau 24 montre ensuite que la suralimentation n'a exercé qu'une influence très minime et non significative sur le nombre et sur le poids des porcelets à 1 naissance. Ce résultat confirme donc les faits observés par plusieurs auteurs (Duncan et LodGe, I96I). Il peut s'expliquer par le fait que les besoins de l'utérus gravide étaient sans doute entièrement satisfaits, même par notre ration la plus basse. Il n'en reste pas moins qu'un supplément alimentaire au-delà des normes paraît incapable d'augmenter la prise de poids des fœtus, alors qu'il en va différemment en ce qui concerne la mère.

Le poids moyen des porcelets à $2 \mathrm{I}$ jours et au sevrage, et dans une certaine mesure le nombre de porcelets sevrés, sont cependant plus élevés dans le lot $\mathrm{H}$. Ce fait traduit la différence de production laitière qui apparaît au cours de la lactation chez le lot suralimenté pendant la gestation ( + I7 p. I00). Il paraît logique de relier ces différences au catabolisme corporel plus élevé qui apparaît chez les truies du lot $H$. Ce résultat est en effet en plein accord avec celui de Smith (I960) et semble montrer que la truie en lactation peut parfaitement utiliser les ressources que constituent " ses réserves " de gestation. A l'issue de cet essai, on pourrait donc penser que l'augmentation du niveau alimentaire de la truie en gestation au-delà des besoins de l'utérus gravide trouve sa justification théorique dans l'amélioration qui en résulte 
de la production laitière. Sur le plan pratique, se pose toutefois le problème du rendement nutritionnel de ce processus. Si l'on s'en tient sommairement à l'efficacité alimentaire ( $\frac{\text { quantité d'aliment }}{\text { quantité de lait }}$ ) calculée sur l'ensemble du cycle (gestation + lactation), il ne semble pas y avoir de grande différence entre les deux régimes (on trouve 0,40 pour le lot $B$ et 0,42 pour le lot $\mathrm{H}$ ). 'Toutefois, ce procédé de calcul est très imparfait, car il ne tient pas compte des variations corporelles et de la composition du lait; il parait donc difficile de conclure sur ce point.

\section{$2^{\circ}$ Réduction du niveau alimentaire}

Cette expérience a pour objet d'examiner les réactions de la Truie gestante à une ration alimentaire ne dépassant pratiquement pas le niveau de l'entretien et, par là, d'apporter de nouvelles précisions sur l'importance et la nature de l'anabolisme gravidique dans des conditions alimentaires variées.

A cet effet, nous avons comparé l'effet de deux régimes, haut et bas, non seulement sur des truies gestantes, mais également sur des truies au repos sexuel, de même poids et prises comme témoins. Dans ce but, 42 truies ayant déjà porté et d'un poids moyen de $230 \mathrm{~kg}$ étaient réparties en 4 lots, dont 2 lots de gestantes et 2 lots de témoins recevant la même ration que les gestantes. L'aliment était le même pour toutes et identique à celui de l'expérience précédente. Pendant une période de mise en condition de 20 jours, les animaux recevaient cet aliment à volonté. Puis, à partir de l'accouplement jusqu'à la parturition (ou une période équivalante pour les témoins), les truies recevaient cet aliment, soit à raison de I, $8 \mathrm{~kg}$ par jour et par roo $\mathrm{kg}$ de poids vif (lot $\mathrm{H}$ ), soit en quantité restreinte d'environ $50 \mathrm{p}$. Ioo (lot $\mathrm{B}$ ). Cette dernière ration fixée à $0,87 \mathrm{~kg} / \mathrm{I}$ oo $\mathrm{kg}$ de poids vif, avait été déterminée préexpérjmentalement sur quelques animaux pour ne permettre que le simple maintien de poids des animaux non gestants : par définition, elle correspondait au besoin d'entretien de 1'animal au repos et paraissait donc très insuffisante pour la couverture des besoins des gestantes.

Les mesures effectuées portaient sur les variations de poids vif des truies (pesées hebdomadaires), sur les variations d'adiposité (mesure aux ultrasons de l'épaisseur du tissu sous-cutané dorsal) et sur le résultat des parturitions.

a) Variation de poids et anabolisme.

Le tableau 25 et la figure II rapportent la répartition des gains de poids et 1'évolution du poids vif des animaux de chaque lot.

Quel que soit le niveau alimentaire, les truies gestantes ont pris beaucoup plus de poids que les témoins au même régime. En particulier, les gestantes du lot B ont gagné $43 \mathrm{~kg}$ (I $8 \mathrm{p}$. Ioo de leur poids initial), soit autant que les témoins du lot $\mathrm{H}$, alors qu'avec la même ration le poids des témoins $B$ n'a pratiquement pas varié (2 p. IOO).

Déduction faite des produits de la conception et des pertes à la parturition, qui sont sensiblement les mêmes dans les deux cas, il reste à la mère un bénéfice corporel en fin de gestation. Le bénéfice pondéral est plus important chez les gestantes du lot $\mathrm{H}$, où il atteint $23 \mathrm{p}$. Ioo du poids initial, que chez les gestantes du lot $\mathrm{B}$ où il ne représente que $8 \mathrm{p}$. Ioo du poids initial. Enfin, si l'on déduit du gain des 
gestantes la part qui revient à la croissance normale (gain des témoins), il reste un anabolisme gravidique vrai non négligeable $(6,5 \mathrm{p}$. Ioo du poids initial), mais qui est sensiblement le même, quel que soit le régime.

TABLEAU 25

Variations de poids

$(\mathrm{kg})$

\begin{tabular}{|c|c|c|c|c|c|}
\hline Lot & $\begin{array}{c}\text { Consommation } \\
\text { totale } \\
(\mathrm{kg})\end{array}$ & $\begin{array}{c}\text { Gain de poids } \\
\text { total }\end{array}$ & $\begin{array}{c}\text { Perte à la } \\
\text { parturition } \\
\text { (produits } \\
\text { de la } \\
\text { conception) }\end{array}$ & $\begin{array}{l}\text { Gain de poids } \\
\text { net }\end{array}$ & $\begin{array}{c}\text { Anabolisme } \\
\text { gravidique } \\
\text { vrai }\end{array}$ \\
\hline $\begin{array}{l}\text { Gestantes } H \ldots \ldots \ldots \ldots \ldots \\
\text { Témoins } H . \ldots \ldots \ldots \ldots \ldots\end{array}$ & $\begin{array}{l}428 \\
445\end{array}$ & $\begin{array}{l}78,5 \\
42,0\end{array}$ & $\begin{array}{c}24,4 \\
0\end{array}$ & $\begin{array}{l}54,0 \\
42,0\end{array}$ & $\begin{array}{l}12,0 \\
0\end{array}$ \\
\hline $\begin{array}{l}\text { Gestantes B } \ldots \ldots \ldots \ldots \ldots \\
\text { Témoins B } \ldots \ldots \ldots \ldots \ldots\end{array}$ & $\begin{array}{l}218 \\
222^{\prime}\end{array}$ & $\begin{array}{rr}42,9 & \\
4,3\end{array}$ & $\begin{array}{c}23,3 \\
0\end{array}$ & $\begin{array}{r}19,6 \\
4,3\end{array}$ & $\begin{array}{c}15,3 \\
0\end{array}$ \\
\hline
\end{tabular}
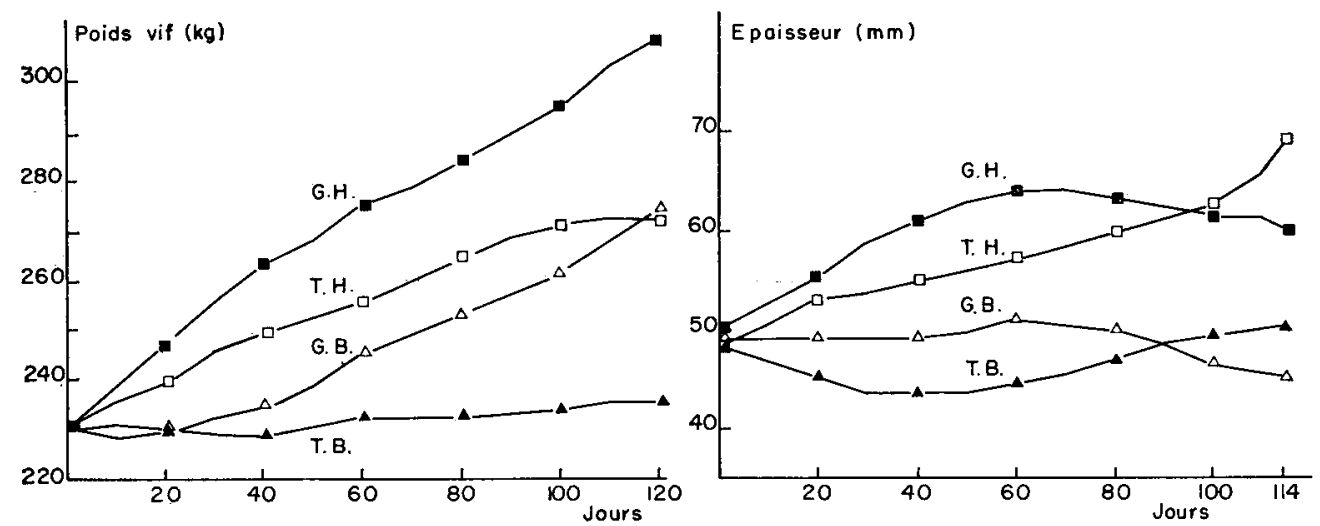

FIG. II. - Influence du niveau alimentaire sur le poids vif et l'épaisseur du tissu adipeux des truies

b) Parturitions.

Les résultats moyens de parturition des deux lots de gestantes sont rassemblés dans le tableau 26 :

Malgré leur niveau alimentaire très restreint, les gestantes du lot $B$ ont produit des portées parfaitement normales en nombre et en poids. Tout au plus peut-on noter un poids moyen des porcelets légèrement plus faible, mais compensé par un nombre de petits plus élevé. Cette observation concorde parfaitement avec celles faites par Champigny (I96I) sur la Ratte, Coop (I950) sur la Brebis et par DeAN et TrIBLE (I959) pour la Truie. Elle montre que quelles que soient les conditions de restriction du régime, la femelle consacre en priorité ses ressources à la croissance du contenu utérin. 
TABLEAU 26

Contenus utérins

\begin{tabular}{|c|c|c|}
\hline & Gestantes $\mathrm{H}$ & Gestantes B \\
\hline Nombre de porcelets nés vivants... & 10,1 & 11,8 \\
\hline Nombre de porcelets mort-nés . ...... & 1,9 & 1,3 \\
\hline Poids moyen des vivants $(\mathrm{kg})$. & 1,24 & 1,20 \\
\hline Poids total de la portée $(\mathrm{kg}) \ldots \ldots \ldots \ldots$. & 14,19 & 15,34 \\
\hline Placenta $(\mathrm{kg}) \ldots \ldots \ldots \ldots \ldots \ldots \ldots \ldots \ldots$ & $3,0^{\prime} t$ & 3,52 \\
\hline Liquides + pertes des mères $(\mathrm{kg}) \ldots \ldots \ldots$ & 6,9 & 6,5 \\
\hline Durée des parturitions $(h) \ldots \ldots \ldots \ldots \ldots$. & 7 & 6 \\
\hline
\end{tabular}

c) Composition corporelle.

La figure II rapporte l'évolution de l'épaisseur du tissu adipeux sous-cutané dans les quatre lots. On constate tout d'abord et quel que soit le régime, que l'augmentation de l'adiposité en fin d'expérience est toujours plus importante chez les témoins que chez les gestantes, ce qui confirme nos observations antérieures. En outre, l'intensité de la lipogenèse varie elle-même avec le régime, puisque l'on note une augmentation de $\mathrm{I} 8 \mathrm{p}$. Ioo des réserves adipeuses chez les gestantes $\mathrm{H}$, alors que les gestantes $B$ accusent une légère diminution $(-8 \mathrm{p}$. roo) qui contraste également avec la faible augmentation des témoins correspondants ( +4 p. Ioo). Il s'ensuit que la composition des gains diffère profondément suivant l'état physiologique et le niveau alimentaire : en valeur absolue et relative, on trouve moins de tissu adipeux et davantage de tissu musculaire chez les gestantes que chez les témoins, la différence étant plus marquée au bas niveau qu'au niveau élevé.

A titre d'illustration, et sous réserve de la validité du calcul, nous avons tenté une estimation de la composition de ces gains (tab1. 27) en supposant que le pourcentage initial de lipides de l'animal était d'environ $40 \mathrm{p}$. Ioo $\left.{ }^{1}{ }^{1}\right)$.

TABLEAU 27

Composition des gains chez les truies gestantes et au repos à différents niveaux alimentaires

\begin{tabular}{|c|c|c|c|c|c|c|}
\hline & \multirow{2}{*}{$\begin{array}{c}\text { Variation } \\
\text { de l'épaisseur } \\
\text { du tissu adipeux } \\
\text { (p. 100) }\end{array}$} & \multirow{2}{*}{$\begin{array}{c}\text { Gain } \\
\text { de poids net } \\
(\mathrm{kg})\end{array}$} & \multicolumn{2}{|c|}{ Gain du tissu adipeux } & \multicolumn{2}{|c|}{ Gain de tissu musculaire } \\
\hline & & & $\mathrm{kg}$ & p. $100 \mathrm{du}$ gain & $\mathrm{kg}$ & p. 100 du gain \\
\hline $\begin{array}{l}\text { Gestantes } H . \ldots \ldots \\
\text { Gestantes } B \ldots \ldots\end{array}$ & $\begin{array}{r}18 \\
-\quad 8\end{array}$ & $\begin{array}{l}54,0 \\
19,6\end{array}$ & $\begin{array}{r}16,0 \\
-\quad 7,3\end{array}$ & $\begin{array}{r}29 \\
0\end{array}$ & $\begin{array}{l}38,0 \\
26,9\end{array}$ & $\begin{array}{r}71 \\
100\end{array}$ \\
\hline $\begin{array}{l}\text { Témoins A } \ldots \ldots \ldots \\
\text { Témoins } B \ldots \ldots \ldots\end{array}$ & $\begin{array}{r}43 \\
4\end{array}$ & $\begin{array}{r}42,0 \\
4,3\end{array}$ & $\begin{array}{r}39,1 \\
3,7\end{array}$ & $\begin{array}{l}93 \\
86\end{array}$ & $\begin{array}{l}3,9 \\
0,6\end{array}$ & $\begin{array}{r}7 \\
14\end{array}$ \\
\hline
\end{tabular}

(1) Cette valeur est empruntée à CLAUSEN (1952) et ne constitue ici qu'une approximation ; toutefois l'erreur relative ainsi commise est la même pour les 4 lots et sans doute assez faible. 
Enfin, on remarque que l'évolution de la lipogenèse au cours de l'expérience varie suivant l'état physiologique : chez les gestantes, il y a d'abord un accroissement des réserves lipidiques (qui paraît d'ailleurs supérieur à celui des témoins), mais à partir du milieu de la gestation, jusqu'à la parturition, on observe une fonte de ces tissus. Chez les témoins, au contraire, la lipogenèse s'intensifie avec le temps. Ces résultats sont parfaitement conformes à ceux des examens post mortem des gestantes à différents stades et, en ce qui concerne les témoins, aux données générales de la croissance (MCMEEKAN, I940).

\section{d) Rendements alimentaires.}

Compte tenu des variations d'importance et de composition des gains réalisés par les truies des différents lots, l'examen des rendements alimentaires présente un intérêt particulier. Nous avons effectué cette comparaison dans le tableau 28 , sur la base de l'énergie et de l'azote des productions rapportés aux ingérés correspondants (rendement brut). Les éléments de calculs sont les valeurs du tableau précédent et la moyenne de nos résultats d'analyse d'échantillons de muscle, de gras, d'embryons et d'aliments.

\section{TABLEAU 28}

Comparaison des rendements énergétiques et azotés bruts chez les truies gestantes et non gestantes

\begin{tabular}{|c|c|c|c|c|c|c|}
\hline & \multicolumn{3}{|c|}{ Énergie } & \multicolumn{3}{|c|}{ Azote } \\
\hline & $\begin{array}{l}\text { Énergie } \\
\text { absorbée } \\
\text { (thermies) }\end{array}$ & $\begin{array}{l}\text { Production } \\
\text { (thermies) }\end{array}$ & $\begin{array}{c}\text { Rendement } \\
\text { (p. 100) }\end{array}$ & $\begin{array}{c}\text { Azote } \\
\text { absorbé } \\
(\mathrm{kg} \text { de } \mathrm{N})\end{array}$ & $\begin{array}{l}\text { Production } \\
(\mathrm{kg} \text { de } \mathrm{N})\end{array}$ & $\begin{array}{c}\text { Rendement } \\
\text { (p. 100) }\end{array}$ \\
\hline Gestantes H.... & 1198 & 220 & 18,4 & 7,40 & 1,64 & 22,1 \\
\hline Témoins $H \ldots . .$. & 1246 & 302 & 24,2 & 7,69 & 0,4 & 5,7 \\
\hline Gestantes B..... & 610 & 21 & 3,4 & 3,87 & 0,92 & 23,7 \\
\hline Témoins B ...... & 627 & 57 & 9,1 & 3,94 & 0,05 & 1,3 \\
\hline
\end{tabular}

Même en tenant compte d'une large marge d'erreur dans ces calculs, plusieurs faits importants apparaissent clairement :

- En ce qui concerne l'énergie, les hauts niveaux sont mieux utilisés que les bas niveaux; d'autre part, quel que soit le régime, l'utilisation de l'énergie paraît: inférieure chez les gestantes à celle des témoins. Il n'y aurait donc pas d'épargne énergétique chez la gestante, mais au contraire une légère augmentation des dépenses qui pourrait être due aux embryons ou à la truie elle-même (augmentation de poids). C'est ce que Brody (I945) appelle le Heat increment de gestation.

- En ce qui concerne l'azote, par contre, le rendement ne paraît pas affecté par le niveau alimentaire global. Mais on note surtout une très grande différence de rétention azotée en faveur des gestantes. Ce résultat confirme parfaitement l'hypothèse de l'épargne azotée réalisée au cours de la gestation, qui apparaissait déjà dans 
nos propres résultats de bilans ou d'analyse corporelle, mais qui repose aussi sur les travaux d'autres auteurs (Rombauts et al., I956 ; CHAMPIGNY, I962 ; LENkEIT et $a l ., \mathrm{I} 956)$.

e) Conclusions.

Cette comparaison de la Truie gestante et non gestante d'une part et de deux niveaux alimentaires, d'autre part, permet de préciser certains aspects du besoin alimentaire de gestation :

Io Quel que soit le niveau alimentaire, la gestante effectue toujour's des gains de poids supérieurs à ceux de la Truie au repos. Ce phénomène prend un relief particulier lorsqu'il s'agit d'une ration qui ne permet pratiquement que le maintien de poids de l'animal au repos. Il faut noter cependant que l'anabolisme gravidique vrai ne semble pas affecté par le niveau alimentaire alors que ce dernier intervient plus particulièrement dans l'importance du gain des tissus adipeux.

$2^{\circ}$ La croissance du contenu utérin ne paraît pas altérée par l'utilisation d'un rationnement très sévère, ce qui prouve :

- la modicité du besoin de gestation proprement dit,

- la priorité nutritionnelle des besoins embryonnaires,

- l'adaptation de la gestante aux bas niveaux alimentaires.

$3^{\circ}$ Cette adaptation semble reposer en partie sur une modification de la composition des tissus de réserves élaborés au cours de la gestation et notamment d'une diminution des tissus gras.

$4^{\circ}$ Il en résulte qu'en dépit de la prise de poids importante, l'efficacité énergétique de la ration ne semble pas améliorée chez la gestante. On note même une légère augmentation du besoin énergétique.

Par contre, l'intensité de la protéinogenèse est très fortement accrue et permet le stockage de quantités importantes d'azote au cours de la gestation, même avec un apport protidique qui correspond au seul entretien des témoins non gravides.

\section{$3^{\circ}$ Effet chronologique}

Ayant montré les principaux effets d'une modification du niveau alimentaire global de la Truie gestante, nous nous sommes demandés si l'intensité de ces derniers pouvait varier suivant le moment où intervenait la modification.

On a vu, par exemple, que la prise de poids maternelle paraît plus importante au début de la gestation, alors que celle du fœtus l'emporte en fin de gestation. Il est donc possible qu'un même supplément alimentaire ait des effets différents sur ces productions, suivant qu'il est distribué au début ou à la fin de la gestation (McCLYMONT, I958). C'est ce à quoi prétendent les "plans de rationnement " ou variation chronologique des apports recommandés par certains auteurs (JESPERSEN, I949; LEROY, I949; HEJE, I956 ; VADLA, I958).

Toutefois, le bien fondé d'une telle pratique n'est pas entièrement démontré et c'est ce que nous avons voulu examiner dans une expérience ou des truies recevaient un même apport d'aliment global selon tune chronologie différente.

Nous avons utilisé à cet effet 48 truies adultes réparties en 4 lots égaux, compte 
tenu du poids individuel, des antécédents et de l'adiposité de chaque animal. Après une période de mise en condition, les truies de 3 de ces lots étaient fécondées et celles $\mathrm{du} 4^{\mathrm{e}}$ lot servaient de témoins non gestants.

Pendant la gestation, ou la période correspondante pour les témoins, les truies de chaque lot étaient nourries individuellement à l'aide d'un aliment complet équilibré contenant Io p. Ioo de matières azotées totales. La ration movenne allouée pour l'ensemble de la gestation était d'un niveau supérieur de I $_{5} \mathrm{p}$. Ioo à celui des besoins d'entretien (niveau $\mathrm{B}$ de l'expérience précédente). Le lot témoin et l'un des lots de gestantes recevaient cette même ration tout au long de la gestation, mais pour les deux autres lots on faisait alterner deux périodes (correspondant chacune à la moitié de la gestation) pendant lesquelles des niveaux bas (entretien) ou haut (entretien majoré de $30 \mathrm{p}$. roo) étaient appliqués. Pendant la lactation les truies recevaient à volonté un même aliment à $\mathrm{I} 6 \mathrm{p}$. Ioo de protides. Le schéma de l'expérience peut ainsi se résumer :

\begin{tabular}{|c|c|c|c|c|}
\hline Lot & Régime & I $^{\text {re }}$ partie gestation & $2^{\mathrm{e}}$ partie gestation & $\begin{array}{c}\text { Lactation } \\
-\end{array}$ \\
\hline$T$ & Témoin & Entretien + I5 p. Ioo & Entretien + I5 p. IOO & \\
\hline C & Constant & Entretien $+\mathrm{I}_{5} \mathrm{p}$. I0o & Entretien + I5 p. roo & ad libitnm \\
\hline-1 & Haut-Bas & Entretien +30 p. I0o & Entretien & ad libitum \\
\hline$-\mathrm{H}$ & Bas-Haut & Entretien & Entretien +30 p. 100 & ad libitum \\
\hline
\end{tabular}

a) Variation $d u$ poids des truies.

Les principaux résultats concernant le poids des truies aux différentes périodes sont rapportés dans le tableau 29.

TABLEAU 29

Variations de poids en fonction de la chronologie des apports

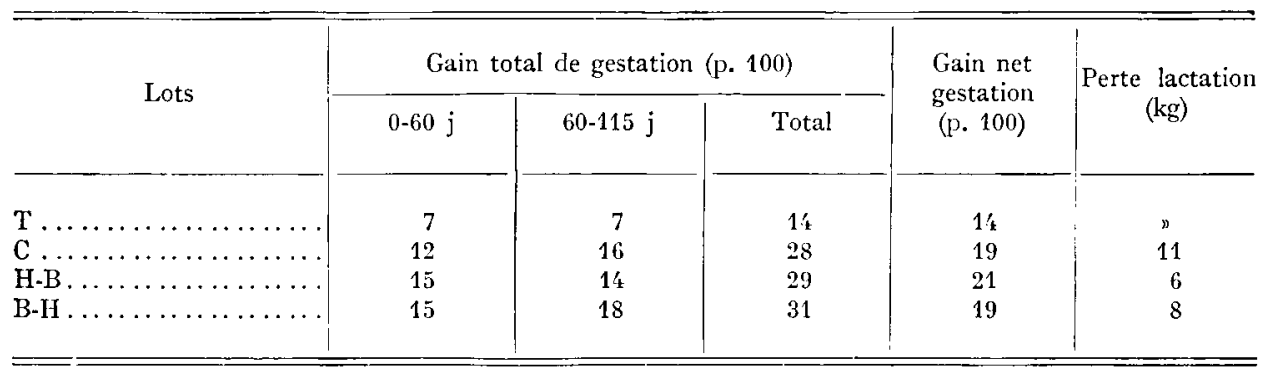

Le résultat le plus marquant concerne la différence de comportement des témoins et des truies gestantes, qui toutes réalisent des gains de poids plus élevés pour un même apport alimentaire. On trouve ici une nouvelle confirmation de la réalité de l'anabolisme gravidique. Par ailleurs, les différences entre les gains de poids des 3 lots de gestantes sont peu importantes et en aucun cas significatives. Tout au plus peut-on parler ici de tendance.

On remarque en effet que le gain total du lot B-H (produits de la conception compris) est peut-être le plus élevé, mais qu'il n'en est plus ainsi lorsque 1'on compare 
les gains nets, ou bénéfices propres de la mère : c'est alors le lot H-B qui l'emporte très légèrement.

Une autre différence apparaît dans la façon dont sont réalisées les gains de poids : chez le lot témoin, les deux périodes donnent lieu à des gains identiques. Il en va de même pour le lot $\mathrm{H}$-B. Par contre, dans les lots $\mathrm{B}-\mathrm{H}$ et $\mathrm{C}$ les gains de poids varient avec le niveau du régime.

b) Tissu sous-cutané.

Le tableau 3 o et la figure I2 rapportent en pourcentage les variations observées chez les truies :

TABLEAU 30

Variation du tissu adipeux sous-cutané dorsal en p. 100 de la valeur à l'accouplement

\begin{tabular}{|c|c|c|c|c|}
\hline \multirow{2}{*}{ Lot } & \multicolumn{3}{|c|}{ Gestation (p. 100) } & \multirow{2}{*}{$\begin{array}{c}\text { Lactation } \\
\text { (p. 100) }\end{array}$} \\
\hline & $0-60 \mathrm{j}$. & $60-11 / \mathrm{j}$. & Total & \\
\hline $\mathrm{T} \ldots$ & 7,8 & 13,8 & 21,6 & $n$ \\
\hline$C \ldots$ & 3,4 & 6,8 & 10,2 & $-10,3$ \\
\hline $\mathrm{H}-\mathrm{B} \ldots$. & 15,8 & $-2,9$ & 12,9 & $\rightarrow \quad 7,6$ \\
\hline $\mathrm{I} 3-\mathrm{H} \ldots \ldots \ldots \ldots \ldots \ldots$ & 1,4 & 5,6 & 7,0 & $-11,0$ \\
\hline
\end{tabular}

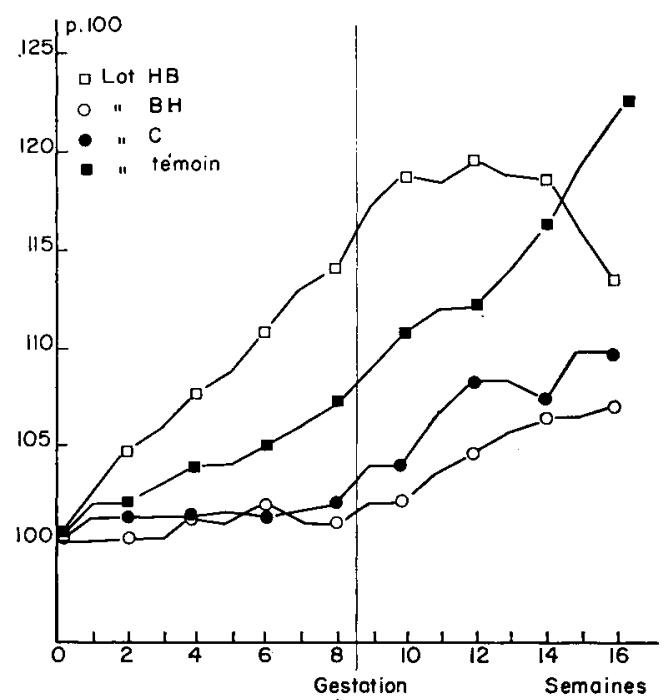

Fic. I 2. - Influence chronologique du niveau alimentaire de gestation sur íadiposité des truies

On constate que pour l'ensemble de l'expérience la lipogenèse a été plus active chez les témoins que chez les gestantes et que parmi ces dernières celles du lot H-B ont réalisé les gains les plus élevés (différence significative à $\mathrm{P}=0,05$ ), devançant dans l'ordre le lot $\mathrm{C}$ et le lot B-H. On remarque aussi l'importance du facteur chro- 
nologique dans la distribution de la même quantité d'aliment : par exemple, le niveau haut a provoqué une lipogenèse importante au début de la gestation $(\mathrm{H}-\mathrm{B})$, mais plus faible en fin de gestation (lot $\mathrm{B}-\mathrm{H}$ ). De même, le niveau bas permet une légère augmentation du tissu adipeux en début de gestation (lot $\mathrm{B}-\mathrm{H}$ ) et provoque une diminution en fin de gestation (lot $\mathrm{H}-\mathrm{B}$ ). La figure $\mathrm{I} 2$ montre que dans ce cas cette mobilisation des lipides a surtout lieu pendant les toutes dernières semaines de la gestation.

c) Parturition et production laitière.

Les différentes caractéristiques des portées à la naissance sont rapportées au tableau 3 I.

\section{TABLEAU 3 I}

\section{Parturitions}

\begin{tabular}{|c|c|c|c|c|c|c|c|c|}
\hline \multirow[b]{2}{*}{ Lots } & \multicolumn{4}{|c|}{ Poids des productions } & \multicolumn{4}{|c|}{ Fotus } \\
\hline & $\begin{array}{c}\text { Fœtus } \\
(\mathrm{kg})\end{array}$ & $\begin{array}{l}\text { Placentas } \\
\quad(\mathrm{kg})\end{array}$ & $\begin{array}{l}\text { Liquides } \\
(\mathrm{kg})\end{array}$ & $\begin{array}{l}\text { Total } \\
(\mathrm{kg})\end{array}$ & $\begin{array}{l}\text { Nombre } \\
\text { vivants }\end{array}$ & $\begin{array}{c}\text { Nombre } \\
\text { morts }\end{array}$ & $\mid \begin{array}{c}\text { Poids moyen } \\
\text { des vivants } \\
(\mathrm{kg})\end{array}$ & $\begin{array}{l}\text { Durée de la } \\
\text { parturition }\end{array}$ \\
\hline G & 14,5 & 2,6 & 3,3 & 20,4 & 10.1 & 0,8 & 1,40 & / $\mathrm{h} 40 \mathrm{mn}$ \\
\hline $\mathrm{H}-\mathrm{B}$ & 13,4 & 2,4 & 2,9 & 18,6 & 10,1 & 1,1 & 1,26 & $4 \mathrm{~h} 40 \mathrm{mn}$ \\
\hline B-H . & 15,6 & 2,9 & 4,8 & 23,3 & 10,6 & 1,5 & 1,38 & $5 \mathrm{~h} 2^{\prime} \mathrm{mn}$ \\
\hline
\end{tabular}

On ne note pas de différence significative entre les différents lots. Toutefois chez le lot B-H l'ensemble des produits de la conception parait plus important que chez les lots $\mathrm{C}$ et $\mathrm{H}-\mathrm{B}$ dans l'ordre. Cette différence paraît provenir du poids total des foetus, très légèrement plus nombreux et surtout des poids des différentes pertes liquides au moment de la parturition. Un niveau alimentaire élevé en fin de gestation semble donc favoriser légèrement la croissance des fœetus. A noter que dans ce cas la durée de la parturition est également un peu plus élevée.

Les performances de lactation ont été sensiblement les mêmes dans les trois. groupes, comme le montre le tableat 32 , aucune différence n'est significative.

TABLEAU 32

Lactation

\begin{tabular}{|c|c|c|c|c|c|}
\hline \multirow{2}{*}{ Lots } & \multicolumn{2}{|c|}{ Croissance des porcelets } & \multirow{2}{*}{$\begin{array}{c}\text { Nombre de } \\
\text { porcelets sevrés }\end{array}$} & \multicolumn{2}{|c|}{ Consommations alimentaires } \\
\hline & $\begin{array}{l}\text { Poids moyen } \\
\text { à } 21 \text { jours }(\mathrm{kg})\end{array}$ & $\begin{array}{c}\text { Poids moyen } \\
\text { à } 56 \text { jours }(\mathrm{kg})\end{array}$ & & $\begin{array}{c}\text { Truies } \\
(\mathrm{kg})\end{array}$ & $\begin{array}{l}\text { Porcelets (kg } \\
\text { par porcelet) }\end{array}$ \\
\hline $\mathrm{C} \ldots .$. & 5.8 & 17,4 & 8,6 & 383 & 13,6 \\
\hline $\mathrm{H}-\mathrm{B} \ldots \ldots \ldots \ldots$ & 5,2 & 12,3 & 8,0 & 361 & 11,5 \\
\hline B-H $\ldots \ldots \ldots \ldots$ & 5,4 & 16,6 & 8,5 & 368 & 12,9 \\
\hline
\end{tabular}




\section{d) Conclusions.}

Les gains de poids totaux (fœetus et produits de la conception compris) réalisés au cours de la gestation ont pratiquement été les mêmes dans les trois groupes expérimentaux. Tout au plus peut-on noter une légère augmentation du poids des produits de la conception dans le lot $\mathrm{B}-\mathrm{H}$, ce qui montre, comme l'avaient trouvé UNDERWOOD (I943) et WALLACE (I948) chez la Brebis, que le supplément alimentaire de fin de gestation a profité en priorité aux foetus. Par contre, en ce qui concerne l'anabolisme gravidique vrai, un supplément alimentaire ne paraît pas plus efficace en fin de gestation qu'au début. C'est ce que confirme le résultat trouvé pour le gain net des truies après parturition : celui-ci est même légèrement moins élevé dans le cas du régime $\mathrm{B}-\mathrm{H}$ que du régime $\mathrm{H}-\mathrm{B}$.

Il est toutefois inexact de penser que des gains de poids réalisés dans ces conditions aient la même valeur. Dans le cas du lot B-H, en effet, la quantité de tissu adipeux élaboré paraît nettement plus importante et ceci est dû essentiellement à l'effet du régime haut au début de la gestation. Si l'on compare les résultats obtenus entre les gestantes et les témoins, on constate qu'un même supplément alimentaire (niveau $\mathrm{H}$ ) provoque chez les gestantes une lipogenèse supérieure à celle des témoins au début de la gestation et inférieure en fin de gestation. On obtient le même classement lorsque l'on compare l'effet d'un niveau bas. Ceci montre très nettement que l'aptitude à stocker de l'énergie sous forme de tissu adipeux est plus élevée au début qu'à la fin de la gestation. Ce qui peut s'expliquer de nouveau par les besoins prioritaires et croissants du foetus.

On en vient ainsi à penser que si l'anabolisme azoté peut se poursuivre d'une façon régulière au profit de la mère tout au long de la gestation, même lorsque les conditions alimentaires sont défavorables, l'anabolisme des tissus lipidiques n'a lieu en fin de gestation que si la ration est abondante (lot B-H). Ceci revient à donner à l'énergie de la ration un rôle de facteur limitant dans les phénomènes d'anabolisme gravidique, hypothèse qu'avait déjà formulée par d'autres voies PIKE (I954) sur la Ratte.

En définitive, les deux régimes $\mathrm{H}-\mathrm{B}$ et $\mathrm{B}-\mathrm{H}$ de notre expérience se distinguent essentiellement par un accroissement des réserves lipidiques de la mère pour le premier et par une légère augmentation du poids des produits de la conception pour le second. Comme on pouvait le penser, le régime $\mathrm{C}$, ou moyen, a eu des effets intermédiaires. Suivant le but recherché, l'un ou l'autre de ces régimes pourrait donc être préconisé. Toutefois, les différences restent faibles et aucune influence immédiate sur la lactation n'a pu être décelée.

\section{B - Efiets sur la lactation}

\section{$\mathbf{I}^{\mathrm{o}}$ Augmentation du niveau alimentaire}

L'augmentation du niveau alimentaire chez la 'Truie en lactation n'est pas aisée à étudier, car le régime normal correspond déjà à une alimentation à satiété dont les effets ont été décrits au début du chapitre. L'examen de conditions alimentaires plus larges présentant malgré tout quelque intérêt, nous avons eu recours à un artifice pour l'effectuer. 
Dans cette expérience, nous avons substitué pendant une courte période à un aliment bien équilibré, mais peu appétible, un autre aliment de valeur sensiblement égale, mais consommé avec plus d'avidité par les animaux. A cet effet, nous avions remplacé, à proportion égale (ro p. Ioo) dans l'aliment, le tourteau de palmiste que les truies n'aiment pas par la levure de distillerie, substance dont 1'action sur 1'appétit est bien connue. Io truies ont été utilisées dans cette expérience, les animaux étant utilisés comme leurs propres témoins, ce qui présentait l'avantage d'éliminer l'influence des facteurs individuels (comme le nombre de porcelets par portée). L'étude portait sur la partie la moins variable de la lactation, du $I 5^{\mathrm{e}}$ au $45^{\mathrm{e}}$ jour, et comportait deux périodes successives, dont l'une d'alimentation normale (niveau B) et l'autre de suralimentation (niveau $\mathrm{H}$ ). Pour tenir compte de l'influence éventuelle du stade de lactation, la succession des périodes était effectuée pour la moitié des truies dans le sens $\mathrm{H}-\mathrm{B}$ et pour les autres dans le sens $\mathrm{B}-\mathrm{H}$.

Les seules mesures effectuées étaient, outre les quantités exactes d'aliment consommées, les productions laitières journalières et les variations de poids au cours de chaque période. Ces résultats figurent dans le tableau 33.

TABLEAU 33

Effet de l'augmentation du niveau alimentaire au cours de la lactation

\begin{tabular}{c|c|c|c}
\hline \multirow{2}{*}{ Régime } & $\begin{array}{c}\text { Ingéré } \\
(\mathrm{kg} / \mathrm{j})\end{array}$ & $\begin{array}{c}\text { Production laitière } \\
(\mathrm{kg} / \mathrm{j})\end{array}$ & $\begin{array}{c}\text { Perte de poids } \\
(\mathrm{kg})\end{array}$ \\
\hline & & 6,01 & 5,0 \\
I3 & 5,13 & 7,01 & 2,8 \\
\hline II & 6,80 & & \\
\hline
\end{tabular}

De cette expérience, extrêmement simple, on peut retirer les conclusions suivantes : une augmentation du niveau alimentaire au cours de la lactation, d'environ 30 p. Ioo au-delà des quantités habituellement ingérées, a pour effet un léger accroissement (I4 p. Ioo) des quantités de lait produites. Ce résultat donne un certain crédit à l'hypothèse suivant laquelle l'ingestion d'aliments pourrait se comporter chez la Truie comme un facteur limitant de la production laitière. Il faut toutefois remarquer que, dans notre expérience, il n'y a pas de proportionnalité entre le supplément d'ingestion et l'amélioration de la production qui apparaît donc comme côtteuse sur le plan nutritionnel, ce que BURT (I957) et GRAY (I962) avaient déjà remarqué chez la Vache laitière. Par ailleurs, n'ayant pas pratiqué de détermination de la composition du lait, nous ne savons pas dans quelle mesure cette amélioration reflète une augmentation effective de la sécrétion des constituants, ou seulement celle du volume de cette sécrétion.

Aux niveaux élevés où étaient placées les truies, les pertes de poids pendant la lactation sont faibles. De ce fait, les différences entre les deux régimes sont forcément modestes. On note toutefois une légère diminution (non significative) de la perte de poids avec le niveau le plus haut. 


\section{$2^{\circ}$ Diminution $d u$ niveau alimentaire}

Deux expériences ont été effectuées pour étudier les effets d'une diminution du niveau alimentaire global. Dans la première, nous avuns utilisé la technique précédente des variations successives de niveau au cours de la même lactation, dans la seconde, nous avons opéré sur des lactations entières.

La première expérience utilisait un dispositif analogue à celui de l'expérience précédente, mais elle est rendue moins critiquable par l'emploi d'un même aliment au cours des deux périodes. Seul le niveau varie : le niveau $\mathrm{H}$ est celui de la consommation ad libitum de l'animal ; le niveau B présente une réduction de $25 \mathrm{p}$. Ioo par rapport aux ingérés de la période précédente. I4 truies ont été affectées à cette expérience et, comme précédemment, réparties en 2 groupes de chronologie différente pour éliminer l'effet dû au stade de lactation. Outre les mesures de production laitière et de variation de poids, des échantillons hebdomadaires de lait étaient récoltés et donnaient lieu à l'analyse de la composition chimique. Les principaux résultats sont rapportés au tableau 34 .

TABLEAU 34

Effet de la diminution du niveau alimentaire au cours de la lactation

\begin{tabular}{|c|c|c|c|c|c|c|c|}
\hline \multirow{2}{*}{ Régime } & \multirow{2}{*}{$\begin{array}{l}\text { Ingéré } \\
(\mathrm{kg} / \mathrm{j})\end{array}$} & \multirow{2}{*}{$\begin{array}{c}\text { Production } \\
\text { lait } \\
(\mathrm{kg} / \mathrm{j})\end{array}$} & \multicolumn{4}{|c|}{ Composition du lait } & \multirow{2}{*}{$\begin{array}{l}\text { Perte de } \\
\text { poids } \\
(\mathrm{kg})\end{array}$} \\
\hline & & & $\begin{array}{l}\text { mat. azotée } \\
\text { (J. 100) }\end{array}$ & $\begin{array}{l}\text { lactose } \\
\text { (p. 100) }\end{array}$ & $\begin{array}{l}\text { lipides } \\
\text { (p. 100) }\end{array}$ & $\begin{array}{l}\text { cendres } \\
(\mathrm{p} .100)\end{array}$ & \\
\hline B & 4,41 & 6,00 & 5,2 & 5,5 & 5,8 & 1,0 & 11,1 \\
\hline $\mathrm{H}$ & 5,73 & 6,64 & 4,9 & 5,7 & 5,6 & 0,9 & 4,1 \\
\hline
\end{tabular}

Ces résultats sont, dans l'ensemble, conformes à ceux de l'expérience précédente : on constate tout d'abord que la réduction du niveau alimentaire a eu pour premier effet une légère diminution de la production laitière (Io p. IOO). Celle-ci s'accompagne d'une augmentation sensible de la perte de poids, ce qui semble indiquer que les truies ont en partie compensé l'effet de la restriction alimentaire en faisant davantage appel à leurs tissus de réserve.

Mais il faut également remarquer la légère augmentation de concentration de tous les constituants du lait à l'exception du lactose, chez les animaux les moins bien nourris. Ce résultat est en tous points, conforme à ceux obtenus par LoDGE (I959 $b$ ) et par Smith (I96I $c$ ) dans des circonstances analogues et par FLUX et PATCHELI sur la Vache (I957). Il montre que la Truie corrige la variation du volume de sa production qui résulte de conditions alimentaires défavorables, en maintenant à un niveau presque identique la sécrétion des lipides et des protides de son lait. Seul le lactose et la quantité d'eau, qui sont étroitement liés, ont varié. I1 en résulte que dans notre expérience la variation effective de production a été assez minime, ce qui peut être l'indice, comme le propose Smith, d'une meilleure utilisation alimentaire chez la laitière rationnée, ou encore d'une participation accrue des ressources endogènes de cette dernière.

Annales de Zootechnie. - I965. 
La deuxième expérience comportait deux groupes de Io truies aussi semblables que possible dont les portées avaient été égalisées à la parturition. Ces truies recevaient un même aliment, d'un type toutefois différent de celui de l'expérience précédente, puisque sa teneur en azote et en énergie était sensiblement plus élevée $(20,6 \mathrm{p}$. Ioo de protides ; 4,8 thermies $/ \mathrm{kg})$, mais qui était distribué en quantité plus restreinte. Dès la parturition et pendant toute la lactation, les truies du I er groupe recevaient une ration constante de $4,2 \mathrm{~kg}$ de cet aliment $(\mathrm{lot} H)$ et celles du $2^{\text {e }}$ groupe une ration du même aliment diminuée de 20 p. Ioo, soit $3,5 \mathrm{~kg}$ (lot B). Comme précédemment, on effectuait la mesure des quantités de lait produites et l'analyse hebdomadaire de la composition des laits individuels; on notait également les pertes de poids des truies, mais aussi les variations d'adiposité mesurées par la technique aux ultrasons. Les résultats pour l'ensemble de la lactation sont rapportés au tableau 35 .

TABIEAU 35

Ëffet de la diminution du niveau alimentaire de lactation

\begin{tabular}{|c|c|c|c|c|c|c|c|}
\hline \multirow[b]{2}{*}{ Régime } & \multirow{2}{*}{$\begin{array}{c}\text { Production } \\
\text { laitière } \\
(\mathrm{kg} / \mathrm{j})\end{array}$} & \multicolumn{4}{|c|}{ Composition du lait } & \multicolumn{2}{|c|}{ Variations corporelles } \\
\hline & & $\begin{array}{c}\text { Mat. azotée } \\
\text { (p. 100) }\end{array}$ & $\begin{array}{l}\text { lactose } \\
\text { (p. 100) }\end{array}$ & $\begin{array}{l}\text { lipides } \\
\text { (p. 100) }\end{array}$ & $\begin{array}{l}\text { cendres } \\
\text { (p. 100) }\end{array}$ & $\begin{array}{c}\text { Perte de } \\
\text { poids } \\
(\mathrm{kg})\end{array}$ & $\begin{array}{c}\text { Perte } \\
\text { l'adiposité } \\
\text { (p. 100) }\end{array}$ \\
\hline$I I \ldots \ldots \ldots$ & 5,23 & 6,2 & 5,3 & 8,2 & 1,0 & 21,7 & 2,1 \\
\hline $\mathbf{B} \ldots \ldots \ldots$ & 5,25 & 6,1 & 5,2 & 8,2 & 1,0 & 30,3 & 11,0 \\
\hline
\end{tabular}

Ces résultats paraissent un peu différents de ceux des deux premières expériences, mais leurs conclusions s'inscrivent parfaitement dans le cadre du même phénomène général :

Une réduction du niveau alimentaire de $20 \mathrm{p}$. Ioo appliquée à l'ensemble de la lactation n'a eu aucun effet appréciable sur la quantité de lait produite et sur la composition de ce lait. I a quantité des différents constituants sécrétée est restée rigoureusement la même dans les deux lots, ce qui par des voies différentes rejoint les résultats obtenus avec la variation chronologique du niveau alimentaire.

Toutefois, ce résultat s'accompagne d'une perte de poids nettement plus élevée et en particulier d'un prélèvement plus important sur les tissus adipeux. En valeur relative, les truies du lot $\mathrm{B}$ ont davantage perdu de lipides que celles du lot $\mathrm{H}$, ce qui semble être le fait d'un déficit essentiellement énergétique.

Ainsi, dans cette expérience comme dans les précédentes on remarque qu'une réduction du niveau alimentaire n'excédant pas $30 \mathrm{p}$. Ioo n'affecte pratiquement pas l'intensité de la lactogenèse, du moins en ce qui concerne les principaux constituants. Ce résultat n'est acquis qu'au prix d'une mobilisation corporelle plus importante. Ceci donne donc une idée des priorités que l'animal établit lui-même entre ses différentes fonctions et surtout de l'impulsion créée par le phénomène de lactation qui, dans les conditions que nous venons de décrire, l'amène à s'adapter aux variations du milieu en sacrifiant ses propres tissus. 


\section{C - Relations gestation-lactation}

Dans ce qui précède nous avons examiné les effets d'une variation du niveau alimentaire au cours d'une seule période gestation ou lactation. On peut se demander ce qu'il arrive lorsque la variation porte sur l'ensemble des deux phases : gestation et lactation. Dans quelle mesure un niveau alimentaire haut ou bas pendant la gestation conduit-il l'animal à utiliser d'une façon différente un niveau de lactation qui peut être lui-même haut ou bas.

Par exemple, on peut imaginer qu'un niveau de gestation élevé, qui permet donc à l'animal d'effectuer des réserves importantes, aide ce dernier à mieux supporter une réduction éventuelle du niveau alimentaire de lactation. Mais quelle est l'efficacité alimentaire dans ce cas ? Vaut-il mieux, à égalité des ingestions, distribuer le régime abondant pendant la gestation ou pendant la lactation? De telles questions posent le problème des relations nutritionnelles entre les niveaux alimentaires de la gestation et de la lactation.

Dans le but de fournir une réponse, nous avons entrepris une expérience, dite de " régimes croisés ", qui constitue un prolongement de l'étude sur les niveaux alimentaires de gestation.

Trente-deux truies provenant de l'expérience dans laquelle nous avions comparé deux régimes de gestation $(\mathrm{H}=$ ad libitum, $\mathrm{B}=$ restriction de $50 \mathrm{p}$. 10o), ont été réparties après la parturition en quatre lots identiques recevant à leur tour un même aliment équilibré de lactation distribué soit à volonté (régime $\mathrm{H}$ ), soit en quantité limitée à raison de $\mathrm{I}, 9 \mathrm{~kg} / \mathrm{IOO} \mathrm{kg}$ de poids vif, ce qui correspondait à une restriction d'environ 50 p. roo (régime $B$ ).

On réalisait de la sorte le dispositif suivant :

Lot $\mathrm{H}-\mathrm{H}$ : niveau élevé gestation - niveau élevé lactation

$\mathrm{H}-\mathrm{B}$ : niveau élevé gestation — niveau bas lactation

$\mathrm{B}-\mathrm{H}$ : niveau bas gestation - niveau élevé lactation

$\mathrm{B}-\mathrm{B}$ : niveau bas gestation - niveau bas lactation

Pendant la lactation, le nombre de porcelets sous les mères était égalisé et maintenu à 8 par portée pour éliminer l'influence de ce nombre sur la production laitière. On notait les renseignements suivants : quantité d'aliment consommée, quantité et composition du lait produit, variations du poids vif et de l'adiposité (méthodes aux ultrasons), croissance des porcelets.

\section{a) Consommations alimentaires}

Si pour les lots rationnés $B$ les consommations furent comme prévu parfaitement identiques, il n'en a pas été de mêtme pour les animaux soumis au régime ad libitum pendant la lactation. A notre surprise, on trouve une différence appréciable de consommation (environ $25 \mathrm{p}$. IOO) entre ces deux lots nourris à satiété qui montre que les animaux soumis au régime $\mathrm{B}-\mathrm{H}$ ont comblé pendant la lactation une partie de leur handicap de gestation (tabl. 36).

Sans nul doute, il s'agit ici d'un phénomène de compensation qui pousse l'animal à consommer davantage après une période de privation, ou au contraire à limiter sa. 
consommation après une période d'abondance. Ce phénomène n'est pas entièrement nouveau, nous l'avions déjà observé chez la Ratte (PÉRISSE et SALMON-LEGAGNEur, I960) et DEAN et TRIBLE (I960) le mentionnent également. Il est également connu chez l'animal en croissance (CALloway et al., rg62).

TABLEAU 36

Consommations des truies soumises aux régimes croisés

\begin{tabular}{|c|c|c|c|}
\hline Lot & $\begin{array}{l}\text { Consommation } \\
\text { gestation } \\
(\mathrm{kg} / \mathrm{j})\end{array}$ & $\begin{array}{c}\text { Consommation } \\
\text { lactation } \\
(\mathrm{kg} / \mathrm{j})\end{array}$ & $\begin{array}{c}\text { Total } \\
(\mathrm{kg})\end{array}$ \\
\hline II-H $\ldots \ldots \ldots$ & 3,69 & ${ }^{\prime}, 9_{\mathrm{k}}^{\prime}$ & 698 \\
\hline $\mathrm{H}-\mathrm{B} \ldots \ldots \ldots$ & 3,78 & 2,96 & 598 \\
\hline $\mathrm{B}-\mathrm{H}, \ldots \ldots \ldots$ & 1,83 & $6,1^{\prime}$ & 567 \\
\hline$B-B \ldots \ldots \ldots$ & 1,91 & 3,01 & 378 \\
\hline
\end{tabular}

On remarquera que, par des voies différentes, les lots $\mathrm{H}-\mathrm{B}$ et $\mathrm{B}-\mathrm{H}$ ont ainsi effectué sur l'ensemble de la période de reproduction des ingestions alimentaires du même ordre de grandeur.

b) Production laitière et croissance des porcelets

Les résultats moyens pour chaque lot sont rapportés dans le tableau 37 .

TABLEAU 37

Productions laitières

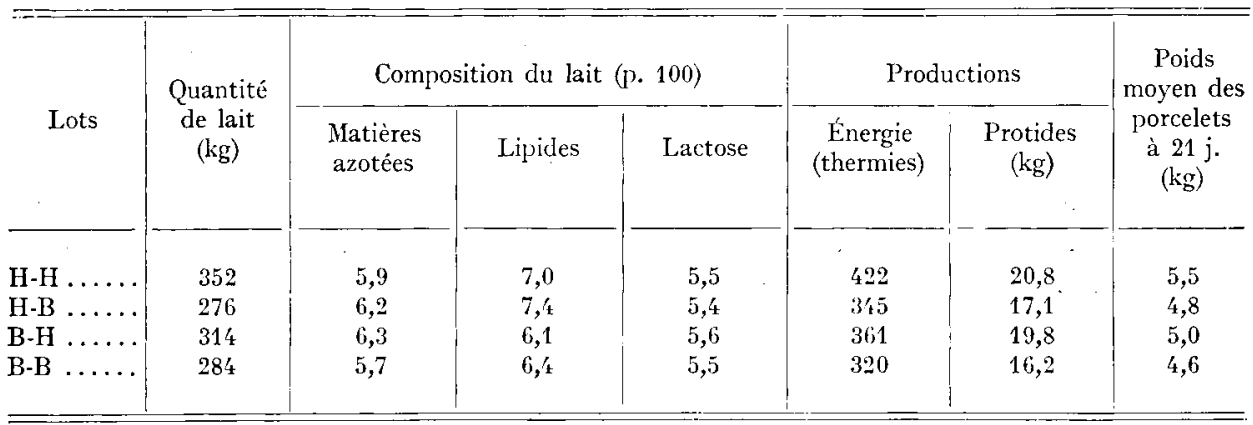

Quantitativement, les productions laitières les plus élevées sont obtenues chez les truies abondamment nourries pendant la lactation (lots $\mathrm{H}-\mathrm{H}$ et $\mathrm{B}-\mathrm{H}$ ). Qualitativement, le lait des truies bien alimentées pendant la gestation (lots $\mathrm{H}-\mathrm{H}$ et $\mathrm{H}-\mathrm{B}$ ) a des teneurs notablement plus élevées en lipides que celui des truies restreintes pendant cette même période, même si ces dernières sont bien alimentées par la suite. Il s'ensuit que la valeur calorifique des laits n'est pas la même (elle est maximale pour 
le lot $\mathrm{H}-\mathrm{B}$ et minimale pour le lot $\mathrm{B}-\mathrm{B})$, ce qui tend à accroître les différences de production d'énergie pour certains lots : c'est ainsi que les truies du lot $\mathrm{H}-\mathrm{B}$, bien qu'ayant donné la même quantité de lait, ont prođuit davantage d'énergie ( $8 \mathrm{p}$. Ioo) que celles du lot B-B. Ces résultats sont reflétés en partie, par le poids des porcelets à 2I jours. Par contre, en ce qui concerne la production de protides, les différences sont peu importantes. Au demeurant, c'est le lot $\mathrm{H}-\mathrm{H}$ qui obtient les meilleurs résultats généraux, suivi par les lots $\mathrm{B}-\mathrm{H}$ et $\mathrm{H}-\mathrm{B}$; par contre, le lot $\mathrm{B}-\mathrm{B}$ réalise des performances nettement inférieures à celles des autres lots, ce qui est en léger désaccord avec les résultats des expériences précédentes, mais s'explique par l'intensité accrue de la restriction alimentaire.

\section{c) Variation de poids}

Comme le montre le tableau 38 , les truies de tous les lots perdent du poids pendant la lactation, mais l'importance de ces variations diffère selon les lots.

TABLEAU 38

Variations de poids au cours de la reproduction

\begin{tabular}{|c|c|c|c|}
\hline \multirow[b]{2}{*}{ Lots } & \multicolumn{3}{|c|}{ Poids vif } \\
\hline & $\begin{array}{c}\text { Gain } \\
\text { gestation } \\
(\mathrm{kg})\end{array}$ & $\begin{array}{c}\text { Perte } \\
\text { lactation } \\
(\mathrm{kg})\end{array}$ & $\begin{array}{c}\text { Bilan } \\
(\mathrm{kg})\end{array}$ \\
\hline $\mathrm{H}-\mathrm{H} \ldots \ldots$ & 60,8 & 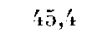 & $+15,4$ \\
\hline $\mathrm{H}-\mathrm{B} . \ldots$ & 49,8 & $60,,_{t}^{\prime}$ & $-10,6$ \\
\hline B-H..... & 22,9 & 7,1 & $+15,8$ \\
\hline B-B . . & 18,5 & 36,6 & $-18,1$ \\
\hline
\end{tabular}

La perte de poids est d'autant plus prononcée que le niveau de gestation est haut et celui de lactation bas (lot H-B). A l'inverse, les truies restreintes pendant la lactation, mais bien nourries pendant la lactation, ne perdent que très peu de poids (lot $\mathrm{B}-\mathrm{H}$ ). Il est assez étonnant par ailleurs, de constater que le lot $\mathrm{B}-\mathrm{B}$ ne perd pas davantage de poids que le lot $\mathrm{H}-\mathrm{H}$ toujours bien nourri. C'est là un phénomène remarquable qu'il convient de souligner et qui rejoint entièrement nos résultats précédents et ceux de DEAN (I960) : on constate ainsi la relation entre les variations de poids au cours des deux périodes et la grande labilité des gains de gestation qui disparaissent presque entièrement quelles que soient les conditions alimentaires de la lactation.

Toutefois, l'évolution de ces variations de poids au cours de la lactation diffère légèrement suivant les régimes. Pour les lots $\mathrm{H}-\mathrm{H}$ et $\mathrm{B}-\mathrm{H}$ la perte de poids a lieu essentiellement au début de la lactation (le lot $\mathrm{B}-\mathrm{H}$ gagne même du poids en fin de lactation), alors que pour les lots B-B et $\mathrm{H}-\mathrm{B}$ la mobilisation corporelle se poursuit avec la même intensité jusqu'au sevrage. Ceci donne à penser que c'est surtout en fin de lactation qu'apparait le plus nettement l'influence directe du régime alimentaire. 
Enfin, le bilan général calculé en fin de reproduction permet de souligner le comportement remarquable du lot B-H. Pour un ingéré total (gestation + lactation) équivalent du lot $\mathrm{H}-\mathrm{B}$, les truies du lot $\mathrm{B}-\mathrm{H}$ réalisent le bénéfice pondéral le plus élevé et du même ordre que celui du lot $\mathrm{H}-\mathrm{H}$ où la consommation était plus importante.

d) Composition corporelle

Le tableau 39 rapporte les variations d'épaisseur du tissu adipeux et, avec les mêmes réserves que précédemment, une estimation de la composition des pertes de poids au cours de la lactation ou en fin d'exercice.

TABLEAU 39

Variation de composition corporelle (gain + , pertes -)

\begin{tabular}{|c|c|c|c|c|c|c|c|}
\hline \multirow{3}{*}{ Lots } & \multicolumn{3}{|c|}{ Épaisseur du tissu adipeux } & \multicolumn{4}{|c|}{ Répartition des variations de poids } \\
\hline & \multirow[b]{2}{*}{$\begin{array}{l}\text { Gestation } \\
\text { (p. 100) }\end{array}$} & \multirow[b]{2}{*}{$\begin{array}{l}\text { Lactation } \\
\text { (p. 100) }\end{array}$} & \multirow[b]{2}{*}{$\begin{array}{l}\text { Bilan } \\
\text { (p. 100) }\end{array}$} & \multicolumn{2}{|c|}{ Lactation } & \multicolumn{2}{|c|}{ Bilan final } \\
\hline & & & & $\begin{array}{c}\text { tissu } \\
\text { adipeux } \\
(\mathrm{kg})\end{array}$ & $\begin{array}{c}\text { autres } \\
\text { tissus } \\
(\mathrm{kg})\end{array}$ & $\begin{array}{c}\text { tissu } \\
\text { adipeux } \\
(\mathrm{kg})\end{array}$ & $\begin{array}{c}\text { autres } \\
\text { tissus } \\
(\mathrm{kg})\end{array}$ \\
\hline $\begin{array}{l}\text { H-H } \ldots \ldots \\
\text { H-B } \ldots \ldots \\
\text { B-H } \ldots \ldots \\
\text { B-B } \ldots \ldots\end{array}$ & $\begin{array}{r}+21 \\
+18 \\
-\quad 8 \\
-\quad 6\end{array}$ & $\begin{array}{l}-18 \\
-30 \\
-\quad 2 \\
-26\end{array}$ & $\begin{array}{l}+3 \\
-12 \\
-18 \\
-32\end{array}$ & $\begin{array}{r}-17 \\
-27 \\
-\quad 2 \\
-21\end{array}$ & $\begin{array}{r}-29 \\
-33 \\
-\quad 5 \\
-13\end{array}$ & $\begin{array}{l}+3 \\
-11 \\
-\quad 7 \\
-18\end{array}$ & $\begin{array}{r}+13 \\
0 \\
+\quad 25 \\
+\quad 10\end{array}$ \\
\hline
\end{tabular}

Sans accorder une trop grande signification à ces résultats, on peut en retenir les traits les plus marquants : au cours de la lactation on observe une mobilisation du tissu adipeux dans tous les lots, mais celle-ci est variable avec les régimes. En valeur absolue et relative, la mobilisation est plus importante chez les animaux recevant un régime restreint pendant la lactation. Proportionnellement, mais à égalité de perte de poids, le lot $\mathrm{B}-\mathrm{B}$ se délipide davantage que le lot $\mathrm{H}-\mathrm{H}$ puisque environ 65 p. Ioo de la perte de poids de ce lot est constitué par du tissu adipeux (contre 36 p. Ioo pour le lot $\mathrm{H}-\mathrm{H}$ ). La sous-alimentation au cours de la lactation affecte particulièrement le tissu adipeux, ce qui rejoint entièrement nos premières observations.

En fin de lactation, le bilan final fait apparaitre dans tous les lots, sauf le lot $\mathrm{H}-\mathrm{H}$, une perte de lipides alors que les autres tissus présentent parfois des gains non négligeables; ceci indique donc une certaine indépendance des différents processus.

e) Rendements alimentaires

Comme nous l'avions fait pour la gestation, on peut calculer les rendements alimentaires, énergétique ou azoté, des différents régimes soit au cours de la lactation, soit sur un cycle complet (tabl. 40 et $4 \mathrm{I}$ ) de reproduction. Nous avons utilisé à cet effet la formule de SurTH (I959) :

$$
\text { Rendement brut : } \frac{\text { Lait } \pm \text { variation de poids }}{\text { aliment ingéré }}
$$


Les résultats diffèrent légèrement suivant le procédé de calcul, mais dans l'ensemble les conclusions restent les mêmes et rejoignent parfaitement celles de SMiru (1959-I960).

TABLEAU 40

Rendements alimentaires de lactation

\begin{tabular}{|c|c|c|c|c|c|c|c|c|}
\hline \multirow[b]{2}{*}{ Lots } & \multicolumn{4}{|c|}{ Énergie } & \multicolumn{4}{|c|}{ Azote } \\
\hline & $\begin{array}{l}\text { Aliment } \\
\text { (th) }\end{array}$ & $\begin{array}{l}\text { Lait } \\
\text { (th) }\end{array}$ & $\begin{array}{l}\text { Variation } \\
\text { de poids } \\
\text { (th) }\end{array}$ & $\begin{array}{c}\text { Rendement } \\
\text { (p. 100) }\end{array}$ & $\underset{\left(\mathrm{kg}_{a}\right)}{\text { Aliment }}$ & $\begin{array}{l}\text { Lait } \\
\text { (kg) }\end{array}$ & $\begin{array}{c}\text { Variation } \\
\text { de poids } \\
(\mathrm{kg})\end{array}$ & $\begin{array}{l}\text { Rendement } \\
\text { (p. 100) }\end{array}$ \\
\hline $\mathrm{H}-\mathrm{II} \ldots \ldots \ldots$ & 761 & 422 & -193 & 29,9 & 6,65 & 3,26 & 1,07 & 32,6 \\
\hline $\mathrm{H}-\mathrm{B} \ldots \ldots \ldots \ldots$ & 456 & 345 & -278 & 14,7 & 3,82 & 2,68 & 1,30 & 36,1 \\
\hline B-H $\ldots \ldots \ldots \ldots$ & $9 x_{4} 6$ & 361 & -26 & 35,4 & 8,25 & 3,10 & 0,18 & 35,4 \\
\hline B-B......... & 465 & 320 & -210 & 23,6 & 4,05 & 2,54 & 0,62 & 47,4 \\
\hline
\end{tabular}

TABLEAU 4I

Rendement alimentaire du cycle de reproduction

\begin{tabular}{|c|c|c|c|c|c|c|c|c|c|c|}
\hline \multirow[b]{2}{*}{ Lots } & \multicolumn{5}{|c|}{ Energie } & \multicolumn{5}{|c|}{ Azote } \\
\hline & $\begin{array}{c}\text { Aliment } \\
\text { (th) }\end{array}$ & $\begin{array}{l}\text { Lait } \\
\text { (th) }\end{array}$ & $\begin{array}{c}\text { Porcelets } \\
\text { (th) }\end{array}$ & $\begin{array}{c}\text { Variation } \\
\text { corporelle } \\
\text { (th) }\end{array}$ & $\begin{array}{l}\text { Rendement } \\
\text { (p. 100) }\end{array}$ & $\begin{array}{c}\text { Aliment } \\
(\mathrm{kg})\end{array}$ & $\begin{array}{l}\text { Lait } \\
(\mathrm{kg})\end{array}$ & $\begin{array}{c}\text { Porcelets } \\
(\mathrm{kg})\end{array}$ & $\begin{array}{c}\text { Variation } \\
\text { poids } \\
(\mathrm{kg})\end{array}$ & $\begin{array}{l}\text { Rendement } \\
\text { (p. 100) }\end{array}$ \\
\hline H-HI & 1919 & 422 & 13 & $\begin{array}{l}+52 \\
+\quad 5\end{array}$ & 25,4 & 16,0 & 3,3 & 0,3 & $+0,4$ & 25,0 \\
\hline $\mathrm{H}-\mathrm{I3}$ & 1644 & 345 & 13 & $-\quad 82$ & 16,8 & 13,7 & 2,7 & 0,3 & $-0,1$ & 21,2 \\
\hline I3-II & 1560 & 361 & 14 & -10 & 23,4 & 13,0 & 3,1 & 0,3 & $+0,7$ & 31,5 \\
\hline $\mathrm{B}-\mathrm{B}$ & 1042 & 320 & 14 & -158 & 16,9 & 8,7 & 2,5 & 0,3 & $-0,2$ & 34,5 \\
\hline
\end{tabular}

- En ce qui concerne 1'énergie, les meilleurs rendements sont ceux des lots B-H et $\mathrm{H}-\mathrm{H}$. Au cours de la lactation, l'énergie des niveaux élevés est plus productive que celle des niveaux bas. Par ailleurs, le lot $\mathrm{B}-\mathrm{H}$ a un rendement très supérieur à celui du lot $\mathrm{H}-\mathrm{B}$, ce dont on peut déduire, en réponse à une question précédente, qu'un même supplément alimentaire est plus efficace lorsqu'il est distribué au cours de la lactation plutôt qu'au cours de la gestation.

- En ce qui concerne l'azote, les conclusions sont moins nettes. A l'exception du résultat asse $z$ inattendu du lot B-B, il semble que le rendement alimentaire varie assez peu suivant le niveau nutritionnel ou le procédé de rationnement, résultat qui apparaissait déjà en ce qui concerne la gestation. Toutefois, lorsque l'on compare les résultats des lots pris deux à deux, on constate que l'utilisation de l'azote est meilleure dans le lot B-H que dans le lot $\mathrm{H}-\mathrm{H}$ et dans le lot $\mathrm{B}-\mathrm{B}$ que dans le lot $\mathrm{H}-\mathrm{B}$, ce qui fait ressortir la supériorité des régimes $B$.

En définitive, et contrairement à ce qui se passe pour l'énergie, il semble qu'en 
valeur relative la Truie tire meilleur parti de l'azote quand le taux d'ingestion est limité. Il s'ensuit donc que le niveau qui provoque la meilleure utilisation de l'énergie n'est pas forcément celui qui provoque la meilleure utilisation de l'azote, ce qui souligne l'une des divergences (ou des relations) qui apparaissent dans l'utilisation des différents nutriments chez la 'Truie en reproduction. Dans nos conditions, c'est le régime $\mathrm{B}$ de gestation, associé au régime $\mathrm{H}$ de lactation, qui semble concilier le maximum d'avantages.

\section{D - Diseussion générale}

Quel que soit le niveau alimentaire global de gestation, mais dans les limites de notre expérience (c'est-à-dire en absence de déséquilibre qualitatif fondamental) nous avons constaté une large indépendance de la croissance embryonnaire (nombre et poids des porcelets) et du régime distribué à la mère. Paradoxalement, semble$\mathrm{t}$-il, c'est même avec les régimes restreints que le nombre de porcelets à la naissance paraît le plus élevé (ces derniers sont alors un peu moins lourds). Ceci est à rapprocher des observations faites sur le Rat (SAlmoN-LEGAGNEur, I960; CHAMpigry, I962), mais diffère quelque peu des résultats de WALIACE (I948) sur la brebis obtenus, il est vrai, avec des restrictions beaucoup plus sévères. Nos expériences conduisent à quelques conclusions : tout d'abord, que les régimes que nous avons utilisés couvraient largement les besoins de l'utérus gravide de la Truie, ce qui laisse supposer que ces besoins sont plus faibles qu'on le pense en général, après les estimations formulées par MoustgaARd (I958) et Mitchell (I93I). On peut aussi imaginer que les synthèses fotales sont réalisées avec un rendement et une efficacité élevés et sans doute supérieurs à ceux de la croissance post natale (BRODy, I945).

Toutefois, comme on ne peut raisonnablement pas exclure l'hypothèse d'une augmentation des besoins métaboliques liée au dévelopement de l'embryon (CHAmPIGNY, I963), le problème se pose de savoir comment ces besoins sont satisfaits en l'absence de toute augmentation des apports alimentaires. En ce qui concerne le besoin azoté, on peut invoquer un double mécanisme : du fait de l'anabolisme gravidique la gestante utilise mieux l'azote que le sujet au repos sexuel; de plus, elle est capable de réduire sa dépense de fond pour faire face aux exigences prioritaires $\mathrm{du}$ fœtus. C'est un des phénomènes nutritionnels les plus remarquables de la gestation que cette épargne azotée ; si le mécanisme est loin d'en être élucidé, du moins sa réalité ne fait plus doute puisqu'elle a été confirmée par de nombreux auteurs sur les espèces les plus diverses (BAR et DAUNAY, I903 ; Poo et al., I939; LENKEIT, I955; Rombauts, I959; Champigny, I96I). Par contre, il en va différemment pour l'énergie : a aucun moment, notre expérience ne nous a permis de conclure à une amélioration de l'utilisation énergétique analogue à celle observée pour l'azote. C'est donc à partir de ressources endogènes que la Truie doit faire face aux besoins croissants de l'utérus gravide. Et c'est là un autre phénomène remarquable, car i1 faut bien admettre que la croissance embryonnaire est le phénomène prioritaire de la gestation. Celui-ci laisse, après la couverture des besoins de l'utérus, un reliquat nutritionnel variable avec le régime et le stade de gestation, à l'usage propre đe la mère. Mais dans certains cas, le capital énergétique propre de la Truie peut se trouver entamé.

On comprend mieux alors le sens des variations du gain de poids et de la compo- 
sition corporelle au cours de la gestation; lorsque le niveau alimentaire est élevé, l'anabolisme gravidique se manifeste pleinement aussi bien pour l'énergie que pour l'azote : la Truie édifie à la fois du muscle et du tissu adipeux. Par contre, si le niveau alimentaire est restreint, la prise de poids est plus faible et ne comporte plus qu'un anabolisme protidique. L'anabolisme lipidique, beaucoup plus coûteux en énergie, est arrêté et la mobilisation du tissu adipeux qui survient est d'autant plus importante que la restriction est plus sévère, ou que le stade de gestation est plus avancé. C'est ce qui explique en général la diminution d'épaisseur du tissu ađipeux sous-cutané dorsal que l'on observe en fin de gestation.

Ces mêmes phénomènes se reproduisent au cours de la lactation. Dans la majorité des cas, les modifications de faible ou moyenne amplitude (30 p. Ioo) apportées au niveau alimentaire global, paraissent insuffisantes pour faire varier d'une façon sensible la sécrétion des constituants du lait (SuIтH, I959-I960). Ce n'est que dans les cas extrêmes qu'un niveau alimentaire haut ou bas distribué pendant la lactation affecte principalement le volume de la sécrétion. Il y a donc lieu de penser que la fonction de lactation se comporte, elle aussi, comme un phénomène prioritaire qui dépend davantage de facteurs individuels que des conditions de milieu.

Il n'y a rien d'étonnant alors à ce que, en cas de restriction alimentaire, 1a Truie prélève sur ses propres tissus les ressources nutritionnelles qui lui font défaut pour les besoins de sa lactogenèse. C'est pourquoi le principal effet d'une variation du niveau alimentaire de lactation est, en définitive, d'accroître ou de diminuer l'intensité de la perte de poids.

Il apparait ainsi qu'une augmentation du niveau alimentaire au cours de la gestation contribue dans une certaine mesure à améliorer les performances de lactation en élevant le niveau des ressources endogènes. Toutefois, cette participation des tissus maternels ne peut être que forcément limitée et il n'est pas dit qu'elle puisse se faire avec un très bon rendement, notamment en ce qui concerne l'énergie ; C'est ce qui explique les résultats obtenus avec les régimes croisés et pourquoi les performances laitières sont supérieures avec le rationnement $\mathrm{B}-\mathrm{H}$ qu'avec la formule H-B. Certes une augmentation des réserves édifiées au cours de la gestation conduit à une mobilisation corporelle plus importante au cours de la lactation et aussi à une augmentation de la production laitière, mais celle-ci reste faible et se traduit essentiellement par une augmentation de la teneur en matière grasse du lait (Smith, Ig6o).

I1 convient d'ailleurs de distinguer dans ces phénomènes l'utilisation de l'azote et celle de 1'énergie : quelle qu'en soit 1'origine, endogène ou alimentaire, quelque soit le niveau de la ration, haut ou bas, le rendement de l'azote chez la Truie en reproduction ne paraît varier que dans de faibles limites. Par contre, l'énergie parait beaucoup mieux utilisée lorsqu'elle est distribuée à un niveau élevé au cours de la gestation et de la lactation.

Ceci conduit donc à effectuer certains rapprochements entre les différentes phases de la reproduction. Dans ce domaine, il convient de souligner certains phénomènes d'ajustement qui apparaissent au cours de la lactation et qui concrétisent un aspect des relations nutritionnelles qui existent entre la gestation et la lactation. Ces ajustements sont de trois ordres :

- Ajustement des consommations : les quantités d'aliment librement consommées pendant la lactation sont d'autant plus importantes que la consommation a 
été plus restreinte au cours de la gestation. Cette observation avait déjà été rapportée par DEAN (I960) et montre que la Truie réagit à une diminution du niveau alimentaire au cours d'une période en exagérant sa consommation au cours de la période suivante.

- Ajustement des variations de poids; il existe une correspondance étroite entre l'importance du gain de poids pendant la gestation et celle de la perte de poids pendant la lactation. Cette relation apparaît quel que soit le niveau alimentaire ; par exemple, un niveau alimentaire élevé pendant la lactation ne prévient pas la perte de poids si le niveau de gestation a été lui-même élevé. Les gains corporels apparaissent donc très labiles et cette plasticité pose le problème du déterminisme de la mobilisation. Certains auteurs ont d'ailleurs évoqué le caractère permanent que présentait, même en l'absence de déséquilibre alimentaire, le catabolisme azoté ou énergétique de la laitière (LENkEIT, I957; VANschoubroEk, I962). Si pour l'azote le phénomène peut trouver une explication dans l'involution nécessaire de l'appareil reproducteur après la parturition, le problème reste entier en ce qui concerne la fonte lipidique.

- Ajustement à des niveaux nutritionnels variés, phénomène bien connu par ailleurs (Morin-Jamain et $a l$., I96I). Un niveau alimentaire élevé est en général mieux utilisé lorsqu'il succède à un niveau bas. Il s'ensuit qu'à égalité de quantités d'aliment consommées, l'efficacité alimentaire d'un régime restreint pendant la gestation et libéral pendant la lactation est supérieure à celle d'un régime successivement abondant puis limité. Ceci paraît surtout vrai pour l'utilisation de l'énergie de la ration.

Ces différents phénomènes aident à mieux comprendre la valeur des résultats obtenus avec le régime $\mathrm{B}-\mathrm{H}$ de notre expérience de régimes croisés : production laitière élevée, faible perte de poids pendant la lactation et en définitive meilleurs efficacité alimentaire.

Rappelons, par ailleurs, qu'un travail préliminaire, poursuivi avec la collaboration de PÉRISSE (I959), avait montré que la Ratte réagit comme la Truie aux conditions alimentaires globales et que les résultats fournis par les régimes croisés au cours du cycle " gestation-lactation " sont strictement identiques chez les deux espèces.

Cela conduit à se pencher d'une façon plus approfondie sur l'influence du régime alimentaire de gestation et 1'anabolisme gravidique quant aux résultats de la lactation et à envisager séparément le rôle des protides et des aliments énergétiques. 


\section{CHAPITRE IV}

\section{RELATIONS ENTRE LES PROTIDES DU REGIME, LA GESTATION ET LA LACTATION}

Nous avons indiqué au chapitre précédent que des opinions assez contradictoires avaient été émises quant à l'influence de l'apport azoté sur la reproduction de la Truie. Toutefois, ces divergences portent davantage sur les rétentions maternelles, dont nous avons souligné la grande variabilité, que sur les contenus utérins beaucoup moins sujets à variation. Peut-être faudrait-il voir aussi dans ces résultats la conséquence d'un manque d'uniformité et d'une certaine imprécision dans les conditions expérimentales qui ne permettent pas de dissocier ce qui revient à l'apport azoté quantitatif de ce qui revient à l'apport azoté qualitatif, ou aux relations de l'azote avec l'énergie de la ration. Il est évident, par exemple, comme le fait remarquer PIKE (I954) que la signification d'un même apport d'azote diffère suivant que les besoins énergétiques sont eux-mêmes couverts ou non. En outre, comme pour les variations du niveau global, il peut apparaître certaines interférences de la gestation sur la lactation, qui n'ont pas toujours été prises en considération.

Aussi, dans l'étude des relations protidiques avons-nous essayé de tenir compte de ces différents aspects, afin de conserver une signification aussi générale que possible aux résultats. A cet effet, nous avons été amenés à répéter certaines expériences avec des techniques diverses (variations de poids, bilans, régimes croisés). De plus, nous avons examiné séparément l'aspect quantitatif et 1'aspect qualitatif du besoin azoté.

\section{A - Eiliets de l'apport quantitatif d'azote au cours de la geslation}

\section{Io Augmentation du niveau azoté en fin de gestation}

Cette première expérience avait pour but d'examiner l'influence d'un supplément alimentaire d'azote au cours du dernier mois de gestation.

D'après LENKEIT et al. (I956), c'est essentiellement en fin de gestation que la Truie paraît capable de tirer profit d'une augmentation de l'apport azoté. Nous avons voulu voir, dans un premier temps, quelle pouvait être l'influence d'un tel supplément sur la prise de poids, les contenus utérins et, au-delà, sur la lactation. Pour quelques auteurs, en effet, le bénéfice d'un supplément azoté apparaît moins au cours de la gestation que dans les résultats de la lactation qui suit (JESPERSEN, I940 ; Stevenson et Elis, I957 ; Ivanov, I957). 
Deux lots de 8 truies, d'un poids moyen de I7o kg, ont été constitués. Pendant les deux premiers mois de gestation, ces truies recevaient une même ration de $3,5 \mathrm{~kg} /$ jour d'un aliment ayant une teneur énergétique de 3,8 thermies $/ \mathrm{kg}$ et apportant I20 g de protides $/ \mathrm{kg}$, qui couvrait largement les besoins énergétique et azoté théoriques de la gestation. Pendant le dernier mois de gestation, les truies des deux lots recevaient un supplément alimentaire de $0,5 \mathrm{~kg}$ par jour, soit du même aliment que précédemment (lot $B$ ), soit d'un concentré azoté de haute valeur biologique ( ${ }^{1}$ ) (lot $\mathrm{H}$ ). Pendant cette dernière période, l'apport d'aliments énergétiques, plus élevé, était rigoureusement identique dans les deux lots; par contre, les truies du lot $\mathrm{H}$ bénéficiaient de $\mathrm{I} 8 \mathrm{~g} \mathrm{~g}$ de protides supplémentaires (soit $25 \mathrm{~g}$ d'azote) par jour. Par rapport à l'ingéré total, les truies du lot $B$ recevaient une ration à $\mathrm{I} 2 \mathrm{p}$. Ioo de protides et celles du lot $\mathrm{H}$ une ration à $\mathrm{I} 5 \mathrm{p}$. Ioo (soit une différence d'environ $20 \mathrm{p}$. Ioo). Pendant la lactation, les truies des deux lots disposaient à volonté d'un même aliment à $16 \mathrm{p}$. Ioo de protides.

Les mesures suivantes ont été effectuées : variation de poids vif, poids des productions utérines, production laitière et composition du lait, croissance des porcelets.

\section{a) Variations de poids.}

Le tableau 42 fait apparaître une légère différence dans les gains de poids de gestation en faveur du lot $\mathrm{H}$. Cette différence n'étant pas significative ne permet pas de conclure avec certitude que le supplément de protides distribué ait contribué effectivement à améliorer la croissance du lot suralimenté. Nos résultats se rapprochent en cela de ceux obtenus par BoAz (I96I) dans des conditions analogues.

TABLEAU 42

Variations de poids au cours de la gestation et de la lactation

\begin{tabular}{|c|c|c|c|c|c|c|}
\hline Lots & $\begin{array}{c}\text { Gain total } \\
\text { gestation } \\
(\mathrm{kg})\end{array}$ & $\begin{array}{c}\text { Gain net } \\
\text { gestation } \\
(\mathrm{kg})\end{array}$ & $\begin{array}{l}\text { Gain net } \\
\text { dernier mois } \\
\text { gestation } \\
(\mathrm{kg})\end{array}$ & $\begin{array}{c}\text { Perte } \\
\text { parturition } \\
(\mathrm{kg})\end{array}$ & $\begin{array}{c}\text { Perte } \\
\text { lactation } \\
(\mathrm{kg})\end{array}$ & $\begin{array}{c}\text { Bilan } \\
(\mathrm{kg})\end{array}$ \\
\hline $\begin{array}{l}\mathrm{B} \ldots \ldots \\
\mathrm{H} \ldots\end{array}$ & $\begin{array}{l}88,7 \\
94,9\end{array}$ & $\begin{array}{l}65,6 \\
68,3\end{array}$ & $\begin{array}{l}28,2 \\
30,8\end{array}$ & $\begin{array}{l}-23,1 \\
-26,6\end{array}$ & $\begin{array}{l}-43,5 \\
-41,5\end{array}$ & $\begin{array}{l}+23,1 \\
+\quad 26,0\end{array}$ \\
\hline
\end{tabular}

Tout au plus peut-on parler d'une légère tendance à favoriser la prise de poids pendant la période de distribution ( 9 p. IOO) compensée d'ailleurs par des pertes légèrement supérieures à la parturition (I2 p. IOO). Pendant la lactation, la chute de poids est un peu plus faible dans le lot $\mathrm{H}$ (différence non significative).

(1) Sa composition était la suivante : farine de poisson : Io; farine de viande : 20 ; levure sèche : 20; tourteau de soja: 40 ; tourteau de palmiste 10 ( $460 \mathrm{~g}$ de mat. azotées $/ \mathrm{kg})$. 
b) Parturition et croissance des porcelets.

Si l'on en juge par le nombre et le poids moyen des porcelets nés vivants (tab1. 43), il ne semble pas que le supplément distribué au lot $\mathrm{H}$ ait contribué à améliorer la qualité de la production utérine, ce qui confirme les résultats de BoAz (I960), mais parait en contradiction avec ceux de JESPERSEN (I940) et de IVANOV (I957). La divergence s'explique sans doute par le niveau relativement élevé auquel se trouvait déjà placé notre lot $B$, alors que l'apport était nettement plus faible dans l'expérience de JESPERSEN. On notera toutefois que le nombre de porcelets mort-nés paraît moins élevé dans notre lot $\mathrm{H}$, ce qu'avait déjà constaté Ivanov (I957). Par ailleurs, le nombre et le poids moyen des porcelets sevrés est très voisin dans les deux lots, ce qui rejoint les résultats de $\mathrm{BoAz}$ (I962), mais va légèrement à l'encontre des conclusions de STEVENSON (I957).

TABLEAU 43

Poids et nombre de porcelets

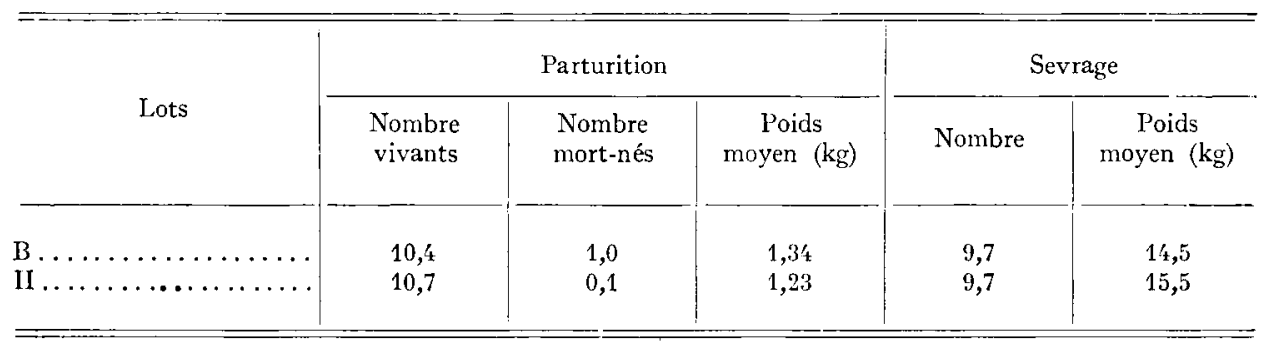

c) Production laitière.

Comme le montre le tableau 44, ni la quantité, ni la composition du lait, ne semblent avoir été affectées par les régimes distribués au cours de la gestation, ce qui va de pair avec les résultats d'autres auteurs.

TABLEAU 44

Productions laitières

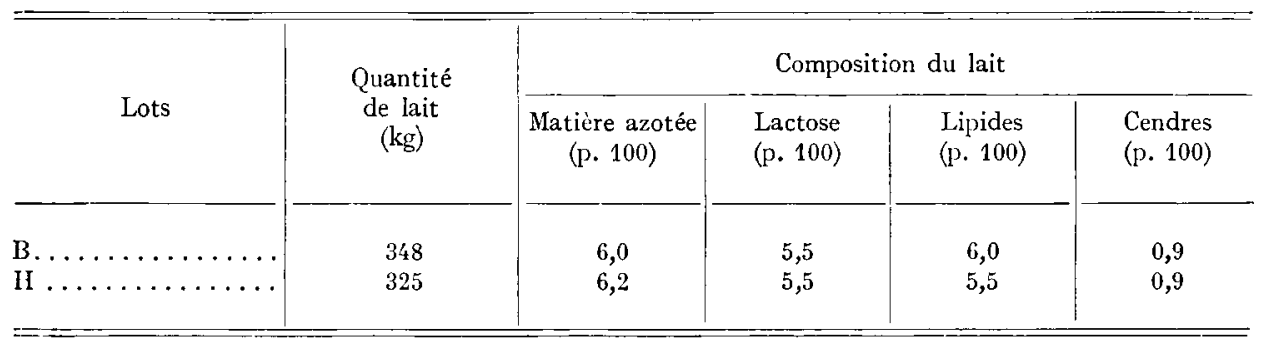

d) Conclusions.

Dans les conditions expérimentales où nous nous étions placé et mise à part une légère augmentation du gain corporel, une augmentation de $20 \mathrm{p}$. Ioo de l'ap- 
port azoté pendant le dernier mois de gestation n'a exercé aucun effet apparent sur les résultats de la parturition ou de la lactation.

A quelques nuances près, nous confirmons les données générales de la littérature ce qui montre que :

I $^{\mathbf{0}}$ Le taux de protides le plus bas de notre expérience, soit I 2 p. Ioo, paraît suffisant pour couvrir les besoins de la protéinogenèse utérine et extra-utérine de la Truie en gestation.

$2^{\circ}$ L'apport azoté ne semble pas, dans ces conditions, être le facteur limitant de la prise de poids chez la Truie contrairement à une observation de PIKE (I954) chez la Ratte.

\section{$2^{\circ}$ Bilans azotés}

LENKEIT (I956) avait remarqué que la prise de poids ne constituait pas un témoin fidèle des rétentions de la Truie gravide. En particulier, les rétentions étaient généralement inférieures à ce que laissait prévoir l'importance des gains de poids. Ainsi était posé le problème des proportions respectives des différents tissus élaborés pendant la gestation.

Nous avons donc comparé les rétentions d'azote de truies placées en cage à métabolisme et soumises à des conditions d'alimentation protéique très différentes. Nous avons utilisé pour cela deux régimes $\mathrm{H}$ et $\mathrm{B}$, constitués de façon à réaliser des apports quotidiens par animal de $44 \mathrm{~g}$ d'azote pour le premier (régime à I I p. roo de protides) et de $108 \mathrm{~g}$ d'azote pour le second (régime à $17 \mathrm{p}$. Ioo de protides).

Chacun de ces régimes était affecté à 4 truies d'un poids moyen de $220 \mathrm{~kg}$. Après une période d'adaptation de 3 semaines, ces truies étaient fécondées et restaient en cage pendant toute leur gestation. On effectuait l'analyse hebdomadaire des ingestas et des excretas et, au moment de la parturition, celle des produits de la conception.

Les données du bilan rapportées à l'ensemble de la gestation figurent au tableau 45 .

TABLEAU 45

Bilans azotés de truies soumises à des niveaux azotés différents

\begin{tabular}{|c|c|c|}
\hline & II & $\mathrm{B}$ \\
\hline $\mathrm{N}$ ingéré total $(\mathrm{kg}) \ldots \ldots$ & 12,33 & 4,93 \\
\hline $\mathrm{N}$ fécal $(\mathrm{kg}) \ldots \ldots \ldots \ldots \ldots \ldots$ & 1,47 & 1,00 \\
\hline $\mathrm{N}$ absorbé $(\mathrm{kg}) \ldots \ldots \ldots \ldots \ldots \ldots \ldots \ldots$ & 10,66 & 3,93 \\
\hline Coefficient d'utilisation digestive (N p.100)...... & $86,,^{\prime}$ & 79,7 \\
\hline $\mathrm{N}$ urinaire $(\mathrm{kg}) \ldots \ldots \ldots \ldots \ldots \ldots \ldots \ldots \ldots$ & 8,34 & 2,51 \\
\hline $\mathrm{N}$ retenu $(\mathrm{kg}) \ldots \ldots \ldots \ldots \ldots \ldots \ldots \ldots$ & 2,32 & 1,42 \\
\hline Coefficient rétention $N($ p. 100$) \ldots \ldots \ldots \ldots$ & 21,76 & 36,1 \\
\hline $\mathrm{N}$ contenu utérin $(\mathrm{kg}) \ldots \ldots \ldots \ldots \ldots \ldots$ & 0,31 & 0,30 \\
\hline $\mathrm{N}$ corporel $(\mathrm{kg}) \ldots \ldots \ldots \ldots \ldots \ldots \ldots$ & 2,01 & 1,12 \\
\hline Gain net gestation $(\mathrm{kg}) \ldots \ldots \ldots \ldots \ldots$ & 56 & 43 \\
\hline 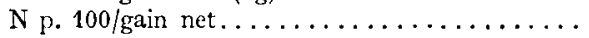 & 3,6 & 2,6 \\
\hline
\end{tabular}


Les pertes fécales sont de même ordre dans les deux lots, ce qui signifie qu'il y a plus d'azote absorbé avec le régime $H$ qu'avec le régime $B$ et se traduit effectivement au niveau du coefficient d'utilisation digestive (C.U.D.).

Les pertes urinaires augmentent considérablement avec l'alimentation hyperprotéique. En valeur absolue, l'azote retenu est plus important avec le régime $\mathrm{H}$ qu'avec le régime $B$. Mais, en valeur relative, c'est le contraire comme le montrent les valeurs du coefficient de rétention azotée (C.R.). La plus grande partie du supplément protéique n'a donc pas été utilisée en raison des limites mêmes de la protéinogenèse. Il y a tout lieu de penser que les truies du lot $\mathrm{H}$ se trouvaient placées dans des conditions où elles approchaient des limites de leur potentiel de croissance protéique. Au demeurant, les rétentions d'azote effectuées par ces truies ont été sensiblement supérieures à celles observées par LENkEIr (I956) et RoMBAUTs (I962) dans des conditions alimentaires analogues.

Il convient dès lors de souligner que cette augmentation de l'azote retenu ne provient pas du contenu utérin, qui, comme dans nos expériences précédentes, est resté constant quel que soit le régime. C'est au niveau des rétentions maternelles ( +75 p. IOO) que se solde le bénéfice dù à l'augmentation des apports azotés, résultat qui concorde parfaitement avec les observations de LENkEIT (I956) chez la Truie, de PIKE (I954) et de Bourder (I960) chez la Ratte.

Nous accorderons, par ailleurs, la plus grande importance à la variation de ces rétentions en fonction des gains de poids réalisés. La comparaison entre ces valeurs donne une idée de la composition des tissus élaborés et constitue donc un témoin plus valable de l'intensité de la protéinogenèse. Dans cet essai, le gain d'azote corporel varie du simple au double, alors que la différence entre les gains de poids vif n'est que de 20 p. Ioo environ : à poids de poids égal, une augmentation de l'apport azoté chez la Truie gestante provoque une augmentation du tissu protéique formé au détriment du tissu adipeux.

\section{$3^{\circ}$ Relations énergie/protéine}

Il restait à examiner le rôle respectif des teneurs en énergie et en azote des aliments dans ces phénomènes d'anabolisme azoté de gestation.

Au cours des expériences précédentes, on a vu que le niveau azoté de la ration exerçait une influence sur l'intensité de la protéinogenèse, mais que c'est surtout du niveau alimentaire global que dépendait en définitive l'importance de la prise de poids. Par ailleurs, PIkE et coll. (I954) ont montré sur la Ratte que le taux énergétique de la ration conditionne en partie la rétention azotée pendant la gestation. Il apparait donc que les apports en protides et en aliments énergétiques agissent de façon complémentaire dans les processus d'anabolisme gravidique, à tel point que l'on peut se demander lequel de ces apports joue le rôle de facteur limitant lorsque l'un et l'autre se trouvent en quantité restreinte dans la ration.

Une expérience a été entreprise dans ce sens et deux niveaux d'alimentation azotée et deux niveaux d'alimentation énergétique ont été comparés en prenant pour critères d'efficacité nos mesures habituelles: gain de poids corporel et variation du tissu adipeux (méthode aux ultrasons), poids et nombre de fœetus à la parturition, production laitière (croissance des porcelets).

Trente truies adultes, d'un poids moyen de $205 \mathrm{~kg}$, ont été réparties en trois lots 
d'égale importance quant au poids, à l'âge et aux antécédents. Après une période préexpérimentale de 3 semaines (un cycle sexuel) pendant laquelle elles recevaient une même ration abondante, les truies étaient fécondées et placées en cases individuelles de porcherie. Pendant toute la durée de la gestation, les animaux recevaient une ration constante de l'un des deux aliments $\mathrm{H}$ ou $\mathrm{B}$ utilisés lors de l'expérience précédente et distribuée de la façon suivante : $2,5 \mathrm{~kg}$ d'aliment $\mathrm{H}$ pour les primes du lot e $\mathrm{N}$ (basse teneur en, teneur élevée en protides), 2,5 $\mathrm{kgg}$ d'aliment $\mathrm{B}$ pour les truies du lot $e n$ (basses teneurs en énergie et en protides) et $4 \mathrm{k}$ d'aliment $\mathrm{B}$ pour les truies du lot $\mathrm{E} N$ (hautes teneurs en énergie et en protides). De la sorte, les ingérés variaient suivant les lots de $44 \mathrm{~g}$ (lot $e n$ ) à $70 \mathrm{~g}$ (lots e $\mathrm{N}$ et $\mathrm{E} \mathrm{N}$ ) pour l'azote et de 8,5 th (lots $e \mathrm{~N}$ et $e n$ ) à I3,7 th (lot $\mathrm{E} \mathrm{N}$ ) pour l'énergie.

Les différents lots étaient donc ainsi caractérisés :

- les lots $e \mathrm{~N}$ et $\mathrm{E} \mathrm{N}$ recevaient une ration sensiblement isoazotée (et de même valeur biologique), mais celle du lot $\mathrm{E} N$ apportait $50 \mathrm{p}$. roo de calories de plus que celle du lot $e \mathrm{~N}$ (celle-ci correspondait sensiblement au niveau de 1'entretien majoré de 20 p. IOO);

- les lots $e \mathrm{~N}$ et $e n$ recevaient des rations isoénergétiques, mais celle $\mathrm{du}$ lot $e \mathrm{~N}$ apportait $55 \mathrm{p}$. Ioo d'azote de plus que celle du lot $e n$;

- pour le lot $\mathrm{E} \mathrm{N}, 1$ 'apport en azote et énergie était de $60 \mathrm{p}$. Ioo plus élevé que pour le lot $e n$.

Pendant la lactation, le nombre de porcelets dans chaque portée était égalisé à 8 pour éliminer l'influence du nombre sur la production laitière. Les truies recevaient à volonté l'aliment et les porcelets pouvaient disposer, à partir de la $3^{\mathbf{e}}$ semaine, d'un aliment équilibré d'un type courant. Le poids moyen des porcelets aux différents âges et la consommation des truies et des porcelets étaient enregistrés.

Les résultats ont été les suivants:

a) Variation $d u$ poids des truies.

Le tableau 46 rapporte l'évolution du poids des truies de chaque lot aux différentes époques considérées:

TABLEAU 46

Variations de poids

\begin{tabular}{c|c|c|c}
\hline \hline Lot & $\begin{array}{c}\text { Gain total } \\
\text { gestation } \\
(\mathrm{kg})\end{array}$ & $\begin{array}{c}\text { Gain net } \\
\text { gestation } \\
(\mathrm{kg})\left(^{*}\right)\end{array}$ & $\begin{array}{c}\text { Perte } \\
\text { lactation } \\
(\mathrm{kg})\end{array}$ \\
\hline$e n$ & -10 & -10 \\
$\mathrm{E} \mathrm{N}$ & 67 & $48^{*}$ & -35 \\
$e \mathrm{~N}$ & 63 & 42 & -12 \\
\hline
\end{tabular}

* Différence significative.

Seul le lot $\mathrm{E} \mathrm{N}$ a présenté pendant la gestation des gains de poids très élevés (30 p. Ioo du poids vif initial) et significativement supérieurs à ceux des deux autres lots. L'examen des résultats de ces derniers montre toutefois qu'un tel résultat n'a 
pu être acquis que parce qu'un taux énergétique suffisant était associé à un taux azoté élevé. En particulier, un même apport azoté, mais avec un niveau d'énergie plus bas (lot $e \mathrm{~N}$ ) a été incapable de promouvoir une prise de poids aussi importante et n'a provoqué que des effets très faiblement supérieurs à ceux d'un régime bas en azote et en énergie (lot $e n$ ). Outre que ces résultats confirment ceux de l'expérience précédente, ils mettent donc l'accent sur l'importance de l'apport énergétique dans les phénomènes d'anabolisme protidique.

Si de nombreux auteurs ont montré en effet que la prise de poids pouvait s'effectuer avec des rations très limitées en azote (Evars, I929 ; Rombauts, I956 ; TIkHoNOV, I957; BOURDEL, I957), c'était à condition que les animaux disposent d'un ingéré énergétique libéral. D'autres auteurs ont signalé également qu'un niveau énergétique élevé suffisait à augmenter les rétentions azotées chez des femelles ges. tantes recevant un apport azoté limité et constant. Ce fut le cas de PrKE (I954) et de Champigny (1962) sur la Ratte et de Dean et Tribble (I959) sur la Truie. Notre expérience va dans ce sens et montre que l'apport en énergie de la ration est davantage un facteur limitant de l'anabolisme protéiqua que le niveau azoté lui-même. CLAWSON et al. (Ig63), ainsi que ELSLEY (I963) sont arrivés récemment à la même conclusion.

Par ailleurs, la teneur en aliments énergétiques conditionne l'utilisation de l'azote de la ration: classés selon leur coefficient d'efficacité protidique, les trois régimes ont donné les résultats du tableau 47 :

TABLEAU 47

Coefficients d'efficacité protidique

\begin{tabular}{|c|c|c|}
\hline Lots & $\begin{array}{l}\text { Par rapport } \\
\text { au gain total }\end{array}$ & $\begin{array}{l}\text { Par rapport } \\
\text { au gain net }\end{array}$ \\
\hline Lot $e n \ldots \ldots \ldots \ldots$ & 1,99 & 1,32 \\
\hline 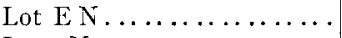 & 1,76 & 1,34 \\
\hline Lot $e N \ldots \ldots \ldots \ldots \ldots$ & 1,37 & 0,91 \\
\hline
\end{tabular}

Les deux lots qui disposaient des régimes présentant le plus faible rapport Azote/Énergie se placent nettement avant le lot où le taux d'azote du régime est le plus élevé. L'azote de la ration est donc mieux utilisé lorsqu'il est associé à un apport énergétique élevé, ou, ca qui revient au même, l'utilisation est moins bonne avec les régimes trop riches en azote. Ce résultat est parfaitement classique et confirme ceux de l'expérience précédente.

\section{b) Composition corporelle.}

Le tableau 48 rapporte, en pourcentage, les variations d'épaisseur du tissu adipeux. En outre, à partir de ces résultats, nous donnons au tableau 49, une estimation de la composition du gain de gestation.

Ces résultats diffèrent sensiblement suivant les lots et montrent bien que les gains de poids réalisés avec les différents régimes n'ont pas la même signification. 
Ils aident à mieux comprendre les rôles respectifs de l'azote et de l'énergie. Lorsque l'apport énergétique est faible, mais que le taux d'azote est élevé (lot $e$ N), l'anabolisme est essentiellement protidique; mais si le taux d'azote est également faible $($ lot $e n$ ), il y a place pour un certain anabolisme lipidique, comme le montrait 1'examen des bilans dans l'expérience précédente. Dans le premier cas, l'énergie est le facteur limitant de la protéinogénèse ; dans le second cas, il ne l'est pas. Lorsque l'apport énergétique et azoté sont également larges (lot $\mathrm{E} \mathrm{N}$ ) la protéinogenèse et la lipogenèse sont toutes deux augmentées, ce qui met encore en relief le rôle de l'apport d'énergie dans la rétention azotée.

\section{TABLEAU 48}

Variation de l'épaisseur du tissu adipeux sous-cutané en p. 100 de la valeur à l'accouplement

\begin{tabular}{|c|c|c|c|c|}
\hline \multirow{2}{*}{ Lot } & \multicolumn{3}{|c|}{ Gestation } & \multirow{2}{*}{ Lactation } \\
\hline & $0-60 \mathrm{j}$. & $60-114 \mathrm{j}$. & Total & \\
\hline $\begin{array}{l}e \mathrm{~N} \\
\mathrm{EN} \\
e n\end{array}$ & $\begin{array}{l}+0,29 \\
+7,5 \\
+5,0\end{array}$ & $\begin{array}{r}+1,1 \\
+9,0 \\
+1,2\end{array}$ & $\begin{array}{r}+\quad 4,0 \\
+\quad 16,5 \\
+\quad 6,2\end{array}$ & $\begin{array}{r}2,0 \\
-\quad 11,1 \\
-\quad 8,7\end{array}$ \\
\hline
\end{tabular}

TABLEAU 49

Composition du gain de poids net de gestation

\begin{tabular}{l|c|c|c|c|c}
\hline \hline \multirow{2}{*}{ Lots } & $\begin{array}{c}\text { Gain de poids } \\
\text { net } \\
(\mathrm{kg})\end{array}$ & \multicolumn{2}{|c|}{ Tissu adipeux } & \multicolumn{2}{|c}{ Tissu musculaire + os } \\
\cline { 3 - 5 } & & $\mathrm{kg}$ & $\begin{array}{c}\text { p. } 100 \mathrm{du} \\
\text { gain net }\end{array}$ & $\mathrm{kg}$ & $\begin{array}{c}\text { p. 100 du } \\
\text { gain net }\end{array}$ \\
\hline & & & & & \\
eN & 45,7 & 3,2 & 7 & 42,5 & 93 \\
EN & 67,6 & 13,2 & 20 & 54,4 & 80 \\
$e n$ & 41,4 & 4,9 & 12 & 36,6 & 88 \\
\hline \hline
\end{tabular}

En bref, c'est essentiellement l'équilibre existant entre les nutriments azotés et énergétiques qui va orienter l'anabolisme gravidique vers la protéinogenèse ou la lipogenèse. Ces conclusions sont comparables à celles formulées par PIKE (I954) chez la Ratte.

Par ailleurs, il se produit une certaine évolution au cours de la gestation. A l'exception du lot $\mathrm{E} N$ qui reçoit le plus d'énergie, la lipogenèse paraît moins active pendant la deuxième partie de la gestation que pendant la première. Ce phénomène n'est pas nouveau, nous l'avions rencontré lors de précédentes expériences. Il confirme la concurrence nutritionnelle qui s'exerce, à partir d'un certain moment, entre la mère et le fotus. A cet égard, les lots $e \mathrm{~N}$ et $\mathrm{E} \mathrm{N}$ ne se conduisent pas de la même façon. Dans le premier, l'intensité de la lipogenèse diminue au cours de la gestation : 
dans le second, elle augmente. Ces différences portent à croire que les effets de la carence énergétique sont surtout sensibles en fin de gestation. Ce serait donc à cette époque que l'énergie de la ration jouerait un rôle de facteur limitant, à la fois vis-à-vis de la protéinogenèse et de la lipogenèse. Il est vraisemblable, en outre, que dans le lot $e \mathrm{~N}$ une partie de l'azote est alors utilisée à des fins énergétiques, ce qui explique le moins bon coefficient d'efficacité protidique obtenu par ce lot. Ceci rejoindrait également les conclusions développées par PIKE (I954).

\section{c) Parturition.}

Les différences observées sont minimes et non significatives: ni le supplément azoté, ni le supplément énergétique ne semblent avoir eu d'effet important sur le développement des fœtus. En particulier, le poids moyen à la naissance des porcelets est aussi élevé dans le lot limité à la fois en azote et en énergie que dans le lot le plus favorisé.

TABLEAU 50

Contenus utérins

\begin{tabular}{|c|c|c|c|c|c|c|c|c|}
\hline \multirow[b]{2}{*}{ Lots } & \multicolumn{4}{|c|}{ Poids des productions } & \multicolumn{4}{|c|}{ Porcelets } \\
\hline & $\begin{array}{l}\text { Porcelets } \\
\quad(\mathrm{kg})\end{array}$ & $\begin{array}{l}\text { Placenta } \\
(\mathrm{k} g)\end{array}$ & $\begin{array}{c}\text { Pertes } \\
\text { liquides } \\
(\mathrm{kg})\end{array}$ & $\begin{array}{l}\text { Total } \\
\text { (kg) }\end{array}$ & $\begin{array}{l}\text { Nombre } \\
\text { de } \\
\text { vivants }\end{array}$ & $\begin{array}{c}\text { Nombre } \\
\text { de } \\
\text { morts }\end{array}$ & $\begin{array}{c}\text { Nombre } \\
\text { total }\end{array}$ & $\begin{array}{c}\text { Poids } \\
\text { moyen } \\
(\mathrm{kg})\end{array}$ \\
\hline$e \mathrm{~N}$ & 14,4 & 3,2 & 3,7 & 21,3 & 11,3 & 1,4 & 12,7 & 1,19 \\
\hline EN & 13,3 & 2,6 & 4,3 & 20,2 & 9,9 & 1,3 & 11,2 & 1,22 \\
\hline$e n$ & 14,3 & 3,0 & 3,9 & 21,2 & 10,4 & 0,9 & 11,3 & 1,32 \\
\hline
\end{tabular}

On peut aussi noter que le nombre de porcelets nés vivants paraît un peu plus faible dans ce dernier lot que dans les deux autres. Compte tenu du nombre de mortnés à la parturition, voisin dans les 3 lots, ceci pourrait indiquer que la mortalité embryonnaire précoce, ou la résorption des ovules fécondés, a été un peu plus élevée dans le lot E N. Comme nous, KRUTyporokh (I957) HaInes (I959) et Waliace (I96I) ont trouvé qu'une augmentation de l'énergie de la ration pouvait conduire, par suite d'une mortalité élevée, à une production de portées moins nombreuses. Il s'agit là d'un phénomène de faible amplitude dans notre cas, qui pourrait aller de pair avec la lipogenèse plus active que nous avons signalée au début de la gestation. Une telle hypothèse a déjà été avancée par d'autres auteurs (MousTAGARD, I958; CARROLL, I952).

d) Lactation.

Comme on pourra en juger par le tableau $5 \mathrm{r}$, les productions laitières des truies. des différents lots ont été très voisines, avec une légère plus value, non significative, pour le lot le plus rationné pendant la gestation.

Ce phénomène trouve une explication dans la consommation alimentaire de 
ces animaux. Celle-ci est notablement plus faible dans le lot $\mathrm{E}$ N, ce qui paraît une contre partie du régime abondant de gestation, observation que nous avons déjà eu l'occasion de formuler. Le fait que ce lot ait eu malgré toute une production laitière voisine de celles des autres lots ne peut s'expliquer que par une mise à contribution plus importante des réserves de gestation. C'est également ce que confirme l'évolution des poids et de la composition corporelle au cours de la lactation. C'est le lot E N qui perd le plus de poids, après avoir effectué les gains les plus importants pendant la gestation Nous trouvons là une nouvelle preuve des relations nutritionnelles qui s'établissent entre la gestation et la lactation.

TABLEAU 5I

Production laitière

\begin{tabular}{|c|c|c|c|c|c|}
\hline \multirow[b]{2}{*}{ Lots } & \multicolumn{2}{|c|}{ Croissance des porcelets } & \multirow{2}{*}{$\begin{array}{l}\text { Quantité de } \\
\text { lait produite } \\
\text { (kg) }\end{array}$} & \multicolumn{2}{|c|}{ Consommation alimentaire } \\
\hline & $\begin{array}{c}\text { Poids moyen } \\
\text { à } 21 \text { jours } \\
(\mathrm{kg})\end{array}$ & $\begin{array}{l}\text { Poids moven } \\
\text { à } 56 \text { jours } \\
(\mathrm{kg})\end{array}$ & & $\begin{array}{c}\text { Truies } \\
(\mathrm{kg})\end{array}$ & $\begin{array}{c}\text { Porcelets } \\
\text { (kg par } \\
\text { porcelet) }\end{array}$ \\
\hline$e N$ & 5,5 & 16,6 & 348 & 370 & 11,0 \\
\hline $\mathrm{EN}$ & 5,3 & 15,9 & 320 & $286^{*}$ & 8,3 \\
\hline$e n$ & 5,4 & 17,5 & 357 & 368 & 8,6 \\
\hline
\end{tabular}

$\left(^{*}\right)$ Différence significative.

e) Conclusions.

Elles peuvent se résumer comme suit:

$I^{0}$ Par rapport au régime le plus faible en azote et en énergie, une élévation du taux d'azote seul augmente faiblement la rétention azotée de gestation et limite parallèlement la formation du tissı gras. Par contre, une augmentation simultanée de la quantité d'azote et d'énergie augmente à la fois la protéinogenèse et la lipogénèse maternelle.

$2^{\circ}$ Le niveau énergétique de la ration, plus que le niveau azoté, conditionne la rétention d'azote et se comporte en facteur limitant de l'anabolisme gravidique.

$3^{\circ}$ Dans nos conditions, ce phénomène se manifeste surtout en fin de gestation.

$4^{\circ}$ Le poids et le nombre des porcelets à la parturition sont peu affectés par les variations de l'apport azoté ou énergétique du régime. Il semble toutefois qu'un taux énergétique élevé puisse être responsable d'une légère augmentation de la mortalité embryonnaire précoce.

$5^{\circ}$ Il n'y a pas d'effet important sur la lactation, mise à part une diminution de l'appétit du lot recevant le plus d'énergie pendant la gestation. Cette réduction s'accompagne d'une mise à contribution plus importante des tissus de réserve édifiés pendant la gestation. 


\section{B - Apport quantitatif d'azote au cours de la lactation}

\section{Io Augmentation du niveau azoté}

WORK et al. (I942) avaient montré qu'en augmentant le taux azoté de la ration de Io à I4 p. IOO au cours de la lactation, on provoquait une amélioration de la production laitière de la Truie et de la croissance des porcelets. Nous avons voulu voir s'il en était encore ainsi lorsque le niveau de référence était déjà élevé (I5 p. Ioo) et quelle était, dans ce cas, l'influence d'un supplément azoté sur la composition du lait et plus spécialement sur la répartition des constituants azotés.

Une expérience portant sur deux lots de 6 truies d'un poids moyen de $2 \mathrm{I} 2 \mathrm{~kg}$ a été entreprise à cet effet. Ces truies recevaient pendant la gestation $2,5 \mathrm{~kg}$ par jour d'un aliment à I4 p. Ioo de protides et pendant la lactation, suivant les cas, $5 \mathrm{~kg}$ par jour d'un aliment de type normal à I 5 p. Ioo de protides $\left({ }^{1}\right)$, permettant la couverture théorique de tous les besoins (lot $\mathrm{B}$ ), ou $5 \mathrm{~kg}$ d'un aliment de même type mais enrichi à I9 p. IoO de protides (lot $\mathrm{H}$ ).

Suivant les lots et compte tenu de leur consommation réelle, les truies recevaient donc au cours de la lactation $700 \mathrm{~g}$ de matières azotées par jour dans le lot normal (B) et $893 \mathrm{~g}$, soit environ $30 \mathrm{p}$. Ioo de plus, dans le lot hyperprotidique (H). Par contre les ingérés énergétiques étaient identiques.

Pendant la lactation, on effectuait les mesures habituelles de production laitière, composition du lait, croissance des porcelets, perte de poids des truies, mais ces mesures étaient complétées par le dosage des principales fractions azotées du lait suivant les techniques que nous avons décrites.

\section{a) Production laitière.}

Le tableau 52 rapporte les principaux résultats obtenus pour les truies de chaque lot.

\section{TABLEAU 52}

Effet du niveau azoté sur la lactation

\begin{tabular}{|c|c|c|}
\hline & Lot B & Lot $\mathrm{H}$ \\
\hline $\begin{array}{l}\text { Quantité de lait produite }(\mathrm{kg}) \ldots \ldots \ldots \ldots \ldots \ldots \\
\text { Composition du lait : }\end{array}$ & 301 & 313 \\
\hline 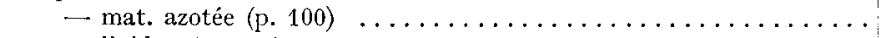 & 6,33 & 6,62 \\
\hline 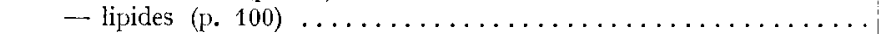 & 6,12 & 5,32 \\
\hline 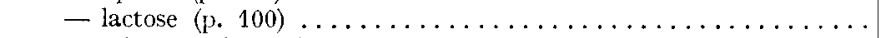 & 5,57 & 5,73 \\
\hline 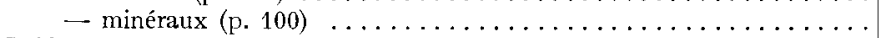 & 0,93 & 0,95 \\
\hline Poids moyen des porcelets à 1 mois $(\mathrm{kg}) \ldots$ & 5,1 & 5,0 \\
\hline Poids moyen des porcelets au sevrage (kg) & 16,2 & 16,7 \\
\hline Perte de poids des truies $(\mathrm{kg}) \ldots \ldots \ldots \ldots \ldots \ldots \ldots$ & 16,8 & 17,8 \\
\hline
\end{tabular}

(1) Orge : 74 ; farine de luzerne : ro ; tourteau de soja : 5 ; farine de poisson : 3 ; levure : 3 ; huile d'arachide : 2 ; mélange minéral : 3 . 
La distribution du régime enrichi en azote semble avoir eu peu d'effet; ni les productions laitières, ni les variations de poids n'ont été modifiées et la richesse azotée du lait n'a été augmentée que de 4 p. Ioo (non significatif), alors que le supplément alimentaire était de $30 \mathrm{p}$. Ioo par rapport au régime normal. Rien de surprenant a priori à ce résultat, le régime normal apportant suffisamment d'azote pour couvrir les besoins de la lactation, une amélioration paraissait donc peu probable, Notre observation confirme celle de STEVENSON (I957), mais concorde aussi avec les résultats obtenus en d'autres circonstances, ou sur d'autres espèces, tels que les travaux de Bowland (I949) et SHEFFy (I952) également sur la Truie, de KarmarKAR (I959) et DEB et al. (I962) sur la Femme, de PERRIN (I958) sur la Brebis et les nombreuses investigations poursuivies sur la Vache (PERKINS, I930 ; BREIREM, I949; StEIN, I957 ; WoODMAN, I957; ROOK, I959 et KIRMEIER, I960). La conclusion générale est qu'il n'y a pas de variation importante de la quantité d'azote sécrétée dans le lait à la suite d'une modification du niveau azoté de la ration.

Dans notre expérience, on peut noter, par contre, une certaine diminution, assez inattendue, de la teneur en lipides du lait sous l'effet du régime le plus azoté. Ce dernier résultat qui rejoint une observation de WiTr (I954) sur la Vache, mériterait d'être confirmé, car il pourrait indiquer qu'un excès d'azote dans la ration réduit d'autant les matériaux énergétiques utilisables aux fins de la lipogenèse du lait.

\section{b) Constituants azotés.}

Le tableau 53 rapporte les teneurs moyennes, pour l'ensemble de la lactation, des principales fractions exprimées en milligrammes d'azote et en p. Ioo de l'azote total, dans le lait de chacun des lots de truies.

TABLEAU 53

Influence de l'apport azoté du régime sur la teneur des différentes fractions azotées du lait de Truie

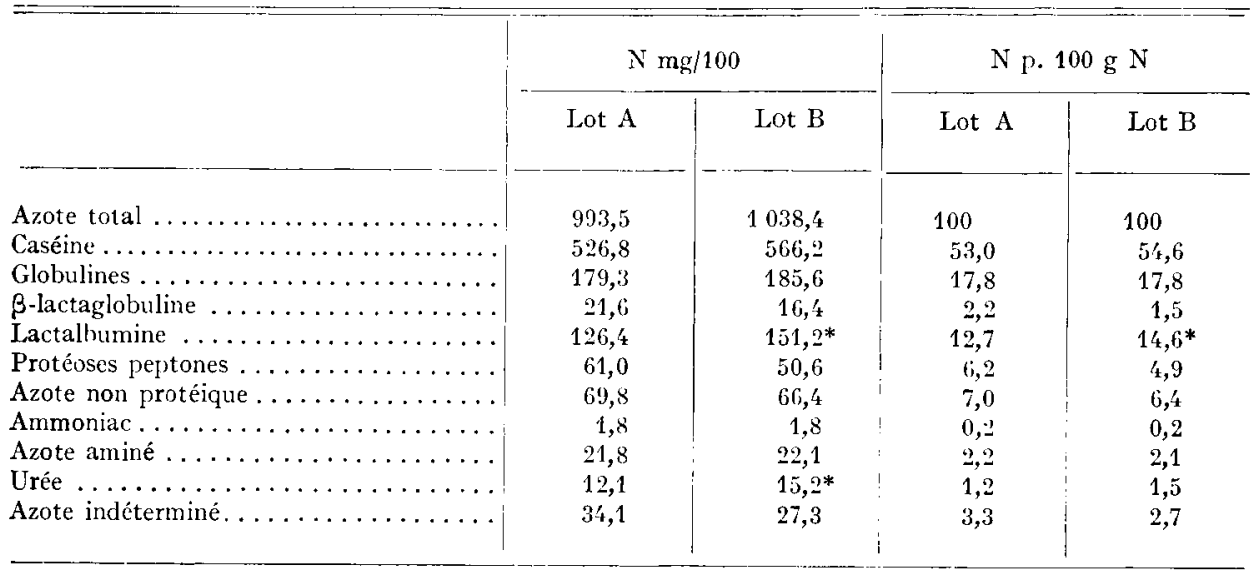

* Différence significative entre les deux lots. 
Compte tenu du faible nombre d'animaux de chaque lot, les différences observées ne sont en général pas significatives, sauf pour la lactalbumine et l'urée.

Il est assez fréquent que certains auteurs signalent une modification de teneur de l'un ou l'autre des constituants azotés sous l'effet du régime. Pour Bowland (I649), Rook (I959) et KARMAKAR (I959) les modifications portent surtout sur les protéines vraies et notamment sur la caséine; pour DEB (I962), PERKIns (I930) et STEIN (I957), seul l'azote non protéique s'élève lorsque la teneur en azote du régime croît. Dans notre expérience, deux fractions ont été augmentées d'une façon significative par le régime hyper azoté : la lactalbumine et l'urée, deux autres ont montré une légère tendance à l'augmentation: la caséine et la globuline, les autres ont été diminuées.

Ces divergences de résultats peuvent, peut-être, s'expliquer en fonction des niveaux alimentaires utilisés: lorsque le niveau de référence est bas, une amélioration du régime peut stimuler la sécrétion laitière et donc favoriser la production d'une plus grande quantité de protéines spécifiques, c'est-à-dire essentiellement de la caséine et des globulines. Lorsque le niveau est élevé, le supplément azoté n'a pas d'effet sur la synthèse de la caséine, mais il peut en exercer une sur la protéinémie du sang et donc sur les teneurs en albumine et en urée du lait dans la mesure où celles-ci proviennent directement du sang. Dans notre cas, le niveau alimentaire de référence était haut et c'est essentiellement ces fractions qui ont été affectées.

\section{$2^{\circ}$ Bilans azotés - Relations avec la gestation}

Le métabolisme azoté des truies en lactation a été étudié par la technique des régimes croisés précédemment décrite. A cette fin, des mesures de bilan ont été effectuées sur les truies déjà suivies au cours de la gestation et qui avaient été soumises à différents niveaux d'alimentation azotée pendant cette période. Les mêmes aliments étaient utilisés au cours de la lactation, mais dans des conditions différentes: les truies recevaient alors une ration uniforme de $5 \mathrm{~kg}$ par jour de l'aliment $\mathrm{H}$ ( 16 p. roo de protides), ou de l'aliment B ( I I p. Ioo de protides). On réalisait de la sorte deux niveaux d'alimentation azotée, $\mathrm{H}$ ou $\mathrm{B}$, qui étaient appliqués chacun à 2 truies selon le dispositif suivant:

B H : Bas niveau gestation - Haut niveau lactation

H B : Haut niveau gestation - Bas niveau lactation

is B : Bas niveau gestation - Haut niveau lactation

Ce dispositif, qu'avaient également utilisé LENKEIT et coll. (I956) était destiné à nous procurer des informations à la fois sur la lactation et sur les relations possibles entre les métabolismes azotés de gestation et de lactation.

Les mesures effectuées étaient les mêmes que pour la gestation, mais comportaient en outre la détermination de la production laitière et de la teneur en azote du lait produit par chaque truie. Par analogie, nous avons appelé, dans nos calculs, azote retenu, la différence entre l'azote absorbé et l'azote urinaire (soit la somme algébrique de l'azote du lait et de l'azote retenu ou perdu par l'organisme) et coefficient de rétention, le rapport de cette valeur à l'azote absorbé. Les résultats pour l'ensemble de la période de lactation ( 56 jours) sont rapportés dans le tableau 54. 
Compte tenu du nombre très limité d'animaux ( 2 par lot), il ne convient pas de prêter une signification trop grande à certains de ces résultats. On peut cependant en souligner les faits essentiels:

Tout d'abord, comme pour la gestation et malgré des différences importantes dans les ingérés, l'azote fécal varie peu en valeur absolue suivant les régimes. Il en résulte que la digestibilité de l'azote est plus élevée pour les truies soumises au niveau $\mathrm{H}$ et de valeur comparable à celle que l'on observait pendant la gestation dans les mêmes conditions. A conditions alimentaires égales, la digestibilité ne varie donc pas avec le stade physiologique, résultat qui rejoint les conclusions de Zivkovic et BOWLAND (I963).

\section{TABLEAU 54}

Bilans azotés de lactation

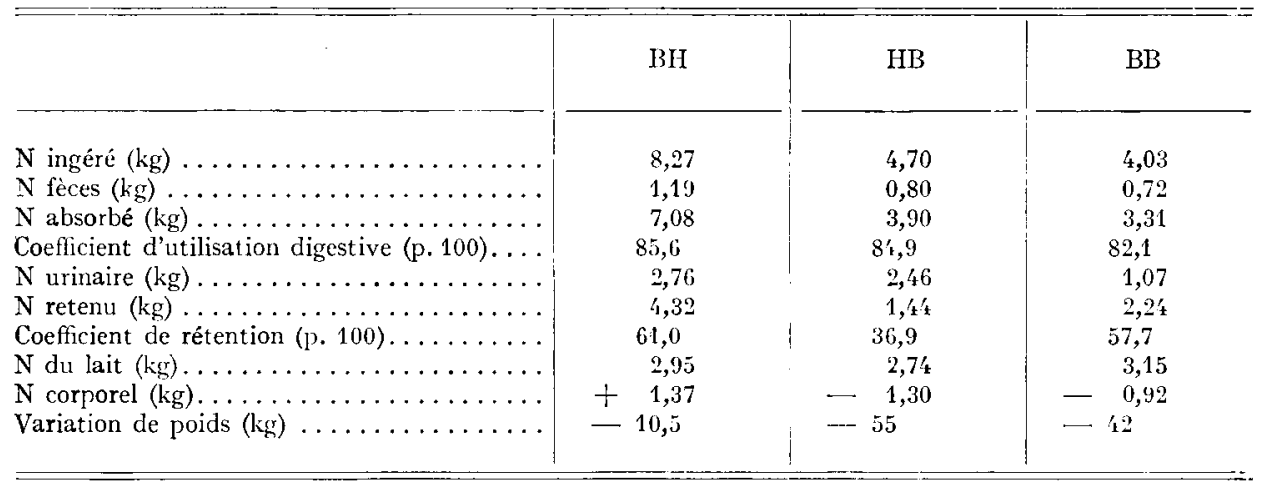

L'azote urinaire offre plus d'intérêt à considérer : en premier lieu, à niveau alimentaire égal, sa valeur est plus faible pendant la lactation que pendant la gestation. En moyenne, 1'excrétion d'azote urinaire est réduite de $30 \mathrm{p}$. Ioo pour les truies au régime $B$ et de $40 \mathrm{p}$. Ioo pour les truies du régime $H$. Il en résulte que 1'azote retenu ainsi que la valeur des coefficients de rétention sont plus élevés au cours de la lactation que de la gestation. Ce résultat remarquable, tout à fait identique à celui qu'observe Rombauts (I96I) chez la Brebis, souligne l'extraordinaire aptitude de la Truie en reproduction à utiliser l'azote de sa ration (HENNIG, I959, I960) et montre que l'effet d'épargne azotée que nous avions observé au cours de la gestation se trouve encore accru par la lactation.

Par ailleurs, l'interprétation des différences d'excrétion urinaire suivant les différents niveaux alimentaires de lactation ne peut se faire qu'en fonction des régimes de gestation : la comparaison des résultats des truies B-H et B-B fait ressortir une excrétion urinaire plus importante $\left(I_{5}^{8} \mathrm{p}\right.$. IOo) chez les premières, ce qui permet de dire que, pour un même régime hypoazoté de gestation, les pertes urinaires sont plus élevées lorsque le régime de lactation est riche en azote, résultat qui paraît logique et conforme à nos observations sur la gestation. Il en va autrement lorsque le régime de gestation n'est pas le même : c'est ainsi que les truies H-B éliminent plus d'azote que les truies B-B et presque autant que les truies B-H. Ce résultat apparaissait déjà dans le travail de LENKEIT et al. (I956) et il confirme nos observations sur le niveau global d'alimentation. Il concrétise un nouvel aspect des relations nutri- 
tionnelles entre la gestation et la lactation : l'utilisation de l'azote est moins bonne au cours de la lactation lorsqu'un bas niveau d'alimentation azotée succède à un haut niveau. Doit-on voir dans ce phénomène, comme le suggère LENkEIT, la preuve d'un catabolisme accru, faisant suite à un anabolisme de gestation élevé? Rien ne permet de le certifier, car les pertes de poids et d'azote corporel paraissent du même ordre pour les truies $\mathrm{H}-\mathrm{B}$ et $\mathrm{B}-\mathrm{B}$. S'il en était ainsi toutefois, il est vraisemblable que cette mobilisation des protéines corporelles se ferait davantage à des fins énergétiques que pour la protéinogenèse du lait, puisque cette dernière ne paraît pas améliorée, alors que l'excrétion d'azote urinaire est augmentée.

Quels que soient les régimes de lactation, il n'est pas inutile de souligner, par ailleurs, que la quantité d'azote sécrétée dans le lait varie peu, ce que nous avions déjà constaté dans l'expérience précédente. Ce résultat permet de faire un nouveau parallèle avec les phénomènes de la gestation: dans l'un et l'autre cas, la fonction de reproduction (contenu utérin ou production laitière) est peu sensible aux variations du régime contrairement aux processus somatiques qui intéressent les variations corporelles.

On retiendra, enfin, sur le plan quantitatif, qu'un régime à i 6 p. Ioo de protides (H) suffit amplement à couvrir les besoins de la Truie en lactation, puisqu'il permet même des rétentions corporelles non négligeables, résultat qu'avaient déjà obtenu LENKEIT (I956) et LODGE (I959) dans des conditions similaires.

\section{$3^{\circ}$ Relations Énergie/Protéine}

Celles-ci sont évoquées au cours du chapitre suivant. Pour ne pas faire double emploi nous n'en parlerons pas ici.

\section{C - Apport qualitatif d'azote au cours de la gestation et de la lactation}

Notre propos n'est pas d'étudier en détail le besoin qualitatif d'azote chez la Truie en reproduction, ce qui nous entraînerait trop loin. Nous avons seulement voulu voir si les facteurs d'épargne quantitative que nous avons constatés au cours de la gestation ou de la lactation se manifestaient également sur le plan qualitatif. Autrement dit, la Truie est-elle capable de tirer parti de protéines habituellement considérées comme déséquilibrées, out, ce qui revient au même, 1a valeur nutritionnelle de telles protéines est-elle la même chez la Truie gestante ou en lactation, que chez l'animal en croissance ou au repos.

Dans le but de préciser ce point, nous avons testé chez les truies en reproduction deux protéines connues pour la différence de leur valeur biologique chez le Rat et chez le Porc en croissance : le tourteau d'arachide et la farine de poisson. Il est donc classique d'opposer la haute valeur biologique des protéines de poisson à la médiocre efficacité de celles d'arachide. Nous verrons toutefois que cette distinction, valable pour l'animal en croissance, s'estompe au point de disparaître lorsqu'il s'agit d'un strjet à l'entretien.

Parmi de nombreuses études, en effet, on peut retenir celles de Jones et al. (I962), Combs (I962) et RÉRAT (I963) qui toutes ont montré que l'arachide provoquait des vitesses de croissance et des rendements alimentaires très inférieurs à ceux du poisson chez des pores de différents âges pesant de 3 à $60 \mathrm{~kg}$. 
Ces mêmes protéines ont été utilisées dans notre expérience comme principales sources azotées de régimes bien équilibrés par ailleurs. Leurs valeurs respectives ont été étudiées sur des truies au cours de deux cycles de reproduction successifs, gestation et lactation.

Comme précédemment, l'emploi de la technique des régimes croisés devait nous permettre d'examiner sur ce point les relations éventuelles entre la gestation et la lactation.

Quarante-six truies primipares ont été utilisées dans cette expérience. Ces truies étaient élevées d'une façon identique et recevaient une même ration équilibrée jusqu'à l'accouplement qui était pratiqué au deuxième oestrus après la puberté (poids moyen des animaux: $135 \mathrm{~kg}$ ).

Les animaux étaient alors répartis en 3 lots expérimentaux de I 2 truies recevant l'un ou l'autre de deux régimes isoazotés (I2 p. IOo) ne diffèrant que par la nature des protides (tourteau d'arachide ou farine de poisson) selon les 3 combinaisons suivantes :

Lot A-P : Arachide pendant la gestation - Poisson pendant la lactation.

Lot P-P : Poisson pendant la gestation et la lactation.

Lot P-A : Poisson pendant la gestation - Arachide pendant la lactation.

Deux lots témoins, de 5 truies non gestantes de même poids initial, étaient constitués et recevaient pendant la durée d'une gestation, soit I I 5 jours, le régime arachide ou le régime poisson. Sauf pour ces deux derniers lots, et après une période de repos de la durée d'un œstrus après le sevrage, l'expérience était répétée au cours d'un deuxième cycle de reproduction avec les mêmes animaux et les mêmes régimes. Toutefois, deux animaux par lot durent alors être éliminés pour raisons diverses (défauts de reproduction).

Les animaux étaient nourris individuellement et recevaient, quelle que soit leur affectation, des quantités journalières d'aliments constantes : $3 \mathrm{~kg}$ pendant la gestation et $4,5 \mathrm{~kg}$ pendant la lactation. Cette dernière ration, légèrement inférieure peut-être aux rations habituellement distribuées aux animaux de ce poids, correspondait au maximum d'ingestion consenti par les truies recevant l'aliment à l'arachide.

Les critères retenus étaient les variations de poids et d'adiposité aux différents stades physiologiques, les efficacités protidiques, les résultats de parturition et les productions laitières.

\section{a) Variations corporelles}

Le tableau 55 rapporte les variations de poids et de l'adiposité des truies au cours des différentes périodes de chacun des 2 cycles considérés.

Le résultat le plus remarquable concerne la différence de comportement entre les témoins et les gestantes ( $\mathrm{I}^{\mathrm{er}}$ cycle). Quel que soit le régime, les truies gestantes ont réalisé des gains de poids très supérieurs à celui des témoins, ce qui montre bien que l'efficacité d'une même protéine est plus grande pendant la gestation que pendant la période de repos sexuel.

La comparaison des deux protéines entre elles fait ressortir les points suivants: aucune différence en ce qui concerne les témoins et légère influence en faveur du 
poisson chez les gestantes. Cette différence tend à s'accuser au cours du deuxième cycle de reproduction (elle passe de 5 p. Ioo à I 2 p. Ioo du gain total) et elle est plus sensible pour le gain net maternel, ou anabolisme de gestation, que pour le gain total qui englobe les productions foetales.

TABLEAU 55

Variations corporelles

\begin{tabular}{|c|c|c|c|c|c|c|c|}
\hline & \multicolumn{4}{|c|}{ Variations de poids } & \multicolumn{3}{|c|}{ Variations d'adiposité } \\
\hline & $\begin{array}{l}\text { Gain total } \\
\text { gestation } \\
(\mathrm{kg})\end{array}$ & $\begin{array}{l}\text { Gain net } \\
\text { gestation } \\
(\mathrm{kg})\end{array}$ & $\begin{array}{c}\text { Perte } \\
\text { lactation } \\
(\mathrm{kg})\end{array}$ & $\underset{(\mathrm{kg})}{\text { Bilan }}$ & $\begin{array}{c}\text { Gain } \\
\text { gestation } \\
\text { (p. 100) }\end{array}$ & $\begin{array}{c}\text { Perte } \\
\text { lactation } \\
\text { (p. 100) }\end{array}$ & $\begin{array}{c}\text { Bilan } \\
\text { (p. 100) }\end{array}$ \\
\hline Témoin $\mathrm{P}$ & $48,2^{*}$ & & & & $25^{*}$ & - & - \\
\hline Témoin A & $50,8^{*}$ & & & & $23^{*}$ & - & - \\
\hline \multicolumn{8}{|l|}{ Ter $_{\text {eycle }}$} \\
\hline A-P & 74,9 & $55,9^{*}$ & 19,8 & 26,1 & $12^{*}$ & 14 & -2 \\
\hline P-P & 78,9 & 62,1 & 20,9 & 41,1 & 17 & 13 & +4 \\
\hline $\mathrm{P}-\mathrm{A}$ & 80,2 & 64,3 & $50,0^{*}$ & 14,3 & 17 & $20^{*}$ & -3 \\
\hline \multicolumn{8}{|l|}{$2 \mathrm{e}$ cycle } \\
\hline $\mathrm{A}-\mathrm{P}$ & 78,4 & $58,6^{*}$ & 23,8 & $3 \mathfrak{k}, 8$ & 13 & 14 & -1 \\
\hline P.P & 87,3 & 68,8 & 39,0 & 29,8 & 16 & 17 & -1 \\
\hline P-A & 90,9 & 72,0 & $70,5^{*}$ & 2,5 & 20 & $23^{*}$ & -3 \\
\hline
\end{tabular}

* Différence significative.

C'est surtout au cours de la lactation que l'écart devient important : la perte de poids est considérablement plus élevée chez les animaux ingérant de l'arachide pendant la lactation que chez ceux qui reçoivent du poisson, quel que soit le régime antérieur de ces derniers. La différence est de l'ordre de roo p. Ioo et paraît également plus élevée au cours du deuxième cycle que du premier.

En ce qui concerne l'adiposité, les différences entre lots sont peu importantes et peu significatives. On peut noter toutefois que le gain de tissu adipeux paraît plus important chez les témoins que chez les gestantes et, chez ces dernières, plus élevé avec le régime poisson. Pendant la lactation, au contraire, le régime arachide paraît augmenter la mobilisation des lipides.

\section{b) Efficacités protidiques}

Le tableau $5^{6}$ rapporte les valeurs que nous avons trouvées. Celles-ci doivent être interprétées avec prudence, car nous avons vu que les variations de poids au cours de la reproduction n'avaient pas la même signification : par ailleurs, dans le cas de la lactation, notre calcul ne tient pas compte de l'azote exporté dans le lait.

Ces valeurs soulignent tout d'abord la meilleure utilisation des protéines par les truies gestantes par rapport aux truies au repos et montrent, en outre, que les différences entre protéines varient suivant la période considérée : mêmes valeurs au 
repos, légère différence pendant la gestation et supériorité marquée des protéines de poisson pendant la lactation (pendant la lactation, les C.E.P. sont négatifs, car il s'agit de perte de poids, et d'autant plus élevés que la protéine est moins efficace).

\section{TABLEAU 56}

Coefficients d'efficacité protidique

\begin{tabular}{|c|c|c|c|}
\hline \multirow{2}{*}{ Lots } & \multicolumn{2}{|c|}{ Gestation } & \multirow{2}{*}{ Lactation } \\
\hline & gain total & gain net & \\
\hline Témoin P........ & 1,2 & & \\
\hline 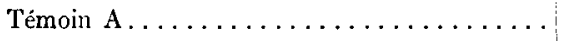 & 1,3 & & \\
\hline 1er cycle & & & \\
\hline 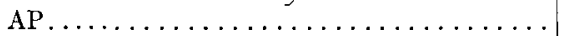 & 1,8 & 1,3 & $-0,9$ \\
\hline $\mathrm{PP} \ldots \ldots \ldots \ldots \ldots \ldots \ldots \ldots \ldots \ldots \ldots$ & 2,0 & 1,6 & $-0,8$ \\
\hline 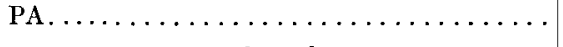 & 2,0 & 1,6 & $-2,1$ \\
\hline $2^{\mathrm{e}}$ cycle & & & \\
\hline AP $\ldots \ldots \ldots \ldots \ldots \ldots \ldots \ldots \ldots \ldots \ldots \ldots \ldots \ldots$ & 1,9 & 1,4 & $-0,9$ \\
\hline $\mathrm{PP} \ldots \ldots \ldots \ldots \ldots \ldots \ldots \ldots \ldots \ldots \ldots \ldots \ldots \ldots$ & 2,2 & 1,7 & $-1,5$ \\
\hline $\mathbf{P A}, \ldots \ldots \ldots \ldots \ldots \ldots \ldots \ldots \ldots \ldots \ldots \ldots \ldots \ldots$ & 2,2 & 1,8 & $-2,9$ \\
\hline
\end{tabular}

c) Parturition

Les principales caractéristiques des portées à la naissance sont rapportées au tableau 57 .

TABLEAU 57

Produits de conception

\begin{tabular}{|c|c|c|c|c|c|c|}
\hline \multirow{2}{*}{ Lots } & \multirow{2}{*}{$\begin{array}{l}\text { Portée } \\
\text { totale } \\
(\mathrm{kg})\end{array}$} & \multirow{2}{*}{$\begin{array}{c}\text { Placenta } \\
(\mathrm{kg})\end{array}$} & \multirow{2}{*}{$\begin{array}{l}\text { Pertes } \\
\text { liquides } \\
\text { (kg) }\end{array}$} & \multicolumn{3}{|c|}{ Porcelets } \\
\hline & & & & $\begin{array}{l}\text { Nombre } \\
\text { vivants }\end{array}$ & Mort-nés & $\begin{array}{l}\text { Poids moyen } \\
(\mathrm{kg})\end{array}$ \\
\hline $1^{\mathrm{er}}$ cycle & & & & & & \\
\hline$A-P \ldots \ldots \ldots \ldots$ & 10,9 & 2,8 & 5,9 & 9,5 & 1,0 & 1,20 \\
\hline P-P $\ldots \ldots \ldots \ldots \ldots$ & 10,0 & 2,3 & 4,5 & 9,5 & 1,0 & 1,05 \\
\hline P-A $\ldots \ldots \ldots \ldots \ldots$ & 9,9 & 2,2 & 2,8 & 9,2 & 0,8 & 1,03 \\
\hline $2^{\circ}$ cycle & & & & & & \\
\hline$A-P \ldots \ldots \ldots \ldots \ldots$ & 13,2 & 3,0 & 3,8 & 11,1 & 1,0 & 1,11 \\
\hline P-P $\ldots \ldots \ldots \ldots$ & 13,1 & 3,1 & 2,4 & 11,7 & 0,6 & 10,8 \\
\hline P-A........... & 12,6 & 3,0 & 2,4 & 11,3 & 1,0 & 1,02 \\
\hline
\end{tabular}

Mise à part l'augmentation générale du poids des productions au cours du $2^{\mathrm{e}}$ cycle, qui semble résulter d'une plus grande prolificité, on n'observe aucune différence significative entre les différents lots. 
En particulier, les porcelets du lot nourri à l'arachide pendant la gestation sont aussi nombreux, et même légèrement plus lourds, que ceux des lots nourris au poisson.

\section{d) Lactation}

Comme le montre le tableau 58 , on ne constate aucune différence dans la croissance des porcelets et dans la production laitière quantitative et qualitative des truies au cours du $I^{\text {er }}$ cycle de reproduction.

Il faut attendre le deuxième cycle pour voir apparaitre une légère diminution de la quantité de lait produite dans le lot recevant de l'arachide pendant la lactation.

TABLEAU 58

Productions laitières

\begin{tabular}{|c|c|c|c|c|c|c|}
\hline \multirow[b]{2}{*}{ Lots } & \multicolumn{2}{|c|}{ Croissance des porcelets } & \multirow[b]{2}{*}{$\begin{array}{l}\text { Nombre } \\
\text { de porcelets } \\
\text { sevrés }\end{array}$} & \multicolumn{3}{|c|}{ Production laitière } \\
\hline & $\begin{array}{l}\text { Poids moyen } \\
\text { à } 21 \mathrm{j} \cdot \\
(\mathrm{kg})\end{array}$ & $\mid \begin{array}{c}\text { Poids moyen } \\
\text { au sevrage } \\
(\mathrm{kg})\end{array}$ & & $\begin{array}{l}\text { Lait } \\
\text { (kg) }\end{array}$ & $\begin{array}{l}\text { Matière } \\
\text { azotée } \\
\text { (p. 100) }\end{array}$ & $\begin{array}{c}\text { Matière } \\
\text { grasse } \\
\text { (p. 100) }\end{array}$ \\
\hline $1^{\text {er }}$ cycle & & & & & & \\
\hline$A-P \ldots \ldots \ldots$ & 4,7 & 15,7 & 8,0 & 305 & 5,6 & 7,0 \\
\hline P-P . & 4,5 & 15,1 & 7,7 & 287 & 5,6 & 6,0 \\
\hline P-A & 4,7 & 15,4 & 7,7 & 295 & 5,5 & 6,8 \\
\hline $2^{e}$ cycle & & & & & & \\
\hline A.P $\ldots \ldots \ldots$ & 4,8 & 17,5 & 9,0 & 341 & - & - \\
\hline P-P . & 5,3 & 18,8 & 8,8 & 359 & - & - \\
\hline P-A . & 4,6 & 17,7 & 8,2 & 315 & & \\
\hline
\end{tabular}

e) Discussion et conclusions

Comme dans nos expériences précédentes, la principale influence d'une modification qualitative du régime alimentaire de gestation, ou de lactation, réside dans les variations, gains ou pertes, de poids corporel des mères.

Io Pendant la gestation le seul effet des protéines de poisson par rapport à celles de l'arachide est une très légère augmentation de l'anabolisme gravidique maternel, à la fois azoté et lipidique, alors que les produits de la conception, et notamment le poids des foetus, ne sont absolument pas modifiés. Des constatations analogues avaient déjà été faites par FowL.ER (I954) et par GARD et al. (I955). Ce dernier notamment avait montré que chez la Truie l'addition de $3 \mathrm{p}$. roo de fish soluble à un régime ne comportant que des protéines d'origine végétale n'améliorait en aucune façon le nombre et le poids des embryons.

Chez les autres espèces, Kiosterman et al. (I95I) arrivent à une conclusion semblable avec la Brebis, mais il faut surtout citer ChAMpigny et JAcouot(I96I) qui ont trouvé, chez la Ratte gravide, que le principal effet d'une limitation quantitative et qualitative de l'ingéré azoté sous forme de gluten, en comparaison avec de la caséine résidait dans la perte de poids relative des mères, alors que les produits de la conception conservaient un développement parfaitement normal. 
Quelle que soit l'espèce, il apparaît en définitive que la différence d'efficacité, pour le maintien de la gestation, de deux protéines d'origine et de valeur très différentes, comme l'arachide et le poisson, est peu importante puisqu'elle n'est ressentie faiblement qu'au niveau de l'anabolisme maternel.

$2^{\circ}$ Il en va tout autrement au cours de la lactation. Si en effet, au cours du premier cycle de reproduction, il n'apparait aucune différence dans les productions laitières des truies recevant les différents régimes, ce résultat n'a pu être acquis qu'au prix d'une mobilisation beaucoup plus élevée des tissus corporels chez les truies nourries à l'arachide. Ce résultat reflète donc bien une nette différence de valeur biologique pour la production laitière entre les protéines utilisées, mais celle-ci a été en partie masquée par le rôle de tampon que jouent les réserves tissulaires. Ceci met l'accent sur la participation, habituelle ou non, de l'azote corporel à la synthèse des protéines du lait et de l'état dynamique, inmédiatement disponible, des réserves azotées édifiées au cours de la gestation.

Cette mobilisation des tissus, pour pallier l'insuffisance qualitative du régime azoté s'accompagne, chez la 'Truie, d'une certaine fonte lipidique (c'est-à-dire d'une utilisation majorée des lipides) plus élevée dans le cas d'un protide de mauvaise qualité. Ceci confirme la liaison qui existe entre les métabolismes azoté et énergétique. Il faut remarquer toutefois qu'en valeur relative, rapportée à la perte de poids totale, les truies ont perdu deux fois moins de tissu adipeux avec le régime à l'a rachide qu'avec le poisson. Ceci indique donc que la relation est complexe.

Au cours du deuxiène cycle de reproduction, les phénomènes sont encore accentués et l'on note, à côté de la perte de poids plus élevée des animaux du lot P-A, une certaine diminution de la production laitière. Peut-être faut-il voir ici la conséquence d'effets cumulatifs avec le temps? Plus simplement, on peut imaginer que les animaux plus lourds qu'au premier cycle, mais recevant la même ration, ont eu des déficits plus. importants dus à une augmentation $d u$ besoin d'entretien.

Quelles que soient les circonstances, on constate donc chez la Truie en lactation que des protéines de valeurs diverses peuvent avoir des effets différents. Ceci confirme les observations faites par MUELLER et COX (I937) sur la Ratte et par WERNER et HENNIG (I960) sur la 'Truie et rejoint également les opinions émises par différents auteurs quant à la valeur biologique des protéines au cours de la lactation (MAYNARD, I962 ; BREIREM, I957).

On ne peut manquer de souligner ici les différences qui apparaissent en fonction de l'état physiologique. C'est ainsi que, dans notre expérience, le choix des protéines, qui n'a eu aucune influence lorsqu'il s'agissait d'animaux en fin de croissance ou à l'entretien, a marqué très faiblement les résultats de la gestation et d'une façon beaucoup plus nette ceux de la lactation. Cette constatation, qui reflète la variabilité des valeurs biologiques, montre également les limites de cette notion. Elle permet d'établir une certaine hiérarchie des besoins qualitatifs suivant les fonctions considérées. Pour la Truie en reproduction, les besoins qualitatifs d'azote auraient un caractère plus strict pour la lactation que pour la gestation et à plus forte raison que pour l'entretien.

$3^{\circ} \mathrm{En}$ ce qui concerne les interactions gestation-lactation, on constate que l'emploi d'une mauvaise protéine au cours de la gestation n'a entraîné aucun effet néfaste apparent sur les résultats de la lactation ou sur la croissance des porcelets. Inversement, l'emploi d'une bonne protéine au cours de la gestation ne protège pas. 
la Truie de l'effet d'une protéine de mauvaise qualité au cours de la lactation. I1 ne semble donc pas que, chez la Truie en reproduction, l'effet de la qualité des protides alimentaires puisse se prolonger au-delà de la période de distribution considérée, résultat qui a été parfois contesté.

\section{I) - Discussion générale}

On ne peut manquer d'être impressionné par le fait que, dans tous nos résultats, les principales différences observées en rapport avec le régime ont trait aux variations de poids.

Dans les limites de ces expériences, tout semble se passer comme si l'accumulation ou la mobilisation des tissus de réserve, dont nous avons déjà souligné la grande plasticité chez la 'Truie, se fait dans la limite des disponibilités laissées par les deux fonctions prioritaires que sont, chez la femelle en reproduction, la croissance des embryons et la production laitière.

Cette hypothèse permet de comprendre, comme l'avait déjà souligné PIKE(I954) chez la Ratte, que toute amélioration du régime alimentaire se traduit d'abord par une augmentation de l'anabolisme de gestation et une diminution du catabolisme de lactation. C'est dans cette optique que nos résultats s'inscrivent dans l'étude du besoin quantitatif et qualitatif d'azote en fonction de l'état physiologique de l'animal.

En ce qui concerne l'aspect quantitatif, on constate tout d'abord que le besoin azoté de l'utérus gravide est relativement modique puisqu'il est pleinement satisfait par une ration contenant moins de I 2 p. Ioo de protides totaux et que celle-ci permet à la mère des gains presque plus importants que celui des témoins. Il y a là une nouvelle démonstration de l'effet d'épargne provoqué par la gestation et qui peut trouver une explication éventuelle au niveau des modifications des équilibres hormonaux de gestation évoquées par Bourdel, (I960) et par Rombauts (I962).

Il en va de même pour la lactation. Certes le besoin azoté est plus élevé, mais contrairement à une opinion classique (LENkEIT, I956) il peut être parfaitement couvert par une ration contenant moins de $16 \mathrm{p}$. Ioo de protides qui permet même un bilan légèrement positif. Si l'apport est moins important, la production laitière n'est pas réduite pour autant, mais la Truie emprunte davantage à ses protéines corporelles.

Tant en ce qui concerne la gestation que la lactation, le principal effet d'un supplément azoté dans la ration au-delà de ces taux est d'accroître les rétentions corporelles, ou le cas échéant de réduire les pertes pendant la lactation. Si l'on en juge par les résultats de certains bilans, ces phénomènes peuvent parfois s'accomplir sans qu'il y ait de variations de poids notables, ce qui sous-entend l'existence de remaniements de différentes masses de l'organisme et de modifications de la composition corporelle.

L'importance et la nature du gain de poids de gestation semblent dépendre en effet essentiellement du contenu énergétique de la ration puisque celles-ci ne sont modifiées de façon importante que lorsqu'un taux énergétique élevé est associé à un niveau azoté élevé. Comme chez l'animal en croissance, un supplément d'azote exige un ajustement énergétique convenable pour améliorer l'efficacité de la ration. Il en va de même au cours de la lactation. 
Quant à I'influence plus directe de l'apport azoté de la ration sur la production laitière, on peut mentionner une légère action sur la composition du lait. Contrairement, semble-t-il, à ce que l'on observe dans d'autres espèces, un niveau azoté élevé accroît légèrement la richesse en azote du lait, modification qui porte essentiellement sur les protéines non spécifiques du lait (albumine) ou les éléments non protéiques (urée, ammoniac). Toutefois, la quantité totale d'azote de la production n'est généralement pas modifiée pour autant, car l'on observe parfois une diminution parallèle du volume de la sécrétion. Une certaine diminution de la teneur du lait en lipides peut aussi survenir ce qui met en relief un autre aspect des relations entre protéines et énergie au cours de la lactation.

En ce qui concerne l'aspect qualitatif, les besoins relatifs de gestation et delactation se manifestent un peu différemment. La qualité des protéines utilisées n'a qu'une influence négligeable sur le développement des produits de la conception. Les besoins prioritaires de l'utérus gravide sont toujours satisfaits grâce au rôle de supplémentation que peuvent jouer à l'égard du foetus les protéines maternelles en présence d'un aliment azoté de valeur insuffisante C'est peut être la raison pour laquelle au cours de la gravidité l'anabolisme des tissus extra-utérins paraît le seul à être affecté par la valeur biologique des protéines. Ce résultat est en parfait accord avec les conlusions de CHAMpigNy chez la Ratte.

Au cours de la lactation, la qualité de l'azote de la ration se manifeste de façon plus sensible, mais son effet s'exerce aussi davantage sur la mobilisation des protéines corporelles que sur la quantité de lait sécrétée. Il faut en effet 1'usage prolongé sur une longue période ( 2 cycles complets de reproduction) d'un protide de mauvaise valeur biologique pour voir apparaître les premiers signes d'une baisse de production laitière. Dans tous les cas, 1'importance du besoin qualitatif d'azote est donc liée à ce qu'on pourrait appeler le besoin somatique de l'animal et qui met en jeu l'édification de tissu musculaire au cours de la gestation, ou son catabolisme au cours de la lactation.

Sil'on considère maintenant les relations entre la gestation et la lactation, on constate que l'influence de l'apport azoté qualitatif ou quantitatif au cours de la gestation se traduit essentiellement par la mise à la disposition de la truie laitière d'une plus ou moins grande masse de tissu protéique, dont le catabolisme ne revêt en aucun cas un caractère obligatoire ou indispensable (sauf peut-être en ce qui concerne l'involution de l'utérus au cours de la première semaine de lactation). L'ampleur de la mobilisation dépend avant tout de la façon dont sont couverts les besoins de lactation, notamment le besoin énergétique et le besoin qualitatif pour les protéines du lait et, dans une faible mesure, de l'importance des réserves édifiées pendant la gestation. I1 existe par ailleurs une certaine disproportion entre les besoins qualitatif et quantitatif d'azote de la 'Truie en gestation et en lactation, qui incite à se préoccuper davantage de la valeur de l'apport au cours de la lactation, bien que ce dernier puisse être effectué dans des conditions très avantageuses d'utilisation. De son côté, compte tenu de la modicité relative du besoin de l'utérus gravide et des facultés anabolisantes très élevées de la gestante, 1'apport azoté de gestation doit pouvoir, sans préjudice pour l'animal, être réduit à niveau assez voisin de celui de l'entretien. L'accent doit être mis par contre sur la nécessité de réaliser un apport énergétique adapté à chaque état physiologique. 


\section{CHAPITRE V}

\section{RELATIONS ENTRE LES LIPIDES DU RÉGIME, LA GESTATION ET LA LACTATION}

Plutôt que d'examiner l'ensemble des relations énergétiques qui concernent la gestation et la lactation, nous avons préféré nous limiter dans ce chapitre à quelques aspects de relations strictement lipidiques.

Les variations de l'adiposité corporelle jouent un grand rôle chez la Truie en gestation et en lactation. Il en va de même de la teneur du lait en lipides. Celle-ci est très élevée et contribue à elle seule à assurer plus de la moitié du contenu énergétique de cette sécrétion.

Par ailleurs, les graisses alimentaires constituent une forme commode d'enrichissement énergétique des rations, mais leur utilisation peut poser quelques problèmes qui leur sont propres (digestibilité, métabolisme intermédiaire).

Aussi, est-ce cet aspect particulier des relations entre le tissu adipeux, les lipides du lait et les graisses alimentaires que nous avons voulu examiner ici. Plus exactement, les expériences que nous rapportons maintenant ont eu pour objet l'étude de la participation relative des graisses de la ration et des lipides de dépôt à l'élaboration des lipides du lait.

Au cours d'un chapitre précédent, nous avions indiqué qu'une augmentation de niveau alimentaire au cours de la gestation avait pour effet un accroissement des dépôts adipeux, mais que ces derniers étaient mobilisés en plus grande quantité au cours de la lactation et que parallèlement on observait une modification de la teneur en matière grasse du lait. Ce résultat laissait présumer du rôle des lipides corporels en tant que précurseurs de ceux du lait. Il était intéressant de voir si une participation analogue ne pouvait être invoquée pour les lipides alimentaires distribués au cours de la lactation, auquel cas une comparaison et une étude des relations entre les deux phénomènes paraîtrait s'imposer.

Notre expérimentation a été conduite dans ce sens, en examinant d'abord l'influence de l'ingestion de lipides sur la production laitière et ensuite en effectuant une étude plus détaillée des origines exogènes ou endogènes de différents types d'acides gras du lait.

\section{A - Influence de l'introduction de lipides dans la ration de la truie en lactation}

Si le rôle des lipides de la ration sur la sécrétion du lait a été souvent examiné chez certaines espèces, comme la Vache laitière, on dispose de peu d'études de ce genre chez la 'Truie. Seuls WILETT (I946) et Norman (I955) ont montré que l'adjonc-

Annales de Zootechnie. - I965. 
tion de différentes graisses animales au régime pouvait provoquer des modifications importantes (de l'ordre de 20 p. Ioo) du taux de lipides du lait de Truie, ce qui contraste singulièrement avec les résultats beaucoup plus modestes que 1'on observe généralement chez les Ruminants (SHORLAND, I956 ; DEUEL, I957 ; JARRIGE, I958 ; GAR'TON, I963). Différentes explications peuvent convenir à ce phénomène, soit que 1'apport de lipides permette de combler une simple insuffisance énergétique (ce qui ressort de la plupart de nos expériences), soit que ces lipides provoquent une modification du rapport énergie/azote de la ration dans un sens qui favorise la lipogenèse, soit enfin que les lipides exercent, chez la Truie, une action spécifique sur la sécrétion des constituants lipidiques du lait.

Pour essayer de choisir entre ces différentes hypothèses, nous avons entrepris une expérience portant sur 40 truies en lactation destinée à examiner l'influence d'un régime fortement enrichi en graisse. Nous avons utilisé à cet effet du saindoux, graisse la plus physiologique chez le Porc, dans l'espoir de placer les animaux dans des conditions analogues à celles de l'utilisation de leurs propres dépôts adipeux.

Quatre régimes ont été utilisés, correspondant chacun à un lot expérimental :

Lot $\mathrm{T}$ : Régime de base sans graisse

Lot $\mathrm{S}$ : Régime de base $+\mathrm{I}_{7} \mathrm{p}$. roo saindoux (ce régime était isoazoté au précédent, mais apportait 20 p. Ioo de calories supplémentaires).

Lot SP : Régime de base + I7 p. Ioo saindoux +3 p. Ioo farine de poisson (ce régime apportait $20 \mathrm{p}$. Ioo de calories et $20 \mathrm{p}$. Ioo de protides, de plus mais avec le même rapport $\mathrm{N}$ /calories que le régime $\mathrm{T}$ ),

Lot $s p$ : Même régime que le lot $\mathrm{SP}$, mais avec un rapport réduit de $20 \mathrm{p}$. Ioo (régime isoazoté, isoénergétique au premier, mais $30 \mathrm{p}$. Ioo del'énergie provient des lipides).

Dans ces trois derniers lots, du saindoux ou de la farine de poisson remplaçaient une partie de l'amidon du régime de base ( $\left.{ }^{1}\right)$. Les différents régimes avaient alors la composition chimique suivante :

Régime

Les rations journalières distribuées étaient les mêmes pour les 3 premiers lots : $4,2 \mathrm{~kg}$ d'aliment sec; le lot $s p$ recevait une ration plus faible de $20 \mathrm{p}$. Ioo, soit $3,5 \mathrm{~kg}$.

Les 4 lots étaient constitués chacun de ro truies adultes (ayant déjà accompli une lactation) qui avaient reçu au cours de la gestation une alimentation équilibrée convenable. A la parturition, les portées étaient égalisées à 9 porcelets. On déterminait pour chaque truie les variations de poids et d'adiposité, la production laitière hebdomadaire et la composition du lait. Les principaux constituants (azote, lipides, lactose, cendres) étaient dosés suivant les techniques habituelles, mais les acides gras faisaient l'objet de déterminations particulières : les acides gras polyéniques,

(1) Blé : 50 ;farine de luzerne : Io ; tourteau de soja : 7 ; farine de poisson: 5 ; amidon : 20 ; minéraux : 4; 
étaient dosés spectrophotométriquement après isomérisation alcaline (PAQUOT et al. 1962). La teneur en acide oléique était calculée après détermination de l'indice d'iode et celle en acides gras saturés par différence.

En outre, sur 5 truies de chaque lot, on a déterminé la digestibilité apparente des aliments (énergie, protéines) par la méthode à l'oxyde de chrome, (RAymond et Minson, I955).

Les résultats ont été les suivants :

\section{a) Digestibilité}

Le tableau 59 indique pour chaque régime les coefficients moyens de digestibilité apparente de l'azote et de l'énergie. A partir de ces coefficients, nous avons calculé les quantités de matière azotée et d'énergie digestibles ingérées.

TABLEAU 59

Étude de la digestibilité

\begin{tabular}{|c|c|c|c|c|}
\hline Régimes & $\mathrm{T}$ & $\mathrm{S}$ & SP & $\mathrm{sp}$ \\
\hline $\begin{array}{l}\text { Coefficient d'utilisation digestive de la matière azotée } \\
\text { p. } 100, \ldots \ldots \ldots \ldots \ldots \ldots \ldots \ldots \ldots \ldots \ldots \ldots \ldots\end{array}$ & 85 & 86 & 87 & 86 \\
\hline Matière azotée digestible, p. 100 de la matière sèche ... & 14,95 & 14,93 & 17,90 & 17,90 \\
\hline Matière azotée digestible par animal et par jour (g)... & 628 & 627 & 752 & 626 \\
\hline $\begin{array}{l}\text { Coefficient d'utilisation digestive de l'énergie p. } 100 \ldots \ldots \\
\text { Énergie digestible/g matière sèche (cal) } \ldots \ldots \ldots \ldots \ldots \\
\text { Énergie digestible par animal par jour }(\mathrm{th}) \ldots \ldots \ldots \ldots \ldots\end{array}$ & $\begin{array}{r}81 \\
3118 \\
13,09\end{array}$ & $\begin{array}{l}77 \\
3727 \\
15,65\end{array}$ & $\begin{array}{r}79 \\
3737 \\
15,69\end{array}$ & $\begin{array}{r}76 \\
3625 \\
12,69\end{array}$ \\
\hline Énergie digestible (Cal.)/g matière azotée digestible $\ldots$. & 21 & 21 & 21 & 20 \\
\hline
\end{tabular}

Comme on peut le constater, les digestibilités apparentes ont été assez peu affectées par la présence de graisse dans les régimes, surtout en ce qui concerne la matière azotée. Toutefois, il semble que l'utilisation digestive des nutriments énergétiques ait été un peu plus faible avec les régimes contenant du saindoux (différence non significative), ce qui rejoint les observations de Kuryvial. (I962) et de Bol,ToN (Ig60).

\section{b) Quantitéc de lait produites et composition du lait}

Les quantités totales de lait $(\mathrm{kg})$ produites en moyenne par les truies de chaque lot, au cours des 8 semaines de lactation ont été les suivantes :

$\begin{array}{ll}\text { Lot } \mathrm{T} & 302 \pm 33 \\ \text { Lot } \mathrm{S} & 33 \mathrm{I} \pm 28 \\ \text { Lot SP } & 293 \pm \mathrm{I} 8 \\ \text { Lot } \mathrm{sp} & 295 \pm 36\end{array}$

Les truies du lot $\mathrm{S}$, qui recevaient un supplément de saindoux seul, ont produit: un peu plus de lait que les autres (différence significative à $\mathrm{P}=0,05$ ). Mais il est. 
étonnant de voir que le lot SP, qui recevait autant de calories que le lot S et davantage de protides, a produit moins de lait que ce dernier.

Le tableau 60 rapporte, pour chaque lot, la teneur moyenne du lait en ses principaux constituants et la figure I3 l'évolution de ces constituants au cours de la lactation.

TABLEAU 60

Composition chimique du lait

(g p. $100 \mathrm{ml}$ de lait frais)

\begin{tabular}{|c|c|c|c|c|c|}
\hline Constituants & Eau & Mat. azotée & Lipides & Iactose & Cendres \\
\hline Lots & & & & & \\
\hline $\mathrm{T} \ldots \ldots \ldots$ & $80,4 \pm 0,3$ & $5,9 \pm 0,3$ & $7,1 \pm 0,2$ & $5,6 \pm 0,2$ & $0,89 \pm 0,03$ \\
\hline$\ldots \ldots \ldots$ & 80,0 上 0,9 & $5,9 \pm 0,4$ & $7,8 \pm 0,2$ & $5,4 \pm 0,2$ & $0,96=0,0_{t}^{\prime}$ \\
\hline ...... & $79,3 \pm 0,8$ & $6,2=0,3$ & $8,2 \pm 0,2$ & $5,3 \pm 0,2$ & $1,02 \pm 0,08$ \\
\hline $\mathrm{sp} \ldots \ldots$ & $79,0 \div 0,8$ & $6,1=0,3$ & $8,2=0,2$ & $5,2 \pm 0,2$ & $1,02 \therefore 0,04$ \\
\hline
\end{tabular}

Les différences les plus importantes concernent les teneurs en lipides : les truies des lots recevant du saindoux ont produit un lait contenant Io à $\mathrm{I} 5 \mathrm{p}$. Ioo de graisse de plus que le lait sécrété par les truies du lot $T$. Le phénomène est surtout visible en fin de lactation. Au début de la lactation, les taux de lipides sont semblables dans les 4 lots, mais alors que dès la $2^{\mathrm{e}}$ semaine le taux de matière grasse du lot $\mathrm{T}$ baisse d'une façon classique, celui des trois lots recevant de la graisse se maintient à une valeur anormalement élevée.

Les teneurs moyennes en matière azotée ne révèlent aucune différence notable entre les lots ; on peut remarquer par contre que le taux de lactose est légèrement plus élevé (non significativement) dans le lot témoin et diminue moins vite au cours de la lactation que dans les trois autres lots. Inversement, la teneur en minéraux totaux est significativement plus élevée dès le début dans le lait des truies supplémentées en graisse.

Compte tenu des quantités de lait, les productions totales de chacun des principaux constituants s'établissent ainsi (tabl. 6r).

TABLEAU 6I

Quantités totales produites des principaux constituants du lait $(\mathrm{kg})$

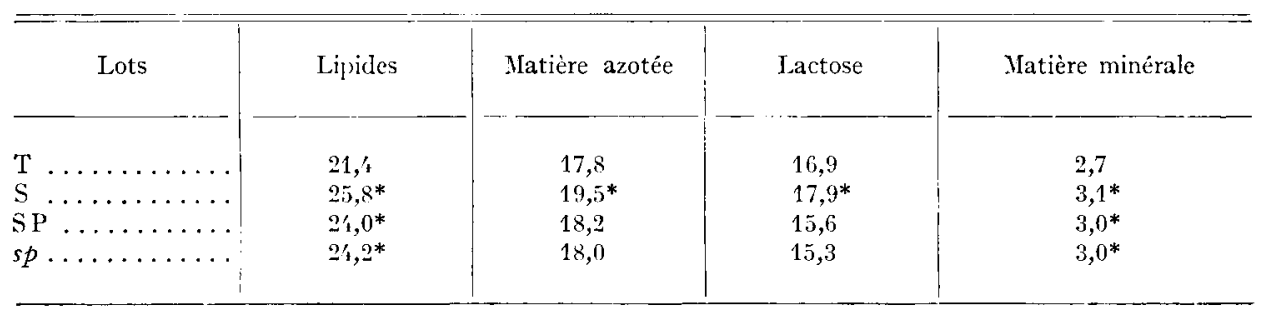

* Différence significative avec le lot I. 

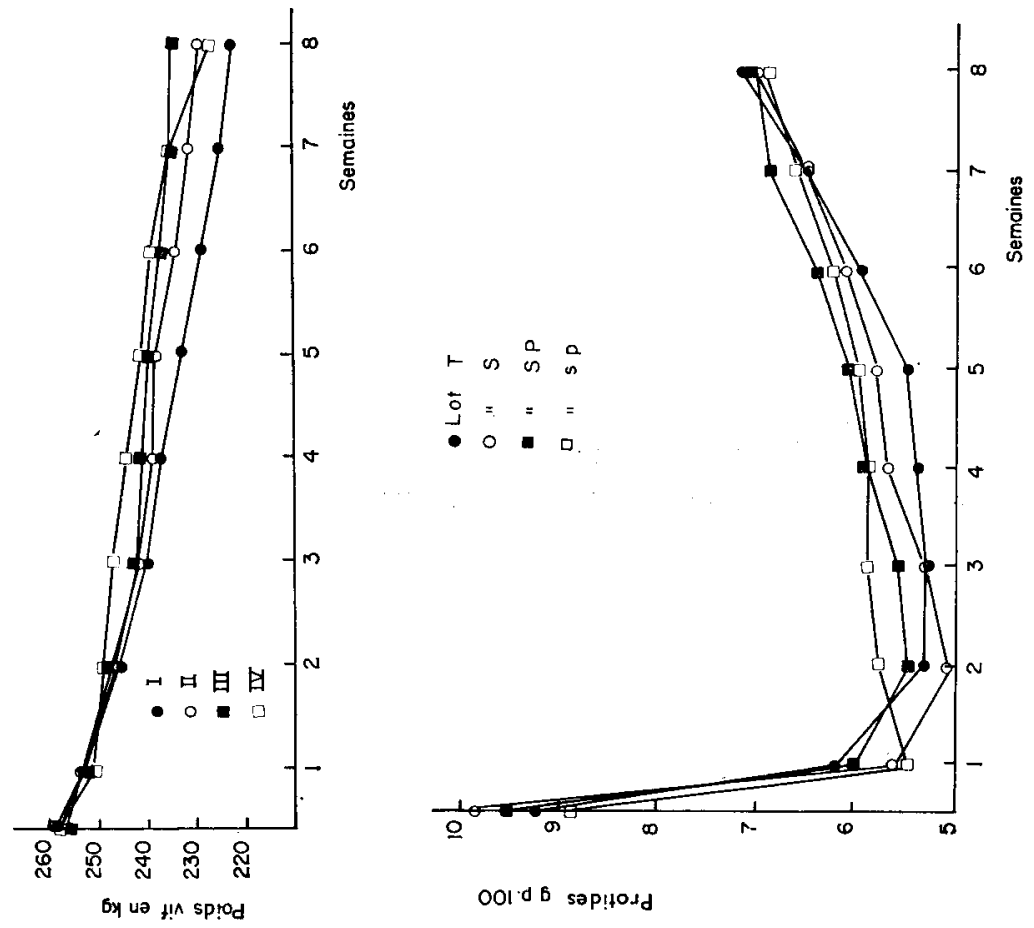

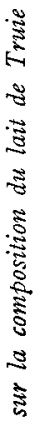
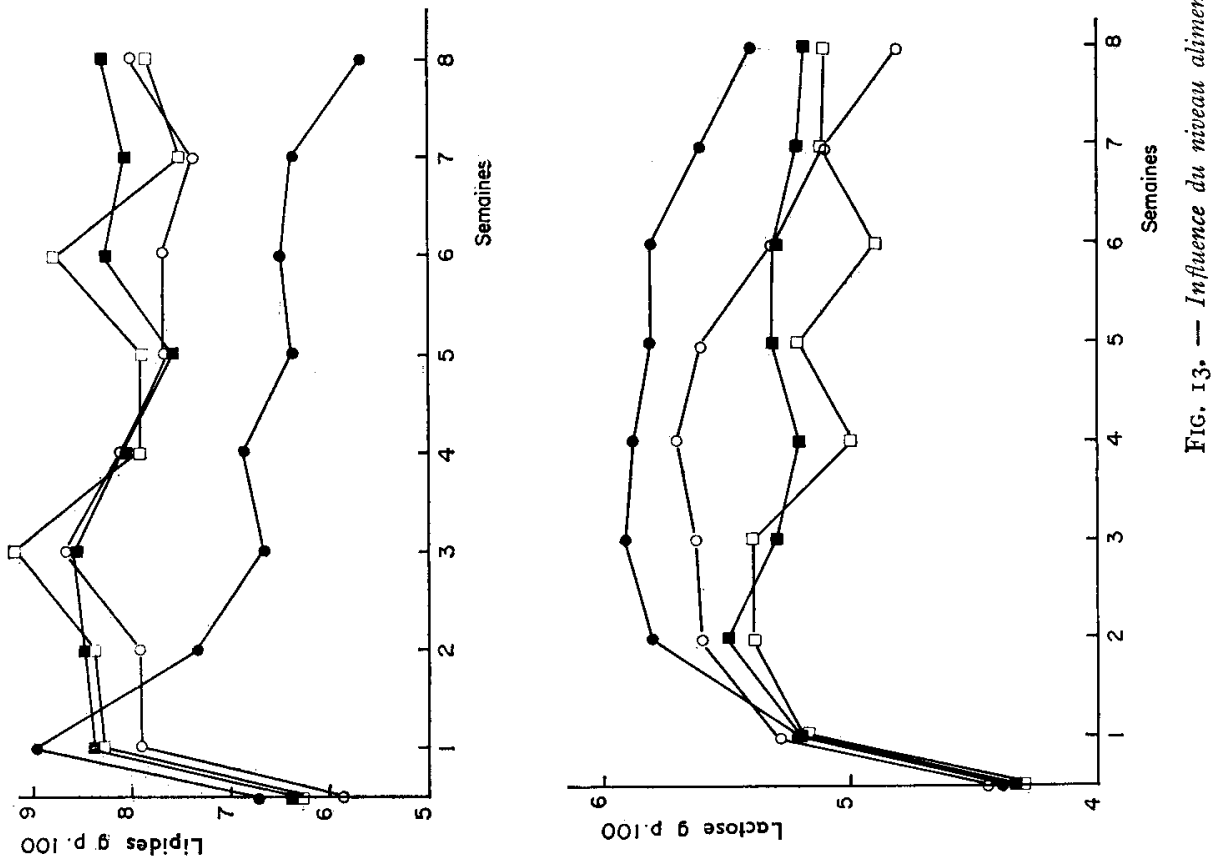
L'ensemble de ces premiers résultats peut donner lieu à quelques commentaires:

S'il était logique de s'attendre à une variation des quantités de constituants sécrétés dans le lait sous l'effet d'une augmentation de l'apport alimentaire (lots S et SP), la façon dont ce résultat a été obtenu est un peu étonnante. Bien plus que l'augmentation de la quantité de lait dans le lot $\mathrm{S}$, le fait le plus important est l'augmentation du taux de sécrétion de la matière grasse dans le lait des trois lots qui recevaient des calories lipidiques. Ce phénomène prend d'ailleurs un relief particulier dans le lot $s p$ pour lequel la seule modification du régime portait sur la nature des calories, l'apport total de nutriments étant le même que celui du lot témoin.

On ne peut manquer de trouver ici une différence avec ce qui se passe dans d'autres espèces, chez les Ruminants par exemple, où comme le rapportent JARRIGE et JoURNET (I959) l'effet de l'introduction de graisse dans la ration, lorsqu'il existe, porte plus sur la quantité de lait produite que sur une modification du taux butyreux (Loost I et $a l$., I944). Chez la Truie, au contraire, à l'exception de notre lot S, c'est le taux de matière grasse qui est modifié et non la quantité de lait, ce qui confirme pleinement nos autres expériences et a fait dire en d'autres circonstances à SHEFFY (I952) que le mécanisme de régulation de la sécrétion des lipides du lait, dans le cas d'une augmentation de l'apport alimentaire, ne serait pas le même chez ces différentes espèces. Bien qu'on ait signalé aussi chez des vaches laitières des cas analogues à ce que nous avons observé (ALLEN, I94I), l'explication d'un tel phénomène paraît possible si l'on admet que chez la Truie la graisse du régime peut participer plus ou moins directement à l'élaboration des lipides du lait, alors que chez les Ruminants la graisse ne serait utilisée en général qu'après des remaniements importants et n'aurait même parfois qu'un rôle énergétique banal.

Dans notre expérience en effet (tabl. 6I), seule la production de lipides du lait a été notablement modifiée. Tout au plus peut-on noter, à côté, une légère augmentation, difficilement explicable d'ailleurs, de la sécrétion des matières minérales ( + Io $p$. IOO), mais qui va de pair avec une très faible diminution de la teneur en lactose. Nous avons déjà eu l'occasion de souligner les relations étroites que l'on pouvait trouver chez la Truie entre les teneurs de certains constituants, comme le lactose, et les quantités de lait sécrétées. Il n'est donc pas étonnant ici que les quantités de lait aient peu varié, puisque la sécrétion du lactose n'a été elle-même que peu affectée.

L'évolution au cours de la lactation de la teneur du lait en matière grasse n'est pas sans intérêt. On peut en effet trouver deux interprétations au fait que l'influence des graisses du régime n'est visible qu'après la fin de la première semaine. Il est légitime de penser qu'au début de la lactation les lipides du lait proviennent en partie des lipides corporels, ce qui réduirait d'autant l'influence du régime. Autre hypothèse : jusqu'à la fin de la première semaine, le niveau de la production serait tel que les glucides de la ration suffisent à assurer la lipogenèse à son taux le plus élevé. Par la suite, les lipides corporels peuvent faire défaut, ou le niveau de la production s'élever au-delà des possibilités des hydrates de carbone; à ce moment, seuls les régimes supplémentés en graisse permettent le maintien des lipides du lait à un haut niveau de sécrétion.

La comparaison des différents lots recevant de la matière grasse fait aussi apparaître quelques points intéressants : par exemple, le supplément de protéines alimentaires donné au lot SP n'a eu que peu d'effet, mise à part une légère augmentation du taux de matière azotée du lait. Sur un plan différent, les résultats du lot $s p$ peuvent 
surprendre ; ils montrent tout d'abord, qu'à taux énergétique égal, les lipides semblent présenter une meilleure efficacité pour la lipogenèse du lait que les hydrates de carbone, ce qui a été parfois contesté jusqu'à présent (FRENCH, I952). Mais il est curieux de constater que l'amélioration qui en a résulté est la même que celle des rations plus abondantes contenant elles-mêmes des lipides, comme celles des lots $S$ et SP. Ceci semblerait indiquer que, quel que soit le niveau calorique de la ration, les graisses du régime sont utilisées en priorité par la mamelle. Toutefois, ce phénomène reçoit plus loin une autre explication, compte tenı des variations corporelles des truies, car les truies du lot $s p$ se délipident plus que les autres au cours de la lactation.

\section{c) Répartition des acides gras du lait}

Le tableau 62 rapporte les valeurs moyennes trouvées pour les indices d'iode et les acides gras du lait des 4 lots de truies.

\section{TABLEAU 62}

Répartition des acides gras du lait (')

(g p. roo g lipides totaux)

\begin{tabular}{|c|c|c|c|c|c|}
\hline Acides gras & A. g. saturés & $\begin{array}{l}\text { A. oléique + } \\
\text { palmitoléique }\end{array}$ & A. linoléique & A. arachidonique & $\begin{array}{c}\text { Indice d'iode } \\
\text { des T. G. }\end{array}$ \\
\hline & & & & & \\
\hline $\mathrm{T} \ldots \ldots \ldots \ldots$ & 35,5 & 54,5 & 5,0 & 0,5 & 59,8 \\
\hline$s \ldots \ldots \ldots \ldots$ & 31,0 & 57,1 & $6, \overline{5}$ & 0,8 & 65,8 \\
\hline $\mathrm{sP} \ldots \ldots \ldots$ & 30,7 & 57,5 & 6,7 & 0,7 & 66,1 \\
\hline sp $\ldots . . . . . .$. & 30,7 & 58,6 & 5,8 & 0,6 & 65,0 \\
\hline
\end{tabular}

(1) Nous n'avons pas fait figurer l'acide linolénique que nous n'avons trouvé qu'à l'état de traces.

Ces résultats font apparaître, dans tous les lots ayant reçu du saindoux, une augmentation légère mais significative des teneurs en acides gras insaturés. Cette augmentation porte sur tous les acides gras insaturés, mais plus spécialement sur l'acide linoléique (lot SP).

Aussi les modifications subies par les lipides du lait dans les lots supplémentés en saindoux ne sont pas seulement quantitatives, mais aussi qualitatives. Ceci constitue une nouvelle indication du passage plus ou moins direct de certains acides gras du régime dans le lait : l'enrichissement relatif des lipides du lait en acide linoléique ne peut s'expliquer que si celui-ci a été prélevé dans le régime, puisque l'animal n'en synthétise normalement pas. Il est vraisemblable que l'augmentation de la teneur en acide oléique et arachidonique procède dı même mécanisme. Ce phénomène n'est pas nouveau, il a déjà été signalé à des degrés divers dans d'autres espèces, notamment chez la Vache (KUzDzAL-SAvoIE, I959), chez la Ratte (BEARE, I96r) et chez la Femme (InsulL, I959), mais jamais encore chez la 'Truie.

Mais un fait demeure curieux dans notre expérience, c'est que les teneurs des 
différents acides gras insaturés dans le lait deviennent supérieures à ce qu'elles étaient dans la matière grasse de départ $\left(^{1}\right)$. Un tel phénomène avait déjà été rencontré par FÉvRIER (I959) et confirmé par Flanzy (I963) sur les graisses de réserve de porcs en croissance. Quelles sont les hypothèses pour l'expliquer? Tout d'abord, on peut penser que seule la fraction la plus insaturée des graisses, dont une partie n'est pas synthétisée par l'animal est affectée par ce phénomène ; il en résulterait une sorte de concentration de cette fraction dans le lait, avec corrélativement une diminution de la fraction saturée. On peut imaginer aussi qu'au cours du métabolisme des graisses, il survient certaines modifications de structure et que des glycérides insaturés sont mis en plus grand nombre à la disposition de la mamelle (FLANZY, I963). Mais ce qu'il faut retenir surtout c'est que, quel que soit le mécanisme envisagé, la composition des graisses du lait de Truie a tendance à se rapprocher de celle des dépôts adipeux maternels plus insaturés que le saindoux utilisé dans notre expérience. Ceci montre que la lipogenèse du lait et celle des dépôts procèdent des mêmes phénomènes chez cette espèce et qu'il y a au cours de la lactation des interrelations entre la graisse du régime, la graisse des dépôts et les lipides du lait, qui rendent ce problème particulièrement complexe.

\section{d) Variations corporelles des truies}

Même dans les lots recevant de la graisse, les truies de cette expérience ont perdu du poids. Toutefois, les pertes pondérales et les variations de l'adiposité ont affecté différemment les truies de chaque lot comme le montre le tableau 63 .

TABLEAU 63

Variations corporelles des truies

\begin{tabular}{|c|c|c|c|}
\hline & \multirow{2}{*}{$\begin{array}{l}\text { Perte de poids } \\
(\mathrm{kg})\end{array}$} & \multicolumn{2}{|c|}{$\begin{array}{l}\text { Diminution de l'épaisseur } \\
\text { du tissu adipeux sous-cutané }\end{array}$} \\
\hline & & $\mathrm{mm}$ & $\begin{array}{l}\text { p. } 100 \text { de la valeur } \\
\text { à la parturition }\end{array}$ \\
\hline $\mathrm{T} \ldots \ldots$. & $36,7 \pm 7,4$ & $5,4 \pm 2,7$ & 13 \\
\hline$S \ldots \ldots$ & $28,4 \pm 13,4$ & $4,0 \pm 4,4$ & 11 \\
\hline$S P \ldots \ldots \ldots$ & $21,7 \pm 7,4$ & $3,1 \pm 2,3$ & 11 \\
\hline$s p \ldots \ldots \ldots$ & $30,3 \pm 11,9$ & $8,0 \pm 2,8$ & 21 \\
\hline
\end{tabular}

Le lot témoin a perdu significativement plus de poids que les lots au saindoux $\mathrm{S}$ et SP. Il semble qu'il en ait perdu plus également que le lot $s p$ (même niveau azoté et énergétique), mais la différence n'est pas significative. On peut noter aussi chez ce dernier une perte de poids très sensible au cours de la dernière semaine delactation.

Le catabolisme lipidique (diminution du tissu adipeux sous-cutané) a été sensiblement le même dans les 3 premiers lots et significativement plus important dans le

(1) Le saindoux que nous avons utilisé avait la composition suivante : a. saturés : 37,9 p. 100; a. oléique 5 I,6 p. 100; a. linoléique : 5,6 p. I00; a. arachidonique :0,3 p. I00. 
dernier lot. On peut noter que ce phénomène s'est manifesté dès la première semaine de lactation. Il peut s'interprêter comme l'indication d'une intervention des graisses du régime dans la perte de poids. La carence alimentaire supportée habituellement par la Truie en lactation serait donc essentiellement énergétique.

Il faut toutefois remarquer que la variation de poids la plus faible a été enregistrée dans le lot SP qui recevait, en plus de la graisse, un supplément de protéines. Ceci indique bien que ces dernières exercent également un effet protecteur vis-à-vis de la perte de poids et que, dans certains cas, une mobilisation des protéines tissulaires peut s'effectuer au bénéfice de la lactation. Que ces protéines soient utilisées en tant que source d'azote ou d'énergie, c'est ce que nous ne savons pas. Mais il est bien certain que la seule augmentation du niveau énergétique de la ration ne suffit pas pour arrêter le catabolisme de lactation.

C'est dans le lot sp que la fonte des lipides corporels a été la plus importante et c'est également dans ce lot que le taux de matière grasse sécrétée dans le lait est le plus élevé.

Il est vraisemblable que, dans ce cas, les graisses corporelles ont participé, directement ou non, à la lipogenèse du lait. Nous trouvons ici un nouvel exemple des relations qui se créent chez la Truie entre l'aliment, les dépôts et le lait.

\section{e) Conclusion}

Le premier effet de l'introduction de $\mathrm{I} 7 \mathrm{p}$. Ioo de saindoux dans le régime alimentaire de truies en lactation a été une augmentation de la sécrétion des lipides du lait. A une exception près, cette augmentation n'a pas été le résultat de la production d'une plus grande quantité de lait, mais au contraire d'une élévation de la teneur du lait en graisse. Cet enrichissement du lait, relativement important (I5 p. IOO), apparaît même dans le cas d'un régime isoénergétique et izoazoté. La teneur des autres constituants du lait, sauf peut être celle des matières minérales, n'est pas modifiée.

Corrélativement, la modification de la teneur en matière grasse s'accompagne d'un changement dans la répartition des acides gras et notamment d'un enrichisselent en acides insaturés (oléique et linoléique) dont l'origine doit être recherché soit dans les graisses de dépôts, soit directement dans les apports alimentaires.

L'introduction de graisse dans le régime freine plus ou moins la perte de poids maternelle atı cours de la lactation; son plein effet est atteint lorsque les truies reçoivent également un supplément protéique. Le problème d'une intervention des graisses alimentaires dans la lipogenèse du lait et la mobilisation du tissu adipeux au cours de la lactation est ainsi clairement posé.

\section{B - Relations se rapportant aux acides gras polyinsaturés}

Pour déceler les différentes origines possibles des lipides du lait, nous avons choisi de travailler avec des régimes enrichis en acide linoléique, car ce dernier étant peu synthétisé par l'animal, il devenait plus facile de réaliser un "marquage " des graisses de dépôt et de suivre les passages dans le lait. Par ailleurs, cette expérience apportait des informations sur l'utilisation des acides gras polyinsaturés par la Truie en reproduction. 
A cet effet, 36 truies adultes d'un poids moyen de $215 \mathrm{~kg}$ ont été utilisées et réparties en 3 lots recevant suivant les cas, au cours de la gestation ou de la lactation, un régime contenant Io p. Ioo d'huile de maïs ( $\left.{ }^{1}\right)$ (régime $\mathrm{L}$ ) ou essentiellement glucidique (régime G). Ces deux régimes étaient équilibrés pour 1'apport azoté (I4 p. IOO), vitaminique et minéral et les rations distribuées dans les 3 lots étaient isoénergétiques, isoazotées et de même valeur biologique. Le schéma de l'expérience était le suivant :

Lot I G : Régime lipidique pendant la gestation et glucidique pendant la lactation,

Lot $G \mathrm{~L}$ : régime glucidique pendant la gestation et lipidique pendant la lactation,

I ot $\mathrm{G} G$ : régime glucidique pendant toute l'expérience (témoin).

Pendant la gestation les régimes étaient distribués ad libitum đe façon à intensifier la lipogenèse, mais pendant la lactation les animaux étaient rationnés à $4 \mathrm{~kg} / \mathrm{j}$ pour les lots $\mathrm{LG}$ et GG et $3,6 \mathrm{~kg} / \mathrm{j}$ pour le lot GL. De la sorte, les truies recevaient au cours de la lactation exactement les mêmes quantités de protides et d'énergie dans tous les lots (520 $\mathrm{g}$ de protides/jour, $x_{5,5}$ thermies/jour).

On suivait tout au long de l'expérience les variations de poids et d'adiposité des animaux (mesure aux ultrasons de l'épaisseur du tissu adipeux sous-cutané dorsal). En outre, on effectuait sur chaque truie des prélèvements de tissu adipeux sous-cutané dorsal au début et à la fin de la gestation et à la fin de la lactation.

Pendant la lactation, les portées étaient égalisées à 8 porcelets, et l'on effectuait la mesure de la production laitière et la récolte d'échantillons de lait hebdomadaires.

Outre les déterminations habituelles de la composition du lait, on dosait les acides gras du lait et du tissu adipeux par spectrophotométrie dans l'ultraviolet.

\section{a) Variations corporelles}

Compte tenu des régimes distribués au cours de la gestation et comme le montre le tableau 64, les variations de poids et d'adiposité ont été importantes.

\section{TABLEAU 64}

Variations corporelles

\begin{tabular}{|c|c|c|c|c|c|c|}
\hline \multirow{2}{*}{ Lots } & \multicolumn{3}{|c|}{ Variations de poids } & \multicolumn{3}{|c|}{ Variation de l'épaisseur du tissus adipeux } \\
\hline & $\begin{array}{c}\text { Gestation } \\
(\mathrm{kg})\end{array}$ & $\begin{array}{l}\text { Lactation } \\
\quad(\mathrm{kg})\end{array}$ & $\begin{array}{c}\text { Bilan } \\
(\mathrm{kg})\end{array}$ & $\begin{array}{c}\text { Gestation } \\
\text { (p. 100) }\end{array}$ & $\begin{array}{c}\text { Lactation } \\
\text { (p. 100) }\end{array}$ & $\begin{array}{l}\text { Bilan } \\
\text { (p. 100) }\end{array}$ \\
\hline $\begin{array}{l}\text { LG . } \\
\text { GL . } \\
\text { GG . }\end{array}$ & $\begin{array}{l}94,3 \\
84,8 \\
87,4\end{array}$ & $\begin{array}{r}70,6 \\
-51,5 \\
-56,1\end{array}$ & $\begin{array}{r}+\quad 23,7 \\
+\quad 33,3 \\
+\quad 32,3\end{array}$ & $\begin{array}{l}24,6 \\
20,1 \\
15,9\end{array}$ & $\begin{array}{l}-25,7 \\
-18,2 \\
-14,6\end{array}$ & $\begin{array}{l}-1,1 \\
+\quad 1,9 \\
+\quad 1,3\end{array}$ \\
\hline
\end{tabular}

(1) Orge : 68 ; son : ro; arachide : 5 ; poisson : 4 ; huile de maïs (à 45 p. roo d'acide linoléique :Ic; minéraux : 3 . 
Au cours de la gestation, les prises de poids sont importantes et légèrement plus élevées, bien que non significativement dans le lot qui recevait des lipides. I'augmentation d'épaisseur du tissu adipeux suit sensiblement la variation de poids et paraît également plus importante dans le lot L,G.

Comme dans la plupart de nos expériences précédentes, les pertes corporelles au cours de la lactation s'équilibrent sensiblement, tout au moins en ce qui concerne le tissu adipeux, avec les gains de gestation. Il en résulte que si l'on note en fin de reproduction un certain bénéfice pondéral du même ordre dans les 3 lots, celui-ci ne porte que sur les tissus non adipeux et laisse les animaux, quels que soient les régimes, dans un état d'adiposité voisin de celui du départ.

Il en va différemment sur le plan de la répartition des acides gras : le tableau 65 rapporte à cet effet la composition du tissu adipeux sous-cutané des truies de chaque lot aux différents stades de l'expérience.

TABLEAU 65

Teneurs en acides gras des dépôts adipeux de la Truie au cours de la reproduction

(p. Ioo lipides totaux).

\begin{tabular}{|c|c|c|c|c|c|c|c|}
\hline Lot & $\begin{array}{c}\text { Stade } \\
\text { phỵsiologique }\end{array}$ & A. oléique & $\begin{array}{l}\text { A. linoléi- } \\
\text { que }\end{array}$ & $\begin{array}{l}\text { A. diènes } \\
\text { conjugués }\end{array}$ & $\begin{array}{l}\text { A. linolé- } \\
\text { nique }\end{array}$ & $\begin{array}{c}\text { A. arachido- } \\
\text { nique }\end{array}$ & A. saturés \\
\hline I.G & $\begin{array}{l}\text { Accouplement } \\
\text { Tin gestation } \\
\text { Fin lactation }\end{array}$ & $\begin{array}{l}56,0 \\
54,7 \\
53,0\end{array}$ & $\begin{array}{r}6,7 \\
15,5 \\
15,0\end{array}$ & $\begin{array}{l}0,28 \\
0,45 \\
0,39\end{array}$ & $\begin{array}{l}0,2 \\
0,1 \\
0,1\end{array}$ & $\begin{array}{l}0,1 \\
0,2 \\
0,2\end{array}$ & $\begin{array}{l}32,5 \\
25,1 \\
27,2\end{array}$ \\
\hline GL & $\begin{array}{l}\text { Accouplement } \\
\text { Fin gestation } \\
\text { Fin lactation }\end{array}$ & $\begin{array}{l}57,1 \\
57,7 \\
57,4\end{array}$ & $\begin{array}{l}6,2 \\
6,6 \\
7,8\end{array}$ & $\begin{array}{l}0,28 \\
0,30 \\
0,27\end{array}$ & $\begin{array}{l}0,2 \\
0,2 \\
0,1\end{array}$ & $\begin{array}{l}0,1 \\
0,2 \\
0,2\end{array}$ & $\begin{array}{l}31,9 \\
30,9 \\
30,6\end{array}$ \\
\hline GG & $\begin{array}{l}\text { Accouplement } \\
\text { Fin gestation } \\
\text { Fin lactation }\end{array}$ & $\begin{array}{l}57,1 \\
57,7 \\
58,6\end{array}$ & $\begin{array}{l}6,4 \\
6,3 \\
6,2\end{array}$ & $\begin{array}{l}0,28 \\
0,27 \\
0,27\end{array}$ & $\begin{array}{l}0,1 \\
0,2 \\
0,1\end{array}$ & $\begin{array}{l}0,1 \\
0,1 \\
0,1\end{array}$ & $\begin{array}{l}31,7 \\
31,2 \\
30,6\end{array}$ \\
\hline
\end{tabular}

Le premier effet d'une distribution d'huile de maïs au cours de la gestation (lot LG) a été une augmentation importante de la teneur en acide linoléique et, dans une certaine mesure, en diènes conjugués du tissu adipeux. Parallèlement, on observe une diminution en valeur relative de la teneur en acides gras saturés ; un calcul simple montre qu'il se dépose ainsi environ I $\mathrm{kg}$ d'acide linoléique dans le tissu adipeux des truies LG, soit environ 45 p. Ioo des quantités ingérées, contre un dépôt ou une synthèse nuls d'acides gras saturés. Ce résultat est parfaitement classique et rejoint les observations faites sur des sujets en croissance de diverses espèces monogastriques : Homme, Rat, Poulet, Porc (Eliris, I93 ; DAM et Fisgel, I958 ; Bhalerao et al., I960 et I96I; BEARE, I96I; SELL et HodgSON, I962; LEAT, I962; MAN et PoPE, I 962 ; Ostwald et $a l$., I962 ; Kingsiury et al., I962 ; SweEney et al., I963; Marion, I963; Cr.́MENT et al., Ig63).

Ces modifications persistent au cours de la lactation même en l'absence de toute distribution d'huile après la parturition. On constate, en effet, qu'en dépit de la 
mobilisation importante du tissu adipeux qui survient, la composition en acides gras des dépôts des truies du lot LG est pratiquement la même en fin de lactation, qu'au moment de la parturition. Cette longue persistance de l'acide linoléique dans les tissus est à rapprocher des observations faites sur le Rat par OsTWALD et al. (Ig62). Tout porte donc à croire que dans nos conditions les différents acides gras des dépôts sont mobilisés sensiblement à la même vitesse et non d'une façon préférentielle comme cela a été constaté en d'autres occasions (WAGNER et al., I958; JACQUOT et al., I959 ; CRAIG, I963). De nombreux auteurs pensent, en effet, que les acides polyinsaturés par exemple sont catabolisés moins vite que les autres, mais il s'agit en général d'une mobilisation à des fins énergétiques pour lesquelles il est connu que les acides gras courts sont utilisés préférentiellement (LONGNECKER, I939). Il n'y a rien d'impossible à ce qu'il en soit différemment chez l'animal en lactation et plus spécialement chez la Truie.

Par ailleurs, la distribution d'huile de maïs au cours de la lactation (lot GL) n'apporte pratiquement pas de modification de la composition des dépôts (l'augmentation de I p. roo de la teneur en acide linoléique n'est pas significative). Ce résultat contraste avec celui de la gestation et semble indiquer que l'acide linoléique au cours de la lactation ne s'incorpore pas aux graisses de dépôt, mais qu'il est probablement utilisé à d'autres fins.

\section{b) Quantités de lait produites et composition du lait}

Les quantités de lait produites ne diffèrent pas sensiblement dans les 3 lots. Il n'en est pas de même pour la composition du lait, notamment pour la teneur en matière grasse (tab1. 66).

TABLEAU 66

Production laitière

\begin{tabular}{|c|c|c|c|c|c|c|}
\hline \multirow{2}{*}{ Lots } & \multirow{2}{*}{$\begin{array}{c}\text { Quantités } \\
\text { de lait } \\
\text { (kg) }\end{array}$} & \multicolumn{5}{|c|}{ Composition du lait } \\
\hline & & $\begin{array}{c}\text { Eau } \\
(\text { p. 100) }\end{array}$ & $\begin{array}{l}\text { Mat. azotée } \\
\text { (p. 100) }\end{array}$ & $\begin{array}{l}\text { Lipides } \\
\text { (p. 100) }\end{array}$ & $\begin{array}{l}\text { Lactose } \\
\text { (p. 100) }\end{array}$ & $\begin{array}{l}\text { Cendres } \\
\text { (p. 100) }\end{array}$ \\
\hline LG & 285 & 80,1 & 5,8 & 6,6 & 5,5 & 0,9 \\
\hline GL & 265 & 78,8 & 6,3 & 8,1 & 5,3 & 1,0 \\
\hline $\mathrm{GG}$ & 274 & 79,1 & 6,0 & 6,4 & 5,7 & 1,0 \\
\hline
\end{tabular}

Comme dans l'expérience précédente, la distribution d'huile au cours de la lactation (lot GL) a eu pout effet une augmentation importante de la quantité de lipides sécrétés dans le lait $(+22 \mathrm{p}$. Ioo), sans qu'il y ait pour autant une modification du volume de la sécrétion. Ce résultat obtenu, à niveau énergétique alimentaire égal, confirme donc le rôle particulier des lipides alimentaires dans la lipogenèse du lait. Comme précédemment également, la teneur en lipides du lot GL, se maintient à un niveau élevé, alors qu'elle diminue considérablement dans les deux autres lots. Par contre, mise à part une légère augmentation de la teneur en matières azotées au début de la lactation, qui peut peut-être s'expliquer par l'effet protecteur du régime 
riche en acide linoléique (NAISMITH, I962), on ne note pas d'autre modification de la sécrétion des principaux constituants sous l'influence de l'huile distribuée au cours de la gestation ou de la lactation,

\section{c) Répartition des acides gras du lait}

Le tableau 67 et la figure 44 rapportent les principales variations de la répartition des teneurs en différents acides gras (exprimées en p. roo des lipides totaux), en fonction des régimes et du stade de lactation.

TABLEAU 67

Réparition des acides gras du lait

\begin{tabular}{|c|c|c|c|c|c|}
\hline Lots & $\begin{array}{l}\text { Saturés } \\
(p .100)\end{array}$ & $\begin{array}{c}\text { Oléique }+ \\
\text { palmitoléique } \\
(\text { p. 100) }\end{array}$ & $\begin{array}{l}\text { Linoléique } \\
(\mathrm{p} .100)\end{array}$ & $\begin{array}{l}\text { Arachidonique } \\
\text { (p. 100) }\end{array}$ & $\begin{array}{c}\text { Diènes } \\
\text { conjugués } \\
\text { (p. 100) }\end{array}$ \\
\hline LG & $30, \overline{5}$ & 50,0 & 14,1 & 1,0 & 0,41 \\
\hline $\mathrm{GL}$ & $24, y^{\prime}$ & 48,4 & 22,0 & 0,8 & 0,55 \\
\hline \multirow[t]{2}{*}{$\mathrm{GG}$} & 34,6 & 51,9 & 8,1 & 0,9 & 0,26 \\
\hline & & & & & \\
\hline
\end{tabular}

Les variations les plus importantes se rapportent aux teneurs en acide linoléique.

Le résultat le plus remarquable est celui du lot LG qui, bien que n'ayant pas reçu d'huile de maïs pendant la lactation, présente néanmoins une augmentation importante par rapport au lot $\mathrm{GG}$, de la teneur en acide linoléique de son lait Cette augmentation ne peut avoir comme origine que le régime distribué pendant la gestation. On peut déduire dans ce cas qu'une partie importante des lipides du lait chez 1a Truie provient des dépôts adipeux constitués pendant la gestation. Le fait que dans le lot LG et dans le lot GG (qui ne reçoit pas d'huile de maïs) la teneur en acide linoléique du lait s'équilibre parfaitement avec celle des dépôts adipeux, semble montrer que la lipogenèse induite par la gestation constitue chez la Truie une étape habituelle de la sécrétion de certains acides gras du lait. Ceci souligne au passage l'un des rôles dévolus à l'anabolisme gravidique, lorsque celui-ci comporte l'élaboration de réserves adipeuses.

Les résultats du lot GL, sont plus classiques, et confirment les possibilités de transfert des acides gras polyinsaturés du régime au lait. L'augmentation considérable de la teneur du lait en acide linoléique et, à un moindre degré, en diènes conjugués, ne peut s'expliquer que par une utilisation directe des acides gras par la mamelle en activité, puisque la teneur en acide linoléique des réserves n'a pas été augmentée. Ce résultat rappelle celui de notre expérience avec le saindoux et il est tout à fait comparable à ceux qu'ont observés dans les mêmes conditions INSUL, et al (I959) chez la Femme et BEARE (I96I) chez la Ratte.

L'examen de la figure I4 révèle des variations importantes de l'évolution des teneurs des différents acides gras en fonction des régimes. Les différences les plus caractéristiques concernent l'acide linoléique : on constate que la teneur du lait en acide linoléique s'accroît très fortement au cours de la lactation dans le lot GL, alors 
qu'elle reste pratiquement constante dans les deux autres lots. Ce phénomène traduit vraisemblablement la participation croissante des graisses du régime à l'élaboration de celles du lait : en fin de lactation l'acide linoléique, dont l'origine alimentaire ne fait aucun doute, représente plus de 30 p. Ioo des lipides du lait dans le lot GL, ce qui correspond à une utilisation directe par animal d'environ $65 \mathrm{p}$. Ioo de l'acide gras ingéré, valeur supérieure à celle que nous avions trouvée pour les dépôts adipeux de gestation.
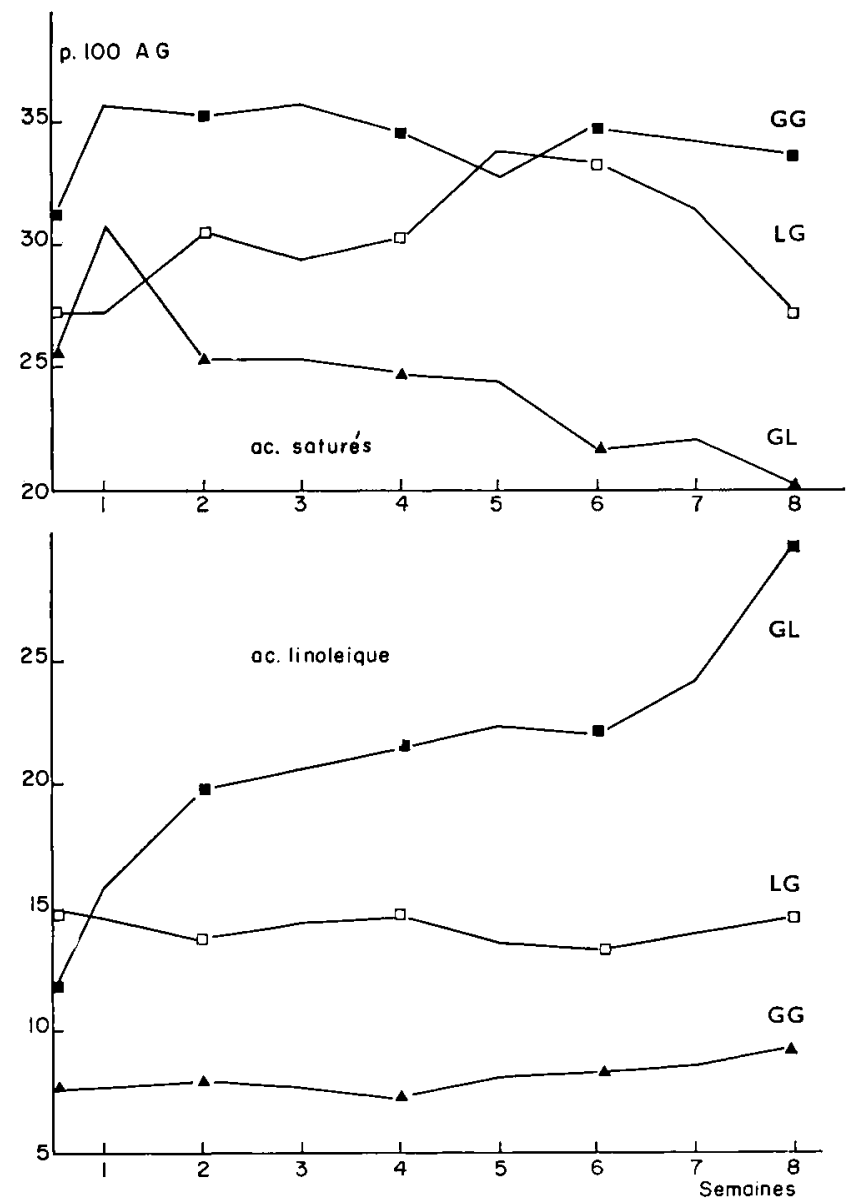

Fig. 14. - Evolution de! a teneur en acides gras du lait en fonction du régime

A l'opposé, la teneur en acides gras saturés diminue régulièrement dans le lot GI, alors qu'elle reste sensiblement constante dans le lot GG et qu'elle tend à augmenter au début de la lactation dans le lot LG. Si l'on admet que cette teneur reflète l'intensité des synthèses d'acides gras chez la Truie en lactation, on peut en conclure que cette dernière diminue, en valeur relative, à mesure que l'utilisation des graisses du régime s'accroît (lot GL). Par contre, on observe une augmentation des acides gras de synthèse dans le lait des truies J,G, ce qui peut être l'indice d'un ralentisse- 
ment de la participation des graisses de dépôt, phénomène qui apparaît dans la plupart de nos expériences. L'examen des teneurs en acide linolénique, dont la détermination est sujette à de nombreuses erreurs, et en acide arachidonique, dont la concentration est faible, ne suggère aucun commentaire.

On ne saurait toutefois déduire de ces différentes observations que la présence d'huile de mais dans le régime a pour effet une diminution des synthèses d'acide gras par la mamelle, hypothèse qui a pourtant été retenue par BoRTz et al. (I963) pour les synthèses hépatiques. Nos précédents résultats étaient exprimés en pourcentage, or un bilan des quantités réellement sécrétées s'impose pour pouvoir conclure. C'est ce que nous avons essayé de faire en calculant les valeurs du tableau 68 .

TABLEAU 68

(uantités totales d'acides gras sécrétées au cours de la lactation

\begin{tabular}{|c|c|c|c|c|}
\hline Lots & $\begin{array}{l}\text { A. totaux } \\
(\mathrm{kg})\end{array}$ & $\begin{array}{l}\text { A. oléique } \\
(\mathrm{kg})\end{array}$ & $\begin{array}{c}\text { A. linoléique } \\
(\mathrm{kg})\end{array}$ & $\begin{array}{l}\text { A. saturés } \\
(\mathrm{kg})\end{array}$ \\
\hline $\begin{array}{l}\text { LG } \\
\text { GL } \\
\text { GG }\end{array}$ & $\begin{array}{l}18,8 \\
21,5 \\
17,5\end{array}$ & $\begin{array}{r}9,4 \\
10,2 \\
9,1\end{array}$ & $\begin{array}{l}2,7 \\
4,7 \\
1,4\end{array}$ & $\begin{array}{l}5,7 \\
5,2 \\
6,0\end{array}$ \\
\hline
\end{tabular}

Bien entendu, ce tableau doit être interprété avec prudence. Aux erreurs de détermination près, on constate que la somme acide oléique + saturés, qui traduit schématiquement l'activité de la mamelle, est la même dans tous les cas. Il ne semble donc pas que la présence d'huile de maïs dans le régime au cours de la gestation ou de la lactation n'ait modifié en quoi que ce soit l'intensité de la lipogenèse vraie. La principale différence entre les lots vient des quantités d'acide linoléique sécrétées qui augmentent avec la teneur de cet acide dans le régime ou dans le tissu adipeux.

\section{d) Conclusion}

En bref, il existe chez le Truie en reproduction un certain équilibre dynamique entre les taux des acides gras du régime, des dépôts adipeux et des graisses du lait. Selon la chronologie de la distribution d'huile de maïs, la fixation d'acide linoléique peut se faire préférentiellement dans les graisses de réserve, ou directement dans les graisses du lait. Dans ce dernier cas, on observe une augmentation de la quantité de lipides sécrétés dans le lait, mais ce phénomène ne semble pas faire obstacle aux processus habituels de la lipogenèse, qu'il s'agisse d'une mobilisation des graisses de réserve ou d'une synthèse a novo aux dépens des glucides.

\section{C - Relations se rapportant aux acides gras saturés}

Il restait à examiner si ces processus de transfert à partir du tissu adipeux et du régime s'appliquaient également aux acides saturés et en particulier à ceux à chaîne de longueur moyenne. Par ailleurs, l'expérience précédente n'apportait que peu de 
précisions en ce qui concerne l'importance relative des différents mécanismes (synthèse ou transferts), car les animaux avaient été placés dans des conditions qui exagéraient volontairement le dépôt et la mobilisation des lipides corporels. En outre, le seul " marquage " à l'acide linoléique ne permettait pas de différencier l'origine exogène ou endogène (dépôts) des lipides du lait.

Dans le but de compléter nos premières observations, nous avons entrepris une nouvelle expérience dans laquelle nous avons comparé l'influence d'un enrichissement de la ration en acide laurique et en acide linoléique. Par le jeu de régimes croisés, au cours de la gestation et de la lactation, ce double marquage des lipides devait nous permettre une meilleure séparation des différents processus.

Trois lots de Io truies primipares, d'un poids moyen de $140 \mathrm{~kg}$, recevaient, suivant les cas : un régime contenant $8 \mathrm{p}$. Ioo d'huile de coprah (à $49 \mathrm{p}$. Ioo d'acide laurique), 8 p. roo d'huile de mais (à 46 p. Ioo d'acide linoléique) ou i 8 p. Ioo de manioc (à 80 p. Ioo d'amidon). Le dispositif expérimental était le suivant :

Gestation

Lot $\mathrm{M}-\mathrm{C} \ldots \ldots \ldots \ldots$

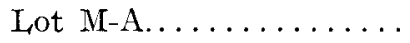

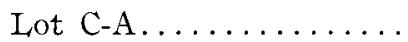

Régime huile de maïs

Régime huile de maïs

Régime coprah
Lactation

Régime coprah

Régime manioc

Régime manioc.

Les rations étaient allouées individuellement aux animaux. Elles étaient calculées de façon à réaliscr un même apport énergétique ( 5 th), azoté (5Io g) et minéral ( $\mathrm{I}_{5} \mathrm{~g}$ g) dans tous les lots. Pendant la gestation, la ration était limitée à $3 \mathrm{~kg}$ par jour de façon à éviter un développement excessif de l'adiposité des animaux préjudiciable à la signification de l'expérience. Pendant la lactation, le niveau était porté à $3,6 \mathrm{~kg} /$ jour dans le lot supplémenté en lipides et à $4 \mathrm{~kg}$ dans les autres.

Les mesures effectuées étaient les mêmes que pour l'expérience précédente, mais les teneurs en acides gras du lait et du tissu adipeux étaient déterminées par chromatographie en phase gazeuse.

\section{a) Variations corporelles}

Quels que soient les régimes, les variations de poids ont été sensiblement les mêmes dans les trois lots (tabl. 69). Les gains de poids de gestation sont plus faibles que ceux de l'expérience précédente, mais plus en rapport avec ce qu'il est courant d'observer dans les conditions habituelles de l'élevage.

TABLEAU 69

Variations corporelles

\begin{tabular}{|c|c|c|c|c|c|c|}
\hline \multirow[b]{2}{*}{ Lots } & \multicolumn{3}{|c|}{ Variations de poids } & \multicolumn{3}{|c|}{ Variations d'adiposité } \\
\hline & $\begin{array}{c}\text { Gestation } \\
(\mathrm{kg})\end{array}$ & $\begin{array}{l}\text { Lactation } \\
\quad(\mathrm{kg})\end{array}$ & $\begin{array}{c}\text { Bilan } \\
(\mathrm{kg})\end{array}$ & $\begin{array}{c}\text { Gestation } \\
\text { (p. 100) }\end{array}$ & $\begin{array}{c}\text { Lactation } \\
\text { (p. 100) }\end{array}$ & $\begin{array}{c}\text { Bilan } \\
\text { (p. 100) }\end{array}$ \\
\hline $\mathrm{M}-\mathrm{C}$ & 55 & -39 & +16 & 4,4 & $-13,4$ & $-9,0$ \\
\hline M-A & 47 & -32 & +15 & 6,4 & $-13,6$ & $-7,2$ \\
\hline $\mathrm{C}-\mathrm{A}$ & 48 & -34 & +14 & 11,1 & $-19,6$ & $-8,5$ \\
\hline
\end{tabular}


De même, les variations d'adiposité sont faibles au cours de la gestation, mais la mobilisation des lipides corporels est nette au cours de la lactation et se traduit dans tous les lots par une diminution d'épaisseur du tissu adipeux sous-cutané.

Sur le plan qualitatif, on observe une modification de la répartition de certains acides gras des graisses de dépôt au cours de la gestation (tab1. 70). Suivant la nature de l'huile ingérée, il apparaît en effet un entichissement du tissu adipeux en acide linoléique ou en acide laurique et myristique. En valeur absolue, c'est l'acide linoléique qui varie le plus.

\section{TABLEAU 70}

Évolution de la répartition des acides gras du tissu adipeux en fonction du régime et du stade physiologique

(p. Ioo des esters méthyliques)

\begin{tabular}{|c|c|c|c|c|c|c|c|}
\hline \multicolumn{2}{|c|}{ Accouplement } & \multicolumn{3}{|c|}{ Parturition } & \multicolumn{3}{|c|}{ Fin lactation } \\
\hline Régimes $\ldots \ldots \ldots \ldots$ & Standard & $\mathrm{MC}$ & MA & $\mathrm{CA}$ & $\mathrm{MC}$ & MA & CA \\
\hline 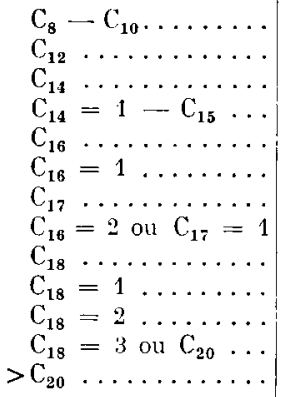 & $\begin{array}{r}0,2 \\
0,3 \\
1,6 \\
0,1 \\
25,3 \\
3,7 \\
0,4 \\
0,3 \\
12,4 \\
41,6 \\
8,2 \\
1,7 \\
1,2\end{array}$ & $\begin{array}{r}0,2 \\
0,4 \\
1,4 \\
0,2 \\
22,2 \\
2,4 \\
0,4 \\
0,2 \\
10,7 \\
43,1 \\
14,0 \\
3,2 \\
1,6\end{array}$ & $\begin{array}{r}0,4 \\
0,4 \\
1,5 \\
0,1 \\
23,3 \\
2,8 \\
0,4 \\
0,4 \\
10,9 \\
43,1 \\
11,1 \\
1,8 \\
0,8\end{array}$ & $\begin{array}{r}0, ' t \\
1,2 \\
3,9 \\
0,1 \\
23,9 \\
3,8 \\
0,7 \\
0,2 \\
11,6 \\
42,9 \\
8,1 \\
2,4 \\
1,4\end{array}$ & $\begin{array}{r}0,3 \\
0,3 \\
1,6 \\
0,5 \\
22,2 \\
2,9 \\
0,4 \\
0,2 \\
10,9 \\
43,5 \\
12,9 \\
2,3 \\
1,6\end{array}$ & $\begin{array}{r}0,3 \\
0,4 \\
1,7 \\
0,1 \\
22,6 \\
3,1 \\
0,1 \\
0,6 \\
10,8 \\
43,8 \\
13,7 \\
1,7 \\
0,9\end{array}$ & $\begin{array}{r}0,2 \\
0,9 \\
3,2 \\
0,2 \\
25,1 \\
3,9 \\
0,5 \\
0,2 \\
11,3 \\
43,5 \\
7,7 \\
1,2 \\
1,1\end{array}$ \\
\hline
\end{tabular}

Dans les deux cas, cette augmentation est composée par une diminution relative des acides saturés $\mathrm{C}_{16}$ et $\mathrm{C}_{18}$.

La lactation, au contraire, n'apporte pratiquement pas de modification à la répartition des acides gras par rapport à la fin de la gestation. Tout au plus peut-on noter une légère tendance (non significative) à la diminution de l'acide linoléique dans tous les lots et à l'augmentation de l'acide palmitique dans le lot C-A.

On notera aussi la présence de constituants intermédiaires entre certains acides gras majeurs, mais pour lesquels notre procédé d'analyse ne donne pas de garantie quant à l'identification et aux pourcentages exacts. Ces fractions semblent peu varier avec les régimes.

Nous avons essayé par ailleurs d'évaluer la quantité d'acides gras fixés ou mobilisés au cours des différentes périodes.

Avec les mêmes réserves que précédemment quant à la validité d'une telle estimation, on obtient pour l'acide linoléique et la somme acide laurique + acide myristique, les résultats du tableau $7 \mathrm{I}$. Bien entendu, ces résultats n'ont qu'une valeur très approximative. 
L'ensemble de ces premiers résultats confirme nos expériences antérieures et s'inscrit parfaitement dans le cadre de l'action plus générale des lipides du régime sur ceux des dépôts, phénomène bien connu et passé notamment en revue par HIIDrTCH (I956) et par FraxçoIs (I959). Chez la Truie, un apport d'acide linoléique pendant la gestation entraîne un enrichissement des dépôts sous-cutanés en ce même acide au détriment des acides saturés $C_{16}$ et $C_{18}$, c'est-à-dire des acides gras de synthèse. Il est en outre significatif que cette modification apparaisse, malgré la faible variation de l'importance des dépôts. On peut ainsi penser qu'il s'agit plus d'une substitution des acides gras que de l'élaboration de nouveaux tissus, élément à retenir en ce qui concerne la vitesse de renouvellement des acides gras du tissuadipeux (Schoknheimer, I937; Börgstrom, I960).

\section{TABLEAU $7 \mathrm{I}$}

Quantités d'acides gras $C_{12}+C_{14}$ et $C_{18}$ fixées ou perdues au cours de la gestation et de la lactation

\begin{tabular}{|c|c|c|c|c|}
\hline & Acides gras & $\mathrm{M}-\mathrm{C}$ & $\mathrm{M}-\mathrm{A}$ & $C-A$ \\
\hline Gestation & $\begin{array}{l}C_{12}+C_{14} \\
C_{18}=2\end{array}$ & $\begin{array}{r}0,0 \\
+\quad 3,7\end{array}$ & $\begin{array}{r}0,0 \\
+\quad 3,9\end{array}$ & $\begin{array}{l}+2,2 \\
-0,1\end{array}$ \\
\hline Lactation & $\begin{array}{l}C_{12}+C_{14} \\
C_{18}=2\end{array}$ & $\begin{array}{l}-0,1 \\
-2,9\end{array}$ & $\begin{array}{l}-0,1 \\
-2,0\end{array}$ & $\begin{array}{l}-1,1 \\
-1,0\end{array}$ \\
\hline Bilan & $\begin{array}{l}C_{12}+C_{14} \\
C_{18}=2\end{array}$ & $\begin{array}{l}-0,1 \\
+0,7\end{array}$ & $\begin{array}{l}-0,1 \\
+1,9\end{array}$ & $\begin{array}{l}+1,1 \\
-1,1\end{array}$ \\
\hline
\end{tabular}

Il en va un peu différemment lorsque le régime contient des acides à chaîne moyenne, comme l'acide laurique apporté par l'huile de coprah. Dans ce cas, le " marquage " des dépôts paraît moins important quantitativement et porte davantage sur l'acide $\mathrm{C}_{14}$ que sur le $\mathrm{C}_{12}$, phénomène déjà signalé par OsWaLd et al. (I962) et par CHRISTENSEN (I963). On peut sans doute l'expliquer par la moins grande spécificité de 1'acide laurique, qui avant de se déposer peut se convertir en acides gras à nombre d'atomes de carbone différent. Par ailleurs, une partie importante de l'acide laurique đu régime peut être utilisée à des fins énergétiques.

Dans le cas présent, le calcul montre qu'approximativement $30 \mathrm{p}$. Ioo de l'acide linoléique ingéré s'est fixé dans les tissus contre I8 p. Ioo d'acide laurique fixé en $\mathrm{C}_{12}$ ou $\mathrm{C}_{14}$.

Pendant la lactation, tout se passe comme si les acides gras du régime ne se déposaient pas dans le tissu adipeux. Il apparaît, au contraire, une mobilisation qui porte sur environ la moitié des acides retenus pendant la gestation (tabl. 7 I).

Comme dans l'expérience précédente, il est intéressant de remarquer que cette mobilisation porte sur l'ensemble des acides gras et sensiblement dans un même rapport pour tous puisque la physionomie des dépôts n'est pas modifiée et que les modifications induites par la gestation semblent persister après la lactation. 


\section{b) Productions laitières}

Les quantités totales de lait produites et la composition moyenne des échantillons récoltés sont indiquées dans le tableau 72 .

TABLEAU 72

Productions laitières

\begin{tabular}{|c|c|c|c|c|c|c|}
\hline \multirow{2}{*}{ Lots } & \multirow{2}{*}{$\begin{array}{l}\text { Lait } \\
(\mathrm{kg})\end{array}$} & \multicolumn{5}{|c|}{ Composition moyenne (p. $100 \mathrm{~g}$ ) } \\
\hline & & Mat. azotées & Lactose & Lipides & Eau & Cendres \\
\hline M-C & 254 & 5,70 & 5,38 & 8,02 & 79,93 & 0,97 \\
\hline M-A & $2 q^{2} 2$ & 5,79 & 5,55 & 6,83 & 80,89 & 0,94 \\
\hline C-A & 246 & $5,7:$ & 5,33 & 6,99 & 80,93 & 0,98 \\
\hline
\end{tabular}

Les quantités de lait produites sont relativement modestes, ce qui n'est pas étonnant chez des truies primipares et sont sensiblement du même ordre dans les 3 lots. Les compositions de ces laits différent essentiellement par leur teneur en lipides totaux, notablement plus élevée $(+$ I 8 p. Ioo) dans le lot M-C (cette modification se fait au détriment de la teneur en eau). Une analyse graphique montre que ce phénomène se manifeste dès la $2^{\mathrm{e}}$ semaine de lactation et s'intensifie avec le temps. Par contre, les teneurs des autres constituants évoluent d'une façon rigoureusement identique pour les différents lots.

Ce résultat confirme pleinement, pour l'huile de coprah, les observations que nous avions pu faire avec le saindoux ou l'huile de maïs. Il montre bien que, quel que soit le type des acides gras (saturés ou non, courts ou longs), les lipides du régime paraissent toujours plus efficaces que les autres nutriments pour maintenir et augmenter la lipogenèse du lait. L'une des explications qui peuvent convenir et à ce phénomène réside dans la participation directe des acides gras du régime à l'élaboration des lipides du lait, mécanisme moins cô̂teux en énergie que la synthèse à partir des glucides.

c) Répartition des acides gras du lait

Le tableau 73 rapporte les proportions relatives moyennes des différents acides gras que nous avons pu séparer dans le lait de Truie.

Comme pour les tissus adipeux, un certain doute peut subsister pour l'identification des acides gras mineurs, ce qui ne prête pas à conséquence, compte tenu des faibles teneurs de ces acides.

Certaines différences de la répartition des acides gras dans le lait des différents lots méritent d'être soulignées : on note en particulier que la teneur en acides laurique et myristique est nettement plus élevée dans le lot M-C que dans les deux autres lots. Par contre, il y a peu de différence pour ces deux mêmes acides entre les lots M-A et $\mathrm{C}$ - $\mathrm{A}$; tout au plus peut-on noter une légère tendance à l'entichissement dans le lot C-A. Ces deux derniers lots se différencient par contre par leur teneur en acide 
linoléique, plus élevée dans le lot M-A et aussi dans le lot M-C. Ce résultat entraîne une diminution corrélative de la teneur en acide palmitique. Enfin, dans le lot M-C, on note un taux d'acide oléique nettement moins élevé que dans les deux autres lots.

\section{TABLEAU 73}

Répartition des acides gras du lait

(p. Ioo des esters méthyliques)

\begin{tabular}{|c|c|c|c|}
\hline Lots . . . . . . . . . . . . . . . . . & $\mathrm{M}-\mathrm{C}$ & M-A & $\mathrm{C}-\mathrm{A}$ \\
\hline 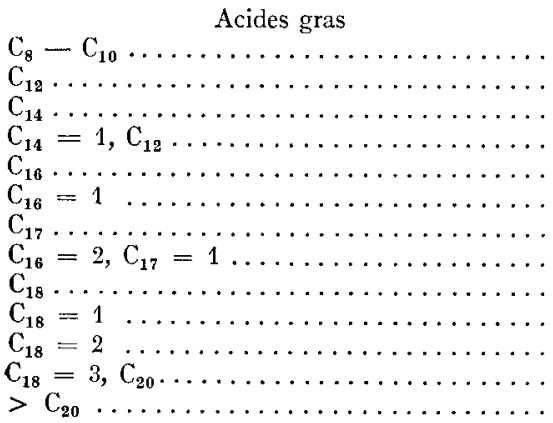 & $\begin{array}{r}0,5 \\
6,3 \\
7,6 \\
0,8 \\
27,8 \\
8,4 \\
0,4 \\
0,4 \\
4,5 \\
32,5 \\
8,6 \\
0,9 \\
1,4\end{array}$ & $\begin{array}{r}0,5 \\
0,9 \\
3,8 \\
0,5 \\
30,4 \\
9,8 \\
0,5 \\
0,4 \\
4,8 \\
37,1 \\
8,6 \\
1,0 \\
1,5\end{array}$ & $\begin{array}{r}0,5 \\
1,2 \\
4,3 \\
0,6 \\
31,7 \\
10,0 \\
0,7 \\
0,5 \\
5,0 \\
36,9 \\
6,2 \\
1,1 \\
1,2\end{array}$ \\
\hline
\end{tabular}

Compte tenu des teneurs en lipides totaux des laits, les quantités des différents acides gras réellement sécrétées par les truies de chaque lot sont sensiblement les suivantes :

TABLEAU 74

Quantilés des différents acides gras sécrétées dans le lait au cours de la lactation (kg)

\begin{tabular}{|c|c|c|c|}
\hline Lots $\ldots \ldots \ldots \ldots \ldots \ldots \ldots \ldots \ldots$ & $\mathrm{M}-\mathrm{C}$ & $\mathrm{M}-\mathrm{A}$ & $\mathrm{C}-\mathrm{A}$ \\
\hline 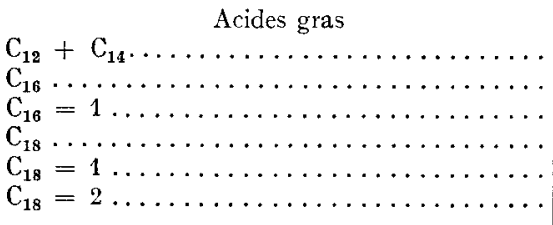 & $\begin{array}{l}2,7 \\
5,5 \\
1,7 \\
0,9 \\
6,4 \\
1,7\end{array}$ & $\begin{array}{l}0,7 \\
4,8 \\
1,5 \\
0,8 \\
5,8 \\
1,3\end{array}$ & $\begin{array}{l}0,9 \\
5,2 \\
1,6 \\
0,8 \\
6,0 \\
1,0\end{array}$ \\
\hline
\end{tabular}

La figure I5 rapporte l'évolution au cours de la lactation des teneurs de quelques acides gras choisis parmi les plus caractéristiques : ces évolutions diffèrent suivant les acides gras et suivant les lots. On constate notamment que les teneurs en acides laurique et myristique augmentent constamment dans le lot $\mathrm{M}-\mathrm{C}$, alors qu'elles restent constantes dans le lot $\mathrm{M}$-A et qu'elles ont tendance à décroître dans le lot C-A. Par contre, la teneur en acide palmitique semble augmenter avec le temps dans les 

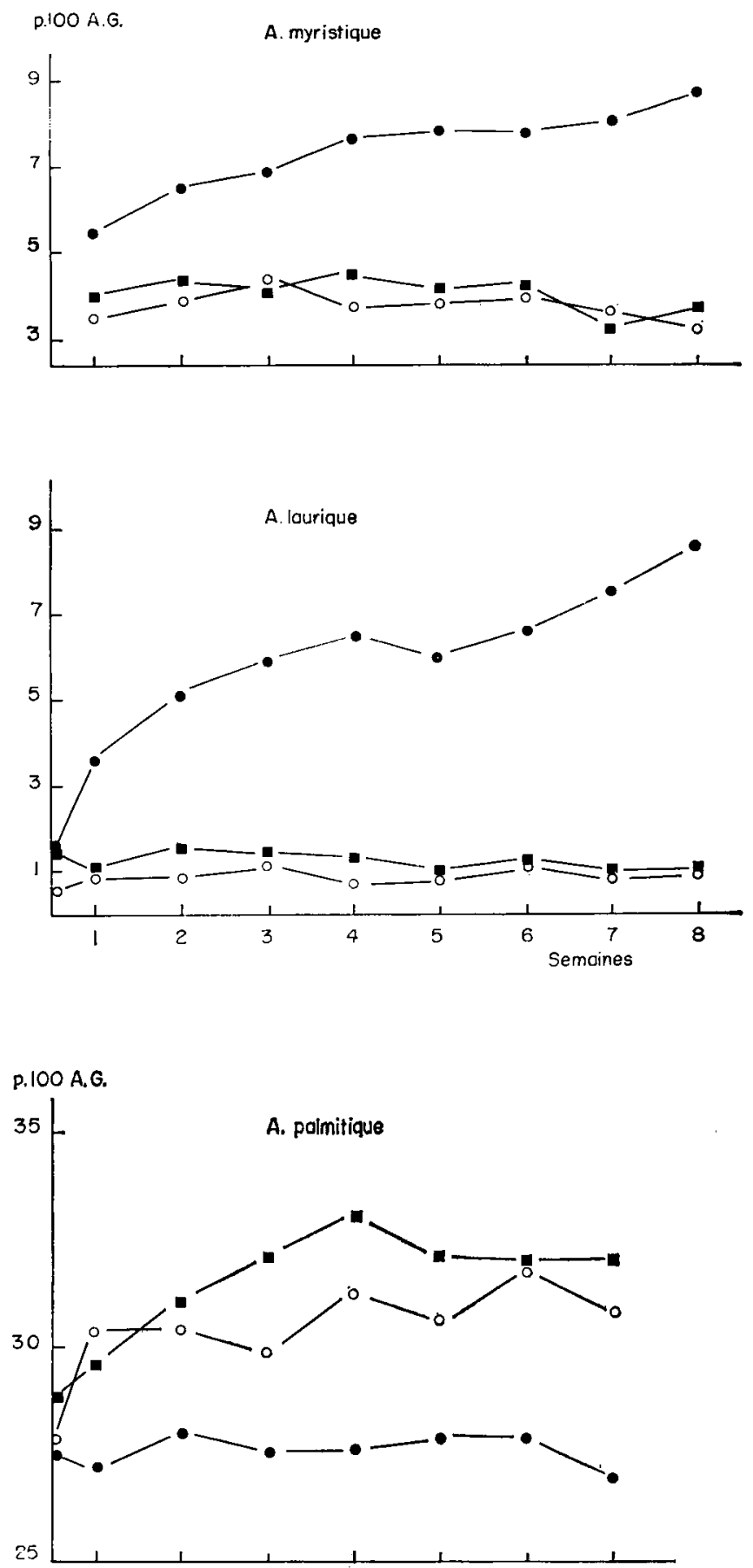

Fig. 15. - Evolution des teneurs en A. G. du lait en fonction du régine - LotMC o Lot MA - Lot CA 

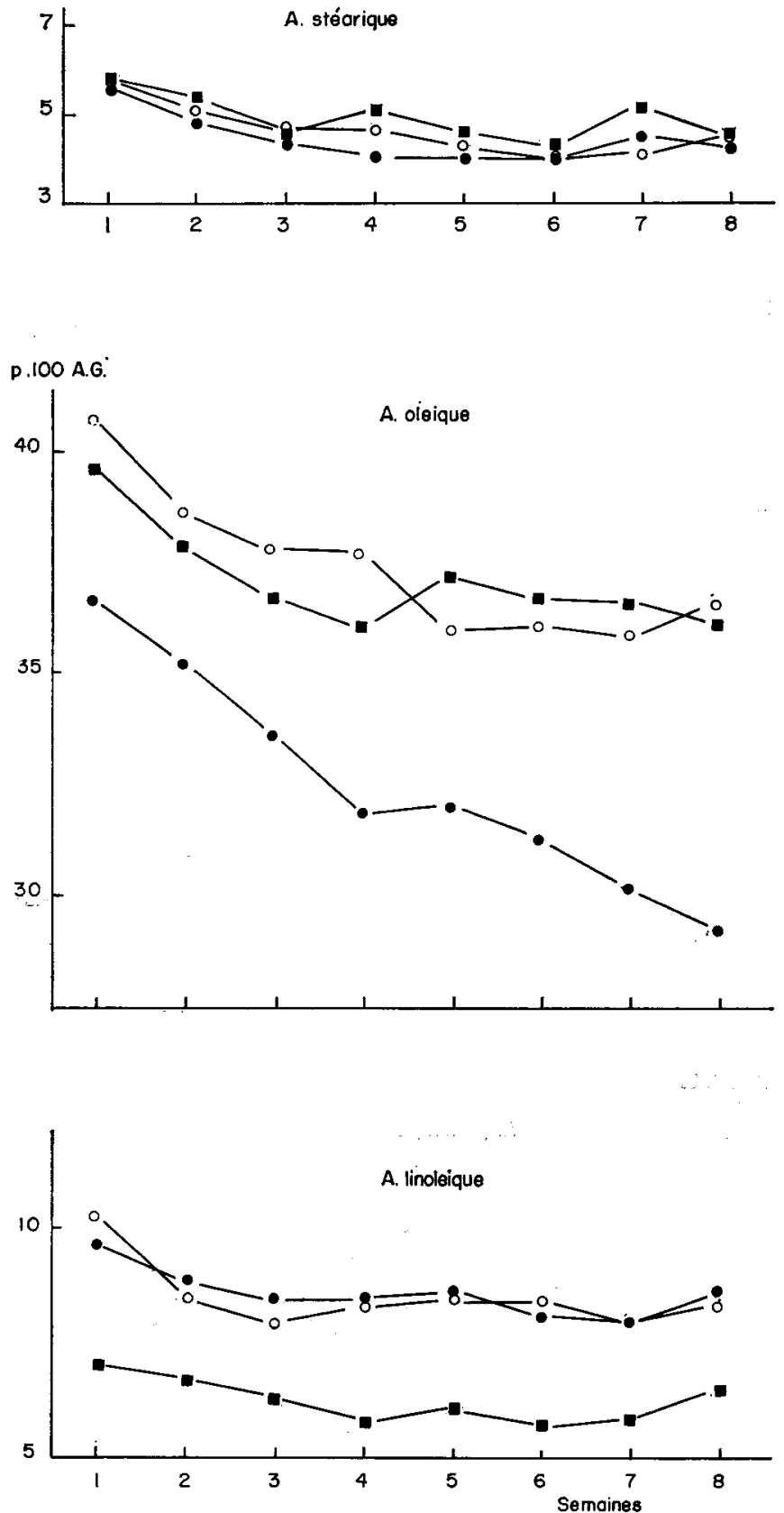

FIG. 15. (suite) - Évolution des teneurs en $A . G$. du lait en fonction du régime - Lot MC o Lot MA - Lot CA 
lots $\mathrm{M}-\mathrm{A}$ et $\mathrm{C}-\mathrm{A}$ et ne pas varier dans le lot M-C. La teneur en acide oléique diminue dans tous les lots, mais surtout dans le lot M-C. Il en va de même de la teneur en acide linoléique, mais la diminution est moins accusée; on observe même une certaine remontée en fin de lactation.

On peut donc donner à l'ensemble de ces derniers résultats l'interprétation suivante :

I $^{\mathrm{O}}$ Tout d'abord, la composition des acides gras du lait de Truie est largement influencée par la nature des graisses du régime, ce qui apparaît dans les résultats du lot M-C. Ce phénomène est général, puisqu'il apparaît avec des types de graisses très différents, ce qui ressort également des observations de BIENFAIT (I957), GaRTON (I957), Halianger (I957), INSUli (I959), BeARE (I96I) et de MaN (I963) sur diverses espèces.

De tels phénomènes ont aussi été signalés chez les Ruminants et passés en revue par Hilditch (I956), par GarTon (I963), et par Kuzdzal-Savore (I958), mais ils sont moins apparents en raison des transformations qui surviennent dans le rumen (ERwIN, I963). Cette utilisation particulière des lipides du régime ne revêt pas un caractère constant, mais tend à s'intensifier avec le temps. Il est en effet significatif que les teneurs en acides laurique et myristique du lait des truies M-C augmentent considérablement du début à la fin de la lactation (fig. I5), alors que celles des lots $\mathrm{M}-\mathrm{A}$ et $\mathrm{C}-\mathrm{A}$ restent pratiquement constantes ou même décroissent légèrement

$2^{\circ}$ L'influence de la mobilisation du tissu adipeux sur la sécrétion des graisses apparaît dans le fait que les triglycérides du lait des lots M-C et M-A contiennent davantage d'acide linoléique que ceux du lait C-A. I1 est d'ailleurs intéressant de souligner que dans le lot M-C les participations des lipides alimentaires et des graisses corporelles ont lieu simultanément. Toutefois, les taux d'acides oléique et linoléique du lait ont tendance à diminuer dans tous les lots au cours de la lactation, ce qui indiquerait une participation décroissante des lipides endogènes, phénomène qu'évoquait déjà notre expérience précédente. Nous ne saurions conclure, par ailleurs, en ce qui concerne les acides gras saturés d'origine corporelle, la teneur des laits en acides gras à chaîne moyenne est très voisine dans les lots M-A et C-A, malgré la différence de composition du tissu adipeux de ces deux lots. Ceci peut être dû à deux raisons : ou bien ces acides ont été dégradés ou convertis en d'autres acides gras après leur mobilisation (par exemple en acide palmitique), ou bien, ce qui est plus vraisemblable, le "marquage " des graisses de dépôt n'était pas suffisant pour provoquer une augmentation de la teneur en acide laurique du lait. Ce phénomène reste à préciser ultérieurement.

$3^{\circ}$ La participation relative des différents précurseurs des lipides du lait peut en partie se déduire des quantités des différents acides gras secrétés dans la production laitière de chaque lot (tabl. 7I) et en partie de l'évolution des teneurs de ces acides gras au cours de la lactation. C'est ainsi qu'il apparaît dans nos concitions qu'approximativement $20 \mathrm{p}$. Ioo des acides en $\mathrm{C}_{12}$ et $\mathrm{C}_{14}$ et $30 \mathrm{p}$. Ioo de l'acide linoléique proviennent, par voie endogène, du régime de gestation ( $\left.{ }^{1}\right)$; environ $70 \mathrm{p}$. Ioo des acides gras à chaîne moyenne et ro à 20 p. Ioo des acides à longue chaîne sont liés à l'ingestion de lipides pendant la lactation; le reste, soit la plus grande partie des

(') La quantité d'acide linoléique réellement endogène est certainement supérieure, mais difficile à apprécier, car une partie provient également des dépôts édifiés avant la gestation. 
acides à longue chaîne, sauf le linoléique, provient d'une autre origine, c'est-à-dire principalement des glucides de la ration. Mais il ne s'agit là que d'estimations. De plus, ces proportions évoluent sans doute au cours de la lactation : s'il paraît clair en effet que la participation des lipides exogènes va en s'accentuant au cours de la lactation, on peut penser que lorsque ceux-ci font défaut, ce sont au contraire les lipides de synthèse qui tendent à l'emporter. C'est ce que montre l'augmentation de la teneur en acide palmitique et la chute moins rapide de la teneur en acide oléique, qui apparaissent dans les lots $\mathrm{C}-\mathrm{A}$ et $\mathrm{M}-\mathrm{A}$.

\section{d) Conclusion}

Cette expérience confirme à nouveau l'existence des différentes origines exogènes et endogènes des lipides du lait de Truie, mais aussi certaines particularités de l'utilisation des graisses alimentaires au cours de la reproduction :

- L'acide laurique est moins sélectivement fixé dans les dépôts au cours de la gestation que l'acide linoléique. Il en résulte qu'au cours de la lactation les tissus de réserve jouent surtout le rôle de pourvoyeurs d'acides insaturés et polyinsaturés.

- Le transfert direct des acides gras saturés du régime du lait se fait dans des conditions analogues à celles des acides gras insaturés, mais avec un rendement un peu inférieur. Il contribue à augmenter d'autant la quantité de lipides sécrétés dans le lait et donc l'efficacité de la ration.

- Quel que soit le régime, l'intensité des synthèses d'acides gras à partir des glucides au cours de la lactation reste importante. Elle paraît indépendante des deux autres processus et ne dépendre, en définitive, que de l'aptitude individuelle de l'animal.

\section{D - Discussion générale}

On ne peut manquer d'être frappé par la grande similitude qui apparaît, chez la Truie, entre la répartition des acides gras des dépôts adipeux et celle des lipides du lait. De telles ressemblances existent chez la plupart ces espèces (HILDITCH, I956), mais elles sont particulièrement nettes chez certains monogastriques (Rat, Femme) surtout lorsque la ration de ces dernières comporte une quantité importante de graisse. L'une des raisons en est que dans ce cas la composition des dépôts adipeux et celle des lipides du lait sont également influencées par celle du régime. Toutefois, cette influence peut s'exercer d'une façon indirecte, puisque toutes nos expériences montrent bien qu'il suffit de réaliser une modification des dépôts adipeux pendant la gestation pour provoquer une modification qualitative ou quantitative de la sécrétion des lipides du lait. Ceci semble montrer qu'une partie au moins des lipides du lait de Truie provient de ces dépôts, où l'animal vient puiser en fonction des besoins de sa lactation. Ceci justifie pleinement, à cet égard, le terme de tissu de réserve.

Les problèmes qui se posent sont alors de savoir quelle est l'extension de ces phénomènes de transfert, s'ils sont généraux ou facultatifs, s'ils s'appliquent indifféremment à tous les acides gras du lait et enfin quelle est la place des lipides corporels à côté des autres précurseurs des graisses du lait.

Notre expérience devrait permettre de répondre partiellement à certaines de ces questions.

On constate tout d'abord qu'en l'absence de toute modification qualitative du 
régime alimentaire, l'influence des lipides de dépôts apparaît dès l'instant où le niveau alimentaire de gestation est élevé. Par contre, elle paraît moins évidente lorsque le niveau alimentaire de lactation est lui-même élevé. Ceci laisse penser que le phénomène est essentiellement fonction des niveaux énergétiques respectifs de la gestation et de la lactation et montre bien qu'il ne constitue qu'un des aspects de la lipogenèse du lait. Ceci reste en accord avec la théorie classique qui veut qu'une part importante des acides gras du lait soit synthétisée à partir des hydrates de carbone de la ration, ou du glucose sanguin (FOLLEY, I96I ; GaRTON, I963).

Toutefois, le fait qu'un supplément de graisse dans la ration de lactation ait un double effet qualitatif et quantitatif sur les lipides du lait confirme l'existence d'une troisième origine possible de ces lipides. Ce phénomène a été souvent rapporté chez les monogastriques, mais il est plus rare chez les Ruminants, notamment lorsqu'il s'agit d'acides gras insaturés à longue chaîne. Le plus surprenant dans notre expérience vient moins du résultat lui-même que du fait qu'il ne semble pas faire obstacle aux autres mécanismes de la lipogenèse, ce qui a parfois été signalé. La distribution de graisse à une truie en lactation se traduit essentiellement par une augmentation du taux de lipides du lait, qui apparaît même à un niveau énergétique constant et rien ne permet de supposer que la part des autres précurseurs soit diminuée d'autant. Tout au plus peut-on observer une légère diminution de la fonte des graisses corporelles, sans que celle-ci soit jamais complètement empêchée.

La mobilisation du tissu adipeux au cours de la lactation apparaît donc comme un phénomène essentiel, sinon obligatoire, dont le déterminisme et les conditicns restent toutefois à préciser.

C'est à l'aide de régimes enrichis en acides gras polyinsaturés que les phénomènes de transfert sont le plus facile à suivre. L'animal n'étant pas capable de synthétiser ces acides en quantité suffisante, il est clair que l'acide linoléique retrouvé dans le lait provient des dépôts adipeux lorsque le régime de lactation n'en contient pas lui-même. Ce phénomène a été volontairement exagéré dans nos conditions expérimentales, mais il est vraisemblable que dans les conditions habituelles d'un régime contenant moins de I p. Ioo d'acide linoléique, le stockage réalisé pendant la gestation est suffisant pour couvrir la presque totalité de la sécrétion des polyènes du lait (compte tenu de ce que celui-ci ne contient pratiquement pas d'acide linolénique).

Par contre, le phénomène est moins certain en ce qui concerne les acides gras saturés, courts ou moyens, du type acide laurique par exemple. Ceux-ci semblent se déposer beaucoup moins facilement que l'acide linoléique au cours de la gestation et n'apparaître dans le lait que s'ils sont distribués au cours de la lactation (les techniques que nous avons utilisées ne nous permettent pas d'en savoir davantage). Ce phénomène n'est pas nouveau (CHRISTENSEN, I957) et peut s'expliquer par l'aspect moins "physiologique " de ces acides gras qui sont peut-être transformés ou utilisés à d'autres fins.

On ne saurait prétendre toutefois que la mobilisation du tissu adipeux se limite aux seuls acides insaturés puisque la composition des dépôts ne varie pratiquement pas au cours de la lactation et ceci quel que soit le régime. Ceci semble indiquer, bien que le phénomène puisse être beaucoup plus complexe, que tous les acides gras sont prélevés à la même vitesse et dans les mêmes proportions, ce qui paraît contraire à certaines observations (LONGNECKER, I.93I), Réciproquement, les glycérides ingérés au cours de la lactation ne se déposent pas et sont utilisés préférentiellement, quelle 
que soit leur nature, pour la lipogenèse du lait (on ignore toutefois s'il y a identité de structure entre les glycérides ingérés et ceux du lait).

Il ne saurait être question enfin, compte tenu de l'imperfection de nos méthodes, d'essayer d'apprécier valablement la part qui revient aux différentes origines, corporelles, exogène et synthétique, des graisses du lait. Ne serait-ce que parce que celles-ci varient visiblement suivant les régimes. Si l'on s'en tient toutefois à l'évolution de la composition du lait au cours de la lactation, nos expériences semblent indiquer une participation décroissante des lipides de dépôt, alors que la participation des glycérides de synthèse et, éventuellement, des graisses du régime irait en augmentant.

Ceci permet de souligner une nouvelle fois la signification nutritionnelle de la mobilisation au cours de la lactation du tissu adipeux édifié pendant la gestation, à une époque où l'appétit de l'animal s'avère très insuffisant poutr faire face à une lipogenèse pourtant très élevée. 


\section{RÉSUMÉ ET CONCLUSIONS GÉNÉRALES}

Ce travail est consacré à l'étude de l'aspect nutritionnel des fonctions de reproduction de la Truie et à la mise en évidence des relations métaboliques qui unissent la gestation et la lactation.

L'introduction définit les objectifs et rappelle l'intérêt, tant sur le plan fondamental que pratique, d'une meilleure connaissance de ces relations. Elles furent déjà illustrées par les travaux de WALLACE (I948) sur la Brebis et de BoURDEL (I96o) sur la Ratte. Elles seront envisagées ici essentiellement sous l'angle de l'utilisation des nutriments énergétiques et azotés.

Le premier chapitre indique les techniques expérimentales mises en œuvre: méthodes physiologiques, biochimiques, anatomiques... appliquées à l'analyse quantitative et qualitative de la variation du poids vif, de l'évolution du contenu utérin et de la production lactée.

Le chapitre suivant délimite le cadre des recherches entreprises en apportant quelques précisions sur le caractère particulier des fonctions de reproduction chez la Truie. Les différents facteurs de variations sont sommairement analysés, ce qui permettra de dégager la part qui revient, dans les phénomènes observés, au stade physiologique, aux conditions individuelles ou de milieu et, en définitive, à la nutrition.

C'est ainsi qu'en ce qui concerne les variations de poids, la gestation estl'occasion d'un anabolisme extra-utérin important qui dépasse en valeur pondérale, ou sur le plan de l'énergie et de l'azote retenus, celui de l'utérus et de son contenu. Ce phénomène est lié en tout premier lieu à une épargne considérable des nutriments azotés qui apparaît d'une façon particulièrement nette en fin de gestation. Il s'ensuit que la gravidité se caractérise également par des variations de composition corporelle et qu'elle se solde par une tendance à la délipidation qui s'intensifie au cours de la lactation.

L'évolution des contenus utérins obéit à des lois bien connues. La production laitière est 1'objet, par contre, de variations importantes qui mettent en jeu de nombreux facteurs tels que l'âge, le poids, le nombre de porcelets, le stade de lactation. L'examen de ces facteurs donne lieu à quelques résultats nouveaux, notammemt dans le domaine de la composition du lait et des relations entre constituants.

Le chapitre III aborde le problème de l'influence du niveau alimentaire global sur les phénomènes de la reproduction. Il met en évidence trois résultats essentiels :

- On note une différence dans le comportement de la femelle suivant son état physiologique (repos sexuel, gestation, lactation). La Truie utilise les nutriments de sa ration d'autant plus efficacement que le besoin nutritionnel est plus intense. C'est 
ainsi qu'un même supplément alimentaire est mieux utilisé par la laitière que par la gestante et par cette dernière que par la Truie au repos.

- De par le jeu des priorités qui s'établissent entre les besoins imposés par les productions (contenu utérin et lait) et les besoins somatiques, l'embryon et la production laitière peuvent s'accommoder de conditions alimentaires difficiles ; l'effet de modifications du niveau nutritionnel global affecte, par contre, l'importance de la mobilisation ou de l'élaboration des tissus extra-utérins. Ces derniers, et plus particulièrement le tissu adipeux, jouent en quelque sorte le rôle de tampon entre les productions prioritaires et les variations du régime.

- Il apparaît toute une série d'ajustements entre la gestation et la lactation (niveau d'ingestion, variation de poids, efficacités alimentaires) qui portent l'animal à rétablir au cours de la lactation un équilibre qui a pu être modifié par les conditions particulières de la gestation. Il en résulte, comme le montrent les expériences de régimes croisés, que c'est au moment où l'aliment est le mieux utilisé, c'est-à-dire au cours de la lactation, que la fourniture d'un apport alimentaire adéquat paraît le plus nécessaire.

Le rôle plus particulier de l'azote dans ces relations est évoqué au chapitre IV. Si la gestante fait preuve d'une aptitude élevée à anaboliser les matériaux azotés, cette aptitude est encore bien plus marquée au cours de la lactation puisqu'elle se manifeste même avec des régimes pauvres en azote et en l'absence de toute augmentation de poids. De ce fait, le besoin azoté spécifique des fonctions de reproduction est moins élevé qu'il ne paraît et l'influence d'une variation de l'apport azoté se traduit moins par une modification pondérale des productions que par l'intensification de la protéinogenèse extra-utérine et par une modification de la composition corporelle. L'azote de la ration ne pouvant être considéré comme un facteur limitant, il s'ensuit que les variations de poids, tant au cours de la gestation que de la lactation, dépendent avant tout de l'apport énergétique, ce qui souligne l'une des différences fondamentales que la reproduction fait apparaitre dans l'utilisation_des nutriments : diminution en valeur relative du besoin azoté, mais augmentation en valeur relative et absolue $\mathrm{du}$ besoin énergétique.

Toutefois, cette notion du besoin de reproduction doit être nuancée en ce qui concerne l'influence de la qualité de l'apport azoté en fonction du stade physiologique : une même protéine, telle l'arachide, n'a pas la même valeur nutritionnelle suivant qu'elle est distribuée à une truie au repos, en gestation ou en lactation. Cette influence de la qualité apparaît surtout dans les variations corporelles. Elle est plus importante au cours de la lactation que de la gestation et de la période de repos, ce qui fixe la hiérarchie de l'intensité des besoins suivant l'état physiologique.

I,es transferts lipidiques permettent d'avoir au chapitre $V$ un dernier aspect des relations nutritionnelles entre la gestation et la lactation. Quelle que soit la période de distribution, les lipides du régime sont acheminés vers une même utilisation : la lipogenèse du lait, mais les voies sont différentes :

- Pendant la gestation, les lipides se déposent dans le tissu adipeux, dont ils contribuent éventuellement à accroître l'importance. Ils sont ensuite mobilisés au cours de la lactation et " marquent " alors les lipides du lait de leurs acides gras caractéristiques. Ce phénomène est plus net pour les acides gras insaturés à chaîne longue que pour les acides gras saturés moyens ou courts, ce qui distingue en cela la Truie des Ruminants. 
- Pendant la lactation, les acides gras ne se déposent pas dans les graisses de réserve, mais leur transfert est direct du régime au lait, ce qui modifie la quantité et la composition des graisses du lait, quel que soit le type des acides gras utilisés. Toutefois, ce phénomène ne diminue pas pour autant l'intensité des autres processus endogènes ou exogènes de la lipogenèse. La mobilisation du tissu adipeux aux fins de la lactation sa poursuit et laisse donc toute leur signification aux "réserves " de gestation.

En définitive, c'est donc essentiellement par le truchement des variations corporelles que s'exerce une grande partie des relations nutritionnelles, énergétiques, protidiques ou lipidiques, entre la gestation et la lactation. Ce phénomène, des plus remarquables, souligne les étonnantes facultés d'adaptation aux conditions alimentaires variées de la Truie en reproduction. Mais si les modalités de ce phénomène sont maintenant mieux connues, son déterminisme, vraisemblablement hormonal, reste encore à préciser.

\section{SUMMARY}

SOME ASPECTS OF THE NUTRITIONAL RELATIONSHIPS

BETWEEN PREGNANCY AND LACTATION IN THE SOW

The work is devoted to a study of the nutritional aspects of the sow's reproductive functions and brings evidence to bear on the metabolic relationships linking pregnancy with lactation. The latter are considered here mainly under the angle of the way the energy and nitrogenous nutrients are utilized.

Chapter I deals with experimental methods put into operation and applied in the quantitative and qualitative analysis of changes in live weight, on the evolution of the intra-uterine content and on milk production. The techniques were applied in 22 experiments covering a total of I 250 sows and calling for the collection and chemical analysis of 4 ooo miscellaneous samples involving milk, tissue, excreta etc.

The next chapter outlines the scope of the experiments undertaken and considers the specific character of the reproductive functions in the Sow.

Thus for instance in the case of changes in weight, pregnancy gives rise to appreciable extra. uterine anabolism which from the standpoint of weight or in regard to retained energy and nitrogen, exceeds that of the uterus and its contents. This phenomenon is linked primarily to considerable savings in the nitrogen nutrients that is particularly marked towards the end of pregnancy. It follows that pregnancy is also characterized by changes in bodily proportions and that it closes on a tendency towards loss of lipids that increases during lactation.

The changes in intra-uterine contents follow known laws. On the other hand, milk production is subject to appreciable fluctuations involving a number of factors such as age, weight, number of Piglets, and phase of lactation. An analysis of these factors yields certain new results, notably as regards the composition of the milk and the relationships between the ingredients.

Chapter 3 deals with the problem of the influence of the overall nutritional level on the phenomena of reproduction. It stresses the importance of three essential features :

I. I difference is noted in the food efficiency of the female at different physiological states, e. g. sexual dryness, pregnancy, lactation. The sow utilizes the nutrients in its feed all the more efficiently as its nutritional requirements are more intense. Thus an identical food additive is better utilized by a lactating sow than by a pregnant one and by the latter than by a dry sow.

2. Arising out of the play of priorities established bet ween the requirements (intra-uterine content and milk) of the productive processes on the one hand, and somatic requirements on the other, both fetus and milk production can become conditioned to difficult nutritional conditions. The changes in overall nutrient level, on the other hand, repercuss on the extent of mobilization or elaboration of extra-uterine tissue. The latter, and more particularly fatty tissue, acts somewhat as a buffer between the priority productions and dietary fluctuations. 
3. A series of adjustments (ingtstion level, weight fluctuation, food efficiency) now appear between pregnancy and lactation, whereby the animal is induced, in the course of lactation, to restore the balance which was modified by the special conditions of pregnancy. The result is that, as experiments in high-low diet planes have shown, the time when food is best utilized - namely during lactation - is the time when an adequate food supplement would appear most necessary.

The specific role of nitrogen in such relationships is considered in Chapter IV. Although the gestating animal shows a conspicuous aptitude to anabolize nitrogenous material, this ability is even more pronounced during lactation, since it manifests itself even with nitrogen-poor diets and without any increase in weight. Owing to this the specific nitrogen requirements of the reproductive functions are lower than they might appear, and the effects of varying the supplementary nitrogen is reflected less in a change in weight of the reproductive functions than in intensified extra-uterine protein deposition and by changes in the bodily composition. As the nitrogen in the feed cannot be considered a limiting factor, it is evident that weight changes, both during pregnancy and lactation are primarily dependent on ingested energy. This emphasises a fundamental difference brought to light by reproduction regarding the utilization of nutrients, namely the reduction in relative value of nitrogen requirements, simultaneously with an increase in both relative and absolute value in energy requirements.

The concept of reproductive requirements however must be tempered as regards the effects of the quality of nitrogen additive in terms of the physiological phase. Thus the same protein such as peanuts does not have the same nutritional value depending on whether it is given to a dry sow, one in pregnancy or one in lactation. This influence of quality appears mainly in bodily changes. It is greater during lactation than during pregnancy, and in the latter than during the dry period. This determines a hierarchy in the intensity of requirements in terms of the physiological state.

The transfer of lipids, considered in Chapter $V$, provides a final aspect of the nutritional relationships between lactation and pregnancy. Whatever the duration of distribution, the food lipids are channeled to the same utilization - the lipogenesis of milk - but the channels are different.

- During pregnancy, lipids are deposited in adipose tissue, to which they ultimately make some contribution. Next they are mobilized during lactation and "label " the milk lipids with their characteristic fatty acids. The phenomenon is more pronounced in the case of long-chain unsaturated fatty acids than in the case of medium or short-chain saturated fatty acids, which is what distinguishes the sow from the ruminants.

- During lactation, fatty acids are not deposited in fatty stores, but a transfer takes place directly from diet to milk, thereby modifying the quantity and composition of the milk fats, whatever the type of fatty acid used up. The phenomenon however does not in any way reduce the intensity of the other endogenous and exogenous processes of lipidogenesis. Mobilizing the fatty tissue for the purpose of lactation continues, thereby enhancing the significance of the pregnancy " stores"

In the final analysis, it is essentially through the action of bodily changes that a major portion of the nutrient, protein, energy, and lipid relationships take place between pregnancy and lactation. This remarkable phenomenon underscores the astonishing faculties of adaptation of the sow during reproduction to a variety of nutritional conditions. Yet though the mechanism of this phenomenon is now a little better understood, its determination - presumably hormonal in origin - still requires clarification. 


\section{RÉFÉRENGES BIBLIOGRAPHIQUES}

Adams C.R., Becker D. E., Terril S. W., Norton H. W., Jensen A. II., yg6o. Rate of ovulation and implantation in swine as affected by dietary protein. J. anim. Sci. 19, 1245 .

AdRian J., RÉrat A., I958. Méthodes d'évaluation de la valeur nutritive des protéines. Cahiers Techn. C. N. C. R. N. A., I.

Allen V. N., I934. The fat percentage of milk as affected by feeding fats to dairy cows. J. dairy Sci. 17, 379 .

ALlen N., FITCH J. B., I94I. The influence of sustained high fat intake upon milk fat production. J. dairy Sci. 24, 516 .

Allex A. D., Lasley J. F., ig6o. Milk production in sows. J. anim. Sci. 19, I50.

American oil chemists society, 1956. Total glycerol. Official Method Ca 14,56.

American oll Chemists society, 1958. Polyunsaturated acids. Official Method Cd $7,5^{8}$.

Aschaffenburg R., Drewry J., x959. New procedure for the routine determination of the various noncasein proteins of milk. Intern. Dairy Congr., 3, 163 I.

ASDELL S. A., 1946. Patterns of mammalian reproduction. Comstock, New-York.

BAdings H. T., I962. Fatty acid composition of milk Phopholipids. Netherl. Milk Dairy J. 16,2 I8.

Baker L. N., Woehling H., Casida L. C., Grummer R. H., r953. Occurence of cestrus in sows following parturition. J. anim. Sci. 12, 33 .

Bar P., Daunay R., I905. Bilan des échanges azotés pendant la grossesse. J. Phys. Pathol. gén. 7, $83^{2}$.

Barber R. S., Braude R., Mrtchell K. G., I955. Studies on milk production of Large-White pigs. J. agric. Sci. 46, 97 .

Beacom S. E., Bowland J. P., I95I. Teneur en acides aminés essentiels (sauf le tryptophane) du colostrum et du lait de Truie. J. Nutrit. 45, 4 I9.

Beare J. I., Gregory E. R. W., Smith D. M., Campbell J. A., i96I. The effect of rapeseed oil on reproduction and on the composition of rat milk fat. Canad J. Biochem. Physiol. 39, 195.

Beare J. L., Murray T. K., Grice H. C., Campbell J. A., i959. A comparison of the utilization of rapeseed gil and corn oil by the rat. Canad. J. Biochem. Physiol. 37, 6r 3 .

Beare J. L., Campbell J. A., Youngs C. G., Craig B. M., i963. Effects of saturated fat in rats fed rapeseed oil. Canad. J. Biochem. Physiol. 41, 605.

Beaton G. H., Ruy M. H., Beare J. L., 1954. Protein metabolism in the pregnant rat. Rev. Canad. Biol. 13, 450 .

Becze J., I958. Données sur le développement intra-utérin des porcelets Middle-White. Allattenvésztés, 7, 305 .

Berge S., Indrebo T., I953. Milk production by sows. Meld. Norg. Landbrukshoegsk. 33, 389.

Bhalerao V. R., Endres J., Kummeron F. A., ig6i. Fatty acid composition of lipides extract from rats, fed milk fat, corn oil, and lard. J. dairy Sci. 44, 1283 .

Bienfait J. M., i 957. Influence du stade de la lactation et de la nature lipidique des régimes sur les caractéristiques et la composition de la matière grasse du lait. Ann. Med. Vet. 101, 45.

Bligh E. G., Dyer W. J., 1959. A rapid method of total lipid extraction and purification. Canad.J.Bio-

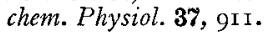

BoAz T. G., Ig62. The significance of leved of protein in the nutrition of the pregnant sow. Veter. Record 74, 1432.

Bolton W., Murty V. N., ig6o. The effect of supplemental fat on the digestibility o the carbohydrates in compounded poultry diets. J. agric. Sci. 55 (Part 2), 203.

Bonsma F.N., I935. Milk production in Large Black sows. Afr. J. Sci.32, 360.

Borgtrom B., rg6o. Metabolism of glycerides, in Bloch K., Lipid metabolism, I 29 Wiley ed. New York.

Bortz W., Abraham S., Chaikoff I. L., r963. Localization of the block in lipogenesis resulting from feeding fat. J. Biol. Chem. 238, 1266.

Bourdel, G., L'anabolisme gravidique : ses caractéristiques, son déterminisne. $4^{\ominus}$ Congrès Intern. Nutrition, Résumé des Communications, 37. 
Bourdel G., Jacquot R., I959. Effets nutritionnels de la prolactine comparés à l'action des placenta laissés in utero chez la Ratte castrée. Étude des courbes pondérales et des bilans. C.R. Acad. Sci. 248, 2249 .

Bourdel. G., Jaçuot R., I959. Effets nutritionnels de la prolactine comparés à l'action des placenta laissés in utero chez la Ratte castrée. Étude de la composition corporelle. C. R. Acad. Sci. 248, 2405.

Botrdel G., 1960. Contribution à l'étude des facultés anabolisantes de la Ratte gravide. Caractères et déterminisme de l'anabolisme protéique. I. Les manifestations de l'anabolisme gravidique. J. Rech. C.N.R.S. 52, I97.

Bourdel G., Quadjovie C., ig60. Comparaison entre les effets nutritionnels de la prolactine et du benzoate d'œstradiol administrés à la Ratte entière et les manifestations anaboliques de la progestation. Arch. Sci. physiol. 14, $3^{21}$.

Bourdel G., 1960. Contribution à l'étude des facultés anabolisantes de la Ratte gravide. Caractères et déterminisme de l'anabolisme protéique. Thèse Doct. ès-Sci. Nat., Univ. Paris (série A, no 3506 ) n ${ }^{\circ} 437^{8}$.

Bourdel G., Jacquot R., Kleis M., Mayer G., 196r. Nutrition et gestation. Ann. Nutr. $15, \mathrm{~B} 337$.

Bourdel G., 1961. Contribution à l'étude des facultés anabolisantes de la Ratte gravide. Caractères et déterminisme de l'anabolisme protéique. III. Effets nutritionnels de la prolactine chez la Ratte entière et castrée. J. Rech. C. N.R.S. 55, $129-139$.

Bowland J. I'., Grummer R. H., Phillips P. H., I949. The effect of the plane of nutrition on the composition of sow's colostrum and milk. J.anim. Sci. 8, 200.

Bowland J. P., Grummer R. M., 1949. The vitamin A and vitamin C content of sow's milk, blood and liver, and the vitamin D content od the milk. J. anim. Sci. 8, 615 .

Bowland J. P., Grummer R. H., Phillies P. H., Bohstedt G., 1949. The effect of the plane of nutrition on the composition of sows colostrum and milk. J.anim. Sci.8, r99.

Boyne A. W., Chalmers M. J., Cuthbertson D. P., ig53. Bilan et répartition de l'azote chez la Ratte gestante et allaitante. Hoppe-Seyler's Z. physiol. chem. 295.

Braude R., Kon S. K., Thompson S. Y., I946. A note on certain vitamins of sow's colostrum. J. dairy Res. 14, 4I4.

Braude R., Coates M. E., Henry K. M., Kon S. K., Rowland S. J., Tilompson S. Y., Walker D. M., 1947. A study of the composition of sow's milk. Brit. J. Nutrit. 1,64.

Bradde O., i951. Nutritive value for rats of sow's milk in comparison with cow's milk. J. dairy Res. 18, 283 .

Breirem K., I949. L'influence de l'alimentation du bétail sur la composition du lait et la qualité des produits laitiers $X I^{\mathbf{e}}$ Congr. Intern. Laiterie, Stockholm Rapport Général Sec. I, 9.

Breirem K., 1957. Nutrition and lactation in domestic animals and particularity in the cow. $4^{\mathrm{e}}$ Congr. Intern. Nutrition, extr. Ann. Alim. $11(3-4), 85$.

Brody S., 1945. Bioenergetics and growlh. Reinhold, New-York.

Brody S., Worstell D. M., Ragsdale A. C., I948. Growth and development with special reference to domestic animals. 63 Heat production and cardiorespiratory activities during gestation and lactation in Jersey' cattle. Univ. Missouri Agric. Exp. Siat. 412, 22.

Burger J. P., 1952. Sex Physiology of pigs. Ondersuepoort J. Vet. Res.,suppl. 2.

BurT A. W. A., I 957. The effect of variations in nutrient intake upon the yield and composition of milk. I. Variation in the amount and type of concentrates fed winter ration. J. dairy Res. 24, 283.

BuRT A. W. A., I 957. The effect of variations in nutrient intake upon the yield and composition of milk. II-Factors affecting rate of eating roughabe and responses to an increase in the amount of concentrates fed. J. dairy Res. 24, 296.

Calloway D. II., Hillf R., Hunson A. II., 1962. Effects of chronic food rectriction in swine. J. Nutr. 76, 365 .

Carlyle W. C., I903. The food requirement of pigs from birth to maturity. Wisc. agric. exper. Sin., Bull. 104.

CARMichael W. J., BRICE J. B., i920. Variations in farrow : with special reference to the birth weight of pigs. Illinois agric. exper. Stn., Bull. 226.

Carrol W. E., Krider J. L., I950. Sreine Production. MC Graw Hill, New York.

CASIDA I. E., I956. Variations in the maternal environment affecting prenatal survival and development Proc. III Intern. Congr. Anim. Reprod., 19.

Cesbron J., 1958. Étude sur le poids à la naissance des porcelets (non publié).

Champigny O., Bourdel G., Jacquot R., 1960. Nutrition.- Bilans énergétiques et azotés de la Ratte au cours de la gestation et sous l'effet de la prolactine. C. R. Acad.Sci. 251, i664.

Champigny O., Jacquot R., 196r. Comportement remarquable de la Ratte gestante en déficience quantirative et qualitative de protides alimentaires. C.R. Acad. Sci. 252, 2765 .

Champigny 0. , 1962. Influence d'une double restriction énergétique et protidique (quantitative et qualitative) sur la gestation et la lactation de la Ratte. C. R. Acad. Sci. 254, I I 55 .

Champigry 0. 1963. Échanges respiratoires et bilans azotés de la Ratte gravide : coût énergétique de l'anabolisme gravidique. C.R. Acad. Sci., 256, 4755 . 
Chapman V. M., lingland D. C., I962. Variation of birth weights within litters of Berkshire swine. J. anim. Sci.21, 970 .

Cinistensen F., DAm H., Enget, P. F., J957. Unsaturated fatty acid composition of subcutaneous fat in rats in relation to diet. Acta Physiol. Scand. $\mathbf{3 8}, 37.3$.

Cirristensen K. D., I $9 \sigma_{3}$. Various fatty acids in fat tissues of pigs of the Danish landrace fed with coconut fat or soybean oil. Acta Agric. Scand. 13, 249.

Clawson A. J., Riciards H. L., Matrone G., Barrick E. R., ig63. Influence of level of total nutrient and protein intake on reproductive performance in swine. J.anim. Sci.22 (3), 662.

Cinistian R. E., Nofziger J. C., 1952. Puberty and other reproductive phenomena as affected by plane of nutrition. J. anim. Sci.11, $7 \mathrm{SO}$.

Clausev H., I952. Investigations concerning the sow milk yield. Nat. Res. Laborat. Anim. Husb., Copenhague.

Clausen H., 1952. Försög med. slagterisvin. Försöglaborat. efterasmode 23 Oct.

CLAWSON A. J., BARRICK I.. R., I962. Energy and protein requirements of first and second litter sows. J. anim. Sci. 21, 991 .

Clenent J., Bolcro P., Loriette C., Raulis J., 1963. Influence de la nature des lipides alimentaires sur la composition et la structure des triglycérides de réserve du Rat blanc. Bull. Soc. Chim. Biol. 45, Io3I.

Combs (r. E., Osfguema F. L., Waldace H. D., Ammermay C. 13., igor. Digestibility of pig starter rations containing various sources of protein. J. anim. Sci. 20, 929 .

Combs G. F., Oserted F. T., Wallace II. D., Amernan C. B., ig63. Digestibility of rations containing different sources of supplementary protein by young pigs. J. anim. Sci. 22, 396 .

Corier G. W., 1923. The problem of embryonic pathology in mammals. Amer. J. .Inat. 31, 523 .

Coop I. E., 1950. The effect of levels of nutrition during pregnancy and lactation on lamb. J. agric. Sci. 40, 3II.

Cowie A. T., Folle S. J., 1947. The measurement of lactational performance in the rat in studies of the endocrine control of lactation. $J$. Entocringl. 5, 9 .

Cox W. M., Mueller A. J., I937. The composition of milk from stock rats and an apparat us for milking small laboratory animals. J. Nutr. 13, 249.

Craig 13. M., Youngs C. G., Beare J. L., Campbell J. A., ig63. Fatty acid composition and glyceride structure in rats fed rapeseed oil or corn oil. Canad. J. Biochem. Physiol. 41, 43.

Cross 13. A., Doonwin R. F., Silver I. A., I958. A histological and functional study of the mammary gland in normal and galactic sows. J. Endocrinol. 17, 63 .

Ducgs R. G., 1934. Studies in lactation. 2-Application of criteria of growth in the suckling young to estimation of lactation in the rat. J. Nutr. 7, Proc. 18.

DagGs R. C., 1934. The effect of various dietary principales on milk productions. Proc. Amer. Inst. Nutrition,. J Nutr,9, 6, supl. p. I3.

DAM H., ENGEL P. F., I958. Unsaturated fatty acid composition of subcutaneous fat and liver fat in rats in relation to dietary fat. Acta Physiol. Scand. 42, 28 .

Davidson H. R., 1930. Reproductive disturbances caused by feeding protein deficient and Ca deficient rations to breeding pigs. J. agric. Sci. 20, 233 .

Davis Ii., J95I. Thiamine, riboflavine, niacine et acide pantothénique dans le lait de la T'ruie. J. dairy Res. 44, I7.

DeAN B. T., Tribble L. F., i959. The effect of feeding during gestation on sow performance. Univ. Missouri, $3^{\mathrm{e}}$ swine day, p. I 2 .

DeAN B. T., TRIBBLE L. F., I960. Effect of level of energy intake during gestation on condition and parformances of swine. J. anim. Sci. 19 (4), I 257.

Dean B. T., Tribble L. F., I960. The effect of level of feeding during gestation on sow perfomance Missouri agric. exper. Stn., $3^{\text {rd }}$ Swine day, 6.

Deb A. K., CAMA H. R., I962. Studies on human lactation. Dietary nitrogen utilization during lactation, and distribution of nitrogen in mother'milk. Brit. J. Nutr. 16, $6_{5}$.

Devel H. J., Martin C. R., Alfin-slater R. B., I956. The effect of fat level of the diet on general nutrition. XII. The requirement of essential fatty acids for pregnancy and lactation. $J$. Nutr. 54, I93.

Deuel. H., I957. The lipids. Interscience Publ., vol. 3, New York.

Dectsch A., Mattsson S., Swartling P., I958. On the composition of the phospholipid fraction of butter with special regard to the polyenoic fatty acids. Milk. Dairy Res. : Report 54, 9pp.

Donald H. P., 1937. The milk consumption and growth of suckling pigs. Emp. J.exper. Agric. 5, 349.

Donald H. P., Flaming I., I938. Effect of prenatal weight. Changes in breeding sows on the number and size of newborn pigs. Emp. J. Exper. Agr. 6, 34I.

Dumont B. L., 1958. Méthodes indirectes de mesure de la graisse corporelle des mammilères. Cahier Tech. C. N. C. E. R. N. A., 11, I55P.

Duncax D. L., Lodge G. A., 1960. Diet in relation to reproduction and the viability of the young. III. Pigs. Commonwealth Bureau, Anim. Nutr. Tech. comm. 2 I.

Dschaparidse D., I936. Die Milchleistung der Schweine. Z. Zucht. B., 34, 349.

Annales de Zootechnie. - i965. 
Dyrendahl S., Olsson B., 1958. Artificial raising of baby pigs. Part. II, additional experiments including the effect of early weaning on the fertility of sows. Acta Agric. Scand. 8,3 .

Enwards F. R., Holley K. T., 1939. Effect of diet oil on body fat of different species. Proc. Aner. Soc. Produc., pp. 376.

Elits N. R., IsBeli, H. S., 1926. Soft porks studies. III. The effect of food fat upon body fat as shown by the separation of the individual fatty acids. J. Biol. Chem. 69, 2.39.

Elsley F. W. H., i963. Communication personnelle.

Evans R. I., 1929. Protein at mineral metabolism on pregnant sows on a normal on high calcium diet. J. agric. Sci. $19,75^{2}$.

Erwin E.S., Sterner W., Marco (i. J., ig/3. Effect of type of oil and site od administration on the fate of fat ty acids in sheep. J. Amer. (hil Chem. Soc. 40 (8), 344.

Farrakks B. N., Krider J. L., (arrold, W. F., 1945. Effect of diet on gestation-lactation performince of sows. J.anim. Sci, 4, +10.

FEvrier R., 1959. Influence de l'alimentation sur l'importance des réserves grasses du Porc. Ann. Nutr. Alinent. 13, $65 \mathrm{~A}$.

Fil.3ier J. T., i 949. Observations on the milk yield of sows. Rep Neal Zew Dep. Agric. 49, 87 .

Flade E., 1955. Milchleinstung und Milchqualität bei Stutten. Tierucht. 9, 38r.

Flaxzy J., 1963. Communication personnelle.

Fiseury 1'., I.eclerc 1., I943. Dosage colorimétricue du Phosphore. Bull. Soc. Chim. Biol. 25, 20 .

FuUx D. S., PATcints M. R., 1957. The effect of short periods of under-nutrition after calving on the establishement of lactation in dairy cows. Veal. Zeal J. Sci. Technol. A 38, 689.

Folley S. J., 1954. Recherches récenles sur la physiologie et la biochimie de la sécrétion lactée. Masson, laris.

Folfex S. J., Greenbaum A. I., 196o. Fatty acid metabolism. Bril. Med. Bull. 16, 228.

Fournier l', Sesbielle II.. 1952. Les échanges de Ca chez le Rat au cours de la gestation, de la lactation et du sevrage. II. Influence d'un régine pauvre en Ca. J. Physiol., 44, 575 .

Fournier P., Susbiflle II., Boukjond A., i953. Jiffet du régime alimentaire sur l'état du squelette de la Ratte en lactation. J. Physiol. 45, 655.

Fowler S. II., Rolbertson G. I., 1954. Some effects of source protein and antibiotic on reproductive performance in gilts. Canad. Anim. Sci. 13, 949.

François A. C., Flanzy J., I959. Données nouvelles sur l'influence de l'alimentatioñosur les graisses de réserve : aspect qualitatif. Ann. Nutril. Aliment. 13, A III.

Franket F. N., Tarassuk N. P., 1955. An extraction-titration mathod for the determination of free fatty acids in rancid milk and creain. J. dairy Sci. 33, 75 I.

Frexcit C. E., Ixgrin R. II., Koxiebel, I. N., Swift R. W., I952. The influence of dietary fat and carbohydrates on reproduction and lactation in rats. J. Vutr. 48, gI.

Gard D. I., Terrill S. W., Becker D. E., I955. Iiffects of the addition of dehydrated alfalfa meal, fisch solubles and a "vitamin $B_{13}$ " concentrate to a purified diet for sows. J.anim. Sci. 14 (2), $5^{62}$.

GarTun G. A., Duxcan W. R. H., 1954. Dietary fat and body fat : the composition of the back fats of pigs fed on a diet rich in cod-liver oil and lard. Biochem. $J .57$, i 20 .

Garton G. A., Duncan W. R. H., 1957. The effect of feeding tung oil on the composition of the lipids of the milk and plasma of cows. Biochen. J., 69, 208.

Garton G. A., 1963. The composition and biosynthesis of milk lipids. J. Lipid. Res. 4, 237.

GarTon G. A., I963. Aspects of lipid metabolism in jarm animals, in Progress in nutrition and allied sciences. Oliver and Boyd, Elinburg and London p. 69.

Gild J. C., Thomson W., 1956. Effect of environmental temperature on suckling pigs and a study of the milk yield of sow. J. agric. Sci. 47, 324 .

Goettsci M., 19+9. Mininal protein requirement of the Rat for reproduction and lactation. Arch. Biochem. 21, 289 .

Gomner, 1933. Poids à la naissance et développement des porcelets. Z. Schweinezuchl 40, 457.

Goode L., Warnick A. C., Wallace H. D., 1960. Effect of enersy level on reproductive performance of gilts, J. anim. Sci. 19,643.

Goode L., WARnick A. C., WaLlace TI. D., ig6r. I:ffect of level of lietary on some reproductive phenomena of gilts. J. anim. Sci. 20, $97 \mathrm{I}$.

Goode L., 1961. The effect of level of energy on some reproductive phenomena of Duroc gills. Univ. Florida Ph. D. Agriculture, animal culture.

Gortner W. A., i945. The lipids of the pig during embryonic development. J. Biol. Chem. 159, i 35 .

Grailam W. R., 1937. The production of urea in the mammary gland. J. Biol. Chem., 120, 29.

Graham N. M., Williams A. J., I962. The effect of pregnancy on the passage of food through of digestive tract of sheep. Austral. J. Agric. Res., 13, 894.

Gray H. G., Trimberger G. W., Vleck (Van L. D., Henderson C. R., I96z. Nutrient intake and efficiency of feed utilization in lactating dairy cows. J. dairy Sci., 45, (5), 675 .

Green W. W., Wivters L. MI., 1946. Cleavage and attachment stages of the pig. J. Morphol., 78, 305. 
Gueguen I.. Salmon-Legagneur E., 1959. La composition du lait de Truie : variation des teneurs en quelques éléments minéraux (l', Ca, N, Na, Mg). C. R. Acad. Sci., 249, $789-79 \mathrm{r}$.

Gutte J. O., Streuter-Petermolier A., I959. Échanges de sodium pendant la gestation et la lactation chez les truies (Al.). Z. Tierphysiol. Tierernähr. Futt., 14, 5.

GutTe J. O., Lenkeit W., I 960 . Energicumsatz und Nährstoffbedarf säugender Sauen, 9. Z. Tierphysiol. Tierernähr. Fult., 15, 165 .

Haines C. I.., Warnick A. C., Wallage H. D., 1955. The effect of two levels of energy intake in gilts on puberty, ovulation, fertilization, embryonic survival and pigs born. J. anim. Sci., 14, (4), $12+6$.

IlAines C. J:., Whrnick A. C., Wallace H. D., i959. The effect of 'Two levels of energy intakes in reproductrice phenomena in Duroc Jersey Gilts. J. anim. Sci., 18, 347 .

Minllanger L. E., Schultze M. O., I957. Effect of dictary lipids on the lipids in rats'milk. Proc. Soc. Exper. Biol. N. Y., 96, (2), 473.

HAmmond J., I9I4. On some factors controlling fertility in domestic animals. J. agric. Sci., 6, 263.

HAMvoND J., I96r. Effect of nutrition on the stage of development of the young at birlh in farm animals (in CIBA Foundation symposium, somatic stability in the newly born de Wolstenhome (. E. W. O'Connor M.). T. \& A. Churchill Itd London, 5.

Hanson L. E., Ferrin E. F., Annan W., i953. The effect of limited feeding on gilts. J.anim. Sci., 12, 919.

Ifays V. W., Speer V.C., Hartiax P. A., i959. The effect of age and supplemental amino acids on the utilisation of milk and soya protein by the young pis. $J$. Nulr., 69, (2), 179 .

Heidebrecht A. A., McVicar R., Ross O. B., Whitehalr C. K., i95I. Composition of swine milk. I- Major constituents and carotene, vitamin A vitamin C. J. Nutr., 44, 43.

IIExry W.A. Woll I'. W., isgi. On the yield and composition of sow's milk. It th. Ann. Rept. Wisc. agric. exper. Sin., 10.

IIenpes W., 1928. Über die Milcheistung der sauen. Deutsch. Gesellsch. Zucht., 17, 37 .

IIENnIG A., I959. Versuche über den Stickstoff-Crundumsatz und zur biologischen Eiweisswertigkeit bei Schweinen, unter besonderer Berücksichtigung vollhähriger weiblicher Tiere. Arch. Tieremälw., 9, 29.

HeNvig J., KRACie J., ig6o. I. Tagung im Institut für Tieremährung der Martin-Luther Universität IIalle-Wit tenberg am 22/23 Sept. 1959 in I Iall-Let in. Ermittlung der biologischen Wertigkeit des Eiweisses an weiblichen Schweinen unter Berücksichtigung der Laktierenden Sau. Z. Tierphysiol. Tierernähr. Futl., 15, 3 I $\mathrm{I}$.

Hibditch 'T. P., 1956. The chemical contslitution of natural fat., Chapman, London, 3 éd.

Hokrlein A. B., I957. The influence of colostrum on antobody response in baby pigs. $J$. 7 mmunol., 78, I 2 .

Houdinière A., 1944. Le colostrum de vache. Le lait, 24, io8.

IIUGHes L. II., 1934. Some effects of vitamin A deficient diet on reproduction of sows. J. agric. Res., $9+3$.

Hughes E. II., HaRt H. G., I935. Production and composition of sow's milk. J. Nutr., 9, 3Ir.

Hytrex F. F., Thomson A. M., ig6r. Nutrition of the lactating Woman, in Kon S. K., Cowre A. T., Milk vol. II, p. 3 .

Insuli W., IIirsci J., James 'T., Airens E. Il., 1959. 'The fatty acids of human milk II. Alterations produced by manipulations of caloric balance and exchange of dietary fats. J. Clin. Iniest., 38, 443.

Jacobsex J', Sorensex P., Caksen H., r957. Enzy investigations on related to fitus formation in cat 1le. Acta Agric. Scand. 7, 103.

JAcovor R., I953. Compétition alimentaire entre la mère et l'enfant. Chronologie des besoins. Ann. Nutr. Alim., 7, 39.

Jacquot R., Abrainim J., Ravelx R., Bevxaud M., Trémolières J., 1959. Mobilisation des graisses de réserve suivant la nature des graisses alimentaires chez le rat. Nutr. Diet., 1, 222.

Jacquot R., 1959. Quelques aspects nutritionnels de la gestation. Conf. Palais de la Dícouverte, Paris, A 253.

Ivanov, 1957. Importance of complete rations for pregnant sows. Suinovodstvo, 2, 27.

JARRIGE R., JouRnet II., I959. Influence des facteurs alimentaires et climatiques sur la teneur en matière grasse du lait. Ann. Nutr. Alim., 13, 233.

Jensen R. G., Gander G. W., ig6o. Tatty acid composition of the monoglycerides from lipolyzed milk fat. J.dainy Sci., 43, I758.

Jensen R. G., Gander G. W., Sampugna J., ig62. Fatty acid composition of the lipids from pooled raw milk. J. datry Sci., 45, (3), 329.

Jespersen J., Olsen II. M., I940. Besoins en protéines des truies. Forsøg. Lab. Kobenhavn 192.

Jespersen J., 1949. Normes d'alimentalion du Porc. Rapp. Part. Ve Congr. Zootechnie Paris, p. 33.

Johansson I., Claesson O., I957. Factors affecting composition of milk. Progress in. Physiol. of Farm animals, vol. 3, 1035, Pergamon ed.

Joirnsen II., Moustganrd J., Olsen N., 1952. Dansk. Maanedsskr. Dyrlaeg., 63, 1.

Jones A.S., Hepburn W. R., Gadenhend A., Boyne A. W., ig62. The effect of variation of protein quality and protein level in diet on the performance of young pigs. Anim. Prow., 4, I 85 . 
JoURnet M., JARRIGE R., Ig6o. lívolution de la secrétion des matières grasses, des matières azotées et du lactose au cours du premier mois de lactation. Ann. Zootech., 9, г33.

JYLLING B., SörexSEx P. II., I960. Investigations on the composition of sow milk. Arsskrift den Kong. Vet. og Landbohojsk. (Danemark), 20.

Karmarkar M. G., Choksiil I. R., Suair V. K., i959. Studies on human lactation, J. Pediat., 55, 48I.

KIngsbery K. J. et al., I 962 . The effect of dietary changes on the fatty acid composition of normal human depot fat. Biochem. J., 84, i24.

Kiermeier F., REnNer F., I960. Einfluss der Fütterung auf den Fiweissgehalt der Milch. Z. Tierphysiol. Tierernähr. Fittermittelkde, Dtsch., 15, 3.32 .

KIRKSFY A.. I'IKE R. I... 1962. Some effects of high and low sodium intakes during pregnancy in the rat. I. Food consumption, weight gain, reproductive performance electrolyte balances, plasma total protein and protein fractions on normal pregnancy. J. Nutr., $7 \%, 33$.

Klostermax E. W., Bulchanan M. L., Bolen D. W., I95I. Levels and sources protein of in rations for pregnant ewes. Canad. Anim. Sci., 10, I63.

Kobliscré S., 1939. Uniformité du poids des porcelets comme une qualité de performance chez les pores et les factcurs l'influençant. Recherches statistiques variées. Zuchtungskunde, 14, 418 .

Kolat s., Jrezczak J., Grycz S., ig6r. Le poids des porcelets à la naissance et leur développement ultérieur (polon.). Presegl. hodowe, 29, i r.

Kosteri.tz II. V., Cambeil. R. M., 1957. Nutrition and gestation. $4^{e}$ Congr. Intern. de Nutrition. Extr. Ann. Vutr. Alim., 11, (3-4), 85 .

KMENT A., SEFFELDNER I1., I 955. Studien über die Becinflussung der hormonalen Sterilisation und Mast weibliche. Schweine durch eiweissreiches oder eiweissarmes lutter. Z. Tierernährung. Tieremalhr. Futtermittelkide, Disch., 10, 193 .

KRizExECKY T., I94I. The independance of average weight of body pigs of litter number. Z. Tiersucht Ziichtunssbiol, , 50, 208 .

Krizevicky J., 1954. Taille de la portée et poids à la naissance chez les animaux à naissances multiples. Podohorpodarstio, 1, 462 .

Kretyporokir F. I., S.aner P. I., 1957. Influence des conditions d'alimentation et d'entretien de truies gestantes. Srinovod., 6, (II), 33 .

KuZDZAL-SAvoles S., i 959 . Influence de l'alimentation et du climat sur la matière grasse du lait de vache. Aspect qualitatif. Ann. Nutr. Him., 13, 207.

KuzDzal-Savolf S., Kizizzal W., ig62. Contribution à l'étude des acides gras du lait de différentes especes animales. C. R. I ${ }^{\text {er }}$ Congr. Inter. Sci. Technol. Alim., Londres, sept. Ig62.

Kuzdzal-Savore S., 1962. Les acides gras du beurre. Connaisasnces actuelles. Ann. Tecinol. agric., 11, I53.

Kuzpzal-Savole S., 1963. Les acides gras du beurre. Comnaissances actuelles. Lait, 43, i 29 .

Kuryviat II. S., Bowland J. P., J3erg R. T., I $g^{62 .}$. Supplemental fat as an energy source in the diets of swine and ritts. I-Foods and energy utilization. Cimad. J. Anim. Sci., 42, 23.

LALEviC D., 1953. Study of the milk performance of Mlorawa sows. Arh. Poliopr. Nauk., 6, I23.

Lamare (de) 1'. B., Shortand F. B., 1944. Composition of sow's milk fat. Nalure, 153, 380.

Lassiter C.A.. II fumman C. F., DCXCAN ( W., 1957. Effect of various protein levels on milk production, body weight changes, and metabolism of lactating dairy cows. (Uuart. Bull. Mich. agric. exper. Sin., 40, 59.

LaUPREcitT E... SMATHODF T., WaLter E., ig62. Zum cinfluss der saugrleistung auf die Ruckenspeckdicke von situen. Z. ZTierzucht. Zü̈chtbiol., 76 , 374.

LaXA O., 193r. La matière grasse du lait de truie. Ann. Fals. Fraudes, Frr, 24, 87.

LEAT W. M. F., 1962. Studies on pig diets containing different amounts of linoleic acid. Brit. J. Nutr., 16, $559 \cdot$

LENKEIT W., GUTTE J. O., I955. Langfristige Intersuchungen zum äusseren und inneren stoffwechsel des graviden und laktierenden Schweines. I-Allgemeine Angaben zur Versuchsmethodik. Z. Tierernähr. Futtermittelkile, Dtsch., 10, 94 .

Lenke.it W., Gutte J. O., Streuter-Pettrmolier A., i955. Langfristige Untersuchungen zum äusseren und inneren Stoffwechsek des graviden und laktierenden Schweines. 2-Mittelung : Der Ablauf der N-bilanz vom Ende der Gravidität bis zum Inde der Laktation bei gleichbleiblender Emährung. Z. Tierernähr. Futtermittelkde, Dlsch., 10, 228.

Lenkeit W., Gutte J. O., Warnecke W., KirchirofF W., 1955. Langfristige Untersuchungen zum äusseren und inneren Stoffwechsel des graviden und laktierenden Schweines. 3 -Die Beziehung der N-Ketention während der Gravidität zum N-Umsatz nach der Geburt bei hoher Nilchteistung und bei vdrhindeter Laktation. Z. Tierernähr. Futtermiltelkde, Dtsch., 10, $35 \mathrm{I}$.

Lenkeit W., Gutte J. O., Kircioff W., Soehngen F. K., Farries F., i956. Weiter Untersuchungen zur Abhängigkeitdes $\mathrm{N}$ umsatzes Während der Laktation. Z. Tierernähr. Fittermittelkde, Disch., 11, 323 .

LENKEIr W., 1957. Zum Linfluss der Fütterung auf die embryonale Entwicklung. Zuchtungskunde, 29, 397 .

Lenkeit W., Molnar S., IANTsciI H. J., GutTe J. O., 1962. Untersuchungren über den begin der Mobilisierung der eingelagerten Körperreserven von $\mathrm{Ca}$, Pund $\mathrm{N}$ in graviditäts-Laktations-Zyklus bei Sauen. Z. Tierphysiol. Tierernähr. Futtermittelkde, Dtsch., 17, 65. 
Leroy A. M., 1949. Normes d'alimentation du Porc. Rapp. gén. Ve Congr. Zootechnie, p. 23, Paris.

Lichton I. J., ig63. Urinary excretion of water, sodium, and total solutes by the pregnant rat. Amer. J. Physiol., 201, 563 .

Likuski H. J. A., Bowland J. P., Berg R. T., 196r. Energy digestibility and nitrogen retention by pigs and rats fed diets containing non nutritive diluents and vaying in protein level. Canad. J. Anim. Sci., 41, (I), 89.

Ling E. R., Kon S. K., Porter J. W., ig6r. 'The composition of milk, in Kon S. K., Covie A. T., Milk, Academic Press, New-York.

Liston R. G., I93I. The composition of mare milk. J.agric. Sci., 21, 669.

LODGE G. A., 1957. Studies on yield and composition of sow's milk. Abstr. 4th Intern. Congr. Nutr., Paris, 26.

LODGE G. A., 1959. Nitrogen metabolism in the lactating sow. J.agric. Sci., 53, i 72.

LODGE G. A., I959. The composition of sow's milk during lactation with particular reference to the relatioship between protein and lactose. J. dairy Res., 26, I 34 .

LODGE G. A., I 959. The energy requirements of lactating sows and the influence of level of food intake upon milk production and reproductive performance. J. agric. Sci., 53, 177 .

LODGE G. A., McPierson R. M., ig6r. Level of feeding during early life and the subsequent reproductive performance of sows. Anim. Prodac., 3, I9.

LOdGe G. A., McDonald I., McPherson R. M., I96I. Further observations on the relative influence of birth weight and creep-fed consumption on the 3 -and 8 -week weights of suckling pigs. Anim. Product., 3, $26 \mathrm{I}$.

Lodge G. A., McDonald I., McPherson R. M., 196I. Weight changes in sows during pregnancy and lactation. Anim. Product., 3, (3), 269.

LODGE G. A., I 962. The nutrition of the lactating sow. in MoRgax, Lewis. Nutrition of pigs and poultry. Butterworths. London, 224.

Lodge G. A., PraitT P. D., 1963. Birth weight and the subsequent growth of suckled pigs. Anim. Produc., 5, 225.

LONGNECKER II. E., I939. Deposition and utilization of fatty acids. II. Thenon preferential utilization and solw replacement of depot fat consisting mainly of oleic and linoleic acids; and a fatty acid analysis of corn oil. J. Biol., Chem., 129, I3.

Loosil J. K., Maynard L. A., Lucas H. L., 1947. Further studies of the influence of different levels of fat intake upon milk secretion. Cornell Uni. agric. exper. Sin., mem. 265, New York.

Lucas I. A. M., Lodge G. A., I961. The nutrition of the young pig. Commonwealth Agric. Bureaux. Techn., Comm. No 22, pp. II9.

Luddy F. F., Barford R. A., Rienenschneider, 1960. Direct conversion of lipid components to their fatty acid methyl esters. J. amer. Oil. Chem. Soc., 37, 447 .

Lush J. L., Hetzer II. O., Culbertson C. C., I934. Factors affecting birth weights of swine. Genetics, 19, 329 .

Macy I. G., Kelly H. J., т96r. Human milk cow's milk in infant nutrition. KON S. K., CowIE A., Milk vol. I I, Acad. Press, New-York.

Magidman P., Herb S. F., Barfurd A., Riemenscinneider R. W., ig62. Fatty acids of cow's milk. A technique employed for identification of fatty acids. J. amer. Oil Chem. Soc., 39, I37.

Majerciak P., I962. Étude de la variation du poids vif des truies durant la gestation et la lactation (tchèque). Zivocisma Vyroba, (4), 287.

Man T., Pope C. V., 1962. Effects of dietary fat on the fatty acids composition of eggs and tissus of the hen Poult. Sci., 41, I 340 .

Man (de) J. M., Bowland J. P., i963. Fatty acid composition of sow's colostrum, milk and body fat as determined by gaz-liquid chromatography. J. dairy Res., 30, 339 .

Marion J. E., WOODROOF J. G., I 963 . The fatty acid composition of breast, thigh, and skin, tissues of chicken broilers as influenced by diatary fats. Poull. Sci., 42, 1202.

Matrsson S., 1962. Fatty acids in milk Phospholipids. XIV intern Dairy Congr., Copenhague II, 537.

Mayer G., KLeiN M., I96r. Ilistology and cylology of the mammary gland, in KoN S. K., Cowie A. T. Milk, vol. I, 47, Acad. Press, New York.

Maynard L. A., Loosli J. K., ig62. Animal nutrition. $5^{e}$ éd. Mc Graw Hill, New York.

MACY I. G., Hunscher H. A., 1934. An evaluation of maternel nitroden and mineral during embryogenic and infants development. Amer. J. Obstetr. Gynecol., $27,878$.

McClymont G. L., Lambourne J., I958. Interactions betwean planes of nutrition during early and late pregnancy. Proc. Austral. Soc. Animal Produc., 2, 135.

McElroy L. W., Draper H. H., J95o. Effet de rations insuffisantes pour des truies reproductrices sur le développement pré et postnatal de leur progéniture. Sci. Agric., 30, 4, 172.

McGillivray J. J., Nalbandov A. V., Jensen A. H., Norton H. W., Becker D. E., ig62. Reproductive performance in gilts starved or fed different levels of energy. J.anim. Sci., 21, 1005.

McGillivray J. J. et al., 1963. Effect of changing energy intake on reproductive performance in gilts. J. anim. Sci., 22, 1127 . 
McKenzie F. F., I926. The normal cestrous cycle in the sow. Missouri agric. exper. Stn. Res. Bull., 86.

McKenzie F. F., I928. Growth and reproduction in swine. Missouri agric. exper. Stn. Res. Bull., I I8.

MCMEEKAN, I940. Growth and development in the pig with special reference to carcass quality characters. J. agric. Sci., 30, 276.

Mitchell II. H., Carroi.t. W. E., Ihamition T. S., Hunt G. J., i93i. Besoins alimentaires de la fécondité chez les porcins. Illinois agric. exper. Sin., Bull, 375, 467 .

Morix-Jamain M., Tremolifies J., Abraham J., Cimampigny O., Jacouot R., ig6r. Unfluence de restrictions alimentaires périodiques sur le comportement nutritionnel du rat blanc : poids vif, bilan azoté dépense énergétique. C.R. Acad. Sci., Fr., 252, 3142.

Morin-Jaman M., Abraham J., Jaçcot R., I 964 . Chronologie des apports alimentaires et capacités de protéinogenese et de lipogenèse chez le rat en croissance : étude des régimes croisés, riches et pauvres en protides. $C$. R. Acad. Sci., 258, 1626.

MoustgaARD J., I959. Nutrition and production in domestic animals. Reproduction in domestics animals, vol. III, H. II. Cole et Cupps, Acad. Press, New York.

Moustgatro J., 1962. Fotal nutrition in the pig. in Morgan, Lewis, Nulrition of pigs and poullry). Butterworths., London, 189 .

Morse I.. M., SсHмidT C. L., I944. Nitrogen balances in rats during pregnancy and lactation. Proc. Soc. exper. Biol. Méd., $5^{6 .}$

Mueller A. J., CoX W. M., 19.37. The effect of changes in diet on the volume and composition of rat milk. J. Biol. Chem., 119, LXXii, Proc.

Mueller A. J., Cox W. M., I946. The effect of changes in diet on the volume and composition of rat milk. J. Nulr., 31, 249 .

NAismith D. J., QuREsir R. U., I962. The role of dietary fat in the utilization of protein. I. Quality and quantity of fat. J. Nutr., 77, 373 .

Naito M., 1958. Oxygen consumption and lactose synthesis rates of mammary gland slices from lactating guinea pigs. J. dairy Res., 25, 17.

National Research Couxcil, ig63. Nutrient requirements for domestics animals. 2. Nutrient requirements for swine., Publ. 295 .

NELsoN M. M., FvaNs II. M., I06r. Dietary requirements for lactation in the rat and olher laboratory animals, in KoN S. K., Cowie A. T., Milk., Acad. P'ress London, I37.

Nfinals L., s960. Entersuchungen und Beobachtungen über Gewinnung, Eigenschaften und für die Ernahrung menschlicher Säuglinge. Zuchtungskunde, 32, (9), $5^{\mathrm{I}} 3$.

Neunals U., 1961. Die Milcheistung der Sau und die 7usammensetzung und Eigenschafetr der Sauen milk. Z. Tiersucht. Zuchtungsbiol., 75, 160 .

Newtox W. H., 1952. Changes in the maternal organism during pregnancy, in Marshall's Physiology of, Reproduction, $3^{\mathrm{e}}$ éd., 2, 442, Longmons, Grreen.

Niwa 'T., Ito S., Yokoyama II., Otsuka M., ig5r. Studies on the milk secretion of the sow. I-On the habits of nursing, milk yield and constituants of milk, etc. of the sow. Bul. Nat. Inst. agric. Sci. Japan Série G, Inim. Husb., 1, I 35 .

NoRDBRING F., I957. The change in total nitrogen, electrophoretic pattern and antibody titre in porcine and bovine colostrum. Acta Soc. Med. Upsal., 62, 35 .

Normai R., SilefFy D. E., Willman J. I', I 955. The effect of supplementary fat in the rations of lactating swine. J.anim. Sci., 14, (4), 219 .

Norman R., 1956. The effect of supplementary fat in the rations of lactating swine. Diss. Abstr., 16, I99.

Olorsson N. E., LARsSon S., I9.30. Moderasuggornas produktion och smagpisarnas urtveckling. Cenlralanstal., Mild $37+$, Husdj. 68.

OsBorne T. B., MeNDeL I. B., TERRY Ji. L., I IIg. A method for expressing numerically the growth promoting value of proteins. J. Biol. Chem., $37,223$.

Osinska 7., I962. Estimation of protein, chemical fat and energy content in pigs. Anim. Produc., 4, $39 \mathrm{r}$.

Oslage H. J., I 963 . Lber den Stoffansatz wachsender Mastschweine. Landw. Forsch. (No spécial 17 ), i 78.

OSIAGE H. J., I963. Untersuchungen uber die Körperzusammensetzung und den Stoffansatz wachsender Mastschweine und ihre Beeinflussung durch die Ernährung. 4. Mitteilung. Einfluss einer eingorahränkten Energiezulfuhr im erste Teil der Mastperiode auf Körperzusammensetzung und Stoffansatz wachsender Masstschweine. Z. Tierphysiol. Tierernähr. Futtermittelkde. Dtsch., 18, 35.

OsLaGE II. J., I963. Untersuchungen für die Körperzusammensetzung und den Stoffanstaz wachsender Mastschweine und ihre Beeinflussung durch die Ern̈̈hrung. 3 Mitteilung. Einfluss einer eingeschränkten Fnergiezufuhr im zweiten Teil der Mastperiode auf Körperzusammensetzung und Stoffansatz wachesender Matschweine. Z. Tierphysiol. Tierernähr. Futtermiltelkde. Dtsch., 18, r4.

Ostwald R., Okey R., Shannon A., Tinoco J., 1962. Changes in tissue lipids in response to diet. I-Fatty acids of subsutaneous, mesenteric and inter-scapular fat. J. Nutr., 76, 34I.

Paqlot C., Mercier J., Lefort D., Mathied Q., Perron R., 1962. Les méthodes analytiques des lipides simples. Ann. Nutr. Alim., 16, I.

Penzes L., 1959. Études sur le "stockage " des protéines chez des truies pendant la gestation (Hongr.) Allattenyésztés, 8, 24.3 . 
Pexzes I.., 1960. Dépôt de protéines et de $\mathbb{N}$ chez les truies gestantes (Hongr.). Rep. Hung. agric. exper. Sin., 53/3, 43 .

Perdee A. S., Phillips P. I1., I954. Failure of Vit. $B_{12}$ to increase survival of rats fed an all-plant diet. J. Nutr., 53, 25 ).

Perkins A. E., I930. Protein studies. Ohio agric. exper. Sin. Bull, 446, I I 5 .

Perisse J., Salion-Legagnele E., i 960 . Intluence du niveau nutritionnel au cours de la gestation et de la lactation de la ratte. Arch. Sci. Physiol., 14, ro5.

PERRIX I. R., I954. The composition of sow's milk during the course of lactation. J. dairy Res., $21,55$.

PERRIN I. R.. 1954. The estimation of the energy of sox's milk from fat and total solids content. J. dairy Res., 21, 63-66.

Perrin D. R., I955. The chemical compositionof the colostrum and milkof the sow. J. dairy Res., 22, 103

Perrin D. R., I958. The chemical composition of the colostrum and milk of the ewe. J. dairy Res., 25, 70

PERry J. S., i955. Fecundity and embryonic mortality in pigs. J. Fmbryol. exper. Morphol., 2, 308.

PIKE R. L., StDDer I. B., Ross M. L., I954. The influence of protein and energy intakes upon nitrogen retention in the pregnant rat. J. Nutr., 52, 297.

Poo L. J., LEW W., Adpis T., I939. Protein anabolism of organs and tissues during pregnancy and lactation. J. Biol. Chem., 128, 69.

Popehina P. S., Borc J. L., I957. Normes d'alimentation pour pores. Svinovodsivo, 4, 25.

Rathnabaiatiry V., Lasley J. F., Mayer, i955. Some envirommental factors affecting litter size swine. J. anim. Sici., 14, (4), I I88.

Raymoxi) W. F., Misson D. J., 1955. The use of chromic oxide for estimating the faecal production of graning animals. J. Brit. Grassl. Soc., 10, 282.

REERT A. R., I 953. Rapport particulier sur les possibilités d'accroitre l'efficacité de l'utilisation des aliments ler Congr. Mondial Zootech., Rome, vol. II, 89.

Ritzman F. G., Colovos N. F., i94I. Traits that determine the efficiency of the pig as a transformer of eneryy. Neze Hampshire agric. exper. Sin. Tech. Bull., 75.

Rippel R. II., Ig62. Reproductive performance of swine fed different sources and levels of protein. J. anim. Sci., 21, гого.

REID J. T., Io6o. Effect of energy intake upon reproduction in farm animals. (The effect of ferm cell damage on animal reproduction. 4 th biennial symp. Anim. Reproduction. June $18-20$, Univ. Illinois Urbana). J. dairy Sci., 43, , (Supplt.) 103.

Reid J. T., I96r. Nutrition of lactating Farm animals, in Kon et Cow1E, Milk vol. II, p. 47

Robertson G. L., Casida I. F., Grumuer R. H., Cilapyas A. 13., i95x. Some feeding and management factors affecting age at puberty and related phenomena in Chester white and Poland China gilts. J.anim. Sci., 10, 647.

Rombatts P., Bourdel G., Jacotot R., I956. Analyse de l'anabolisme gravidique chez le rat blanc en vue de la définition des besoins nutritionnels de la grestation. Arch. Sci. Physiol., 10, 173.

Rombaurs P., 1959. Anabolisme de gestation et lactation. C. R. Acad. Sci., 248, 24 ro.

RoubuUts I'., I959. L'anabolisme de gestation chez la brebis. C. R. Acad. Sci., 248, 1859.

Rombauts 1'., Ig62. Évolution de l'anabolisme gravidique chez la truie en fonction de l'âge de l'animal. Ann. Zootech., 11, 39-51.

Rook S. A., Bowland S. J., 1959. Effect of spring grazing on the constitution of the S. N. F. of milk Intern. dairy Congr., 1, 204.

Rook J. A. F., Line C., Rowland S. J., ig6o. The effect of the plane of energy nutrition of the cow during the late winter-feeding period on the changes in the solids-nit-fat content of milk during the spring grazing period. J. dairy Res., 27, 427 .

RowLAND S. J., I938. The determination of the protein distribution on milk. J.dairy Res., 9, $4 \mathbf{I}$.

Rowland Q. J., Roy J. H. B., Sears H. J., Thompson S. Y., I953. The effect of prepartum milking on the composition of the prepartum and postpartum secretion of the cow. J. dairy Res., $20,16$.

Salyox-Legagiedr E., I956. La mesure de la productions laitiere chez la truie. Ann. Zootech., 5, 95.

SalmoN-LegagNetr E., ig60. Relations nutritionnelles entres la gestation et la lactation. C. R. Acad. Sci., 250, $192 \mathrm{r}$.

Schafer II., Granz L., I 955. Beobachtungen über die Gewichtsverluste der Sauen während der Säugezeit. Züchtungskunde, 27, 37 .

Schomnielmer E., RitTenberg D., 1936. Dzuterium as an indicator in the study of intermediary metabolism. VI-Synthesis and destruction of fatty acids in the organism. J. Biol. Chem., 114, $38 \mathrm{I}$.

Schmid K., Breitschneider, 1954. The external course of the sexual cycle in the sow. Tierzucht., 8, 119.

Self II. L., Grunier R. II., CASIda L. E., I955. The effects of various sequences of full and limited feeting on the reproductive phenomena in Chester White and I'oland China gilts. J. anim. Sci., 14, 573 .

SELF II. L., Grummer R. H., I958. The rate and economy of pigs gains and the reproductive behaviours of sows. J. anim. Sci., 17, 862 .

Self diI. L., Grummer R. H., Hays D. E., Spies II. G., rg6o. Influence of three different feeding level during growth and gestation on reproduction, weight gains and carcass quality in swine. J. anim. Sci., 19, 274 . 
Sell J. L., Hodgson (i. C., 1962. Comparative value of dietary rapeseed oil, sunflower seed oil, soybean oil and animal tallow for chickens. J. Nutr., 76, Part I, I 13.

Shailani K. M., Solmer G. H., I95I. The protein and non protein nitrogen fractions in milk. I-Methods of analysis. J. dairy Sci., 34, 1003 .

Silnimni K. M., Sommer II. H., I95I. The protein and non protein nitrogen fractions in milk. II-Their content in fresh raw milk. J. dairy Sci., 34, I010.

Shefry B. F., Phillis P. II., Dyusza II. A., Grummer R. H., Bohstewt G., I952. Fat, fat constants and phospholipid content of sow's milk. J. anim. Sci., 11, 727 .

Shemfy B. E., Shamaxi K. M., Grumer R. H., Philimps P. H., Sommer H. H., i952. Nitrogen constituents of sow's milk as affected by ration and stage of lactation. J. Yutr., 48, I03.

DHORLAND F. B., I962. The comparative aspects of fatty acils occurence and distribution. in FloRkIN, MIASON, Comparative Biochemistry, vol. III, Acad. Press, New-York.

Sirorland F.B., 1963. The fatty acids in the depot and milk fats of ruminants. Fetle. Seifen Anstrichmiltel $65,302$.

S.itii D. M., 1952. Milk production in the sow. Proc. New Zeal. Soc. An. Prod., 12, Io2.

SMITI D. M., KACK E. I... I 959 . Isolation of Milk phopholipids and determination of their polyunsaturated fatty acids. J. dairy Sci., $\mathbf{4 2},(5), 767$.

Smitir 1. M., I952. Yield and composition of milk of New Zealand Berlishire sows. New Zeal. J. Sci, Technol., 34 A, 65.

Smitil D. M., I959. The yield and composition of milk from sows feed varying proportions of separated milks and concentrates. New Zeal. J. agric. Res., 2, I057.

- Smiti D. M., 1959. The yield and composition of milk from sows feed on three ration levels. Nere. Zeal. J. agric. Res., 2, 1071.

Smiti D. M., I960. The yield and enerry content of milk and the energetic efficiency of sows on different levels of nutrition during gestation and factation. New Zeal. J. agric. Res., 3, 745 .

Somogy I M., 1952. Notes on sugar determination. J. Biol. Chem., 195, r9.

SPRAY C. M., I950. A study of some aspects of reproduction by mean of chemical analysis. Brit. J. Nutr. 4, 354.

Stevenson J. W., Ellis N. R., Daver R. J., i95.t. Effects of gestation and lactation diets on livability of pigs. J. anim. Sci., 13, 1000.

Stevenson J. W., Eulis J. R., 1957. Liffect of gestation diets and creep feeding of livability and weight gains of suckling pigs. J. anim. Sci., 16, 877 .

Stein J. F, i957. Some effects of feeding excess protein to lactating dairy cows. Diss Abstr., 17, 936.

TEAGUE H. S., I955. 'The influence of alfalfa on ovulation rate and other reproductive phenomena in gilts. J. anim., Sci., 14,621.

Tiknonov I. T., 1957. Influence de l'alinentation protéique et de vitamine A sur la croissance et le développement des jeunes truies et leur productivité. Svinozodstzo, $\mathbf{2}, 37$.

Terrill S., Becker D., EDwards R., 1953. Ladino clover pasture and grass legume silage for breed gilts and sows. J. anim. Sci., 6, I4r.

Thompson C. P., I931. Oklahoma tests : Production laitiere des truies. Amer. Soc. Anim. Produc. Proc. p. 266.

Tromson W., Aitken F. C., I959. Diet in relation to reproduction. Part. II-Sheep. Comm. Bureau Anim. Nutr., Tech., Comm. 20, Rowett Inst.

Thomson A. M., Hytten F. E., ig6r. Calorie requirements in human presnancy. Proc. Nulr. Soc., 20, 76.

Totev S. D., I955. Piglings with a birth weight of less than one kilogram. Izv. Inst. Zivotn., 37, 33.

TURNer W., I952. The mammary gland. Lucas, Columbia.

Tribrle L. F., Monson A. J., Ig63. Relative efficiency of production by sows and gilts. J. anim. Sci., 22, 824 .

Urbanyi, 1950. The biochemistry of foetal life. Magy. Allatow. Lapja, 5, 6.

UNderwood E. J., Shier F. L., Cariss H. G., I943. Studies in sheep husbandry in western australia. 4 the influence of a highs level of prenatal feeding in lamb production. J. Dep. Agric.W. Austr., 20, 288.

Vanschoubroek F., Willems A. E. R., Bruynoogile D., I959. The energy and protein requirements of lactating sows. Meded. weearts. Rijksuniv. Gent., 3, 35 pp.

Vanschoubroek F., Embo P., ig62. Recherches concemant le volume, la cause et la nature de la diminution de poids chez les truies pendant la période de lactation (Flamand). Vlaams Diergeneeskd. Tijidschr., 31, I 29.

Van Wagenen G., Newton W. H., i943. Pregnancy in the monkey after removal of the fetus. Surg. Gynecol. Obsteter., 77, 539 .

Venning E. H., Beck J. C., I959. Metabolic siudies in pregnancy, in Recent progress Endocrinology of Reproduction. Acad. Press New-York 345.

VESTAL C. M., 1938. Feeding and management experiments with brood sows and litters. Ind. agric. exper. Stn. Bull., 4I3.

Villiers (de) V., Sorensen P. A., Jakobsen P., Moustgaard J., i958. Ann. Rep. Sterility Res. Inst. Copenhague, $\mathrm{r} 39$. 
Von Gohren R., I865. Analyse der Schweinemilch. Ldw. Vers. Stat., 7, 35 I.

Wagner H., Seelig E., Bernhard K., I958. Physiol. Chem. Hoppe Seylers, 312, I 35.

WAITE R., WiIte J., ROBERTSON A., I956. Variations in the chemical composition of mill. I- The effect of stage of lactation, season, age of cow J.dairy Res., 23, I.

Waldorf D. P., Foote W. C., Self H. L., Charpman A. B., Casida L. E., I957. Factors affecting fetal pig weight late in gestation. J.anim. Sci., 16, 976 .

WALLACE C. R., 1948. The growth of lambs before and after birth in relation to the level of nutrition J.agric. Sci., 38, 93 .

Wasiburn L. E., Brody S., Ragsdale A. C., I939. The influence of fasting and refeeding on milk production, heat production and respiratory coefficient. Missouri agric. exper. Sin. Res. Bull., 295.

Werner A., Iiennig A., ig6o. Die biologische Wertigkeit des Futtereiweisses fur Milchbildung bei säugenden Sauen. Z. Tierphysiol. Tierernähr., 15, I43.

WidDowson E. M., 1950. Chemical composition of newly born mammals. Nature 166, 626.

Willett L. L., Maruyama C., I946. The effect of intake of garbage upon fat content of sow's milk. J. anim. Sci., 5, 365 .

Wallace L. R., 1946. The effect of diet on foetal development. J. Physiol., 104, 84 .

Wallace L. R., i956. The relationship of size and yield to efficiency of cows. Proc. Ruakura Fmrs' Cont. Hamilton, $177^{-86}$

WaLlaCe H. D., 196r. Scientist discussion cirrent research topics at Florida Animal Swine day, Feedstuffs 33, 4 .

Wise F. S., Robertson G. C., I953. Some effects of sexual age on reproduction performance in gilts. J. anim. Sci., 8, 558 .

Wiтt M., I954. Einfluss einer stark überhöten Eiweissagabe auf die Milchmenge und den Fettgehalt der Pilch bei Kühen. Arch. Tierernälar., 5, 166.

Wohlbier W., 1928. Stoffwechselversuche zum Eiveissansatz bei saugenenden Ferkcler. Biochem.Z., 102, 29 .

Wooduan H. E., I957. Ration for livestock. Bull. Min. Agric. Fish. Fd. I4 éd., London, 48, 5 I.

Work S. H., Henke L. A., HARRIS L. E., I942. Besoins en protéines des truies en lactation. J. anim. Sci., 1, 72.

Zeller J. H., Jonhay T. G., Craft W. A., I937. The significance of weight changes in sows during the gestation and suckling periods. Amer. Soc. Anim. Produc., pp. I2r.

Zimmerman D. R., Spies H. G., Self H. L., Casida L. E., 1958. The effect of glucose feeding on ovulation Rate in Gester White gilts. J. anim. Sci., 17, 1212.

Zimmermar D. R., Spies H. G., Self H. L., Casida L. E., ig6o. Ovulation rate in swine as affected by increased energy intake just prior to ovulation. J. anim. Sci., 19, 295.

Zimmerman D. R., Spies H. G., Rigor E. M., Self II. L., Sasida L. E., ig6o. Effect of restricted feeding crossbreeding and season of birth on age at puberty in swine. J.anim. Sci., 19,687.

Zivkovic S., Bowland J. P., I963. Nutrient digestibilities and comparaison of measures of feed energy for gilts fed rations varying in energy and protein level during growth gestation and lactation. Canad. J.anim. Sci., 43, 86.

Zobrisky S. E., Lastey J. F., Brady D. E., i954. Pork carcass evaluation. Missouri. agric. exper. Stn. Res. Bulll, $\mathbf{5 5 4}$. 